UNIVERSIDADE DE SÃO PAULO

INSTITUTO DE GEOCIÊNCIAS

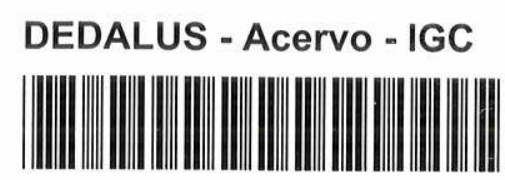

30900004529

\title{
DISPERSÃO DE ONDAS SUPERFICIAIS NA PLATAFORMA SUL-AMERICANA
}

\author{
Remy D. Antezana Paniagua
}

Orientador: Prof. Dr. Georg Robert Sadowski

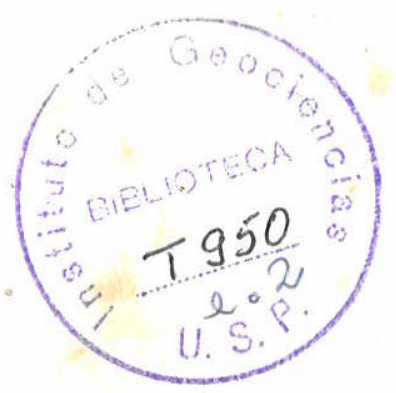

TESE DE DOUTORAMENTO

COMISSĀO EXAMINADORA

nome

Présidente: $\quad$ Dr. G.R.Sadowski

Examinadores:

Dr. I.I.G.Pacca

$\frac{\text { Dr. J.A.B. Gomez }}{\text { Dr. B.B.B.Neves }}$

Dr. N.EIlert
aSS.

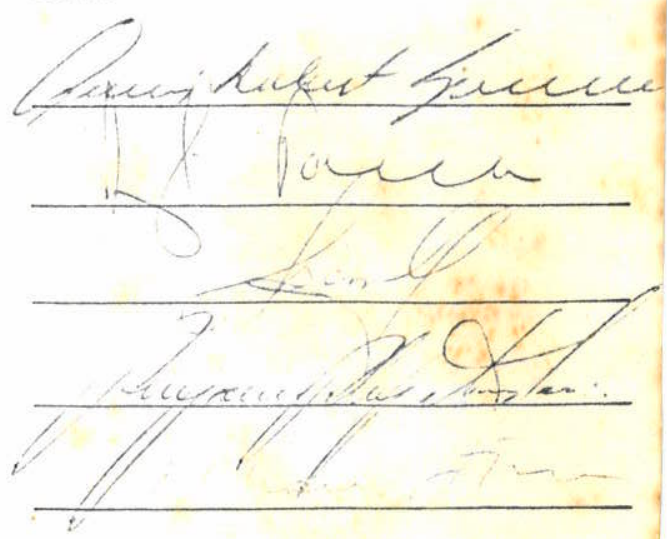


RESUMO

ABSTRACT

AGRADECIMENTOS

Lista de Tabelas

Lista de Figuras

CAPITULO 1 - INTRODUÇÄO
1.1 - Histōrico 1
1.2 - Objetivo do Presente Estudo
1.3
- Plano de Trabalho

CAPITULO 2 - DISPERSÃO DE ONDAS SUPERFICIAIS E TECNICAS DE ANÁLISE

2.1 - Ondas Superficiais 5

2.2 - Parāmetros de Dispersão 9

2.2.1 - Velocidade de fase e velocidade de grupo 9

2.3 - Modelos Teōricos 12

2.3.1 - Método Matricial de Thomson-Haskel1 13

2.3.1.1 - Solução para as 0ndas Rayleigh 13

2.3.1.2 - Solução para as ondas Love 19

2.4 - Técnicas de Anāilise 21

2.4.1 - Método de Filtragem Mūitipla 23

CAPITULO 3 - DADOS BĀSICOS
3. 1
- Estações Sismogrāficas
3.1.1 - Localização das Estações Sismogräficas
3.1.2 - Equipamento Sismogrāfico
3.2 - Dados Sísmicos
3.2.1 - Dados Utilizados 
pägina

3.2.1 - Preparação dos Dados 36

3.3 - Dados Geolōgicos e Geofísicos 40

3.3.1 - Plataforma Sul-Americana 40

3.3 .1 .1 -Estudos Anteriores 40

3.3.1.2 - Aspectos Geolögicos 42

CAPITULO 4 - INTERPRETAÇAO DOS RESULTADOS DE DISPERSAOO E COMPARAÇOES REGIONAIS

4.1 - Velocidades de Grupo 45

4.2 - Anälise das Curvas Experimentais da Velocidade de Grupo 46

4.3 - Modelo Teōrico Proposto 52

4.4 - Comparação com Modelos Crustais de outras Regiões de Escudos 60

CAPITULO 5 - CONCLUSÕES

BIBLIOGRAFIA

APENDICE A

APENDICE B 
Com o propósito de determinar a estrutura e earacterīsticas da crosta e manto superior na Plataforma Sul-Americana foi estudada a dispersão das ondas superficiais com períodos entre 10 e $50 \mathrm{~s}$.

Selecionaram-se 13 sismos, com epicentros distribuīdos no continente de tal forma que permita uma boa cobertura da Plataforma Sul-Americana. Os sismogramas de período longo utiliza dos são das estações sismogräficas de Brasīlia, Rio de Janeiro, Natal e La Paz (Bolívia).

As ondas superficiais dos sismos selecionados foram analisadas mediante a técnica de Filtragem Mūitipla; o resultado é uma matriz de amplitudes em função da velocidade de grupo e do período. As curvas de dispersão teōricas foram determinadas usando-se o método matricial de Thomson-Haskell.

A comparação entre os valores de dispersão teōricas e observados permitiu obter um modelo crustal representativo da região dos escudos do Brasil Central e Atlāntico. A espessura da crosta, segundo esse modelo, é de $40 \mathrm{~km}$.

As variações das velocidades de grupo das ondas Rayleigh para periodos inferiores a $20 \mathrm{~s}$, observadas na maioria dos sismos estudados, parecem estar associados à presença da cadeia andina ou de bacias sedimentares, na trajetōria das ondas superfi ciais.

Comparando-se a curva média de dispersão das ondas Rayleigh representativa da região dos escudos do Brasil central e 
Atlāntico, com suas similares de outras regiões de escudo, encontrou-se uma boa semelhança ccm a estrutura crustal da região afro asiātica. 


\section{ABSTRACT}

Surface wave dispersion analysis for periods between 10 and 50 sec have been accomplished to study the crust and upper man tle structure.

Thirteen South-American events with paths crossing the South American plataform were selected. Long period seismograms from Brasilia, Rio de Janeiro, Natal and La Paz (Bolivia) seismographic stations have been used.

Multiple Filter Tecnique were used to analyze surface wave dispersion; this method gives amplitudes as a function of group velocity and period. Theoretical dispersion curves were obtained by using the Thomson-Haskell Matrix Method.

A crustal model for the Central Brazil and Atlantic shields were obtained by comparing theoretical and observational dispersion curves. This model indicates a crust thickness of $40 \mathrm{~km}$.

Group velocity variations of Rayleigh waves, for periods under $20 \mathrm{sec}$, were observed in almost all cases; these varia tions seems to be associated to the presence of Andean Chain or. sedimentary basin, along the path of surface waves.

The comparison of the mean dispersion curve for Central Brazil and Atlantic shields with dispersion curves for other cratonic regions, showed a similarity with Afro-Asiatic crustal structure. 


\section{AGRADECIMENTOS}

Desejo expressar meu agradecimento ao Dr. Georg. R. Sa dowski pelo apoio e sugestões formuladas durante a execução do presente trabalho.

Estou muito grato ao Dr. Jesus Berrocal pelo apoio cons tante, revisão final do texto, discussões e sugestões formuladas na fase final do trabalho

Agradeço tambēm ao Dr. G. Cordani pela leitura do texto, sugestões e crīticas apresentadas.

Meus reconhecimentos ao pessoal das estações sismogrāficas de Brasīia, Rio de Janeiro, Natal e La Paz por colocarem à minha disposição os sismogramas utilizados no presente trabalho.

Meus reconhecimentos aos colegas do IAG, em especial a F. Hiodo, A. Bassini e C. Fernandes, que direta ou indiretamente deram seu apoio e colaboração no decorrer do trabalho.

Sou grato também ao Setor da Gräfica e do Xerox, prin cipalmente ao Sr. C. Maldonado.

Agradeço igualmente aos Srs. Josē R. Barbosa e A. Tori pelos trabalhos de datilografia e desenho efetuados. 


\section{Lista de Tabelas}

Tabela

Pāgina

3.1 - Dados das estações sismogräficas utilizadas

3.2 - Parāmetros hipocentrais e Distāncias epicentro - esta ção dos sismos utilizados

3.3 - Estudos Geofísicos realizados na Amērica do Sul

4.1 - Parāmetros do modelo teōrico proposto e velocidades de grupo teöricas para as ondas Rayleigh e Love 


\section{Lista de Figuras}

Figura

Pāgina

2.1 - Modelo constituj̃do de um meio elástico semi-infinito limitado pela superficie livre

2.2 - Modelo constituido de um meio semi-infinito e outro meio suprajacente de espessura finita

2.3 - Sismograma de $\operatorname{NAT}(Z)$ mostrando o.fenómeno de dispersão das ondas superficiais Rayleigh do sismo de 25. AG0.75 10

2.4 - Orientação dos eixos e numeração das camadas e interfaces

2.5 - Diagrama de fluxo do processo de Filtragem Müttipla

3.1 - Localização dos epicentros dos sismos selecionados e das estações sismogräficas utilizadas

3.2 - Curvas de resposta dos sismögrafos de período longo da estação RDJ

3.3 - Curvas deresposta dos sismögrafos de perïodo longo das estações de BDF, LPB e NAT

3.4 - Digitizador semi-automático

3.5 - Diagrama de bloco do digitizador

4.1 - Curvas de dispersão observadas para sismos com traje törias atravessando os escudos do Brasil central e Atlāntico

4.2 - Curvas de dispersão observadas para sismos com trajetōrias atravessando o escudo das Guianas 
Figura

4.3 - Curvas de dispersão observadas para sismos com tra jetōrias passando pela bacia do Paranā

4.4 - Comparação das curvas de dispersão para sismos com trajetörias atravessando a bacia do Paranä com a curva mëdia de dispersão para os sismos 55 e 51

4.5 - Curvas de dispersão observadas apresentando oscila ções da velocidade de grupo para períodos abaixo dos $20 \mathrm{~s}$

4.6 - Comparação da curva de dispersão para o sismo 52 com curvas de dispersão para sismos com trajetörias prōximas

4.7 - Curvas de dispersão observadas com oscilações pronunciadas para períodos acima de $20 \mathrm{~s}$.

4.8 - Curvas de dispersão observadas para as ondas Love

4.9 - Comparação entre as curvas de dispersão teōrica e observada

4.10- Comparação do modelo PSA-1 com modelos crustais de outras regiões de escudos 


\section{CAPITULO 1 \\ INTRODUÇÃO}

1.1 - Histōrico

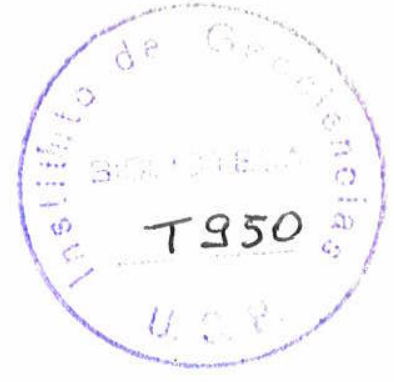

As primeiras tentativas para explicar a propagação de ondas foram realizadas por Poisson (1830), provando que um sōlido elástico, isotrópico, homogēneo e de dimensões infinitas, pode transmitir dois tipos de ondas com velocidades diferentes, geradas por uma perturbação no interior do corpo. Stokes (1849) demons trou que essas ondas causam deslocamentos longitudinais e transver sais nas partīculas do meio, em relação à direção de propagação, e conseguiu expressar as velocidades dessas ondas em função das cons tantes elāsticas e da densidade do meio.

Posteriormente, Rayleigh (1885) provou que as ondas geradas por uma fonte no interior de um corpo se refletem ao atingir a superfície limite desse corpo. Como resultado dessa reflexão, formam-se perturbações que se propagam pela superfície com velocidade inferior à velocidade das ondas transversais. Também foi demonstrado que os deslocamentos causados nas partículas do meio, pe la passagem dessas ondas, são na forma de elipses retrōgradas num plano vertical, com a componente horizontal paralela à direção de propagação. As ondas que apresentam estas características são denominadas ondas Rayleigh.

Mais tarde, 01dham (1900) levou em consideração a suges tão de Lord Rayleigh para interpretação dos registros sîsmicos, e conseguiu identificar além de 2 primeiras fases, que associou às ondas dilatacionais e transversais, uma fase sísmica posterior que 
a chamou de "choque principal" envolvendo deslocamentos horizontais e verticais, e uma grande parcela dos deslocamentos horizontais era transversal à direção de propagação da onda. 01 dham iden tificou o "choque principal" com ondas Rayleigh, porëm a sugestão não foi muito aceita.

Apōs a indentificação das ondas superficiais com deslo camentos horizontais e transversais à direção de propagação, Love (1911) desenvolveu a teoria que explica a existéncia dessas ondas, que levam o seu nome, e demonstrou tambëm, que as ondas de Rayleigh e:as de Love apresentam dispersão ao se propagarem por um semi-es paço constituído de camadas. Algumas características das propriedades dispersivas das ondas superficiais foram discutidas por sto neley (1925) e Jeffreys (1925).

A primeira tentativa de se usar a dispersão das ondas superficiais na investigação da estrutura da crosta, foi realiza da em 1924 por Gutenberg (1959), que encontrou velocidades de grupo (velocidade de um grupo de ondas entre o epicentro e a estação sismogräfica) de ondas com períodos de aproximadamente $30 \mathrm{~s}$, maiores para a crosta oceānica do que para a continental. os primeiros estudos, usando a dispersão de ondas superficiais, determi naram modelos simplistas e irreais devido à complexa teoria. Esses estudos foram intensificados a partir do trabalho publicado por Ewing et al (1957), entretanto, a potencialidade mäxima dessas pesquisas foi alcançada somente com o recurso dos computadores digitais.

Grande parte das pesquisas iniciais com ondas superficiais estava relacionada com a determinação de velocidades de gru po. Determinações precisas dos tempos de chegada de picos e vales 
de um trem de ondas dispersivas (Ewing et al, 1957) contribuiram para melhorar significativamente alguns resultados previamente pu b 7 icados.

os primeiros resultados obtidos com velocidades de fase (velocidade de uma determinada fase entre duas estações sismogräficas) foram em regiões limitadas, com características geolögi cas homogêneas (Press, 1956, 1957; Press et a 1, 1956; Brune e Dor $\operatorname{man}, 1963)$.

0 desenvolvimento de mētodos numëricos (Atterman et al., 1961) e o mëtodo iterativo de Thomson-Haskell (Haskel1, 1953) associados ao emprego de computadores, permitiram inümeros avanços relativos à dispersão das ondas superficiais. Nessa etapa jā era possivel adotar modelos de crosta e manto superior, constituidos de camadas mūitiplas, e tornava-se necessāria a anālise digital dos sismogramas para o processamento automātico.

Sato (1955, 1956, 1958) desenvolveu um método muito ut $\underline{i}$ lizado atualmente, que emprega as transformadas de Fourier, na anā lise das ondas superficiais.

Na dêcada de 60, inümeras tēcnicas de anälise de ondas superficiais tais como o da janela móvel (Dziewonski et al., 1968; Landisman et al., 1969) e da filtragem mültipla (Bloch e Hales, 1968; Landisman et al., 1968) foram aplicadas com resultados alta mente positivos.

Desde 1961, vēm-se efetuando na Amērica do Sul alguns estudos relativos à determinação da estrutura crustal mediante a dsipersão de ondas superficiais/cisternas, 1961; Rubín de Celis, 1967; Antezana, 1969; James, 1969; 0blitas, 1972). 
1.2 - Objetivo do presente estudo

o objetivo do presente trabalho e determinar a estrutu ra e caracteristicas da crosta e manto superior na Plataforma sulamericana, mediante o estudo da dispersão de ondas superficiais geradas por sismos naturais ocorridos ao longo da região andina e parte norte da Amërica do sul.

os resultados obtidos são uma contribuição ao conhecimento das propriedades físicas da crosta e do manto superior.

1.3 - Plano de trabalho

Para a obtenção das curvas de dispersão teöricas e obser vadas, foi necessärio recorrer a alguns conceitos teöricos e ao desenvolvimento matemätico do mëtodo de anālise das ondas superfi ciais, que são apresentados no capitulo 2 .

Todos os dados relativos aos sismos utilizados, a digi tização das ondas superficiais, às caracterīsticas e localização das estações sismogräficas consideradas, e aos aspectos georōgi$\cos$ da região estudada, estão no capĩtulo 3 .

os comentārios referentes à construção das curvas de dispersão de velocidades de grupo observadas, êrros experimentais envolvidos, determinação dos modelos teöricos para a plataforma Sulamericana, e sua comparação com modelos crustais de outras regiões são abordados no capitulo 4 .

Finalmente, no capitulo 5 estão sintetizados os resultados obtidos no presente trabalho. 
CAPITULO 2

\section{DISPERSAO DE ONDAS SUPERFICIAIS E TECNICAS DE ANALISE}

\section{1 - Ondas Superficiais}

As ondas elásticas geradas por um sismo ou explosão pro pagam-se atravēs do interior da Terra ou ao longo das camadas superficiais. Essas ondas elästicas são de dois tipos: as ondas de volume, $P($ longitudinal) e $S($ transversal), que se propagam através do interior da Terra, e as ondas superficiais (Rayleigh, Love Sto neley, Sezawa) que se propagam ao longo das camadas superficiais. Estes dois tipos de ondas, alëm de seguirem trajetōrias diferentes da propagação, diferem tambēm nas caracterīsticas e velocidades de propagação. Nos sismogramas de periodo curto, as ondas de volume são observadas com períodos de aproximadamente 1s, enquanto que as ondas superficiais se apresentam com aproximadamente 20 s de período, nos sismogramas de período longo.

A velocidade de propagação das ondas superficiais depende de um conjunto de propriedades elästicas que variam com a profundidade. A propagação das ondas superficiais não estä totalmente limitada à superfīcie, havendo um decrēscimo exponencial da amplitude com a profundidade e a razão de decrēscimo dessa amplitude depende fundamentalmente do comprimento de onda.

Os fundamentos teöricos das ondas superficiais são abordados em värios textos especializados (Ewing, et al, 1957; Bullen, 1965, Pilant, 1979), de tal modo que neste capítulo será feita apenas uma breve apresentação dos procedimentos bāsicos, necessärios para a obtenção das equações de velocidade das principais ondas 
superficiais (Rayleigh e Love).

Na teoria de propagação das ondas sĩsmicas são supostas deformação infinitesimais e meios isotrōpicos perfeitamente elästi cos. Para simplificar o tratamento analitico, as condições de propagação das ondas superficiais serão tratadas de maneira anāloga à das ondas planas.

Considerando-se um meio constituido de camadas com interfaces planas e paralelas, um sistema de coordenadas cartesianas, tal que o plano $x_{1} x_{2}$ represente a superfície livre, e uma onda pro pagando-se na direção $0 x_{1}$ (Fig. 2.1), de modo que a frento de onda seja paralela ao eixo $0 x_{2}$, em qualquer instante, nesse caso tem-se $\partial u_{i} / \partial x_{2}=0$, onde $u_{i}(i=1,2,3)$ è o destocamento.

As ondas Rayleigh requerem para sua existēncia, um mode 10 constituído de um meio elästico semi-infinito limitado pela superficie livre, de modo que sejam satisfeitas as condições de contorno que determinam que as tensöes e os deslocamentos devem ser nulos na superfície livre $\left(X_{3}=0\right)$ (Fig. 2.1). Neste caso, a velocidade c das ondas Rayleigh ē definida em função das propriedades fí sicas do meio (Bu11en, 1965) atravēs de:

$$
(c / \beta)^{6}-8(C / \beta)^{4}+c^{2}\left(24 / \beta^{2}-16 / \alpha^{2}\right)-16\left(1-\beta^{2} / \alpha^{2}\right)=0
$$

onde,

$$
\begin{aligned}
& \alpha \text { : velocidade das ondas } P \\
& \beta \text { : velocidade das ondas } S
\end{aligned}
$$

A presença das velocidades das ondas $\mathrm{P}$ e $\mathrm{S}$ (componente vertical) na equação acima, implica na existēncia das componentes de deslocamento $u_{7}$ e $u_{3}$, de tal forma que as partículas do meio descrevem elipses retrögradas, onde a razão entre os eixos verti- 


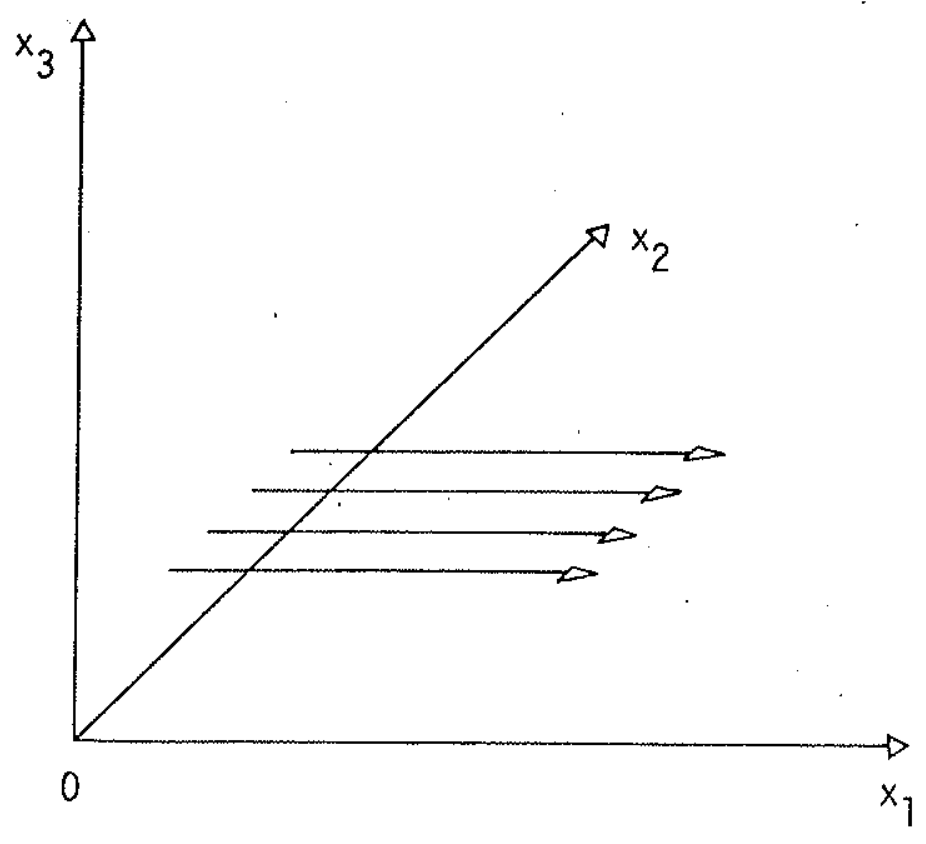

Fig. 2.1 - Modelo constituído de um meio elástico semiinfinito limitado pela superficie livre

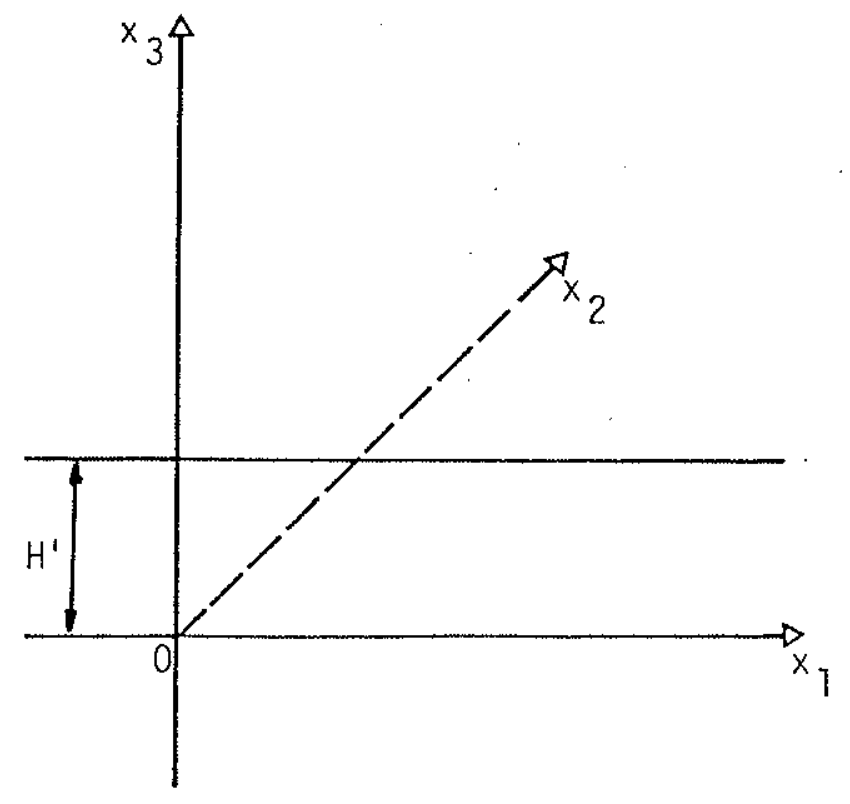

Fig. 2.2 - Modelo constituído de um meio semi-infinito e outro meio suprajacente de espessura finita 
cal e horizontal $\bar{e}$ de aproximadamente $3: 2$, durante a passagem das ondas Rayleigh.

Na equação (2.1.1) a velocidade das ondas Rayleigh està em função das velocidades das ondas $P$ e $S$, e é independente do comprimento de onda $(\lambda=2 \pi / k)$, o que significa que as ondas Rayleigh não apresentam dispersão. A equação de velocidade c das ondas Rayleigh que apresentam dispersão, para um meio constituído de camadas mültiplas, estä representada pela equação (2.3.21) do item 2.3.1.

Em 1911, Love desenvolveu a teoria de transmissão das ondas superficiais, com deslocamentos horizontais e transversais à direção de propagação, num modelo onde se admite o meio-infinito de Rayleigh e outro meio suprajacente de espessura finita ( $\left.H^{\prime}\right)$ (fig. 2.2). Este modelo, com relação ao de Rayleigh, ajusta-se me Thor às condições reais da Terra.

Tratando-se de ondas Love è suficiente considerar a componente de deslocamento $u_{2}$ (paralela ao eixo $0 x_{2}$ ). Desta forma, aplicando-se a condição de contorno, que as tensões devem ser nulas na superfície livre $\left(X_{3}=H^{\prime}\right)$, a equação da velocidade $c$ das on das Love em função das propriedades do meio e do comprimento de onda $2 \pi / k$ (Butien, 1965) é:

$$
\left(1-c^{2} / \beta^{2}\right)-\left[\mu^{\prime}\left(c^{2} / \beta^{\prime 2}-1\right)^{1 / 2}\right] \tan \left[k H^{\prime}\left(c^{2} / \beta^{\prime 2}-1\right)^{1 / 2}\right]=0 \quad(2.1 .2)
$$

onde,

$k:$ nümero de onda

B: velocidade da onda $S$ no meio semi-infinito

$\beta$ : velocidade da onda $S$ no meio suprajacente

$H^{\prime}$ : espessura do mejo finito suprajacente 
Para que as ondas Love possam existir é necessärio que $\beta>\beta^{\prime}$.e $\beta^{\prime}<c<\beta$.

\section{2 - Parāmetros de Dispersão}

A dispersão ē um fenōmeno onde uma perturbação transmị tida muda de forma à medida que o tempo passa, devido à variação da velocidade de propagação da onda com o comprimento de onda.

Para ilustrar este fenōmeno, consideremos o problema da corda vibrante com sua equação acrescida de um termo que repre senta a força adicional proporcional ao deslocamento; dessa forma a equação de movimento seria:

$\rho \frac{\partial^{2} y}{\partial t^{2}}=s \frac{\partial^{2} y}{\partial x^{2}}-h y$

onde: $\rho=$ densidade, $S=$ tensão, $h=$ nova constante. 0 termo - hy representa a força adicional. Uma solução tentativa $\bar{e}$

$y=A \cos [k(x-c t)+\varepsilon]$

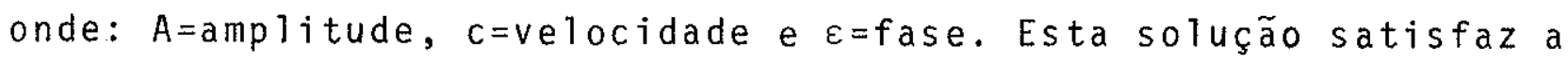
equação (2.2.1) se:

$\rho^{2} c^{2} k^{2}=S k^{2}+h$

se $h=0$, a velocidade $c$ serä definida apenas por $s$ e $\rho$. No entanto, para valores de $h \neq 0, c$ depende de $k$ (e portanto do comprimento de onda $\lambda=2 \pi / k$ e do período $\tau=2 \pi / k c)$, ou seja, a velocidade $c$ de pro pagação da onda serā maior quanto maior for o comprimento de onda. Este fenömeno é chamado de dispersão e pode ser visualizado no sismograma da Fig. 2.3 .

2.2.1 - Velocidade de fase e velocidade de grupo

A diferença entre estas duas velocidades jä foi aponta 


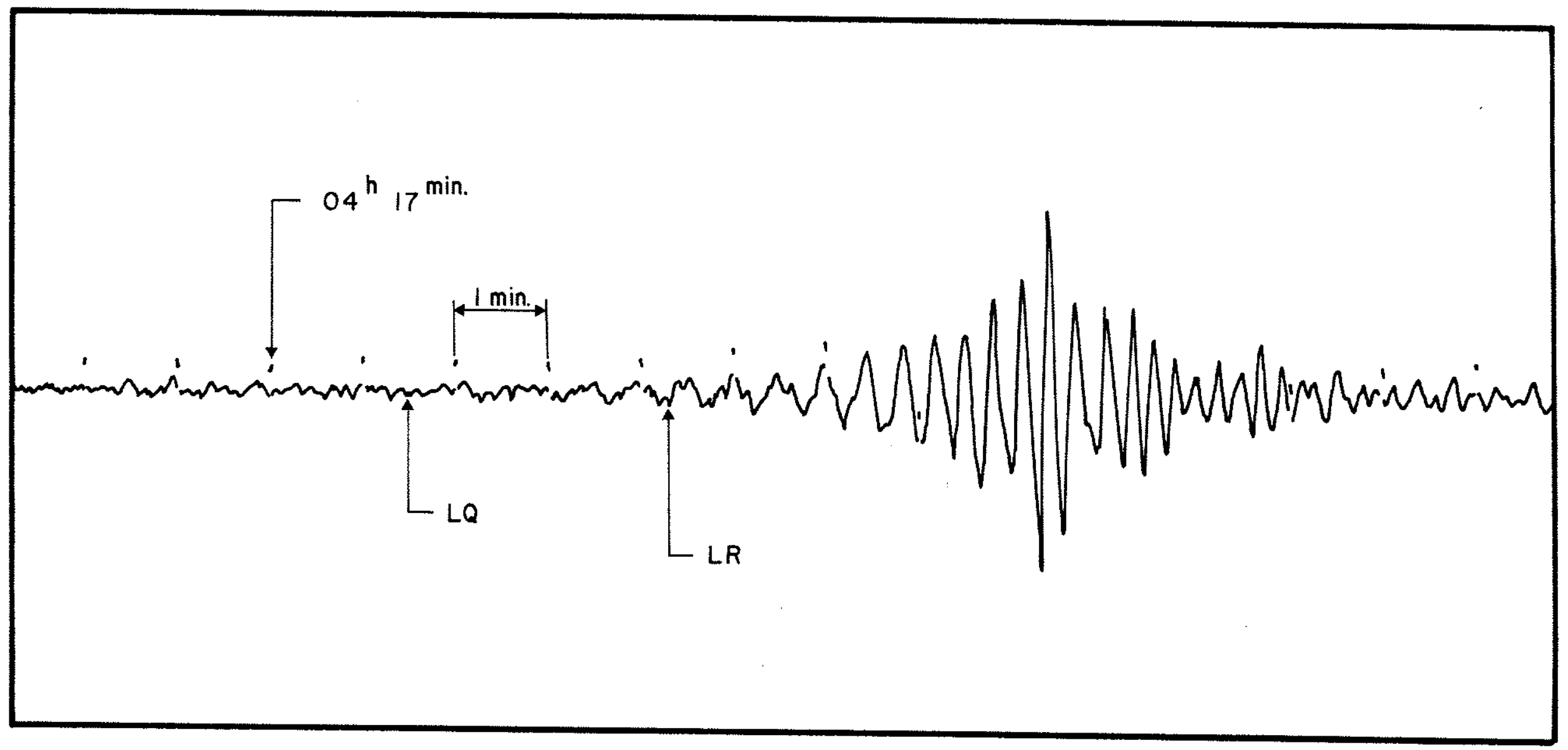

FIG.2.3 - SISMOGRAMA DE NAT (Z) MOSTRANDO O FENŌMENO DE DISPERSĀO DAS ONDAS SUPERFICIAIS DE RAYLEIGH DO SISMO DE 25 AGO 75. 
da nos primeiros trabalhos de Lord Rayleigh, quando abordou problemas relativos a medidas da velocidade da luz.

Para definir estas velocidades è necessārio rever algumas das propriedades da teoria de vibrações. Sabe-se que qualquer sinal sĩsmico pode ser representado pela composição de vibra ções harmōnicas, no entanto, havendo dispersão cada componente harmōnica da onda propaga-se com uma determinada velocidade de fa se, como por exemplo numa onda:

$\phi=A \cos (\omega t-k x)=A \cos \omega(t-x / c)$

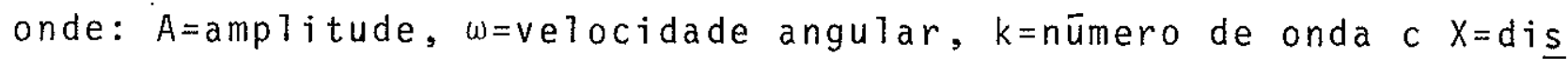
tancia da fonte de um ponto qualquer da onda no instante $t$. Na equação (2.2.4) a velocidade de fase è dada por:

$c=\omega / k$

Como consequência das propriedades de dispersão do meio, um grupo de vibrações harmōnicas podem estar em fase, aumentando a amplitude total, ou em defasagem, ao ponto de se anularem as am plitudes. Este quadro complexo de amplificações e atenuações rela tivas não. è constante, pois muda à medida que a onda se propaga, formando grupos de ondas que se propagam com uma velocidade de gru po U. Por exemplo, uma simples combinação de grupos é obtida da superposição de:

$\omega_{1}=\omega+\Delta \omega ; \quad k_{1}=k+\Delta k$

$\omega_{2} \omega-\Delta \omega ; \quad k_{2}=k-\Delta k$

resultando em:

$\dot{\phi}=A \cos \left(\omega_{1} t-k_{1} x\right)+A \cos \left(\omega_{2} t-k_{2} x\right)$

$\phi=2 A \cos (\omega t-k x) \cos (\Delta \omega t-\Delta k x)$ 
esta onda pode ser descrita como a propagação de uma sucessão de grupos de ondas. Neste caso a velocidade de grupo $U$ é dada por: $U=\frac{\Delta \omega}{\Delta k} \longrightarrow \frac{\partial \omega}{\partial k}$ para $\Delta k \rightarrow 0$

Uma förmula comum para determinar a velocidade de grupo U quando conhecida a velocidade de fase $c$ (em função da frequéncia ou comprimento de onda $\lambda$ ) $\overline{\mathrm{e}}$ a seguinte:

$U=c-\lambda \frac{d c}{d \lambda}$

onde $d c / d \lambda \bar{e}$ positiva para as ondas sismicas superficiais. Assim, - valor da velocidade de grupo para uma determinada frequéncia se rá sempre menor que a velocidade de fase para a mesma frequéncia.

2.3 - Modelos Teöricos

Em Sismologia, assim como nas cutras ciências experimen tais, adota-se a filosofia geral de propor modelos para explicar um determinado fenomeno. Alguns trabalhos tem se concentrado nos estudos da propagação de ondas em vārios modelos, que representam estruturas reais ou hipotéticas da Tarra. 0 uso de modelos teōricos na propagação de ondas tem como objetivo complementar as investigações teöricas e os fenōmenos observados.

No presente trabalho, foi adotado como modelo inicial, - modelo de estrutura crustal da região cratōnica do Canadā (Brune, et al, 1963) devido às semelhanças geotectōnicas existentes entre regiões cratōnicas. Neste modelo foram efetuadas variações das espessuras, das velocidades da onda $S$ e das densidades para ajustar os modelos aos dados observados.

As curvas de dispersão correspondentes aos modelos teoricos de camadas planas, foram obtidas atravēs de um programa de- 
senvolvido em linguagem FORTRAN, que emprega o método matricial de Thomson-Haskell descrito adiante, na solução das funções de disper são das velocidades de grupo das ondas superficiais.

\subsection{1 - Mëtodo matricial de Thomson-Haskell}

As caracterīsticas de propagação de ondas elāsticas nos meios isotrōpicos tornam-se complexas devido às dificuldades encon tradas nas resoluções das equações empregadas. 0 mëtodo matricial de Thomson-Haskell(Haskell, 1953) mostrou-se uma ferramenta muito ütil na avaliação numérica das propriedades de casos especĩficos.

Neste trabalho foj empregado o mëtodo matricial citado acima, no estudo da dispersão das ondas superficiais Rayleigh e Lo ve. A notação matricial apresentada a seguir, é aquela formulada por Haskel1(1953), que usa o método introduzido por Thomson(1950).

2.3.1.1 - Solução para as ondas Rayleigh

0 procedimento descrito por Haskell considera ondas planas propagando-se na direção $+x$, através de um meio constituIdo de camadas sōlidas, homogēneas e isotrōpicas (vide Figura 2.4).

Na notação dada abaixo, o indice m refere-se à m-ësima camada:

$$
\begin{aligned}
\rho_{m} & =\text { densidade } \\
d_{m} & =\text { espessura da camada } \\
\lambda_{m}, \mu_{m} & =\text { constantes elásticas de Lamé } \\
p & =\text { frequéncia angular } \\
c & =\text { velocidade de fase } \\
k & =p / c=2 \pi /(\text { comprimento de onda) }
\end{aligned}
$$

Então: 
INTERFACE

CAMADA

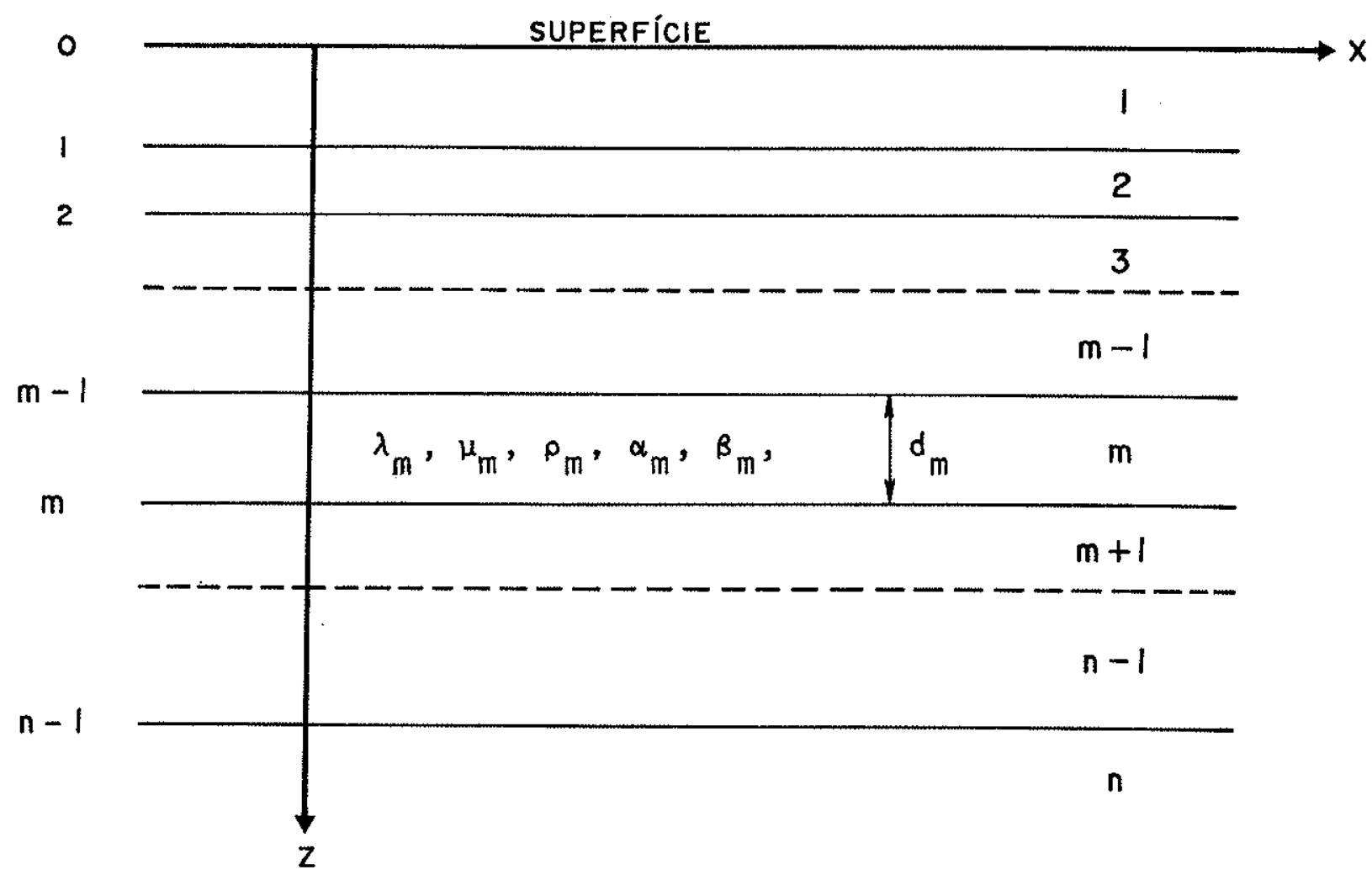

FIG.2.4- ORIENTACÃO DOS EIXOS E NUMERACÃO DAS CAMADAS E INTERFACES. 


$$
\begin{aligned}
& \alpha_{m}=\left[\left(\lambda_{m}+2 \mu_{m}\right) / \rho_{m}\right]^{1 / 2}=\text { velocidade da onda } p \\
& \beta_{m}=\left(\mu_{m} / \rho_{m}\right)^{1 / 2} \quad=\text { Velocidade da onda } \mathrm{s} \\
& r_{\alpha_{m}}= \begin{cases}+\left[\left(c / \alpha_{m}\right)^{2}-1\right]^{1 / 2} & \text { para } c>\alpha_{m} \\
-i\left[\left(1-\left(c / \alpha_{m}\right)^{2}\right]^{1 / 2}\right. & \text { para } c<\alpha_{m}\end{cases} \\
& r_{\beta_{m}}= \begin{cases}+\left[\left(c / \beta_{m}\right)^{2}-1\right]^{1 / 2} & \text { para } c>\beta_{m} \\
-i\left[\left(1-\left(c / \beta_{m}\right)\right]^{1 / 2}\right. & \text { para } c<\beta_{m}\end{cases} \\
& \gamma_{m}=2\left(\beta_{m} / c\right)^{2} \\
& \sigma=Z_{z} \text { : tensão normal } \\
& \tau=X_{z}: \text { tensão tangencial }
\end{aligned}
$$

No desenvolvimento deste mëtodo será utilizado o trata mento clässico dado por Bullen(1965).

Durante a propagação das ondas Rayleigh, na direção $x$, não existe deslocamento nem tensão tangencial na direção y. As soluções periōdicas das equações elästicas de movimento para a m-ës ma camada pode ser dada como a soma das soluções da onda dilatacio nat (BuTlen, 1965):

$\Delta_{m}=\frac{\partial u}{\partial x}+\frac{\partial w}{\partial z}=\exp [i(p t-k x)]\left[\Delta_{m}^{\prime} \exp \left(-i k r_{\alpha_{m}} z\right)+\Delta_{m}^{\prime \prime} \exp \left(i k r_{\alpha_{m}}\right)\right]$

e, as soluções da onda rotacional.

$w_{m}=\frac{1}{2} \frac{\partial u}{\partial z}-\frac{\partial w}{\partial x}=\exp [i(p t-k x)]\left[w_{m}^{\prime} \exp \left(-i k r_{\beta_{m}} z\right)+w_{m}^{\prime \prime} \exp \left(i k r_{\beta_{m}} z\right)\right]$ 
onde,

$\Delta_{m}^{\prime}, \quad \Delta_{m}^{\prime \prime}, \quad w_{m}^{\prime}, w_{m}^{\prime \prime}$, constantes de integração

As componentes de deslocamento e esforço correspondentes à dilatação e rotação, obtidas das equações (2.3.1) e (2.3.2), são:

$u=-\left(\alpha_{m} / p\right)^{2}\left(\partial \Delta_{m} / \partial x\right)-2\left(\beta_{m} / p\right)^{2}\left(\partial w_{m} / \partial z\right)$

$w=-\left(\alpha_{m} / p\right)^{2}\left(\partial \Delta_{m} / \partial z\right)+2\left(\beta_{m} / p\right)^{2}\left(\partial w_{m} / \partial x\right)$

$\sigma=\rho_{m}\left[\alpha_{m}{ }^{2} \Delta_{m}+2 \beta_{m}{ }^{2}\left\{\left(\alpha_{m} / p\right)^{2}\left(\partial^{2} \Delta_{m} / \partial x^{2}\right)+2\left(\beta_{m} / p\right)\left(\partial^{2} w_{m} / \partial x \partial z\right)\right\}\right]$

$\tau=2 \rho_{m} \beta_{m}^{2}\left[-\left(\alpha_{m} / p\right)^{2}\left(\partial^{2} \Delta_{m} / \partial x \partial z+\left(\beta_{m} / p\right)^{2}\left\{\left(\partial^{2} w_{m} / \partial x^{2}\right)-\left(\partial^{2} w_{m} / \partial z^{2}\right)\right\}\right]\right.$

Como condições de contorno na interface entre as 2 camadas, admitem-se que os 4 valores $u, w, \sigma$ e t são contĩnuos. Os deslocamentos são continuos se as correspondentes componentes de velo cidades $\dot{u}$ e $\dot{w}$ são contĩnuas e, admitindo-se que c è a mesma em todas as camadas, as quantidades adimensionais úc e $\dot{w} / c$ tambēm são continuas.

Substituindo-se as equações $(2.3 .1)$ e $(2.3 .2)$ nas equa ções (2.3.3) a (2.3.6) e expressando-se as funções exponenciais na forma trigonomëtrica, tem-se as equações (2.3.7) a (2.3.10), dadas no Apēndice A.

No trabalho de Haskell foi considerada a origem de $z$ na interface $(\mathrm{m}-1)(\mathrm{Fig} .2 .4)$; então a relação linear entre os valores $\dot{u} / c, \dot{w} / c, \sigma$ e $\tau$ nessa interface e as contantes $\Delta_{m}^{\prime}, \Delta_{m}^{\prime \prime}, \quad w_{m}^{\prime}$, $w_{m}^{\prime \prime}$, pode ser dada pela seguinte transformação: 


$$
\left(\dot{u}_{m-1} / c, \dot{w}_{m-1} / c, \sigma_{m-1}, \tau_{m-1}\right)=E_{m}\left(\Delta_{m}^{\prime}+\Delta_{m}^{\prime \prime}, \Delta_{m}^{\prime}-\Delta_{m}^{\prime \prime}, w_{m}^{\prime}-w_{m}^{\prime \prime}, w_{m}^{\prime}+w_{m}^{\prime \prime}\right)
$$

onde,

$$
E_{m}: \text { matriz (2.3.12) (vide Apēndice A) }
$$

De maneira anäloga, fazendo-se $z=d_{m}$, os valores de $\dot{u} / c$, $\dot{w} / c$, o e $\tau$ na interface $m$, podem ser expressos em função de $\Delta_{m}^{\prime}+$ $\Delta^{\prime \prime}$ :

$$
(\dot{u} / c, \dot{w} / c, \sigma, \tau)=D_{m}\left(\Delta_{m}\left(\Delta_{m}^{\prime}+\Delta_{m}^{\prime \prime}, \Delta_{m}^{\prime}-\Delta_{m}^{\prime \prime}, w_{m}^{\prime}-w_{m}^{\prime \prime}, w_{m}^{\prime}+w_{m}^{\prime \prime}\right)\right.
$$

onde,

$$
D_{m}: \text { matriz } \quad(2.3 .14) \text { (vide Apêndice A) }
$$

As constantes $\Delta_{m}^{\prime}, \Delta_{m}^{\prime \prime}, w_{m}^{1}, w_{m}^{\prime \prime}$ podem ser substitujdas nas equações (2.3.11) e (2.3.12), dando uma relação linear entre os va lores $\dot{u} / c, \dot{w} / c, \sigma$ e $\tau$ nas interfaces superior e inferior, da m-ēs $i-$ ma camada:

$$
\left(\dot{u}_{m} / c, \dot{w}_{m} / c, \sigma_{m}, \tau_{m}\right)=D_{m} E_{m}^{-1}\left(\dot{u}_{m-1} / c, \dot{w}_{m-1} / c, \sigma_{m-1}, \tau_{m-1}\right)
$$

onde

$$
E_{m}^{-1}: \text { inversa de } E_{m} \quad(2.3 .16) \text { (vide Apēndice } A \text { ) }
$$

os elementos do produto das 2 matrizes $a_{m}=D_{m} E_{m}^{-1}$ são mostrados no Apēndice $A$.

$$
\text { Apticando-se as condições de contorno e fazendo-se com }
$$
que os valores $\dot{u} / c, \dot{w} / c, \sigma$ e $\tau$ calculados para a interface superior da camada m, sejam iguais aos da base da (m-1)-ēsima camada, temmse:

$$
\left(\dot{u}_{m} / c, \dot{w}_{m} / c, \sigma_{m}, \tau_{m}\right)=a_{m} a_{m-1}\left(\dot{u}_{m-2} / c, \dot{w}_{m-2} / c, \sigma_{m-2}, \tau_{m-2}\right)
$$


Aplicando-se o processo iterativo, tem-se:

$\left(\dot{u}_{n-1} / c, \dot{w}_{n-1} / c, \sigma_{n-1}, \tau_{n-1}\right)=a_{n-1} a_{n-2} \ldots a_{1}\left(\dot{u}_{0} / c, \dot{w}_{0} / c, \sigma_{0}, \tau_{0}\right)$

Atravēs da inversa da equação (2.3.11) para a n-ēsima camada, tem-se:

$\Delta_{n}^{\prime}+\Delta_{n}^{\prime \prime}, \Delta_{n}^{\prime}-\Delta_{n}^{\prime \prime}, w_{n}^{\prime}-w_{n}^{\prime \prime}, w_{n}^{\prime}+w_{n}^{\prime \prime}=E_{n}^{-1} a_{n-1} a_{n-2} \ldots a_{1}\left(\dot{u}_{0} / c, \dot{w}_{0} / c, \sigma_{0}, \tau_{0}\right)$

A equação (2.3.19) è generalizada, sendo vālida para o caso de ondas de volume e de ondas superficiais propagando-se num meio de camadas mültiplas. Limitando-se às ondas superficiais, não existem esforços na superficie livre, portanto $\sigma_{0}=\tau_{0}=0$ e $\Delta_{n}^{\prime \prime}=w_{n}^{\prime \prime}=0$, afim de que as ondas superficiais decresçam com a profundidade.

Substituindo-se o produto das matrizes $E_{n}^{-1} a_{n-1} a_{n-2} \cdots$ $a_{1}$ por J, na equação $(2.3 .19)$ :

$\left(\Delta_{n}^{\prime}, \Delta_{n}^{\prime \prime}, w_{n}^{\prime}, w_{n}^{\prime \prime}\right)=J\left(\dot{u}_{0} / c, \dot{w}_{0} / c, 0,0\right)$

A forma explīcita da equação acima è dada pela relação (2.3.21) no Apēndice A. Substituindo-se $\Delta^{\prime}{ }_{n}$ e $W^{\prime}{ }_{n}$ :

$\frac{\dot{u}_{0}}{\dot{w}_{0}}=\frac{\mathrm{J}_{22^{-J_{12}}}}{\mathrm{~J}_{11}-\mathrm{J}_{21}}=\frac{\mathrm{J}_{42^{-J_{32}}}}{\mathrm{~J}_{31}-\mathrm{J}_{41}}$

Como os elementos da matriz J dependem dos parāmetros $k$ e c, a equação (2.3.2 2) fornece uma relação implîcita entre c e k, que ē a função de dispersão da velocidade de fase.

2.3.1.2 - Solução para as Ondas Love

No caso de ondas Love, as condições de contorno impostas para cada interface säo a continuidade das componentes trans- 
versais de deslocamento $v$ e do esforço $Y_{Z}$.

De um modo anālogo ao caso das ondas Rayleigh, Haskell mostrou que os valores das componentes de deslocamento e esforço, na interface $(m-1)$, pode ser escrita da seguinte forma:

$$
\begin{aligned}
& (\dot{v} / c)_{m-1}=i k\left(v_{m}^{\prime}+v_{m}^{\prime \prime}\right) \\
& \left(Y_{z}\right)_{m-1}=i k \mu_{m} r \beta_{m}\left(v_{m}^{\prime \prime}-v_{m}^{\prime}\right)
\end{aligned}
$$

$\mathrm{Na}$ interface m tem-se:

$$
\begin{aligned}
& (\dot{v} / c)_{m}=\left(v_{m}^{\prime}+v_{m}^{\prime \prime}\right) i k \cos Q_{m}-\left(v_{m}^{\prime \prime}-v_{m}^{\prime}\right) k \operatorname{sen} Q_{m} \\
& \left(Y_{z}\right)_{m}=-\left(v_{m}^{\prime}+v_{m}^{\prime \prime}\right) k \mu_{m} r_{\beta_{m}} \operatorname{sen} Q_{m}+\left(v_{m}^{\prime \prime}-v_{m}^{\prime}\right) i k \mu_{m} r_{\beta_{m}} \cos Q_{m}
\end{aligned}
$$

$$
\text { Substituindo-se } v^{\prime}{ }_{m} \text { e } v^{\prime \prime}{ }_{m} \text { nas equações }(2.3 .23) \text { e }
$$

$3.24):$

$$
\begin{aligned}
& (\dot{v} / c)_{m}=(\dot{v} / c)_{m-1} \cos Q_{m}+\left(Y_{z}\right)_{m-1} \mu_{m}^{-1} r_{\beta_{m}}^{-1} i \operatorname{sen} Q_{m} \\
& \left(Y_{z}\right)_{m}=(\dot{v} / c)_{m-1} i \mu_{m} r_{\beta_{m}} \operatorname{sen} Q_{m}+\left(Y_{z}\right)_{m-1} \cos Q_{m}
\end{aligned}
$$

A matriz $a_{m} \bar{e}$ dada pela relação (2.3.26) do Apēndice A. Fazendo-se $a_{n-1} a_{n-2} \cdots a_{1}=A$ como no caso das ondas Rayleigh, temse uma equação anāloga à (2.3.18):

$$
\begin{aligned}
& (\dot{v} / c)_{n-1}=A_{11}(\dot{v} / c)_{0}+A_{12}\left(Y_{z}\right)_{0} \\
& \left(Y_{z}\right)_{n-1}=A_{21}(\dot{v} / c)_{0}+A_{22}\left(Y_{z}\right)_{0}
\end{aligned}
$$$$
\text { Usando-se a equação (2.3.23), para } m=n \text { : }
$$

$$
v_{n}^{\prime}+v_{n}^{\prime \prime}=A_{11}(i k)^{-1}(\dot{v} / c)_{0}+A_{12}(i k)^{-1}\left(Y_{z}\right)_{0}
$$




$$
v_{n}^{\prime \prime}-v_{n}^{\prime}=A_{21}\left(i k \mu_{n} r_{B_{n}}\right)^{-1}(\dot{v} / c)_{0}+A_{22}\left(i k \mu_{n} r_{B_{n}}\right)^{-1}\left(v_{z}\right)_{0}
$$

As condições para a existencia das ondas superficiais são: $\left(Y_{z}\right)_{0}=0$ e $v_{n}^{\prime \prime}=0$. Portanto a expressão (2.3.28) fica reduzida a:

$$
A_{21}=-\mu_{n} r_{B_{n}} A_{11}
$$

No caso de duas camadas, o termo $A$ é igual a $\alpha_{1}$ e a equação (2.3.29) è expressa numa forma bem conhecida, que é a equa ção de dispersão das ondas Love:

$$
\tan Q_{1}=-i\left(\mu_{2} r_{\beta_{2}} / \mu_{1} r_{\beta_{1}}\right)
$$

2.4 - Tēcnicas de anāitise

0 conhecimento atual das propriedades fisicas do interior da Terra estā associado ao desenvolvimento de tēcnicas de anā lise de ondas sísmicas superficiais. A aplicação das propriedades de dispersão das ondas superficiais no estudo da estrutura crustal iniciou-se em 1924, com Gutenberg(1959). Mais tarde, värios trabaThos relativos a estas ondas foram publicados, tais como os de Sato(1955, 1956), Ewing et al (1957), Press(1956, 1957), Press et a (1956), Brune et al(1960), Haskel1(1953), Landisman et al(1969), Block e Hales(1968), etc.

A partir da dēcada de 50, foram desenvolvidas värias técnicas de anālise das ondas superficiais, visando a determinação das velocidades de grupo e de fase, tais como:

a) O Método Clássico elaborado por Sato(1955, 1956), que utiliza a transformada de Fourier para se obter informações de fase. Esta téc nica desenvolvida para determinar c a partir de dados de duas esta 
ções, elimina o problema da diferença de fase no foco, que dificu] ta a determinação de c a partir de dados de uma estação somente;

b) o Mëtodo de Correlação Cruzada, (Landisman et al, 1969) onde a dispersão das ondas superficiais entre duas estações ē representada pelo processo de deconvolução do sinal da segunda estação com relação à primeira. Alēm da diferença de fase entre as estações, 0 espectro do sinal contēm informações de amplitude. Portanto, a fun ção da diferença de fase entre as estações é calculada pela transformada de Fourier do correlograma cruzado. Existem vārias formas de correlação cruzada tais como as propostas por Aki(1964), Block e Hales(1968);

c) o Método das Somas e Diferenças, introduzido por Block e Hales (1968), que se baseia no seguinte principio: quando duas funções estão em fase, para uma determinada frequéncia, a soma atingirä 0 valor māximo enquanto que a diferença, o mīnimo. A resolução deste método pode ser melhorada, aplicando-se a razão das matrizes de amplitudes da diferença e da soma.

Na determinação da velocidade de grupo são utilizados: a) o Mëtodo clässico de Pico e vale, que se inicia pela identifica ६̧ão e numeração dos picos ou vales do sinal. Na etapa seguinte, de terminam-se os perīodos pela medida do gradiente da curva do número do pico em função do tempo de chegada. As velocidades de grupo para cada perĩodo, são calculadas dividindo-se a distáncia epicentral pelo tempo de propagação de cada pico ou vale. Majores detalhes sobre este mëtodo podem ser encontrados nos trabalhos de Press (1956,1957), Ewing e Press(1952), Press et a1, (1956), Brune e Dor man(1963), Rubin de Celis(1967), e outros;

b) o Mētodo da Janela Mōvel, desenvolvido por Landisman et al, (1969), 
$\bar{e}$ equivalente ao mëtodo analögico proposto por Ewing et al, (1959). o sinal sismico digitizado è multiplicado por uma função janela móvel centrada em determinados pontos, correspondentes a uma série de intervalos de velocidades de grupo. A cada intervalo de ve locidade de grupo aplica-se a transformada de Fourier, obtendo-se como resultado uma matriz, onde as amplitudes são dadas em função da velocidade de grupo e do período;

c) O Método da Filtragem Mūltipla, que foi o adotado no presente trabalho, serā descrito com detalhes mais adiante.

0 critērio de escolha deste ültimo método para a determinação das velocidades de grupo, è que permite obter resultados com uma resolução em frequência, maior que nos outros dois më todos citados acima (Dziewonski et al, 1968). o mētodo clāssico de Pico e Vale não pode ser aplicado no caso de ondas superficiais com uma relação sinal/ruĩdo muito pequena, ou quando o sinal sĩsmico estā contaminado por outras fases sísmicas. Segundo Block e Hales(1968) este método apresenta sērias dificuldades para fragmen tos não dispersivos do sinal e no caso de ondas superficiais com dispersão normal e inversa. Uma das desvantagens do mētodo da Janela Mōvel é a distorção introduzida pelos processos de truncamen to e modulação da sērie temporal, quando aplicados à uma função ja nela (Dziewonski et a), 1969; Landisman et ai, 1969).

\subsection{1 - Mëtodo da Filtragem Mürtipla}

0 método proposto por Block e Hales(1968) permite a filtragem do sismograma com o recurso de um conjunto de filtros de banda estreita e determinação das envolventes das amplitudes instantâneas. Atravēs dos conceitos de amplitude e fase instantäneas 
pode-se obter o atraso de fase em função do tempo, admitindo-se que o tempo de propagação do grupo de ondas ē uma função monotōni ca da frequéncia.

Segundo Goodman(1960), a amplitude $A_{n}(t)$ e a fase $\phi_{n}$ (t) instantāneas são definidas pela relação:

$A_{n}(t) e^{i \phi_{n}(t)}=h_{n}(t)+i q_{n}(t)$

onde,

$h_{n}(t), q_{n}(t)$ : funções em fase e em quadratura, respectivamente.

0 espectro em quadratura $Q_{n}(w)$ determinado a partir do espectro de fase $H_{n}(w) \bar{e}$ :

$$
Q_{n}(w)=H_{n}(w) e^{i \pi / 2}
$$

As sēries de Fourier permitem efetuar a seguinte trans formação:

$$
a_{k}^{\prime}=-b_{k} \quad ; \quad b_{k}^{\prime}=a_{k}
$$

onde $a_{k} e b_{k}$ são os coeficientes do seno e cosseno do espectro em fase; $a_{k}^{\prime}$ e $b_{k}^{\prime}$ são os coeficientes do espectro em quadratura.

Aplicando-se a transformada de Fourier, que permite retornar ao dominio do tempo, as amplitudes e fases instantâneas säo dadas por:

$$
\begin{aligned}
& A_{n}(t)=\left[h_{n}^{2}(t)+q_{n}^{2}(t)\right]^{1 / 2} \\
& \phi_{n}(t)=\arctan \left[a_{n}(t) / h_{n}(t)\right]
\end{aligned}
$$


A tēcnica de filtragem mūitipla e usada para estudar variações da amplitude (ou energia) do sinal em função da velocidade e período. Inicialmente, deve-se escolher uma função filtro que possua uma boa resolução, prōximo de cada frequéncia central. A função adotada è a gaussiana, que preenche estes requisitos, se gundo testes efetuados por Dziewonski et al(1969). A função gaussiana deve ser considerada como equivalente à função filtro ōtima. A função filtro no dominio da frequência é dada por:

$$
\left.H_{n}(w)=e^{-\alpha\left[\left(w-w_{n}\right) / w\right.}\right]^{2}
$$

onde,

$w_{n}$ : frequéncia central.

A transformada de Fourier de $H_{n}(w)$ e:

$h_{n}(t)=\frac{\sqrt{\pi}}{2 \alpha} w_{n} \cdot e^{-\left(w_{n} t\right)^{2} /(4 \alpha)} \cdot \cos \left(w_{n} t\right)$

A solução da equação acima depende basicamente do parâmetro $\alpha$, cujo valor $\overline{\mathrm{e}}$ dado por $\alpha=\beta /(B A N D)^{2}$, onde (BAND) $\overline{\mathrm{e}}$ a largura de banda relativa e

$$
\beta=\ln \left[\begin{array}{l}
H_{n}\left(w_{n}\right) \\
H_{n}\left(w_{1}, n\right)
\end{array}\right]=\ln \left[\begin{array}{l}
H_{n}\left(w_{n}\right) \\
H_{n}\left(w_{u, n}\right)
\end{array}\right]
$$

sendo $w_{u, n}$ e $w_{1, n}$ os limites de banda superior e inferior de um filtro simētrico.

Para fins práticos de computação, é conveniente truncar as amplitudes pequenas dos extremos da funcão $H_{n}(w)$, evitando - se portanto cálculos desnecessärios. O filtro com a função gaussiana truncada $\bar{e}$ dado abaixo: 


$$
H_{n}(w)=\left\{\begin{array}{l}
0 \quad \text { para } w<(1-\text { BAND }) \cdot w_{n} \\
e^{-\alpha\left(\left(w-w_{n}\right) / w\right)^{2}} ; \text { para }\left(1-\text { BAND ). } w_{n} \leqslant w \leqslant(1+B A N D) \cdot w_{n}\right. \\
0 \quad ; \text { para } w>\left(1+\text { BAND ). } w_{n}\right.
\end{array}\right.
$$

No diagrama de fluxo do processo de filtragem mültipla (Figura 2.5 ), estão representados os seguintes estägios de execução:

1) o sismograma digitizado a intervalos constantes $\Delta t \bar{e}$ introduzido no computador, observando-se que o intervalo de digitizacão deve ser adequadamente escolhido, para evitar o "aliasing" do sinal; 2) a sērie de tempo observada é expandida a um valor adequado de potencia de dois, para possibilitar a aplicação da transformada de Fourier räpida. Entretanto, o comprimento da sērie expandida è determinado principalmente pela resolução de frequéncia desejada. Neste trabalho tem sido usado o comprimento de 572 pontos. A função no domĩnio do tempo è convertida em sëries seno e cosseno atra vēs do alqorítmo de Cooley-Tukey (Blackman e Tukey, 1965) e da Transformada de Fourier räpida;

3) as distorções instrumentais de amplitude e fase possivelmente presentes, podem ser eliminadas neste estägio, recorrendo-se ä cur va de resposta instrumental;

4) são determinadas as frequencias centrais dos filtros a serem usados posteriormente. Os periodos correspondentes a estas frequen cias centrais estão representados na abscissa da Fig. B-01(Apēndice B); 


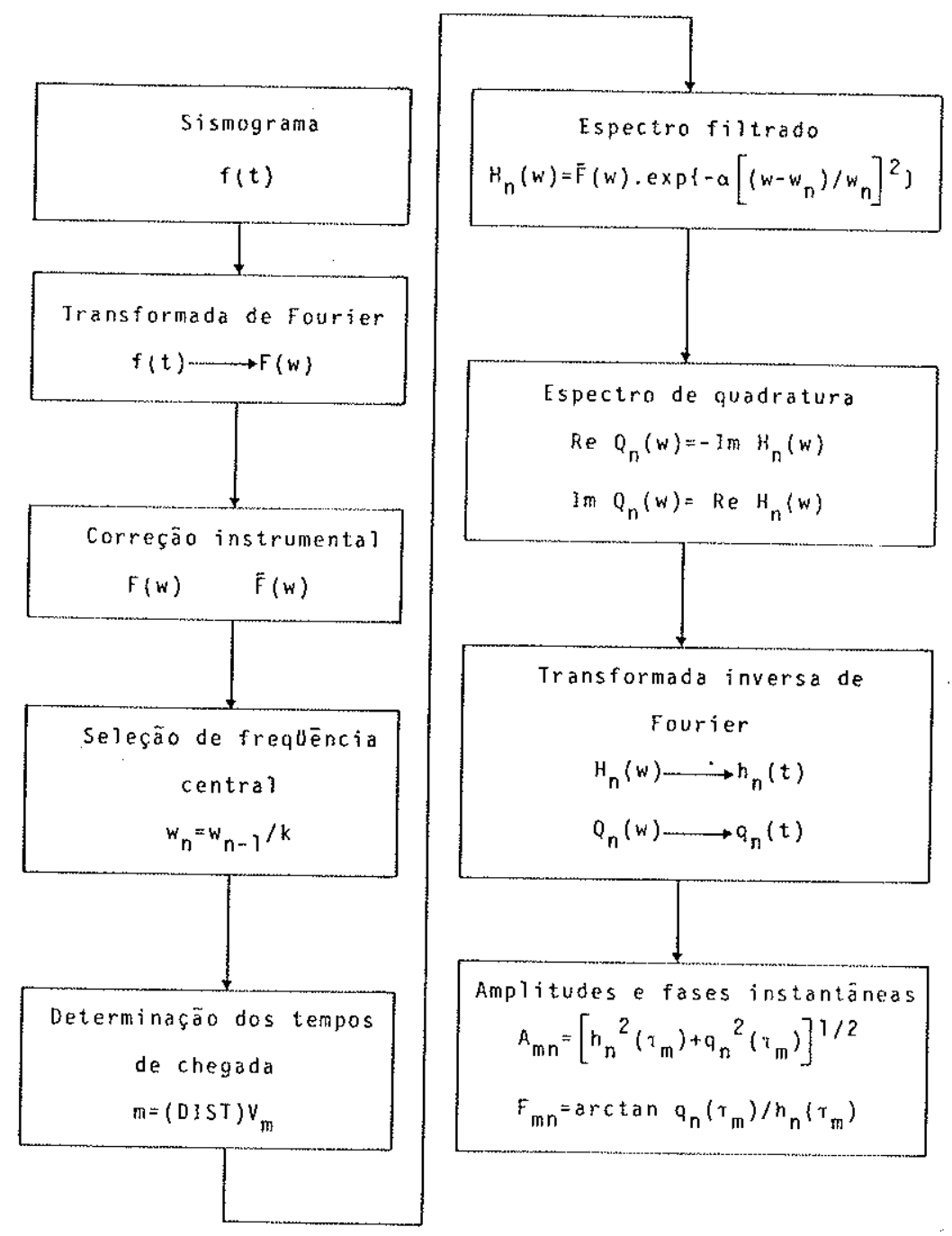

Fig. 2.5 - Diagrama de fluxo do processo de Filtragem Mūitipla 
5) o conjunto de tempos relativos aos valores prē-selecionados de velocidades de grupo é determinado. Estes valores de velocidades são dados na ordenada da Fig. B-01 (Apêndice B);

6) o processo de filtragem do espectro sísmico è realizado pelo empreao da função filtro, que é simétrica em relacão à frequéncia central;

7) o espectro em quadratura é obtido dos dados de amplitudes e fạ ses espectrais;

8) a transformada de Fourier inversa do espectro em quadratura è calculada, empregando-se o mesmo algoritmo citado no estagio 2;

9) as amplitudes e fases espectrais instantāneas sao calculadas pa ra os tempos de cheqada de cada grupo de ondas.

Finalisando, os procedimentos descritos nos estagios de 6 a 9 , são repetidos para cada frequencia central. 
CAPITULO 3

DADOS BASSICOS

3.1 - Estacões sismogräficas

3.1.1 - Localizaçao das estacões sismogräficas

Os registros usados no presente estudn correspondem às seguintes estações sismogräficas: Brasîlia(BDF), Natal(NAT), Rio de Janeiro(RDJ) e La Paz(LPB), que pertencem à Rede Mundial de Estações Sismogräficas Padrão(WWNSS), com excessão de RDJ. Esta ūiti ma possui equipamento sismogrä́fico de perīodo longo com as mesmas caracteristicas dos da rede WWNSS. Algumas informações sobre as es tações sismogräficas utilizadas neste trabalho são apresentadas na Tabela 3.1. Outras caracterịsticas relativas à estação sismogräfica de RDJ é encontrada no trabalho de Berrocal e Antezana(1977). A localização das estações sismogräficas utilizadas ē indicada por triāngulos no mapa da Fig. 3.1.

\subsection{2 - Equipamento Sismogräfico}

0 nümero de estações sismogräficas que vēm adotando sis temas de registro digital ou analógico em fita magnética é crescen te, mas grande parte das estações ainda empregam sistemas de regis tro visual, como a maioria das estações da WWNSS, que representam - conijunto de estações sismográficas mais importante, devido ao nū mero e disponibilidade centralizada de cópias de sismogramas.

A Rede Mundial de Estações Sismogrāficas Padrão foi instalada no perīodo 1961 a 1965 e è formada de aproximadamente 112 estacões distribuídas ao redor da Terra. 0 período natural dos sis 
TABELA 3.1 - DADOS DAS ESTAÇŌES SISMOGRAFICAS UTILIZADAS

\begin{tabular}{|c|c|c|c|c|}
\hline ESTAÇO & LAT.(graus) & LONG. (graus) & ALTURA(m) & AMPLIFICAÇAO(vezes) \\
\hline BDF & $15,66 \mathrm{~S}$ & $47,90 \mathrm{~W}$ & 1258 & 1500 \\
\hline LPB & $16,53 \mathrm{~S}$ & $68,10 \mathrm{~W}$ & 3292 & 1500 \\
\hline NAT & $5,86 \mathrm{~S}$ & $35,28 \mathrm{~W}$ & 50 & 1500 \\
\hline RDJ & $22,89 \mathrm{~S}$ & $43,22 \mathrm{~W}$ & 29 & 1500 \\
\hline
\end{tabular}




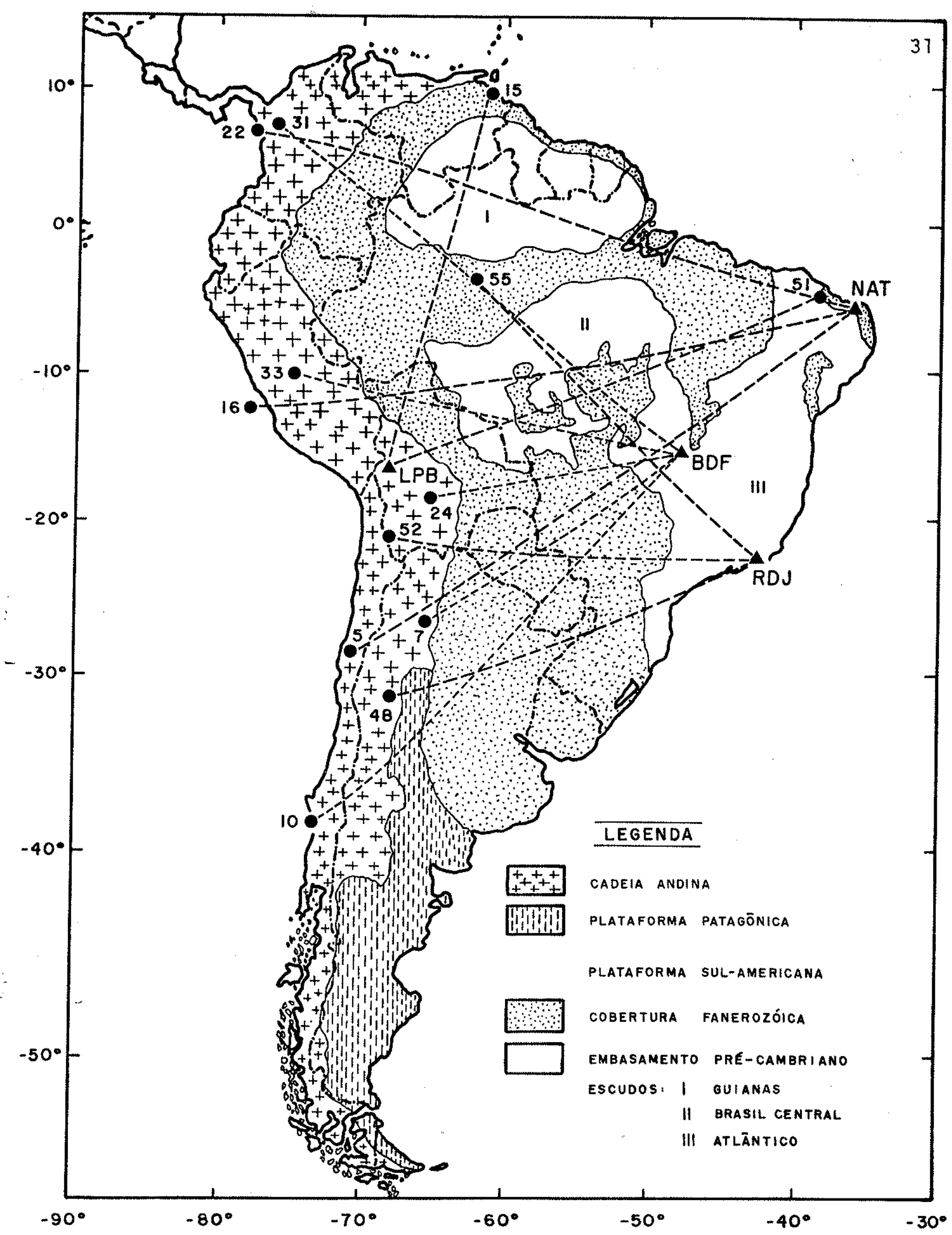

F1G. 3.1- LOCALIZACÃO DOS EPICENTROS DOS SISMOS SELECIONADOS E DAS ESTAGŌES SISMOGRÁFICAS UTILIZADAS. 
mömetros de período longo foi ajustado inicialmente para 20 segun dos e o período dos galvanōmetros para 100 segundos.

Em 1965, o período natural dos sismōmetros de toda a rede foi reduzido para 15 segundos, mas o dos galvanömetros perma neceu inalterado. O registro é feito em papel fotogrāfico, a uma velocidade de $15 \mathrm{~mm} / \mathrm{minuto}$, com pulsos de calibração no iñ̃cio e tērmino de cada registro de 24 horas. As características atuais da estação RDJ são idēnticas às do sistema WWNSS, com exceção do período do galvanōmetro, que é de 75 segundos.

Os sismómetros de perĩodo longo da estação RDJ são do tipo Sprengnether na componente vertical(Z) e Lehner-Griffith nas componentes horizontais(NS,EW), (Miller, 1963). Nas estações de NAT, BDF e LPB os sismómetros das trēs componentes de periodo lon go são do tipo Sprengnether. Uma descrição detalhada das características do equipamento sismogrāfico da rede de estações padrão ē encontrada no Manual de Operação e Manutenção do Sistema WWNSS (1962). Nas Figs. (3.2 e 3.3) são apresentadas as curvas de resposta do equipamento das estações sismogräficas utilizadas.

\section{2 - Dados sísmicos}

\subsection{1 - Dados utilizados}

Foram selecionados sismos da região andina ocorridos entre 1970 e 1983. Os parāmetros dos sismos escolhidos foram extraídos do catālogo fornecido pelo NOAA (National Oceanic and Atmospheric Administration), em fita magnética, contendo informações sobre a sismicidade mundial ocorrida desde 1900 atë 1978. Os sismos ocorridos entre 1979 e 1983 foram selecionados dos Boletins mensais, publicados pelo USGS (United States Geological Survey). 


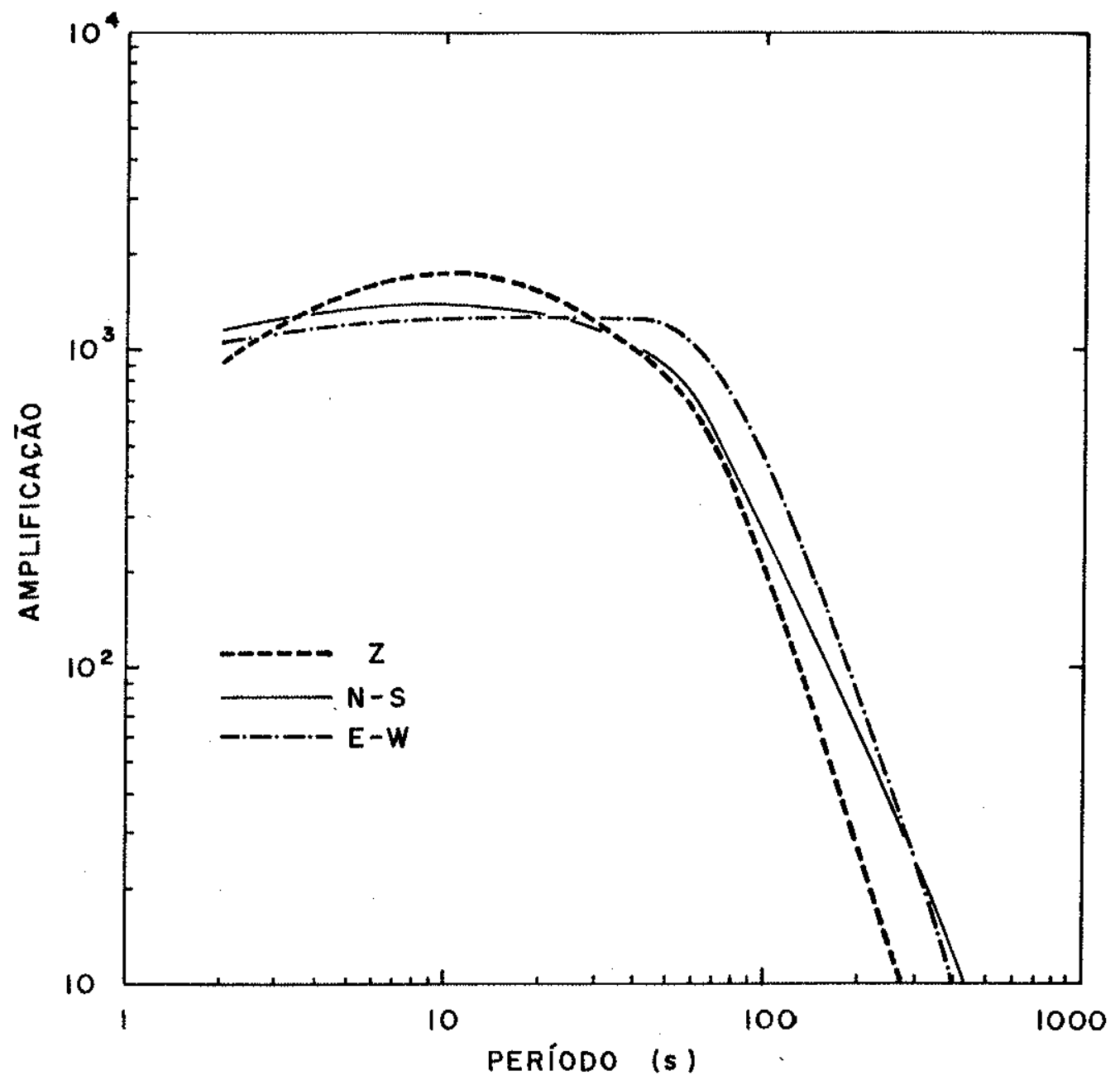

FIG.3.2-CURVAS DE RESPOSTA DOS SISMÓGRAFOS DE PERIODO LONGO DA ESTACÃO RDJ. 


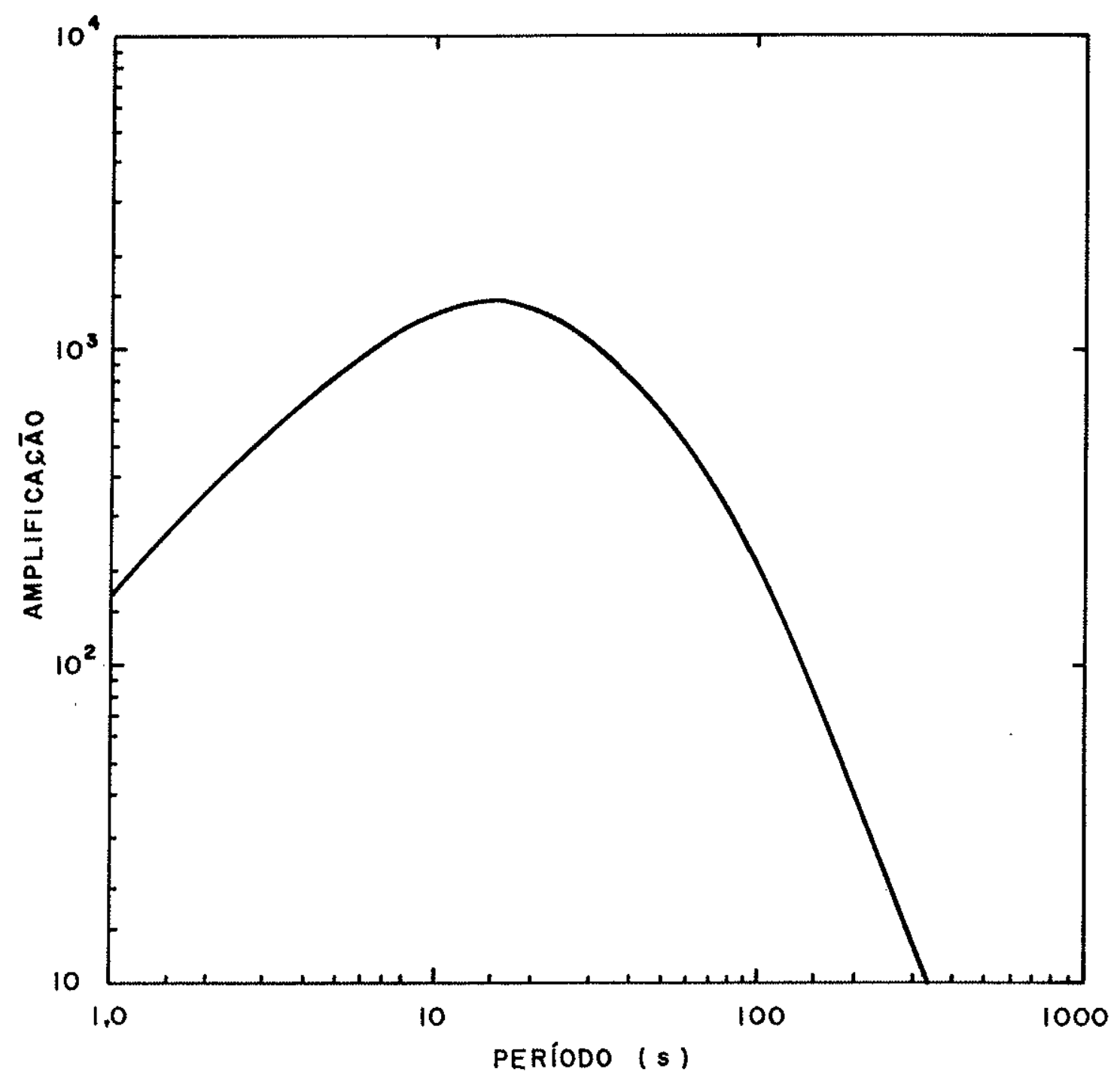

FIG.3.3- CURVA DE RESPOSTA DOS SISMÓgRAFOS DE PERÍODO LONGO DAS ESTACÕES DE BDF, LPB, E NAT. 
$\mathrm{Na}$ escolha dos sismos foram adotados os seguintes cri térios:

a) - profundidade focal (h) rasa ( $\mathrm{h}<70 \mathrm{~km})$,

b) - magnitude $m_{b}>5,0$,

c) - localização do epicentro na crosta continental da Amērica do Su1.

A profundidade focal e a energia liberada (magnitude) adotadas são parāmetros fundamentais no estudo e registro das ondas superficiais a distancias epicentrais de $16^{\circ}$ a $43^{\circ}$.

A escolha de sismos com epicentros na borda leste dos Andes é uma tentativa de limitar, na medida do possīvel, a propagação das ondas superficiais em regiões onde a estrutura crustal seja aproximadamente uniforme. Entretanto, a influéncia da "raiz" dos Andes, na propagação das ondas superficiais tambēm foi estuda da, utilizando-se sismos com epicentros a oeste dos Andes. Para complementar o estudo foram utilizados sismos que ocorreram na parte $N$ da América do Sul, e em territörio brasileiro, tais como o de Pacajus-CE em 20.NOV.80 registrados por LPB, e o que ocorreu prōximo de Codajās-AM em 05.AG0.1983, registrado por RDJ.

A classificação dos sismogramas baseou-se na qualidade de registro das ondas superficiais, nas trës componentes de pe rỉodo longo, Z(vertical), NS(Norte-Sul) e EW(Leste-Oeste). Entre os fatores que contribuíram para eliminar grande parte dos 56 sis mos prē-selecionados podem ser apontados os seguintes: a)- sismogra mas saturados pelas ondas superficiais ou com nîveis de ruido ele vado, suficientes para mascarar o sinal sísmico; b)-paradas ocasio nais no funcionamento das estações sismogräficas; c)- sismogramas 
extraviados; d)-sismogramas enviados ao NEIS para microfilmagem e não devolvidos até a época em que foj efetuado o levantamento do material existente.

Concluido o levantamento de sismogramas, verificou-se a existēncia de registros de apenas uma estação para cada sismo; e esse material disponivel consiste de sismogramas nas 3 componen tes para 11 sismos e sismogramas na componente vertical para 2 sismos.

0s 13 sismos, apresentados na Tabela 3.2 , tem seus ep $\underline{i}$ centros distribuídos de tal modo que as trajetōrias das ondas superficiais cobrem toda a região de interesse (vide Fig. 3.1).

\section{2 .2 - Preparação dos dados}

O sismograma ē um registro analōgico onde è gravado a variação da amplitude do sinal, na forma de uma função continua em relação ao tempo transcorrido.

Para analisar este sinal, è necessārio digitizā-lo, is to $\vec{e}$, substituir a função continua por uma sērie discreta de valo res, obtidos a intervalos constantes de tempo, denominados intervalos de digitização $(\Delta t)$.

No processamento de um sinal sísmico por meio da anălise de Fourier, deve-se evitar o fenömeno conhecido como "aliasing", adotando-se um valor $\Delta t$, tal que a frequéncia de Nyquist $\left(f_{N}=1 /(2 \Delta t)\right)$ seja, no mínimo, tão alta quanto a frequéncia mäxima contida no sinal (Blackman e Tukey, 1958; Bahar, 1977). Se $\Delta t$ é muito grande, as frequéncias altas desaparecem, provocando distor ções na reconstrução do sinal original a partir dos dados digitizados; no caso de valores de $\Delta t$ muito pequenos, o tempo de proces 
TABELA 3.2

Parämetros Hipocentrais e Distâncias Epicentro - Estação dos Sismos Utijizados

\begin{tabular}{|c|c|c|c|c|c|c|c|c|}
\hline \multirow[t]{2}{*}{ NO } & \multirow[t]{2}{*}{ DATA } & HORA ORIGEM & COORD. & GEOG. & \multirow{2}{*}{$\begin{array}{l}\text { PROF } \\
(\mathrm{km}) \\
\end{array}$} & \multirow{2}{*}{$\begin{array}{c}\text { MAGN I TUDE } \\
m_{b}\end{array}$} & \multirow{2}{*}{$\begin{array}{c}\text { DISTANCIA } \\
(\mathrm{km})\end{array}$} & \multirow{2}{*}{$\begin{array}{c}\text { ESTAÇAO DE } \\
\text { REGISTRO }\end{array}$} \\
\hline & & $\mathrm{h} \quad \mathrm{m} \quad \mathrm{s}$ & LAT & LONG & & & & \\
\hline 5 & 19. NOV. 73 & $18: 40: 05,2$ & $28,5 \mathrm{~s}$ & $70,9 W$ & 58 & 5,7 & $4.507,9$ & NAT \\
\hline 7 & 07. JAN. 74 & $76: 35: 57,8$ & $26,9 \mathrm{~S}$ & $65,7 \mathrm{~W}$ & 33 & 5,8 & $2.221,4$ & BDF \\
\hline 10 & 27. AGO. 74 & $06: 24: 07,0$ & $38,3 \mathrm{~s}$ & $73,4 W$ & 23 & 5,4 & $3.538,3$ & $B D F$ \\
\hline 15 & $15 . A B R .75$ & $09: 47: 43,6$ & $09,3 \mathrm{~N}$ & $61,5 \mathrm{~W}$ & 47 & 5,4 & $2.944,2$ & $L P B$ \\
\hline 16 & 18.ABR. 75 & $12: 34: 09,8$ & $12,5 \mathrm{~s}$ & $78,0 \mathrm{~W}$ & 33 & 5,3 & $4.741,6$ & NAT \\
\hline 22 & $25 . A G 0.75$ & $03: 57: 20,2$ & $06,9 \mathrm{~N}$ & $77,8 w$ & 47 & 5,2 & $4.924,0$ & NAT \\
\hline 24 & $22 . F E V .76$ & $08: 09: 22,3$ & $18,4 \mathrm{~s}$ & $65,2 W$ & 41 & 5,3 & $1.864,4$ & $B D F$ \\
\hline 31 & 01. SET. 77 & $17: 37: 10,3$ & $07,4 \mathrm{~S}$ & $76,2 \mathrm{~W}$ & 28 & 5,3 & $4.024,1$ & $B D F$ \\
\hline 33 & 02. NOV .77 & $14: 47: 57,2$ & $10,1 \mathrm{~s}$ & $74,8 w$ & 48 & 5,5 & $2.978,3$ & $B D F$ \\
\hline 48 & 27. AG0.78 & $00: 28: 22,7$ & $31,3 \mathrm{~s}$ & $67,8 W$ & 10 & 5,6 & $2.609,8$ & RDJ \\
\hline 51 & 20. NOV. 80 & $03: 29: 42,9$ & $04,5 \mathrm{~s}$ & $38,3 w$ & 10 & $5 ; 1$ & $3.512,1$ & $\angle P B$ \\
\hline 52 & $11 . D E Z .80$ & $18: 15: 03,5$ & $21,3 \mathrm{~s}$ & $68,2 W$ & 80 & 6,1 & $2.579,1$ & RDJ \\
\hline 55 & $05 . A G 0.83$ & $06: 21: 42,4$ & $03,6 \mathrm{~s}$ & $62,2 W$ & 21 & 5,5 & $2.952,4$ & RDJ \\
\hline
\end{tabular}


samento de dados aumenta excessivamente, sem acrescentar novas in formações, na reconstrução do sinal original.

A digitização das ondas superficiais neste trabalho, foi efetuada com um digitizador semi-automätico (Figura 3.4) elaborado e construído no IAG (Hiodo et al, 1983) que fornece automa ticamente os valores da amplitude do sinal e do intervalo de digi tização quando acionado um interruptor manual nas suscessivas posições do cursor.

0 aparelho possui 2 sensores de posição do tipo poten ciométrico, nas 2 componentes ortogonais. Estes elementos resisti vos, com linearidade de $0,25 \%$ e resolução de $5 \%$, estão localizados na mesa digitizadora (parte B da Figura 3.5), onde estão acoplados mecanicamente por fios flexiveis de aço, a um dispositivo móvel dotado de retículo, que realiza deslocamentos ortogonais.

A fonte de tensão variāvel empregada permite o ajuste do ganho do sistema de digitização. Esta fonte ē conectada a um circuito de ajuste do zero nas 2 componentes, que possibilita a mudança de referēncia (parte A da Fig. 3.5). 0 sinal analógico que é proporcional ao deslocamento em relação a uma linha de referēncia escolhida, é convertido num sinal digital atravēs de um siste ma de integração de dupla rampa. o valor da tensão (deslocamento) $\vec{e}$ lido num visor eletroluminescente de $31 / 2$ digitos. A comutação entre as componentes vertical e horizontal é feita atravës de um circuito monoestável de disparo controlado pelo interruptor $S$.

Todo o sistema utilizado possui um coeficiente de tem peratura muito baixo, sendo sua resolução e reprodutibilidade da ordem de $0,1 \mathrm{~mm}$, nos 2 eixos. Dependendo da velocidade de registro dos sismogramas os $\Delta t$ minimos seriam: $0,4 \mathrm{~s}$ para registros com $15 \mathrm{~mm} /$ 


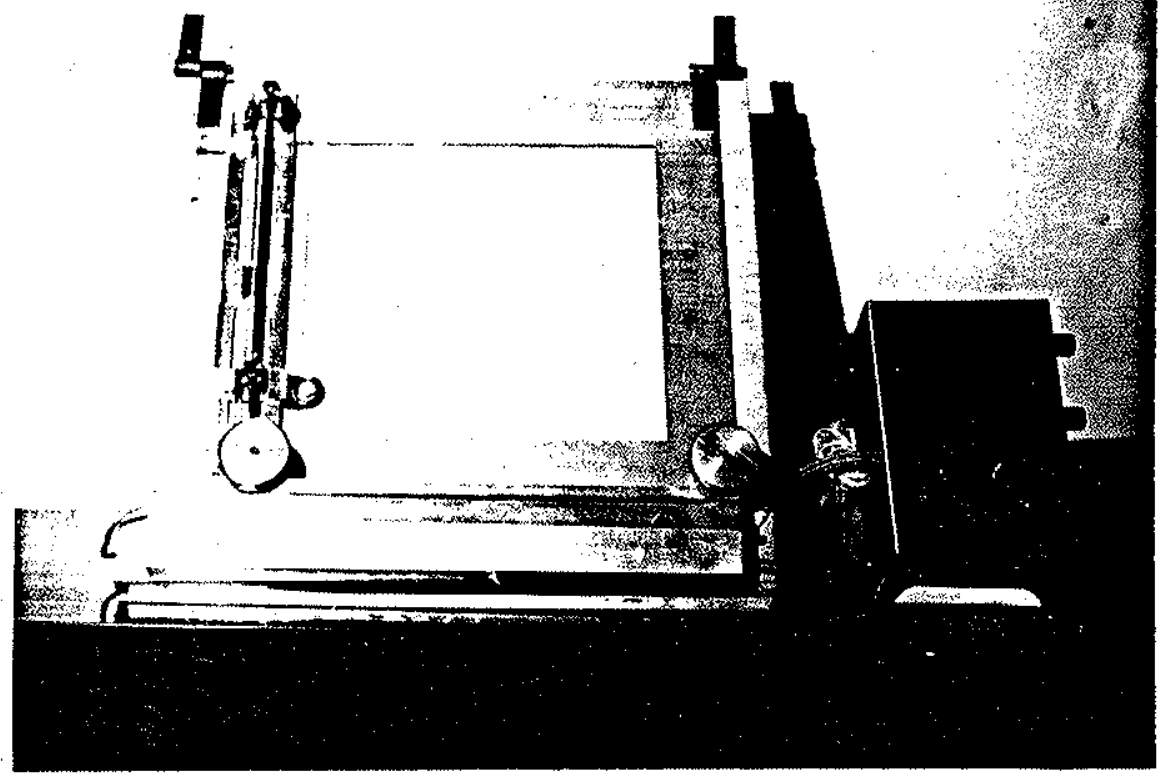

Fig. 3.4 - Digitizador Semi-Automático 


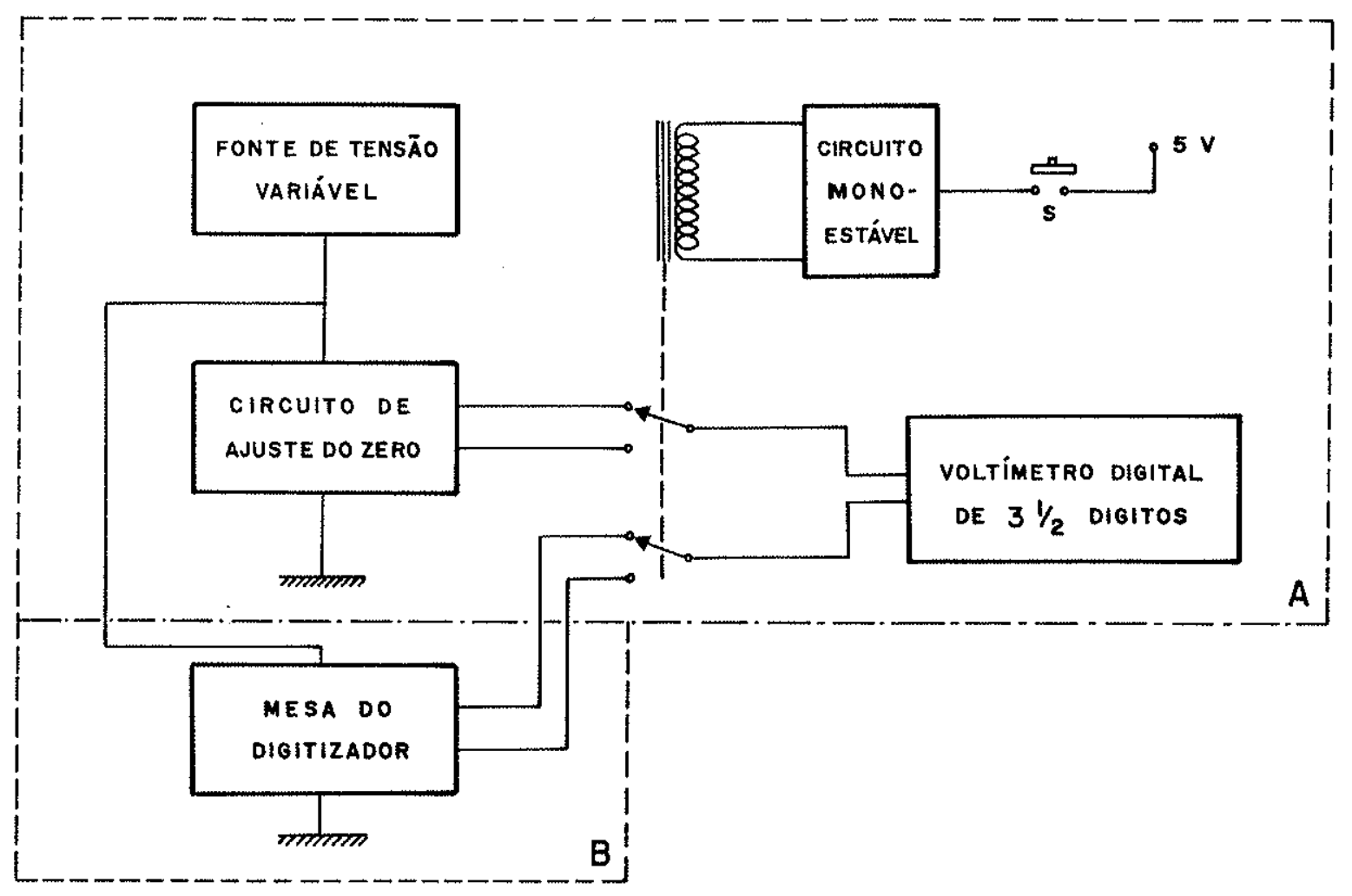

FIG.3.5 - DIAGRAMA DE BLOCO DO DIGITIZADOR 
minuto e $0,05 \mathrm{~s}$ para registros com $120 \mathrm{~mm} / \mathrm{minuto.} \mathrm{Neste} \mathrm{trabalho,}$ onde os sismogramas foram registrados com $15 \mathrm{~mm} / \mathrm{minuto}$, foi utilizado um $\Delta t=1,0 \mathrm{~s}$.

A velocidade média de leitura ( 8 pontos/minuto) e as precisões conseguidas, utilizarido-se o digitizador seni-automātico, são superiores àquelas obtidas por digitização manual.

3.3 - Dados geolōgicos e geofísicos

3.3.1 - Plataforma SuT-Americana

3.3 .1 .1 - Estudos anteriores

os trabalhos efetuados com o objetivo de se determinar a estrutura da crosta da Amërica do Sul, iniciaram-se na década de 1950 , concentrando-se na região andina, onde a extraordinäria fisiografia e as deformações tectônicas profundas teriam sido os aspectos relevantes, que chamaram a atenção dos pesquisadores. Na região da Plataforma Brasileira são poucos os estudos geofísicos realizados, visando o conhecimento da estrutura crustal.

$\mathrm{Na}$ Tabela 3.3 são apresentados os resultados mais relevantes obtidos de vārios estudos geofísicos, na Amērica do Sul.

Trabalhos de sísmica de refração (Giese e Shutte 1975), usando explosões artificiais da mina de Itabira, permitiram deter minar a estrutura da crosta ao longo do perfil Itabira-Serra Negra. Os resultados obtidos indicam a presença de 2 camadas na cros ta: a superior que apresenta uma velocidade da onda $P$ aproximadamente constante de $6,2 \mathrm{~km} / \mathrm{s}$ e seu limite inferior estaria a uns $30 \mathrm{~km}$ de profundidade e a inferior, cuja base estaria a aproximada mente $42 \mathrm{~km}$ de profundidade, apresentando uma velocidade crescente 
TABELA 3.3

\begin{tabular}{|c|c|c|c|c|c|c|}
\hline \multirow{2}{*}{ Autcor } & \multirow{2}{*}{ AnO } & \multirow{2}{*}{$\begin{array}{c}\text { Espessura } \\
\text { Crosta }\end{array}$} & \multicolumn{2}{|c|}{ Velocidade } & \multirow{2}{*}{ Regiäo } & \multirow{2}{*}{ Método } \\
\hline & & & Crosta & Manto & & \\
\hline Wuensctiel. & 2953 & 65 & - & - & N. Chile & Gravimetria \\
\hline Aldrich, et.al. & 2958 & 55 & - & - & N. Onile & Refraçä \\
\hline \multirow[t]{6}{*}{ woolland } & 1961 & 64,9 & 6,45 & 8,0 & Altiplano (Penu) & Refração \\
\hline & 1961 & 51,7 & 6,38 & 8,0 & Flano de Altipla & Refrą̧āo \\
\hline & & & & & no (Peru) & \\
\hline & 1961 & 70,3 & 6.6 & 8,0 & Altiplano (Chile) & Refraç̄̈o \\
\hline & 3961 & 56,5 & 6,52 & 8,0 & Gile fflanoo do & Refraçāo \\
\hline & & & & & Altiplano) & \\
\hline Cisternas & 1961 & 50 & - & - & Huancayo & Ondas Sup. \\
\hline Lomitz & 3962 & 70 & - & - & Crile-Bolivia & Gravinetria \\
\hline Raitt & 1964 & 60 & - & - & N. Ohile & Grav.e Sism \\
\hline Anzoleaga & 1964 & 65,7 & 5,2 & 8,36 & Ia Paz & Refiaçāo \\
\hline Santa Cruz & 1964 & 57,6 & 6,5 & 8,25 & La Paz & Refraçäo \\
\hline Careaga & 1967 & 64,6 & - & - & La Paz & Espec.de and \\
\hline \multirow[t]{2}{*}{ Rubin de Celis } & 1967 & 42,2 & 6,13 & 8,02 & Xa Paz-Antofag. & Ondas sup. \\
\hline & & 48,5 & 6,13 & 8,02 & Ia Paz-Arequipa & Ondas sup. \\
\hline Fermandez, et.al. & 1968 & 64,6 & 6,76 & - & Ia Paz. & Espec. de ond \\
\hline \multirow[t]{4}{*}{ Antezana } & 2969 & 4. & 5,8 & 8,2 & La Paz-Antofag. & Ondas sup. \\
\hline & & & 6,75 & & & \\
\hline & & 50 & 5,8 & 8,1 & La Paz-Arequipa & Ondas Sup. \\
\hline & & & 6,6 & & & \\
\hline Jbiett & 1969 & 71,7 & 6.2 & 8,17 & la $\mathrm{Paz}$ & Espec de ond \\
\hline James & 1971 & 50 & - & - & $\begin{array}{l}\text { S. Peru-Bolivia- } \\
\text { N. chile }\end{array}$ & Ondas Sup. \\
\hline Cola & 1972 & $68-70$ & - & - & La Paz-Cuzco & Refração \\
\hline \multirow[t]{3}{*}{ Oblitas } & 1972 & 7 & 5,7 & 7,9 & Escudo Brasilejro & Ondas Sup. \\
\hline & & 12 & 6,3 & & & \\
\hline & & 20 & 6,4 & & & \\
\hline Giese e Shutte & 1975 & $28-30$ & 6,2 & 8,2 & Minas Gerais & Refraçã \\
\hline \multirow[t]{2}{*}{ Telleria-lejsek } & 1975 & 68,5 & - & - & SW de la paz & Gravinetria \\
\hline & & 58 & - & - & NE de la paz & Gavimetria \\
\hline Blitzkow & 1978 & $38-40$ & 6,2 & 8.2 & Minas Gerais & Gravimetria \\
\hline & & & 7,4 & & & \\
\hline DHPH/CPRM & 1979 & $32-43$ & - & - & Bahia & Gravimetria \\
\hline
\end{tabular}


com a profundidade, variando de 6,2 a $8,2 \mathrm{~km} / \mathrm{s}$.

No levantamento gravimētrico efetuado por Blitzkow et al (1978) na mesma região citada, obteve-se profundidades normais de 38 a $40 \mathrm{~km}$ para a descontinuidade de Moho, sendo a espessura crus tal mäxima observada de $45 \mathrm{~km}$, no $10 \mathrm{cal}$ de uma intensa anomalia ne gativa, situada entre Itabira e Guanhães.

Uma determinação teōrica das profundidades da descontinuidade de Moho foi efetuada no Estado da Bahia (DNPM/CPRM, 1979), baseando-se em dados de geologia regional e de anomalias gravimétricas. 0s resultados indicam uma espessura crustal de aproximada mente $43 \mathrm{~km}$, na região de Macaūbas, e uma diminuição da mesma, che gando a atingir $32 \mathrm{~km}$ na faixa costeira e no extremo NNW do Estado da Bahia.

Dados gravimétricos e magnetométricos do Nordeste (Rand 1976, 1978; Rand et al 1980) e levantamentos gravimëtricos da faj xa litoränea nordestina (Haralyi e Hasui 1982a, 1982b) sugerem um decrēscimo da espessura da crosta, ao longo da margem continental. Mais ao sul, na parte costeira do Paraná e de Santa Catarina, as evidēncias gravimétricas indicam um possivel aumento da espessura crusta1, na região situada entre Chaminē e Garuva.

Pela anāitise das ondas superficiais de sismos da cadeja Meso-Atlāntica, oblitas (1972) propós um modelo onde a espes sura média crustal è de $39 \mathrm{~km}$, valor este tambēm sugerido por Knize et al (1984) atravēs de estudos sismolögicos na ārea do reservatō rio de Sobradinho.

3.3 .1 .2 - Aspectos geolögicos

As principais regiões geotectōnicas da Amērica do Sul 
são a Cadeia Andina, a Plataforma Patagonnica e a Plataforma SulAmericana (vide Fig. 3.1) (Almeida et al, 1981).

A Plataforma Sul-Americana (A1meida, 1971) que ocupa a maior parte do continente sul-americano e formada por um embasamento Prē-Cambriano e coberturas fanerozōicas. 0 embasamento composto de rochas Igneas e metamōrficas ē subdividido em 3 grandes escudos: das Guianas ao $N$, do Brasil Central ao $S$ do rio Amazonas, e Atlāntico, ao longo da borda oriental. As coberturas sedimentares e vulcano-sedimentares fanerozōicas da Plataforma SulAmericana, acumuladas desde o inicio do Siluriano, preenchem 3 grandes bacias intracratōnicas: a do Amazonas, do Parnaíba e do Paranā. Pela natureza do embasamento e coberturas da plataforma Sul-Americana, em territōrio brasileiro, foram identificadas 10 provincias estruturais (Almeida et al, 1981).

A bacia sedimentar do Amazonas compreende 4 sub-bacias, (Porto e Szatmari, 1982): Acre, Alto, Mëdio e Baixo Amazonas, separadas por estruturas elevadas do embasamento. A Sub-Bacia do Acre, onde predominam afloramentos de sedimentos cenozöicos, $\vec{e}$ separada da Sub-Bacia do Alto Amazonas pelo Arco de Iquitos. Nas sub-bacias do Médio e Baixo Amazonas encontram-se os registros mais completos da histōria paleozōica das bacias. Os Altos de Purus e Monte Alegre separam as sub-bacias do Alto e Mëdio Amazonas, e a do Mëdio e Baixo Amazonas, respectivamente.

o pacote sedimentar da Bacia Amazōnica alcança espessuras da ordem de $4 \mathrm{~km}$ no Alto Amazonas, atingindo $6 \mathrm{~km}$ ou mais, no Mëdio e Bajxo Amazonas (Porto e Szatmari, 1982).

A Bacia do Parnatba, considerada como uma bacia intra cratōnica isolada, originou-se no fim do Siluriano ou no inicio 
do Devoniano. Os sedimentos eopaleozoicos, estão distribuídos em manchas irregulares sobre o embasamento prē-siluriano, ao leste da Bacia do Parnäba. A camada sedimentar na parte central desta ba cia chega a atingir espessuras de ate $3 \mathrm{~km}$. (Almeida et a 1,1981 ).

Na maior parte da Bacia do Paraná, os sedimentos meso zöicos recobrem os depōsitos do Paleozōico. Esta bacia é i imitada por arcos estruturais, tais como os da Canastra, São Vicente, Assunção, Martin Garcia e Serra do Mar. Na parte central da bacia a espessura dos sedimentos $\bar{e}$ da ordem de $4,5 \mathrm{~km}$. (Almeida et a1, 1981).

Milhares de derrames individuais de lava foram acumuladas na bacia do Parană. A espessura observada dessa sequéncia de derrames pode ultrapassar os $1000 \mathrm{~m}$ em alguns locais; a espessura mäxima (1529m), no entanto, foi encontrada num poço perfurado em Presidente Epitäcio (Sanford e Lange, 1960). 


\section{CAPITULO 4}

INTERPRETAÇÃO DOS RESULTADOS DE DISPERSAOO E COMPARAÇOES REGIONAIS

\section{1 - Velocidades de Grupo}

As "turvas de dispersão observadas", para os modos fun damentais das ondas Rayleigh e Love, foram determinadas mediante a Técnica de Filtragem Mültipla (Bloch e Hales, 1968).

o programa em Fortram utilizado para analisar a dispersão das ondas superficiais, fornece como resultado uma matriz de amplitudes (em $d B$ ) em função de velocidade de grupo e do perĩo do, e para visualizar o verdadeiro relevo espectral do sinal analisado, foram traçadas curvas de amplitudes com intervalos de 5 dB. A curva de dispersão observada, ou seja, a curva experimental a ser adotada, $\vec{e}$ a traçada em função da topografia espectral seguin do os valores mäximos do relēvo que apresentam menor inclinaçäo. Seguindo este procedimento foram traçadas as curvas de dispersão das Figs. B-01 a B-35 do Apêndice B. Em alguns casos as curvas de dispersão traçadas estão sujeitas ao ērro experimental, relaciona do com a precisão de localização da energia mäxima no espectro em quadratura, porēm esse érro é inferior a $0,04 \mathrm{~km} / \mathrm{s}$ na maioria dos casos.

Outra possivel fonte de ērro pode ser atribuĩda a imprecisão na determinação epicentral(efetuada pelo NEIS) que é no māximo de $50 \mathrm{~km}$; no entanto essa imprecisão representa ērros de no mäximo $3 \%$ da velocidade.

Nas Figuras do Apéndice B são apresentadas, para os 13 sismos estudados, as "curvas de dispersão observadas" tanto pa 
ra as ondas Rayleigh (componentes vertical e radial) quanto para as ondas Love (componente transversa1), exceto para os sismos 16 e 33 para os quais foram determinados somente as curvas de disper são para as ondas Rayleigh (componente vertical), uma vez que os sismogramas das componentes horizontais estavam com problemas de registro.

Para os sismos analisados nas 3 componentes, $\bar{e}$ notāvel a semelhança encontrada entre as curvas de dispersão das componentes vertical e radial das ondas Rayleigh (vide Figuras do Apẽndice B).

4.2 - Anälise das curvas experimentais da velocidade de grupo

0 estudo combinado "das curvas de dispersão observadas" com as trajetōrias percorridas pelas ondas superficiais permite agrupar os eventos com a finalidade de correlacionar as estruturas geolōgicas (por ex. cadeia andina, escudo e bacias sedimentares) com a forma das curvas de dispersão.

A maioria das curvas de dispersão observadas apresen tam uma boa concordancia nas velocidades de grupo para periodos acima de $24 \mathrm{~s}$, o que indica que a estrutura das camadas inferiores da crosta è relativamente uniforme ao longo da maior parte das tra jetōrias estudadas.

As curvas de dispersão dos sismos 55 e 51 (Fig. 4.1), correspondentes a eventos com a maior parte de suas trajetörias atravessando os escudos do Brasil Central e Atlāntico, são consideradas, devido à semelhança entre elas, como representativas da estrutura crustal nesses escudos. Os sismos 15 e 31 (Fig. 4.2), com trajetōrias atravessando o escudo das Guianas, apresentam cur 


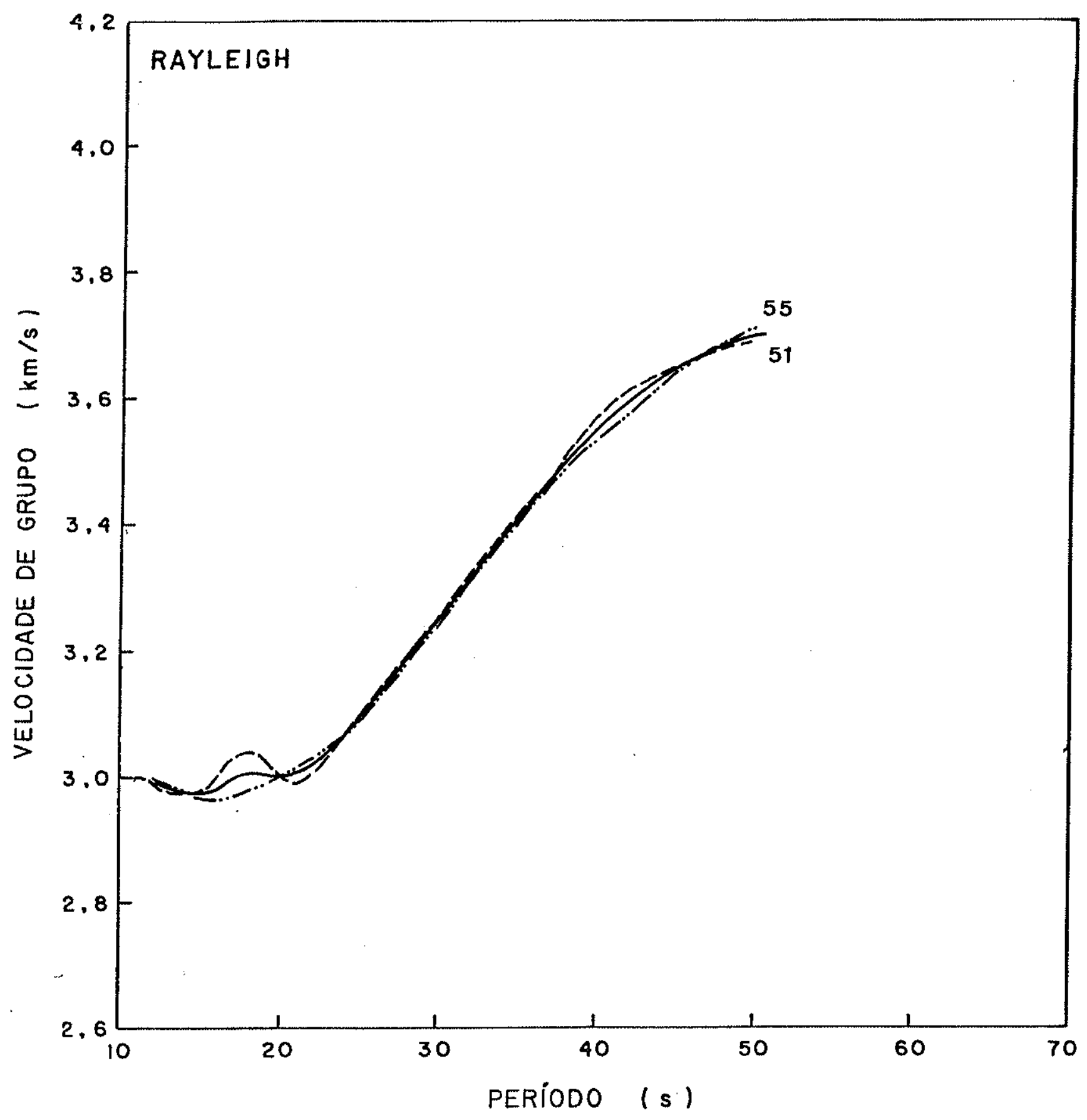

Fig. 4.1 - Curvas de dispersão observadas para sismos com traje törias atravessando os escudos do Brasil Central e Atiāntico. Curva mēdia de dispersão (traço contĩnuo). 


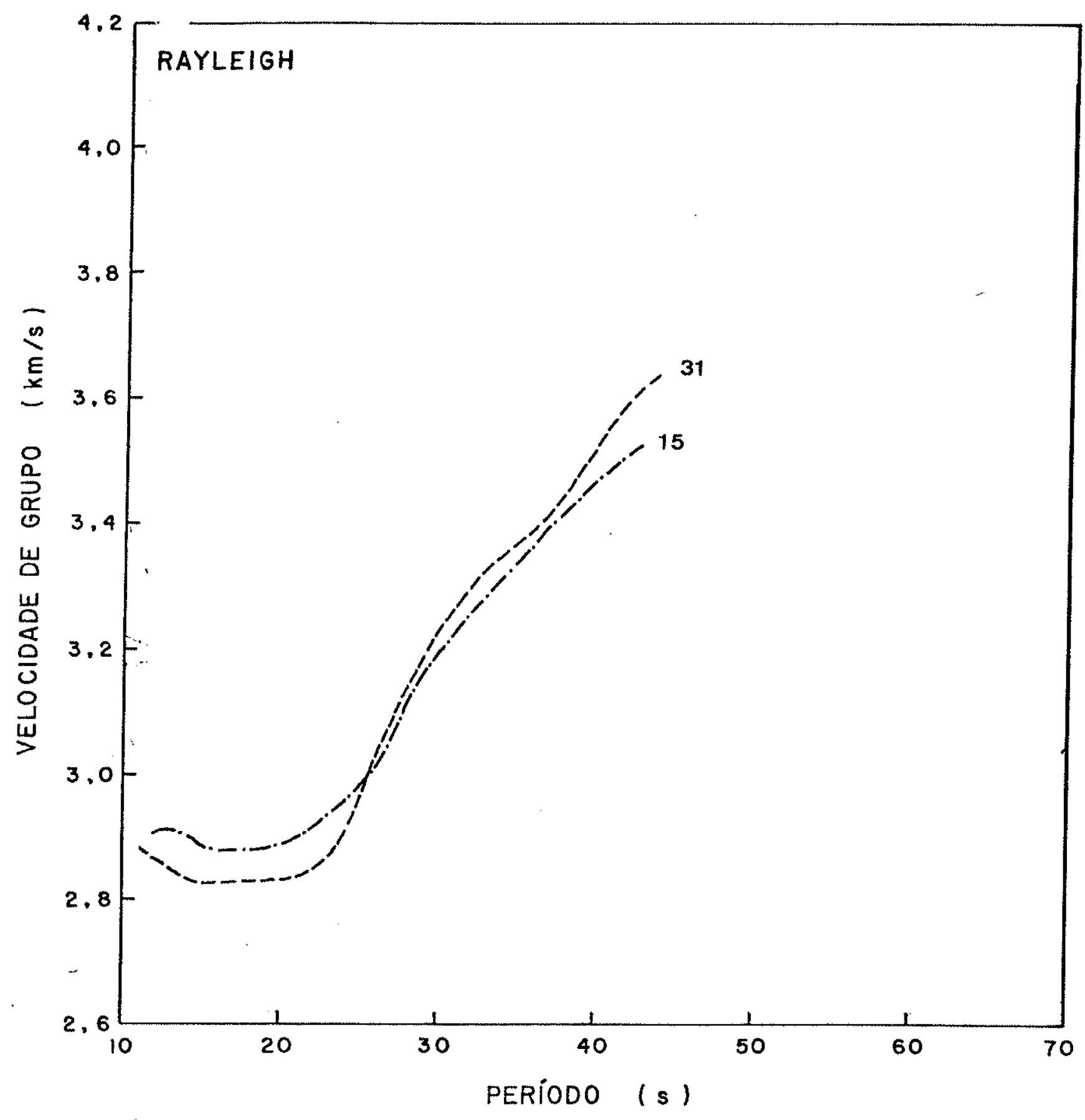

Fig. 4.2 - Curvas de dispersão observadas para sismos com traje törias atravessando o escudo das Guianas. 
vas de dispersão parecidas, porēm as velocidades de grupo são menores (em $\simeq 0,06 \mathrm{~km} / \mathrm{s}$ ) que as observadas para os sismos 55 e 51 , 0 que sugere diferenças na estrutura desses escudos.

os sismos com trajetōrias atravessando a bacia do Pa ranā $(24,5,7,48,10)$ (Fig. 4.3) apresentam curvas de dispersão parecidas para perīodos acima dos $20 \mathrm{~s}$, no entanto há diferença nas velocidades de grupo para periodos abaixo dos $20 \mathrm{~s}$.

os sismos 24,5 e 7 , com trajetōrias na parte $N$ da ba cia do Paranä, mostram curvas de dispersão semelhantes para perīo dos abaixo dos 20s, (Fig. 4.3) mostrando-se uma semelhança mais pronunciada para os sismos 5 e 7 , cujas trajetōrias são muito prō ximas. As velocidades de grupo minimas observadas para este conjunto de curvas estão em torno de $2,8 \mathrm{~km} / \mathrm{s}$.

os sismos 10 e 48 que atravessam a parte central e meridional da bacia apresentam curvas de dispersão com a mesma ten dência, principalmente para períodos abaixo dos $20 \mathrm{~s}$ (Fig. 4.3). As velocidades de grupo minimas observadas estão por volta de $2.87 \mathrm{~km} / \mathrm{s}$.

Comparando-se a mëdia das curvas de dispersão para os sismos 55 e 57 , representativa da estrutura crustal nos escudos do Brasil Central e Atlāntico, com as curvas de dispersão para os sismos que cruzam a bacia do Paranā (Fig. 4.4), verifica-se que as velocidades de grupo, na faixa dos 10 a $20 \mathrm{~s}$, de perĩodo, são menores para os sismos com trajetōrias na bacia; insinuando que os sedimentos da bacia influem na velocidade de grupo das ondas Rayleigh para períodos abaixo dos $20 \mathrm{~s}$.

Na maioria dos sismos estudados, cujas ondas superf ciais se propagam por uma parte dos Andes, se espera uma influên- 


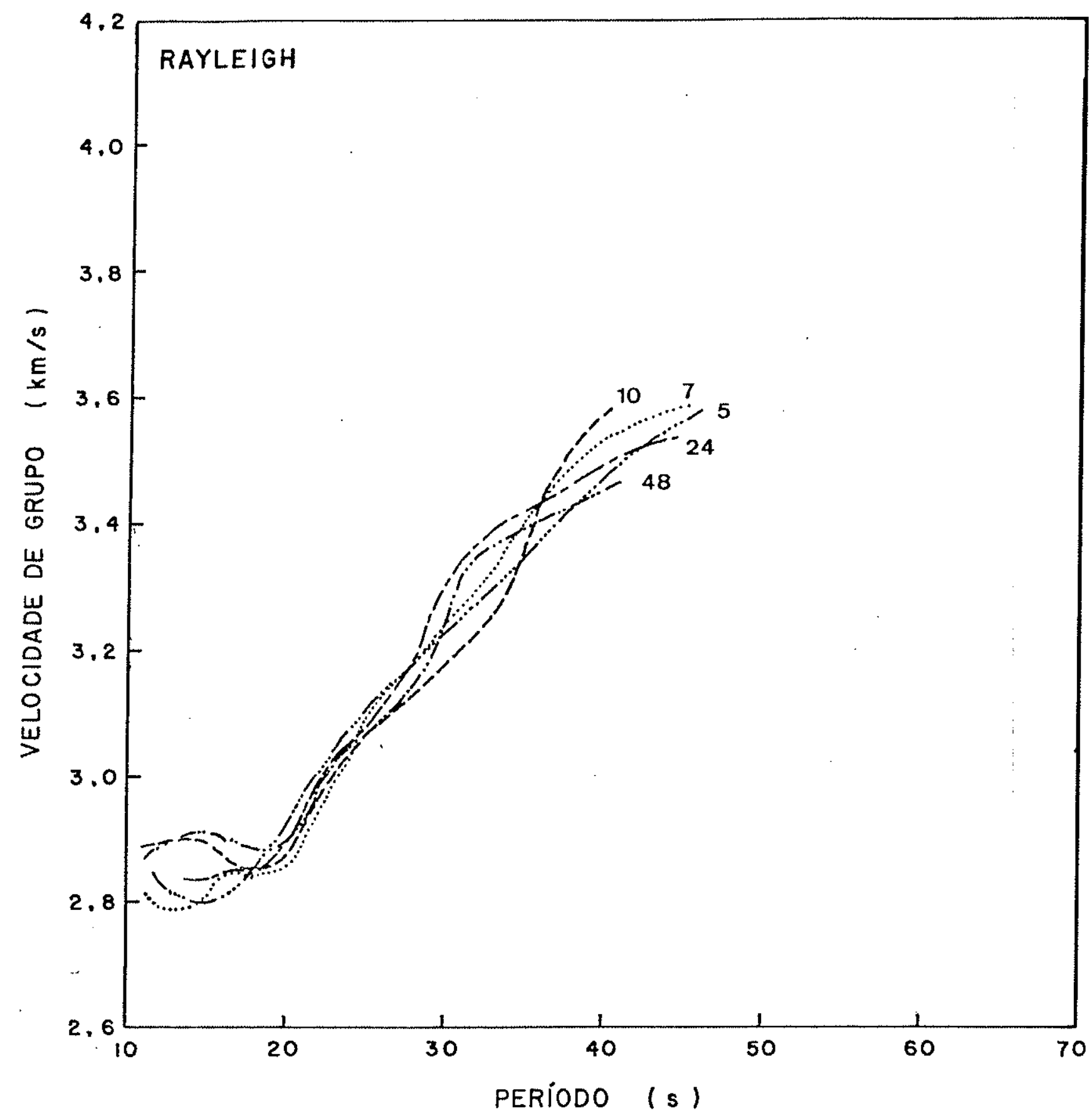

Fig. 4.3 - Curvas de dispersão observadas para sismos com traje törias passando pela bacia do Paranä. 


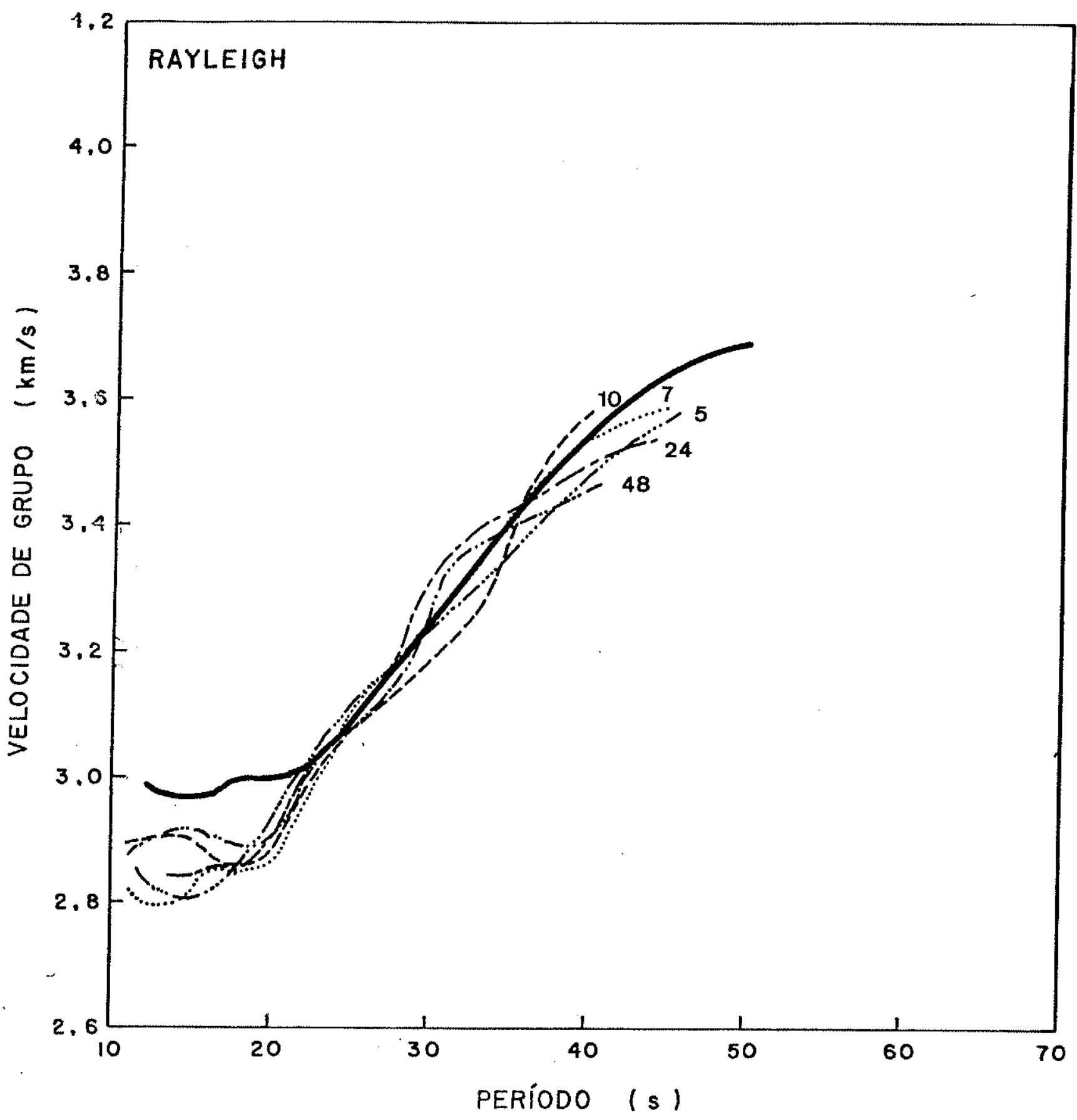

Fig. 4.4 - Comparação das curvas de dispersão para sismos com trajetōrias atravessando a bacia do Paraná com a curva mëdia de dispersão para os sismos 55 e 51 (traço continuo) 
cia dessa estrutura na velocidade das ondas Rayleigh. As curvas de dispersão dos sismos 10, 48,7,24,52,16,15 e 51 (Fig. 4.5) apre sentam oscilações na faixa dos 10 a 20 s de periodo. Estas oscilacões, embora ausentes em alguns eventos, parecem caracterizar a influência da cadeja andina nas curvas de dispersão.

Finalmente, algumas tendēncias anōmalas das curvas de dispersão foram observadas, como por exemplo a do sismo 52 que apresenta, para períodos acima de $20 \mathrm{~s}$, velocidades de grupo. meno res (em $\simeq 0,15 \mathrm{~km} / \mathrm{s})$ que as observadas para sismos com trajetōrias prōximas (Fig. 4.6); é possível que a localização do epicentro nu ma provāvel descontinuidade lateral (Berrocal, 1974) afete as velocidades de propagação das ondas Rayleigh. Por outro lado, oscilações pronunciadas das curvas de dispersão para os sismos 10 , $48,24,16$ e 22 (Fig. 4.7) nos períodos acima de 20 s, provavelmen te sejam causadas pela estrutura mais profunda dos Andes; outras curvas de dispersão tambēm apresentam estas oscilações, porēm mais atenuadas.

As curvas de dispersão observadas, das ondas Love, apresentam um espalhamento pronunciado (Fig. 4.8) provavelmente causado por interferéncias de modos superiores ou por heterogenei dades horizontais existentes na crosta (Haske11, 1953; L.ee e Solomon, 1975). As curvas de dispersão das ondas Love, portanto, não foram utilizadas neste trabaiho.

4.3 - Modelo Teörico Proposto

0 modelo de estrutura crustal, proposto por Brune e Dorman (1963) para o escudo canadense foi tomado como modelo inicial. Mudanças sucessivas dos parámetros do modelo (velocidade das 


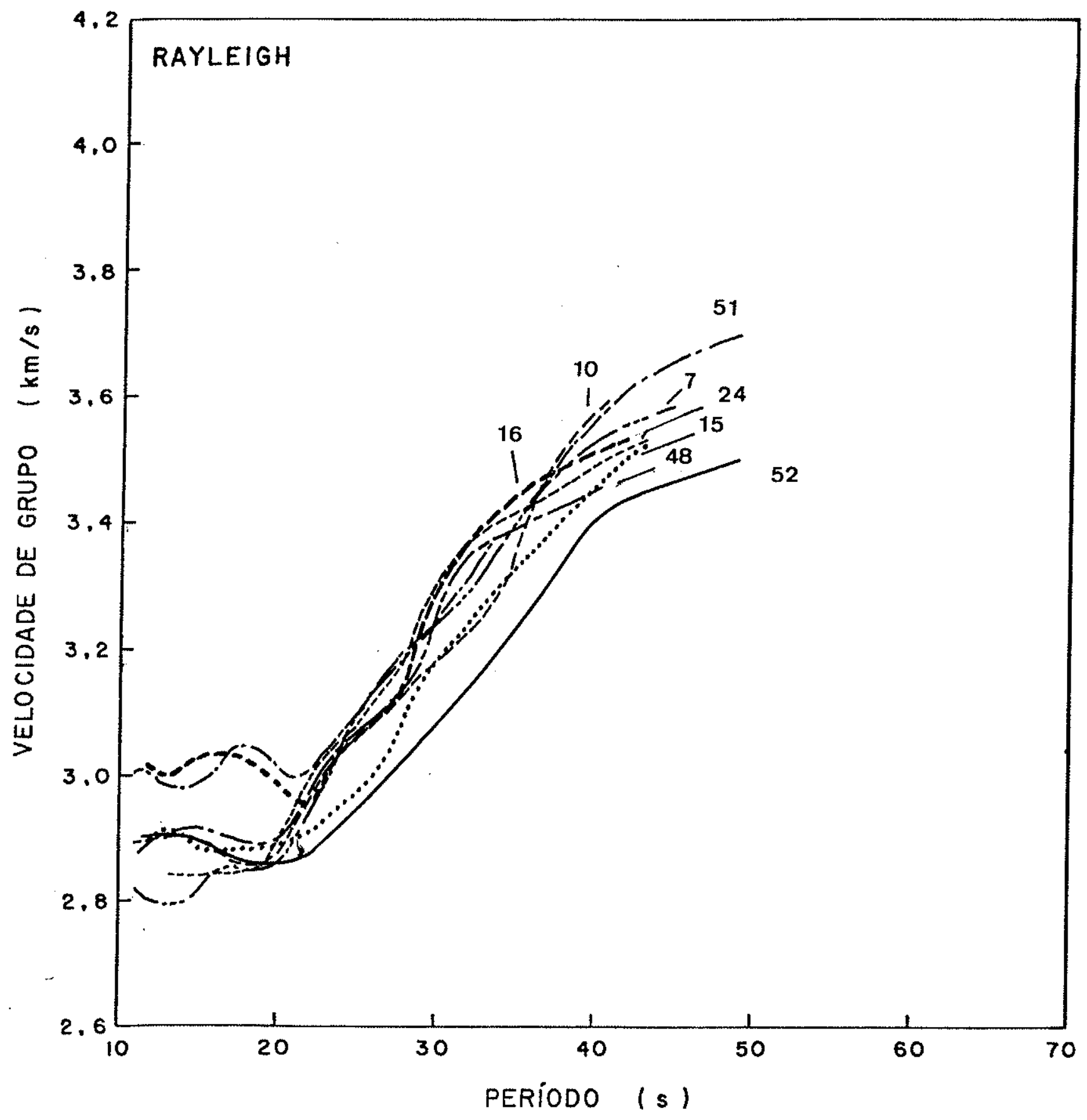

Fig. 4.5 - Curvas de dispersão observadas apresentando oscilações da velocidade de grupo para períodos abaixo dos $20 \mathrm{~s}$ 


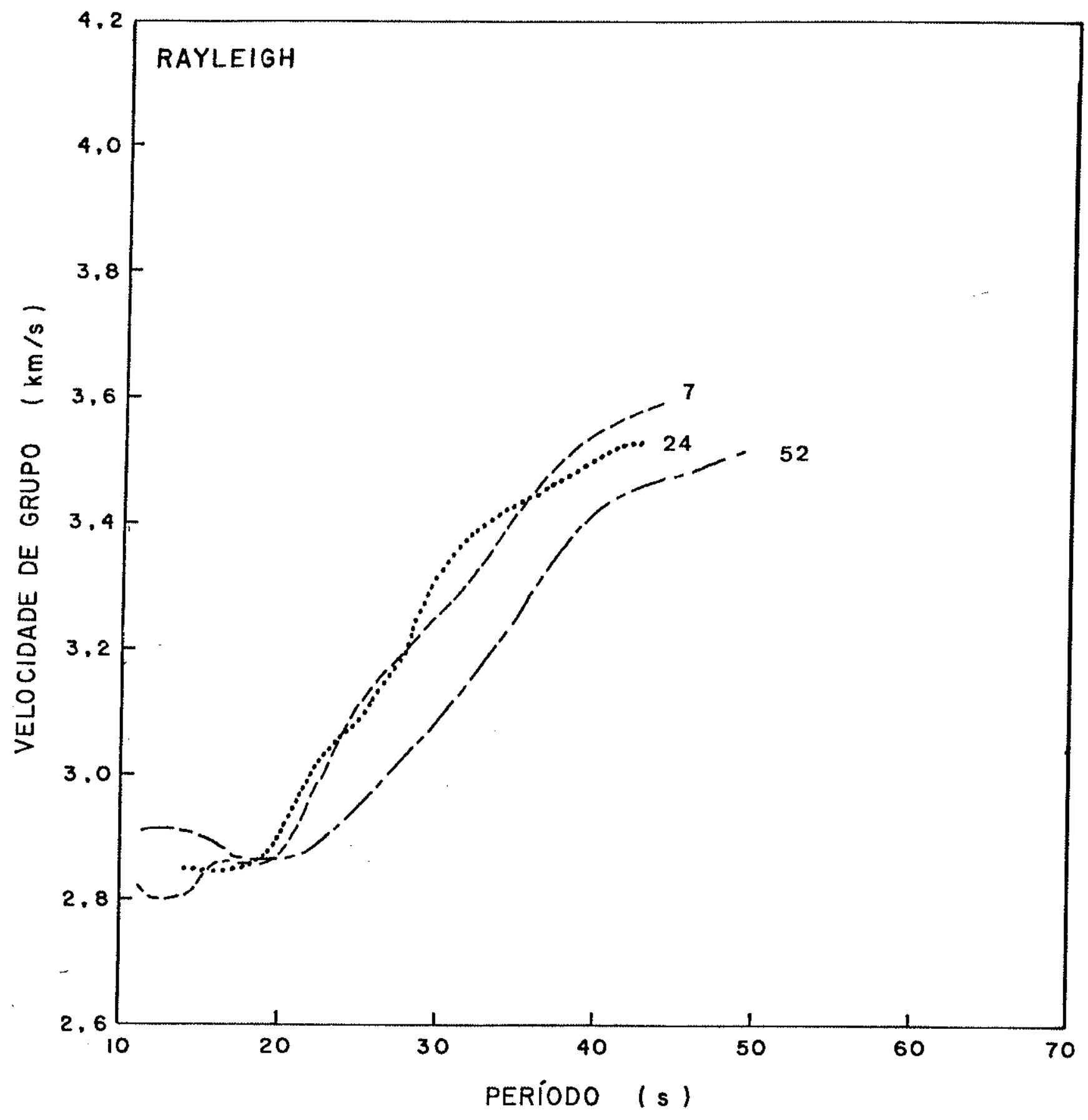

Fig. 4.6 - Comparação da curva de dispersão para o sismo 52 com curvas de dispersão para sismos com trajetōrias próximas 


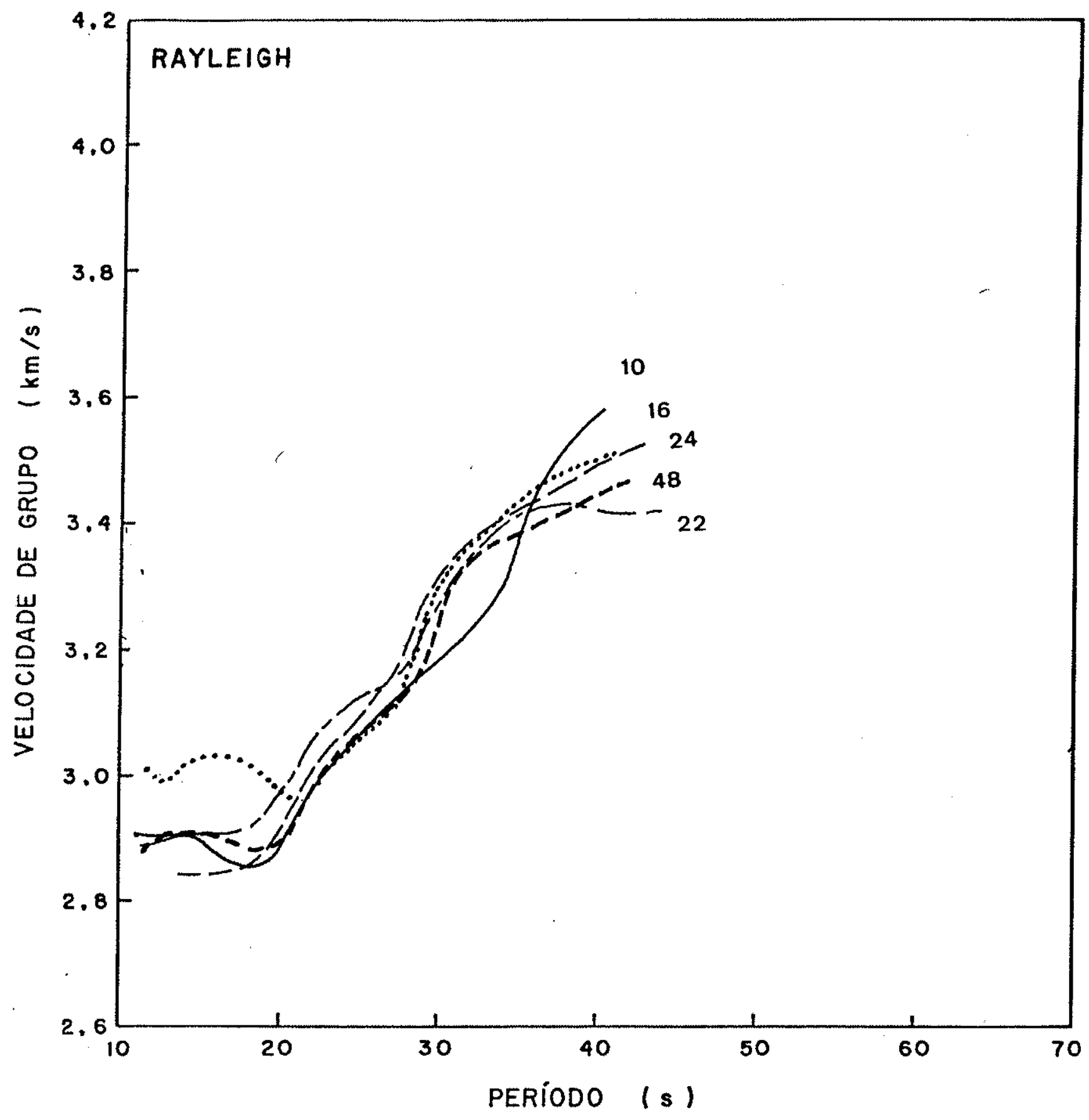

Fig. 4.7 - Curvas de dispersão observadas com oscilações pronunciadas para periodos acima de 20 s. 


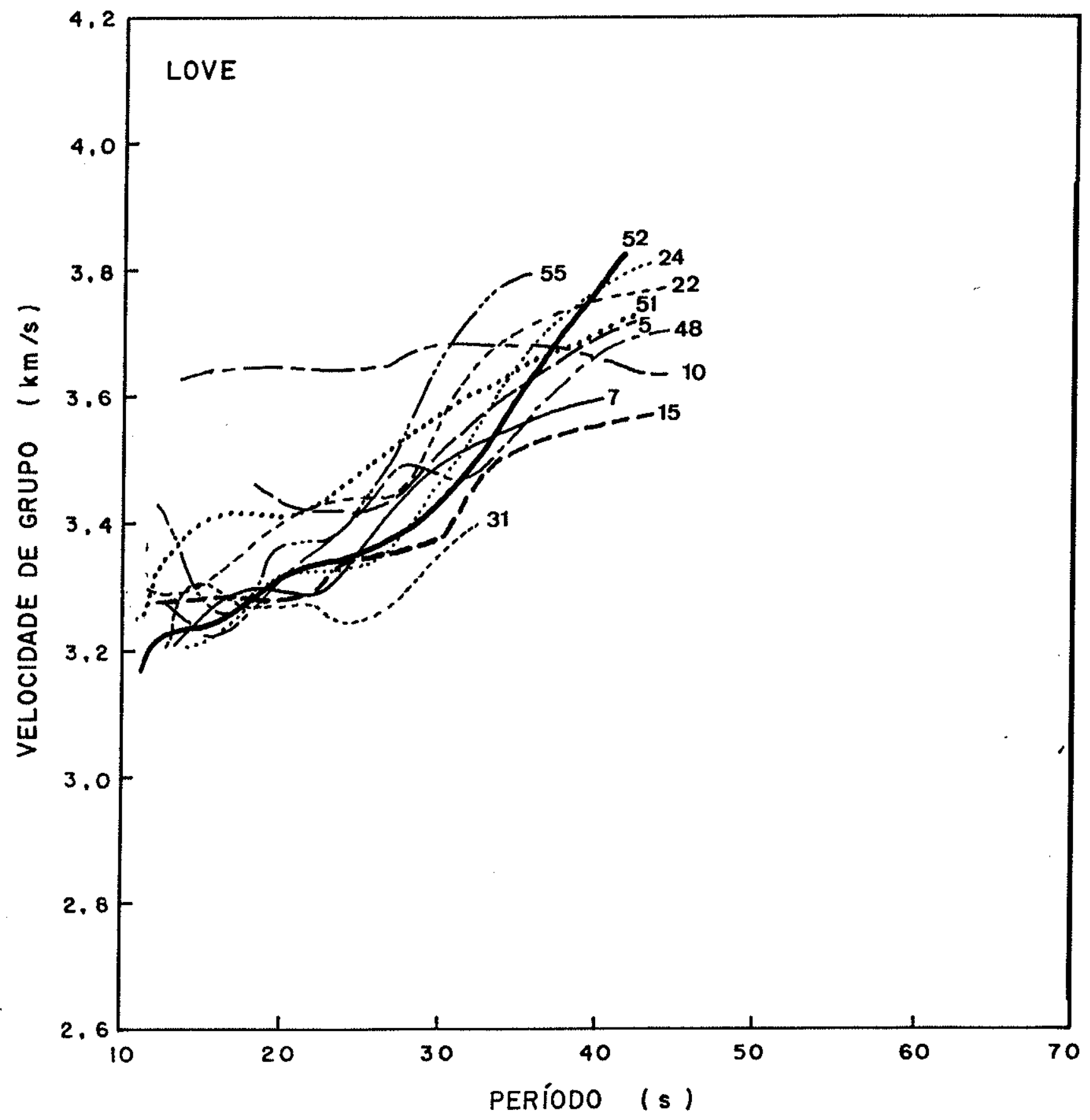

Fig. 4.8 - Curvas de dispersão observadas para as ondas Love 
ondas $\mathrm{P}$ e $\mathrm{S}$, espessura das camadas e densidade) permitiram obter dezenas de famîlias de curvas de dispersão teöricas, nas quais foi possivel observar variações maiores quando a velocidade da on da $S$ ou a espessura eram alteradas e variações menores para mudan ças na densidade.

A quantificação das variações na velocidade de grupo das curvas teōricas facilitou bastante o ajuste dos parāmetros do modelo aos dados observados, para períodos acima de $20 \mathrm{~s}$, porēm certas dificuldades foram enfrentadas na tentativa de se conseguir o ajuste com as porções ramificadas da curva de dispersão observada, isto $\bar{e}$, na faixa compreendida entre 12-24s de período. Apōs sucessivas iterações chegou-se à conclusão de que o melhor ajuste, na faixa de 12-24s de periodo, sö pode ser obtido comprometendo o ajuste da porção restante dos dados observados ou adotando-se um modelo irreal.

Os parämetros do modelo teörico selecionado (PSA-1) e os valores de velocidade de grupo das ondas Rayleigh e Love, calculados para períodos entre 10 e $80 \mathrm{~s}$, são apresentados na Tabela 4.1. A partir destes valores foi traçada, para as ondas de Rayleigh, a curva de dispersão teörica para ser comparada com sua similar obtida experimentalmente.

A curva de dispersão do modelo PSA-1 ē a que se ajus ta melhor à curva mēdia de dispersão observada para os sismos 55 e 51 (Fig. 4.9). As espessuras calculadas para as camadas da cros ta são: 5,15 e $20 \mathrm{~km} \pm 10 \%$. A espessura crustal determinada ( $40 \mathrm{~km}$ $\pm 10 \%$ ) é muito pröxima da espessura encontrada por oblitas (1972) que utilizou ondas superficiais com trajetōrias atraves da crosta continental e oceānica. 
TABELA 4.1

DISPERSKO DE ONDAS SUPERFICIAIS

RAYLEIGH - MODELO PLAT. SULAMERICANA (PSA-1)

ESTRUTURA

\begin{tabular}{|c|c|c|c|}
\hline $\begin{array}{l}5.700 C \\
8.1000 \\
6.6000 \\
7.900 C\end{array}$ & $\begin{array}{l}3.36 c c \\
3.5600 \\
3.7400 \\
4.6000\end{array}$ & $\begin{array}{l}-7000 \\
2-2000 \\
3=0000 \\
3.3000\end{array}$ & $\begin{array}{r}5.0000 \\
15.0000 \\
20.0000 \\
C .0200\end{array}$ \\
\hline
\end{tabular}

CURVA DE DISPERSAO MODO FUNDAMENTAL

\begin{tabular}{|c|c|c|c|}
\hline Perĩodo & Vel. Fase & Vel. Grupo & $x$ \\
\hline $\begin{array}{l}70.9368 \\
58.1059 \\
50.0647\end{array}$ & $\begin{array}{l}4 . \operatorname{css32} \\
4-\cos 32 \\
3.9932\end{array}$ & $\begin{array}{l}3.9275 \\
:-8564 \\
:-7761\end{array}$ & $\begin{array}{l}\text { c. } 0219 \\
0.0269 \\
0.0314\end{array}$ \\
\hline $44-5251$ & 3.9632 & 3.6918 & 0.0355 \\
\hline 40.5804 & 3.9332 & 3.6074 & C. c.393 \\
\hline $\begin{array}{l}37-6526 \\
35.2217\end{array}$ & $\begin{array}{l}3.9 c 32 \\
3.8732\end{array}$ & $\begin{array}{l}2-5254 \\
3-4444\end{array}$ & $\begin{array}{l}D-c 428 \\
0.0461\end{array}$ \\
\hline $23-3967$ & 3.8432 & $3-3744$ & $0-0492$ \\
\hline 31.4653 & 3.8132 & 2.3073 & c. 0524 \\
\hline 29.9431 & 3.7832 & $2-24 E 3$ & 0.0555 \\
\hline $2 E .5700$ & 3.7532 & 3.1919 & 0.0586 \\
\hline 27.3312 & 3.7232 & $2 . x 441$ & 0.0617 \\
\hline 26.1736 & 3.6932 & 3.1030 & c. $C B=0$ \\
\hline $25-10828$ & $3.6 E 32$ & $3-C B B E$ & D.0684 \\
\hline $24-7408$ & 3.6332 & 3.0407 & 0.0719 \\
\hline 23.0310 & 3.6032 & $3-c 193$ & 0.0757 . \\
\hline 22.0431 & 3.5732 & $=0041$ & 0.0798 \\
\hline $2 x-c \varepsilon 23$ & $\pm=5432$ & $\angle-9950$ & 0.0842 \\
\hline 20.0772 & 3.5132 & $\bar{z}=9937$ & 0.0291 \\
\hline 15.0754 & 3.6832 & $2=9940$ & $0.09 k 6$ \\
\hline $1 \varepsilon_{.0432}$ & 3.4532 & 3.0015 & C. 200 Z \\
\hline $16-7647$ & $3-4232$ & 7.0139 & $c-1082$ \\
\hline $15-720 E$ & 3.3932 & 3.0304 & 0.1170 \\
\hline 14.5863 & 3.3632 & 2.0504 & 0.1281 \\
\hline 13.2303 & 3. 3332 & 2.0723 & C. 1425 \\
\hline 12.5135 & $3.3<32$ & 2.0942 & c.1524 \\
\hline
\end{tabular}

LOVE - MODELO PLAT. SULAMERICANA (PSA-1)

\begin{tabular}{|c|c|c|c|}
\hline Período & Vel. Fase & Vel. Grupo & $k$ \\
\hline $\begin{array}{l}74-94 C C \\
67.7826\end{array}$ & $\begin{array}{l}4.4400 \\
4.4100\end{array}$ & $\begin{array}{l}4.1785 \\
4.1120\end{array}$ & $\begin{array}{l}0.0129 \\
0.0210\end{array}$ \\
\hline $62-0432$ & $4-3800$ & 4.0689 & $D-D 23 t$ \\
\hline $57.281 \mathrm{C}$ & 4.3500 & 2.5894 & c.02s \\
\hline $5 \geq-2253$ & $4-3200$ & $2.933 E$ & 0.0273 \\
\hline 45.5990 & $4-2900$ & $3-2812$ & 0.0295 \\
\hline $66-58 c 3$ & 4.2600 & 3.8323 & 0.0317 \\
\hline 43.7827 & 4.2300 & 2.7867 & 0.0339 \\
\hline $41-2424$ & $6: 200 \mathrm{C}$ & 2.2443 & 0.0363 \\
\hline $3 E-9111$ & 4.1700 & $3-7052$ & c.03er \\
\hline $36-7516$ & $4-1600$ & $3-E \in 91$ & 0.0413 \\
\hline 34.7343 & 4.1100 & 2.6361 & c. $c \wedge 40$ \\
\hline $32-8355$ & $4-\operatorname{cecc}$ & $3-5060$ & c. 0469 \\
\hline 31.0356 & 4.0500 & $\begin{array}{rl}2 \\
3 \\
3 & 5525\end{array}$ & c-c500 \\
\hline $\begin{array}{l}25-3184 \\
27.5700\end{array}$ & $\begin{array}{l}8-0200 \\
3.9900\end{array}$ & $\begin{array}{l}3.5545 \\
7-5328\end{array}$ & 0.0533 \\
\hline $\begin{array}{l}27.6780 \\
26.0785\end{array}$ & 3. 9600 & $\begin{array}{l}2-5328 \\
\geq \leq \pm 132\end{array}$ & $\begin{array}{l}0.0569 \\
c .0602\end{array}$ \\
\hline $24-5333$ & 3.9300 & 3.4973 & 0.0652 \\
\hline $23-2250$ & $3.900 \mathrm{c}$ & $z-4 B 33$ & 0.0700 \\
\hline 21.5442 & 3.8700 & $x=4717$ & C. C75t \\
\hline $2 C-0845$ & $3.84 C C$ & $3-4623$ & $c_{-0215}$ \\
\hline $18-5374$ & 3.8100 & $2-4550$ & c.0885 \\
\hline 17.1956 & 3.7200 & 3.4497 & c. 0967 \\
\hline $15-r s t s$ & $3-\gamma \leq 0 \mathrm{C}$ & $\pi-445]$ & $c-1084$ \\
\hline 14.2985 & 3.7200 & $2-4438$ & 0.1121 \\
\hline $12-8332$ & 3.6900 & $\geq-4623$ & 0.1327 \\
\hline 11.1529 & 3.6500 & $3.44 C 9$ & c. 1512 \\
\hline
\end{tabular}

Parämetros do modelo teōrico proposto e velocidades de grupo teöricas para as ondas Rayleigh e Love 


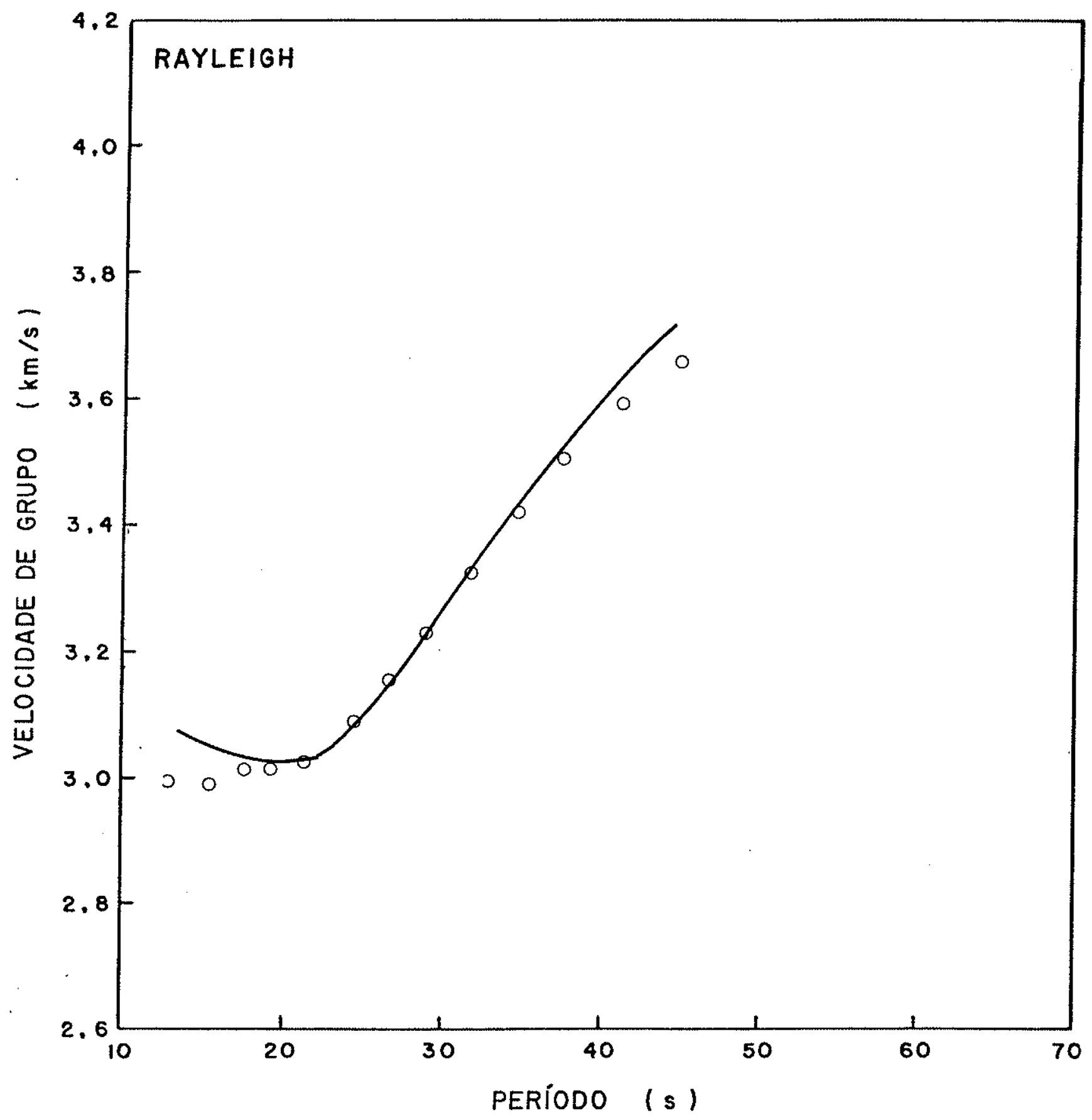

Fig. 4.9 - Comparação entre as curvas de dispersão teōrica (traço continuo) e observada (o). 
0 modelo crustal proposto por Blitzkow et al (1978) tambēm foi testado, porēm as velocidades de grupo encontradas fo ram extremamente superiores aos dados experimentais.

4.4 - Comparação com modelos crustais de outras regiões de escudo Pelos postulados da Teorīa da Tectónica Global, espe ra-se uma semelhança entre as estruturas crustais das regiões de escudo do Brasil e da Africa, principalmente com a parte $N$, porēm os dados disponiveis se limitam à parte leste e sul da Äfrica.

Alēm das curvas de dispersão teöricas para trajetōrias continentais através dos escudos afro-asiätico e do Brasil, a Fig. 4.9 tambëm apresenta para comparação, curvas de dispersão teóricas dos escudos canadense e australiano.

As curvas de dispersão para as trajetōrias AlaskaPalisades, Kariba-Pretōria e Charles Towers-Perth apresentam velocidades de grupo superiores às determinadas para a Plataforma Sul-Americana; notāndo-se uma boa concordāncia (RMS $=0,02 \mathrm{~km} / \mathrm{s}$ ) nos períodos acima dos $25 \mathrm{~s}$, entre as curvas de dispersão para as regiões de escudo afro-asiätica e do Brasil, indicando uma seme Thança entre as estruturas destas regiões. 


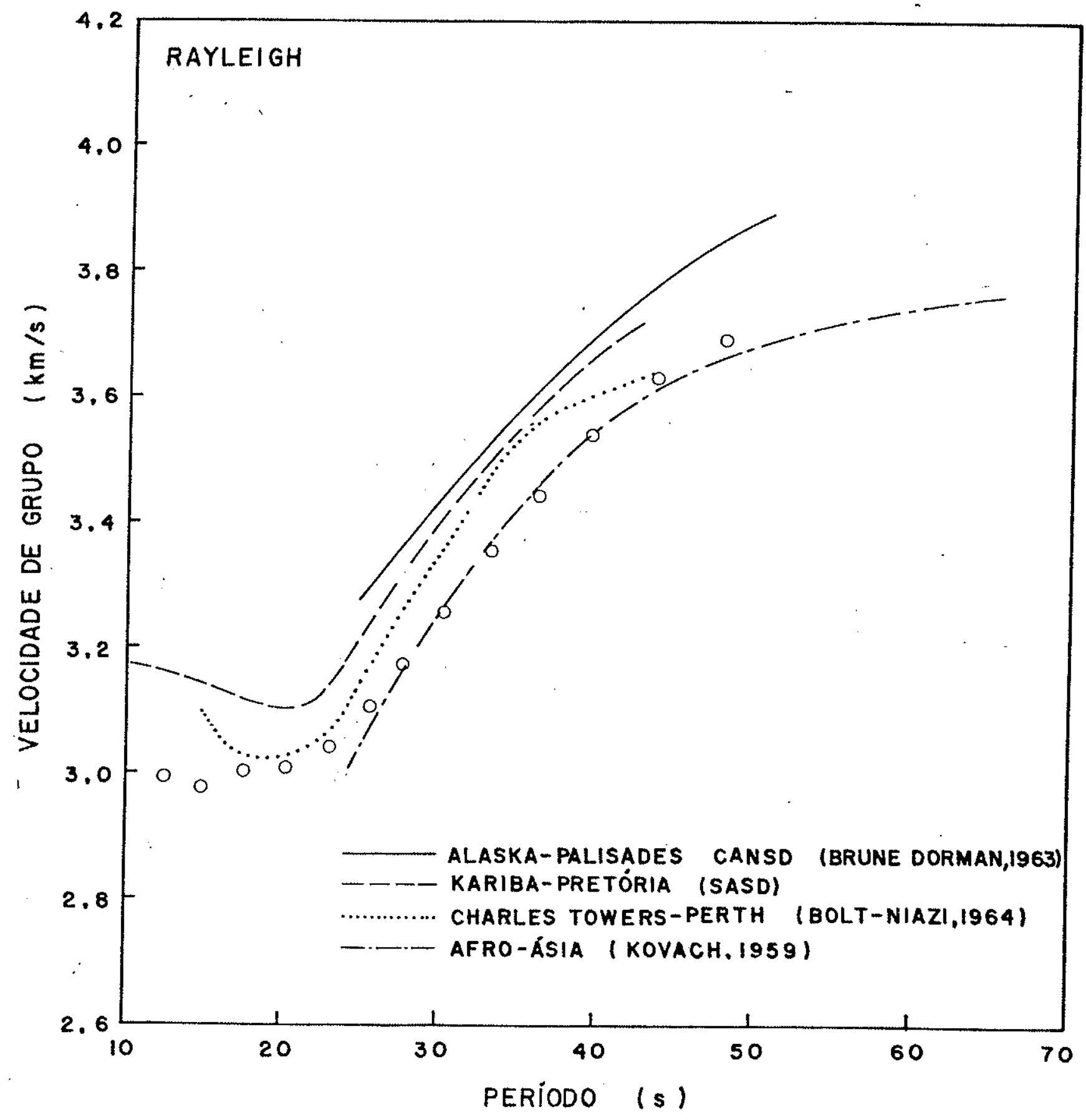

Fig. 4.10 - Comparação do modelo PSA-1 (o) com modelos crustais de outras regiões de escudos. 
CAPITULO 5

\section{CONCLUSOOES}

Os resultados obtidos, no presente trabalho, mediante o estudo das ondas superficiais são os seguintes:

- A semelhança encontrada entre as curvas de dispersão da velocidade de grupo das ondas Rayleigh, nos periodos acima dos 20s, indica que a estrutura crustal è relativamente uniforme na $\mathrm{Pla-}$ taforma Sul-Americana, e propõe-se o modelo PSA-1, com uma espessura crustal de $40 \mathrm{~km} \pm 10 \%$, como representativo da estrutura da crosta e manto superior na região estudada.

- A observação de velocidades de grupo baixas $(\approx 2,85 \mathrm{~km} / \mathrm{s})$, na fa $\underline{i}$ $x a$ dos 10 a 20 s de perído, para trajetōrias que cruzam a bacia do Paraná mostram a influência causada pelos sedimentos dabacia nas curvas de dispersão das ondas Rayleigh. Estudos efetuados com ondas superficiais, com periodos na faixa dos 2 a $20 \mathrm{~s}$, de sismos proximos podem fornecer resultados mais precisos da bacia sedimentar.

- As oscilações observadas na maioria das curvas de dispersão, nos periodos abaixo dos 20 s, parecem insinuar a influéncia dos Andes nas velocidades de grupo das ondas Rayleigh.

- A comparação da curva média de dispersão obtida no presente tra balho com suas similares de outras regiões, estabelece uma seme Ihança da estrutura crustal dos escudos do Brasil Central e At]āntico com a do escudo afro-asiātico.

- O digitizador semi-automätico construido no IAG, com precisões de $0,1 \mathrm{~mm}$, mostrou-se eficiente na digitização dos registros das ondas superficiais. 


\section{BIBLIOGRAFIA}

Aki, K - 1964-Study of Love and Rayleigh Waves from Earthquakes with Fault Plane Solutions or with Known Faulting Part 2. Application of the Phase Difference Method. Bu1.T. Seism. Soc. Am., 54, 529-558.

Aldrich, -1958- The Earth's Crust. Carnegie Inst. of Wash. Year Book, 1957-58.

Almeida, F.F.M. de (1971)-Geochronological division of the Precambrian of South America. Rev. Bras. de Geociēncias, vol. 1, nọ 1, $13-21$.

Almeida, F.F.M de, Hasui, Y.; Brito Neves B.B. de, e Fuck, R. A. -(1981) - Brazilian Structural Provinces: an introduction. Earth Science Rev., 17, 1-29.

Alekseev, A.S.; e colaboradores -1973-Seismic Studies of Low Velo city Layers and Horizontal Inhomogeneities with in the crust and Upper Mantle on the Territory of the USSR.

Alterman, Z.; Jarosch, H e Pekeris, C.L.-(1961)-Propagation of Rayleigh Waves in the Earth. Geophys. J.R.Astr.Soc., 4, $219-241$.

Antezana, R. -1969-Composiciōn Geofísica de la Estructura Cortical bajo los Andes Centrales. Observ. San Calixto, Pub. nọ 7. La Paz-Bolīvia. 90 pägs.

Anzoleaga, R. - 1964 Algunas Consideraciones sobre la Corteza Terres tre debajo de los Andes. Tesis de Grado. Fac. de Geologia, UMSA. La Paz-Bolivia.

Arora, S.K.; Varghese, T.G. e Krishnan, C.A. -1970-Some Aspects of the Structure of Southern India Based on Recent Bhadrachalam Earthquakes, Nature, 225, 261-262. 
Bahar, L.Y.-(1977)- Optimal Digitization of Earthquake Records. Nuclear Engineering and Design; 44, 263-267.

Berrocal, J. - (1974)- South American Seismotectonics from SAAS Data. Tese PhD. Univ. de Edinburg.

Berrocal, J. e Antezana, R. -(1977)-Importáncia de las Estaciones Sismogräficas del Brasit en los Estudos de Sismicidad e Tec tönica en la América del Sur. Apresentado no I Congresso Ibero-Latinoamericano de Geofisica. Caracas-Venezuela.

Berry, M.J. e Fucks, K. -(1973)-Crustal Structure of the Superior and Grenville Provinces of the NE Canadian Shield. Bull. Seism. Soc. Am., 63, 1393-1432.

Blackman, R.B. e Tukey, J.W. -(1958)- Measurement of Power Spectra : Dover Pub. Inc., New York, 190 pags.

Blitzkow, D.; Gasparini, P.; Mantovani, M.S.M.; e de Sä, N.C. -1978Crustal Structure of Southeastern Minas Gerais, Brazil, deduced from Gravity measurements. Rev. Bras. de Geociēncias, $9,39-43$.

Bloch, S. e Hales, A.L. -(1968)- New Techniques for the Determination of Surface Waves Phase Velocities. Bull. Seism. Soc. Am., 58, $1021-1034$.

Bloch, S.; Hales, A.L.; e Landisman, M. -1969-Velocity in the Crust and Upper Mantle of Southern Africa from Multi-Mode Surface Wave Dispersion. Bul1. Seism. Soc. Am., 59, 1599-1629.

Bolt, B.A.; Doyle, H.; e Sutton, D. -1958- Seismic Observations from the Atomic Explosions in Australia. Geophys. J., I, 135-145. Bolt, B.A. e Niazi, M. -1965-Dispersion of Rayleigh Waves across Australia. Geophys. J., 9, 21-35. 
Brune, J. e Dorman, J. -(1963)-Seismic Waves and Earth Structure in the Canadian Shield. Bul1. Seism. Soc. Am., 53, 167-209. Bullen, K.E. - (1965)- An Introduction to the Theory of Seismology. Cambridge University Press 381 pags.

Careaga, J. -1967- Estudio de la Corteza Terrestre en La Paz mediante el Espectro de Ondas Sĩsmicas. Tesis de Grado. Fac. de Geol., UMSA. La Paz-Bolivia.

Cisternas, A. -1961-Crustal Structure of the Andes from Rayleigh Wave Dispersion. Bu11. Seism. Soc. Am., 51, 381-387.

Cleary, J. e Doyle, H. -1962- P times to Australian Stations from Nuclear Explosions. Bul1. Seism. Soc. Am., 52, 673.

DNPM/CPRM (1979) Levantamento Gravimëtrico no Estado da Bahia. Re latōrio Preliminar.

Dziewonski, A.; Landisman, M; Bloch, S.; Sato, Y e Asano, S.-(1968)Progress Report on Recent Improvements in the Analys is of Surface Wave Observations. Journ. Phys. of the Earth, 16 , Special Issue, $1-26$.

Dziewonski, A.; Bloch, S.; Landisman, M. (1969)- A Technique for the Analysis of Transient Seismic Signals. Bull. Seism. Soc. Am. , 59, $427-444$.

Ewing, M. e Press, F. (1952)-Crustal Structure and Surface Wave Dispersion. Part II, Solomon Island Earthquake of July 29 , $1950,42,315-325$.

Ewing, M.; Jardetzky, W.S.; e Press, F. (1957)-Elastic Waves in Layered Media. McGraw-Hi11, New York, $380 \mathrm{pag}$.

Ewing, M.; Mueller, S.; Landisman, M. e Sato, Y. (1959)-Transient Analysis of Earthquake and Explosion Arrivals. Geofis. Pura e Appl., 44, 83-118. 
Fernandez, L.M. e Careaga, J.-1968- The Thickness of the Crust in Central United States and La Paz, Bolivia, from the Spectrum of Longitudinal Seismic Waves. Bull. Sejsm. Soc. Am., $\underline{58}$, $717-741$.

Goodman N.R. (1960)-Measuring Amplitude and Phase. Journ. Franklin Inst., $260,437-450$.

Gumper, F. e Pomeroy, P. -1970-Seismic Wave Velocities and Earth Structure in the African Continent. Bul1. Seism. Soc. Am., $60,657-688$.

Gutenberg, B. (1959)-Physics of the Earth's Interior. Academic Press 240 pag.

Hales, A.L. e Sacks, F.S. -1959-Evidence for an Intermediate Layer from Crustal Structure Studies in the Eastern Transval. Geophys. J., 2, 15-33.

Giese, P. e Shutte, J. (1975)-Preliminary Report on the Results of Seismic Measurements in the Brazilian Coastal Mountains in March/Apri1, 1975. Un pub1. Report Brazil Germany, Sci. agr., 11 pags.

Haralyi, N.L.E. e Hasuy, Y. (1982a)-The Gravimetric information and the Archean Proterozoic Structural Framwoork of Eastern Brazil. Anais do ISAP Abstracts Bahia, vol. 12, 160-166. Haralyi, N.L.E. e Hatsuy (1982b)-Compartimentação Geotectōnica do Brasil Oriental com base na Informação Geofísica. Anais do XXXII Congr. Bras. de Geol., Bahia, vol. 1, 374-385.

Haske11, N.A. (1953)- The Dispersion of Surface Waves inMultilagered Media. Bul1. Seism. Soc. Am., 43, 17-34. 
Hiodo, F.Y.; Antezana, R. e Shukowski, R.S.M. -(1983)-Sistema de Di gitização de Registros Grāficos; SBPC, $35^{\text {a }}$ Reunião Anual, Belēm-Parā.

Ibiett, A. -1969-Analisis Espectral de Ta Corteza Terrestre en La Paz mediante Ondas Sismicas.P de Corto Período. Tesis de Grado. Fac. de Geol., UMSA. La Paz; Bolivia. 145 pāgs.

James, D.E. -1971- Andean Crustal and Upper Mantle Structure. Jour. Geophys. Res., 76, 3246-3271.

Jeffreys, H. (1925)-On the Surface Waves of Earthquakes. M.N.R.A.S. Geoph. Supp1., I, 282-292.

Knize, S.; Berrocal, J. e de 01iveira, D.M. -(1984)-Modelo Prelimi nar de Velocidades Sísmicas da Crosta atravēs de Explosões locais Registradas pela Rēde Sismogräfica de Sobradinho-BA.

Landisman, M.; Dziewonski, A. e Sato, Y.-(1969)-Recent.Improvements in the Analysis of Surface Waves Observations. Geophys.J.R. Astr. Soc., 17, 369-403.

Lee, W.V. e Solomon, S.C. -(1975)-Inversion Schemes for surface Wa ves Attenuation and $Q$ in the crust and the Mantle. Geophys. J.R.Astr.Soc., $43,47-71$.

Loczy, L. -(1970)-Role of Transcurrent Faulting in South America Tectonic Framework. Am. Assoc. of Petr. Geol., 54, 21112719.

Lomnitz, C. -1962-On Andean Structure. Jour. Geophys. Res., 67, 351 363.

Love, A.E.H. (1911)-Some problems of Geodynamics. Dover Publications, Inc., New York. 
Miller, H.J. -(1963)-Calibration of Long Period Seismographs at 13 Stations throughout the World. Lamont. Geol. Observatory Palisades. Scientific Report 24.

Narain, H. - 1973-Crustal Structure of the Indian Sub-continent. Tectonophysics, 20, 249-260.

Oblitas, J. (1972)-Estructura del Escudo Brasileño a partir de lä Dispersion de Ondas Superficiais. Univ. de Chile. Publ., nọ 153.

0cola, L.C. -1972-Crustal Low Velocity Zones under the Peru-Bolivia Altiplano. Geophys. J., 30, 199-209.

01 dham, R.D. - (1900)- On the Propagation of Earthquake Motion to Great Distance. Phil. Trans. Roy. Soc. Lond., Al94.

01 iver, J. e Ewing, M. -(1958)- Normal Modes of Continental Surface Waves. Bul1. Seism. Soc. Am., 48, 33-49.

Pilant, W.L. (1979)- Elastic Waves in the Earth. Developments in Solid Earth Geophysics. Elsevier Pub. Co. New York, 493 pags. Porto, R. e Szatmari, P., (1982)-Classificação Tectōnica das Bacias Sedimentares Terrestres do Brasil. XLV RANE-ARPEL-Mēxico. Poisson, S.D. (1831)- Mémoire sur la propagation du mouvament dans les milieux êlastiques. Paris, Mem. de l'Acad.

Press, F. (1956)-Determination of Crustal Structure from Phase Velo city of Rayleigh Waves. Part I: Southern California. Bull. Geo1. Soc. Am., 67, 1647-1658.

Press, F. (1957)-Determination of Crustal Structure from Phase Velo city of Rayleigh Waves, Part II: San Francisco Bag Region. Bu11. Seism. Soc. Am., 47, 87-88. 
Press, F.; Ewing, M.; e 0liver, S. (1956)-Crustal Structure and Surface Wave Dispersion in Africa. Bul1. Seism. Soc. Am., 46, $97-103$.

Raitt, R.W. -1964-Geophysics of the South Pacific, Research in Geo physics, 2, MIT Press, Cambridge, Mass.

Rand, H.M. (1976)- Estudos Geofísicos na Faixa Litorānea ao Sul do Recife. Tese de Livre Docéncia. UFPE, Recife, 112 pag. Rand, H.M. (1978)- Anālise Gravimētrica e Magnetomētrica de Estructu ra Superficial da Faixa Costeira do Nordeste Brasileiro. Anais do XXX Congr. Bras. de Geol., vol. 5, 2336-2346. Rand, H. Sial, A.N.; Brito Neves, B.B. e Manso, V.U. (1980)-Gravi metric Magnotometric Study of the Late Precambrian Sergipe Folding System, Northest Brazil. Anais do XXXI Congr. Bras. de Geol. vol. 5, 2700-2708.

Rayleigh, L. (1885)- On Waves Propagated along the Plane Surface of an Elastic Solid. London, Proc. Math. Soc., vol XVII, pag. 4-11.

Reddy, P.K. -1971-Crustal and Upper Mantle Structure in India from Body Wave Travel Time Studies of Shallow earthquakes. Thesis. Andhra Univ. Waltair. 257 pägs.

Rubin de Celis, J.A. (1967) Investigaciōn de la Estructura Cortical de los Andes Centrales Mediante ondas Sismicas de Superfí cie. Tesis de Grado. Fac. de Geol. UMSA, La Paz-Bolivia.

Sanford, R.M. e Lange, F.W. -(1960)- Basin Study Approach for 0 il Evaluation of Paranā Miogeosyncline of South Brazil. Amer. Ass. Petrol. Geol., 44, 1316-1370. 
Santa Cruz, J. -1964- Contribuciōn al Estudio de la Discontinuidade de Mohorovicic al NW de La Paz. Tesis de Grado. Fac. de Geol., UMSA. La Paz-Bolivia.

Sato, Y. (1955)-Analys is of Dispersed Surface Waves I. Bul1. Earthq. Res. Inst., 33, 33-47.

Sato, Y. (1956)-Analys is of Dispersed Surface Waves II. Bull. Earthq. Res. Inst., 34, 9-18.

Sato, Y. (1957)-Analys is of Dispersed Surface Waves III. Bull. Earthq. Res. Inst., 34, 131-138.

Sellevoll, M.A. e Warrick, R.E. -1971-A Refraction Study of the Crustal Structure in Southern Norway. Bull. Seism. Soc.Am., $61,457-471$.

Sollogub, V.B.; e colaboradores -1973- New DSS Data on the Crustal Structure of the Baltic and Ucranian Shields. Tectonophysics, $20,67-84$.

Stokes, G.G. (1849)- On the Dynamical Theory of Diffraction. Cambridge, Trans. Phil. Soc., vol. IX.

Stoneley, R. (1925)-Dispersion of Seismic Waves.M.N.R.A.S., Geophys. Supp 1., 1, 280-282.

Tandon, A.N. e Chaudhury, H.M. -1968- Koyna Earthquake of December 1967. Sci. Rep. Ind. Met. Dept., nọ 59, 1-12.

Telleria, J.R. e Lejsek, J.K. -1975- Interpretaciōn Tectōnica del Perfil Gravimétrico Charanã-San Borja, Bolivia. Inst. de Invest. Físicas, IGB, UMSA; Serie E, nọ 1 .

Thomson, W.T. - (1950)- Transmission of Elastic Waves through a Stratified Solid Medium. Jour. App1. Phys, 21, 89USCGS - (1962) - Operation and Maintenance Manual WWSS. 
Willmore, P.L.; Hales, A.L. e Gane, P.G. -1952- A Seismic investigation of Crustal Structure in the western Transval. Bull. Seism. Soc. Am., 42, 57-80.

Woollard, G.P. e Steinhart, J.S: -1961- Seismic Evidence Concerning Crustal Structure. Carnegie Inst. of Wash. Pub1. 622, 344383.

Wunsche1, P.C. -1953- Gravity Measurements and their Interpretation in South America. Geophysics, 18, 257. 
APENDICE A 
Ondas Rayleigh.

$\dot{u} / c=-\left(\alpha_{m} / c\right)^{2}\left[\left(\Delta_{m}^{\prime}+\Delta_{m}^{\prime \prime}\right) \cos k r_{\alpha_{m}} z-i\left(\Delta_{m}^{\prime}-\Delta_{m}^{\prime \prime}\right) \operatorname{senk} r_{\alpha_{m}} z\right]-\gamma_{m} r_{\beta_{m}}\left[\left(\omega_{m}^{\prime}-\omega_{m}^{\prime \prime}\right)\right.$

$\left.\cdot \operatorname{cosk} r_{\beta_{m}} z-i\left(\omega_{m}^{\prime}+\omega_{m}^{\prime \prime}\right) \operatorname{senk} r_{\beta_{m}} z\right]$

$\dot{\omega} / c=-\left(\alpha_{m} / c\right)^{2} r_{\alpha_{m}}\left[-i\left(\Delta_{m}^{\prime}+\Delta_{m}^{\prime \prime}\right) \operatorname{senk} r_{\alpha_{m}} z+\left(\Delta_{m}^{\prime}-\Delta_{m}^{\prime \prime}\right) \cos k r_{\alpha_{m}} z\right]+\gamma_{m}\left[-i\left(\omega_{m}^{\prime}-\omega_{m}^{\prime \prime}\right)\right.$

. senkr $\left.{ }_{\beta_{m}} z+\left(\omega_{m}^{\prime}+\omega_{m}^{\prime \prime}\right) \cos k r_{\beta_{m}} z\right]$

$\sigma=-\rho_{m} \alpha_{m}^{2}\left(\gamma_{m}-1\right)\left[\left(\Delta_{m}^{\prime}+\Delta_{m}^{\prime \prime}\right) \cos k r_{\alpha_{m}} z-i\left(\Delta_{m}^{\prime}-\Delta_{m}^{\prime \prime}\right) \operatorname{senkr} \alpha_{m} z\right]-\rho_{m} c^{2} \gamma_{m}^{2} r_{\beta_{m}}\left[\left(\omega_{m}^{\prime}-\omega_{m}^{\prime \prime}\right)\right.$

$\left.\cdot \cos k r_{\beta m} z-i\left(\omega_{m}^{\prime}+\omega_{m}^{\prime \prime}\right) \operatorname{sen} k r_{\beta m} z\right]$

$\tau=\rho_{m} \alpha_{m}^{2} \gamma_{m} r_{\alpha_{m}}\left[-i\left(\Delta_{m}^{\prime}+\Delta_{m}^{\prime \prime}\right) \operatorname{sen} k r_{\alpha_{m}} z+\left(\Delta_{m}^{\prime}-\Delta_{m}^{\prime \prime}\right) \cos k r_{\alpha_{m}} z\right]-\rho_{m} c^{2} \gamma_{m}\left(\gamma_{m}-1\right)$

$\cdot\left[-i\left(\omega_{m}^{\prime}-\omega_{m}^{\prime \prime}\right) \operatorname{sen} k r_{\beta_{m}} z+\left(\omega_{m}^{\prime}+\omega_{m}^{\prime \prime}\right) \cos k r_{\beta_{m}} z\right]$

$E_{m}=\left[\begin{array}{c}-\left(\alpha_{m} / c\right)^{2} \\ 0 \\ -\rho_{m} \alpha_{m}^{2}\left(\gamma_{m}-1\right)\end{array}\right.$

$0 \quad-\gamma_{m}{ }^{r} \cdot \beta_{m}$

0

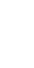


$D_{m}=\left[\begin{array}{llll}-\left(\alpha_{m} / c\right)^{2} \cos P_{m} & i\left(\alpha_{m} / c\right)^{2} \operatorname{sen} P_{m} & -\gamma_{m} r_{\cdot} \beta_{m} \cos Q_{m} & i \gamma_{m} r_{\beta_{m}} \operatorname{sen} Q_{m} \\ i\left(\alpha_{m} / c\right)^{2} r_{\alpha_{m}} \operatorname{sen} P_{m} & -\left(\alpha_{m} / c\right) r_{\alpha_{m}} \cos P_{m} & -i \gamma_{m} \operatorname{sen} Q_{m} & \gamma_{m} \cos Q_{m} \\ -\rho_{m} \alpha_{m}^{2}\left(\gamma_{m}-1\right) \cos P_{m} & i \rho_{m} \alpha_{m}^{2}\left(\gamma_{m}-1\right) \operatorname{sen} P_{m} & -\rho_{m} c^{2} \gamma_{m}^{2} r_{\beta_{m}} \cos Q_{m} & i \rho_{m} c^{2} \gamma_{m}^{2} r_{\beta_{m}} \operatorname{sen} Q_{m} \\ -i \rho_{m} \alpha_{m}^{2} \gamma_{m}{ }_{\alpha} \alpha_{m} \operatorname{sen} P_{m} & \rho_{m} \alpha_{m}^{2} \gamma_{m}{ }_{\alpha_{m}} \cos P_{m} & i \rho_{m} c^{2} \gamma_{m}\left(\gamma_{m}-1\right) \operatorname{sen} Q_{m} & -\rho_{m} c^{2} \gamma_{m}\left(\gamma_{m}-1\right) \cos Q_{m}\end{array}\right]$

onde $P_{m}=k r_{\alpha_{m}} d_{m} ; \quad Q_{m}=k r_{\beta_{m}} d_{m}$

$E_{m}^{-1}=\left[\begin{array}{cccc}-2\left(\beta_{m} / \alpha_{m}\right)^{2} & 0 & \left(\rho_{m} \alpha_{m}^{2}\right)^{-1} & 0 \\ 0 & c^{2}\left(\gamma_{m}-1\right) / \alpha_{m}^{2} r_{\alpha_{m}} & 0 & \rho_{m} \alpha_{m}^{2} r_{\alpha_{m}} \\ \left(\gamma_{m}-1\right) / \gamma_{m} r_{\beta_{m}} & 0 & -\left(\rho_{m} c^{2} \gamma_{m} r_{\beta_{m}}\right)^{-1} & 0 \\ 0 & 1 & 0 & \left(\rho_{m} c^{2} \gamma_{m}\right)^{-1}\end{array}\right]$

$(2.3 .15)$

os elementos de $a_{m}=D_{m} E_{m}^{-1}$ são:

$\left(a_{m}\right)_{11}=\gamma_{m} \cos P_{m}-\left(\gamma_{m}-1\right) \cos Q_{m}$

$\left(a_{m}\right)_{12}=i\left[\left(\gamma_{m}-1\right) r_{\alpha_{m}}^{-1} \operatorname{sen} P_{m}+\gamma_{m} r_{\beta_{m}} \operatorname{sen} Q_{m}\right]$

$\left(a_{m}\right)_{13}=-\left(\rho_{m} c^{2}\right)^{-1}\left(\cos P_{m}-\cos Q_{m}\right)$

$\left(a_{m}\right)_{14}=i\left(\rho_{m} c^{2}\right)^{-1}\left(r_{\alpha_{m}}^{-1} \operatorname{sen} P_{m}+r_{\beta_{m}} \operatorname{sen} Q_{m}\right)$ 
A 3

$$
\begin{aligned}
& \left(a_{m}\right)_{21}=-i\left[\gamma_{m} r_{\alpha_{m}} \operatorname{senP}{ }_{m}+\left(\gamma_{m}-1\right) r_{\beta_{m}}^{-1} \operatorname{sen} Q_{m}\right] \\
& \left(a_{m}\right)_{22}=-\left(\gamma_{m}-1\right) \cos P_{m}+\gamma_{m} \cos Q_{m} \\
& \left(a_{m}\right)_{23}=i\left(\rho_{m} c^{2}\right)^{-1}\left(r_{\alpha_{m}} \operatorname{sen}_{m}+r_{B_{m}}^{-1} \operatorname{sen} Q_{m}\right. \\
& \left(a_{m}\right)_{24}=\left(a_{m}\right)_{13} \\
& \left(a_{m}\right)_{31}=\rho_{m} c^{2} \gamma_{m}\left(\gamma_{m}-1\right)\left(\cos P_{m}-\cos Q_{m}\right) \\
& \left(a_{m}\right)_{32}=i \rho_{m} c^{2}\left[\left(\gamma_{m}-1\right)^{2} r_{\alpha_{m}}^{-1} \operatorname{sen} P_{m}+{ }_{m}^{2} r_{\beta_{m}} \operatorname{sen} Q_{m}\right] \\
& \left(a_{m}\right)_{33}=\left(a_{m}\right)_{22} \\
& \left(a_{m}\right)_{34}=\left(a_{m}\right)_{12} \\
& \left(a_{m}\right)_{41}=i \rho_{m} c^{2}\left[\gamma_{m}^{2} r_{\alpha_{m}} \operatorname{sen}_{m}+\left(\gamma_{m}-1\right)^{2} r_{\beta_{m}}^{-1} \operatorname{sen} Q_{m}\right] \\
& \left(a_{m}\right)_{42}=\left(a_{m}\right)_{31} \\
& \left(a_{m}\right)_{43}=\left(a_{m}\right)_{21} \\
& \left(a_{m}\right)_{44}=\left(a_{m}\right)_{11}
\end{aligned}
$$

$$
\begin{aligned}
& \Delta_{n}^{\prime}=J_{11} \dot{u}_{0} / c+J_{12} \dot{\omega}_{0} / c \\
& \Delta_{n}^{\prime}=J_{21} \dot{u}_{0} / c+J_{22} \dot{\omega}_{0} / c \\
& \omega_{n}^{\prime}=J_{31} \dot{u}_{0} / c+J_{32} \dot{\omega}_{0} / c \\
& \omega_{n}^{\prime}=J_{41} \dot{u}_{0} / c+J_{42} \dot{\omega}_{0} / c
\end{aligned}
$$


Ondas de Love

$a_{m}=\left[\begin{array}{c}\cos Q_{m} \\ i \mu_{m} r_{\beta_{m}} \operatorname{sen} Q_{m}\end{array}\right.$

$$
\left.\begin{array}{c}
i \mu_{m}^{-1} r_{\beta_{m}}^{-1} \operatorname{sen} Q_{m} \\
\cos Q_{m}
\end{array}\right]
$$


APẼNDICE B 


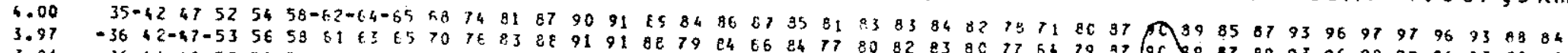

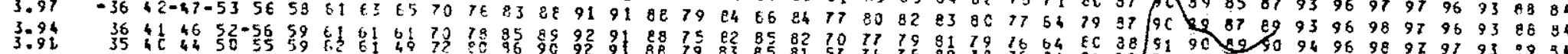

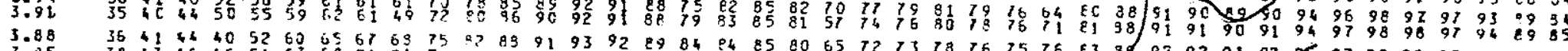

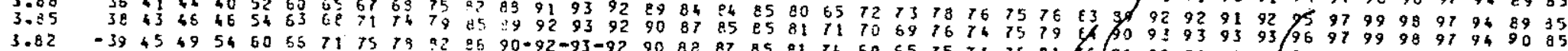

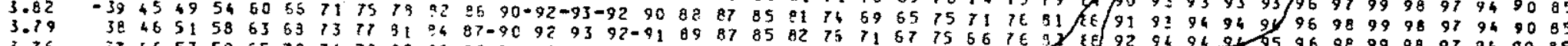

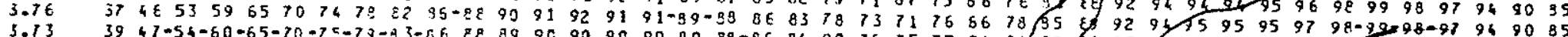

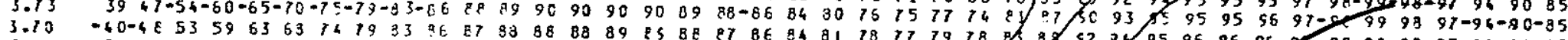

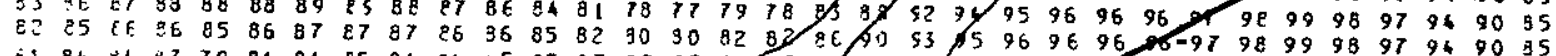

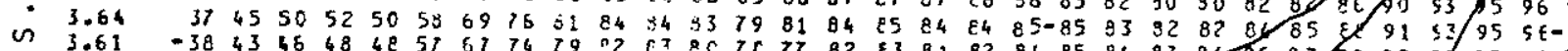

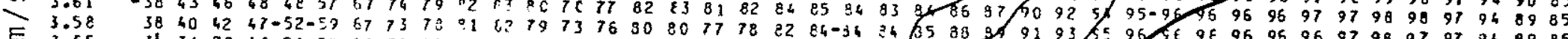

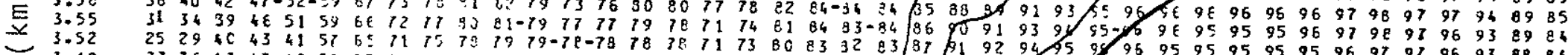

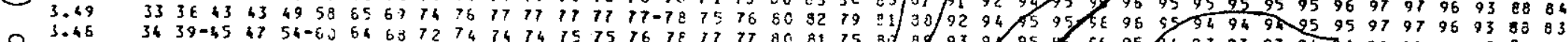

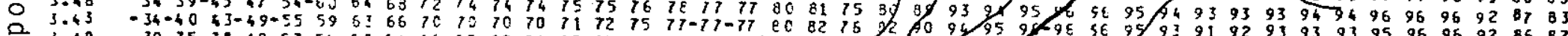

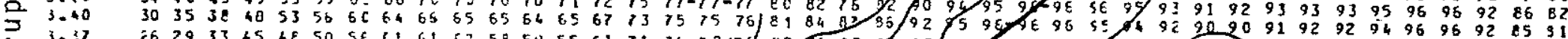

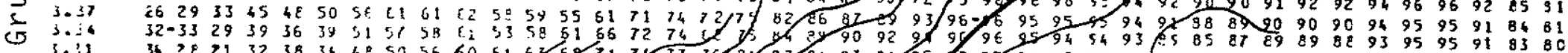

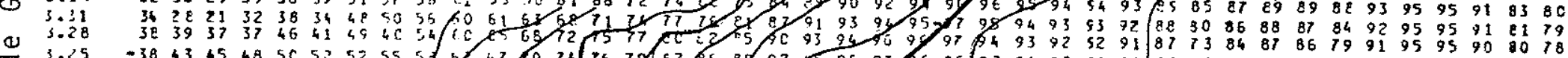

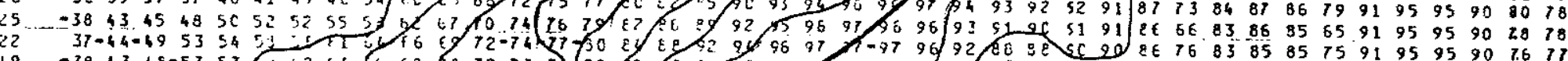

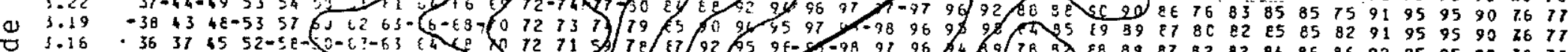

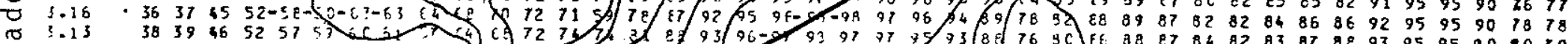

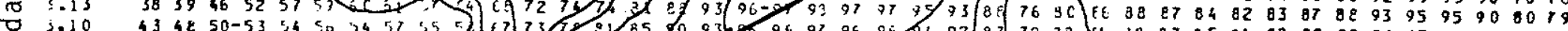

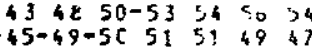

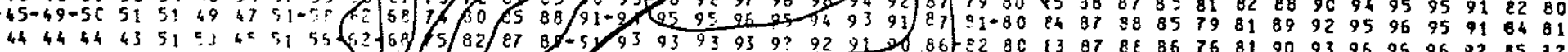

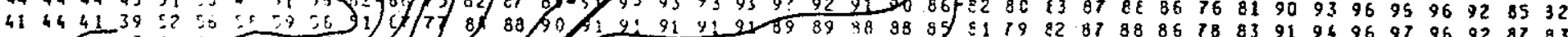
$34,45153 \quad 50$.

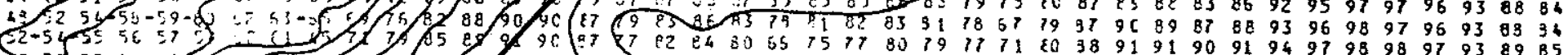

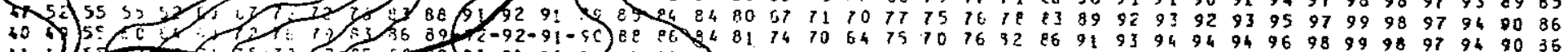
41 .

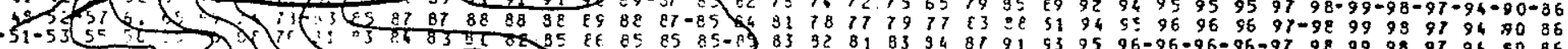

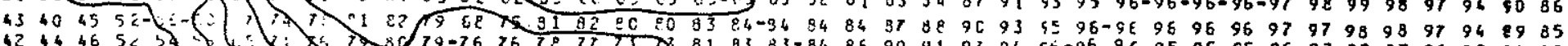

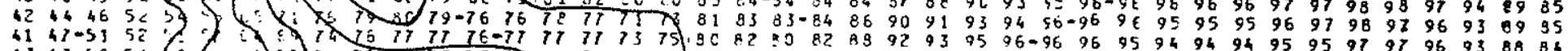

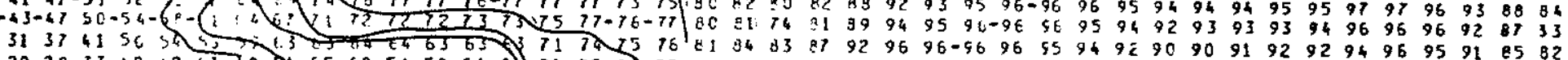

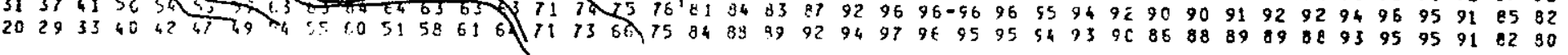

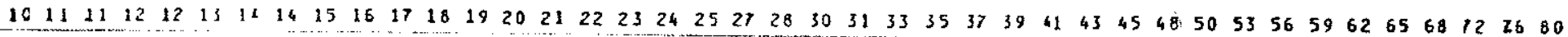
Período ( $s$ )

Fig. B- 01 


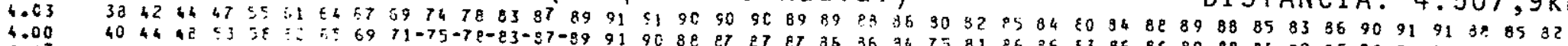

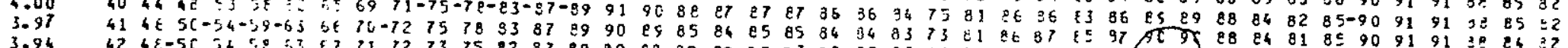

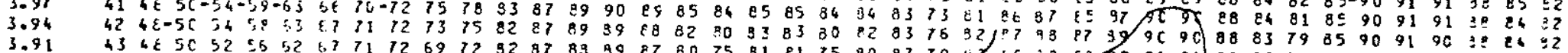

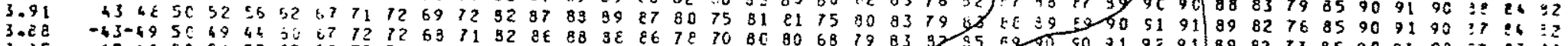

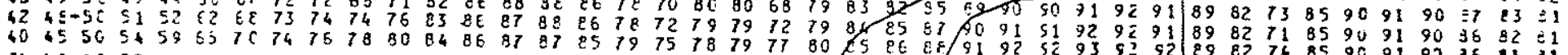

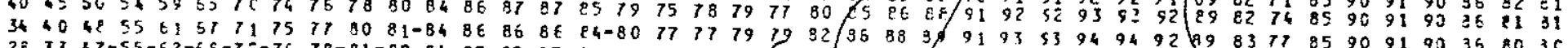

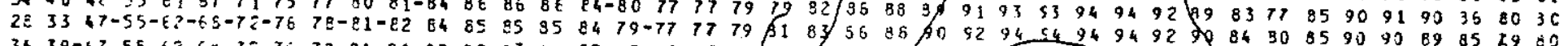

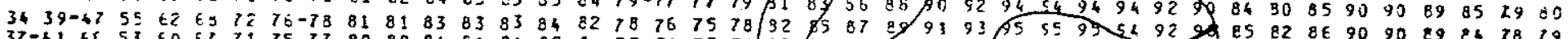

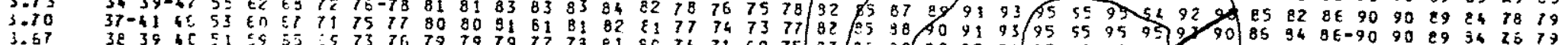

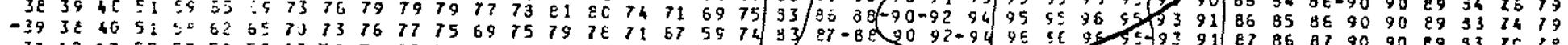

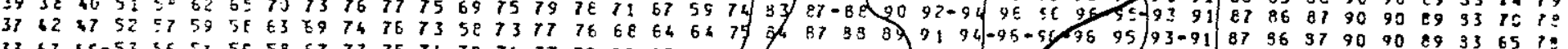

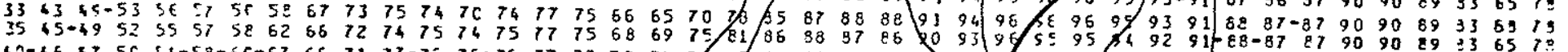

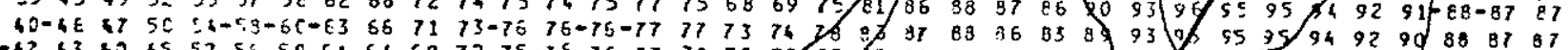

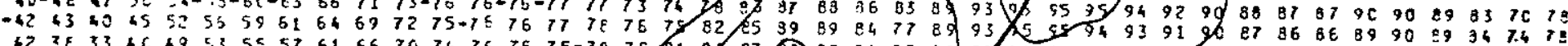

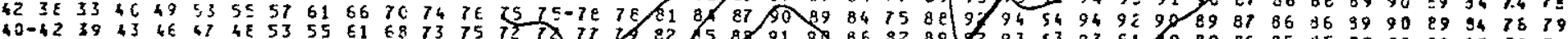

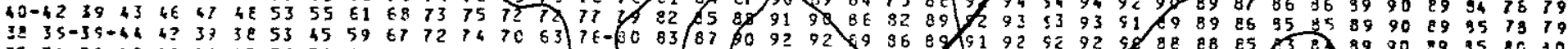

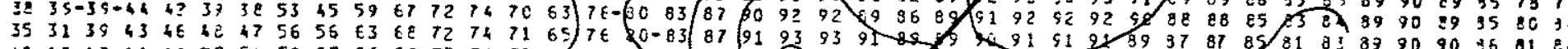

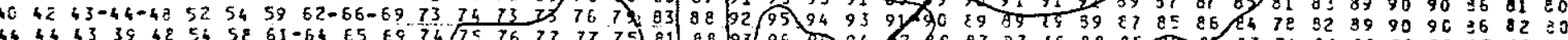

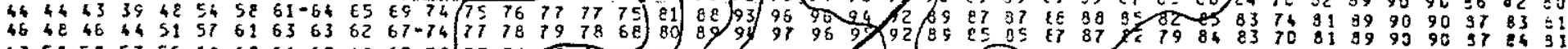

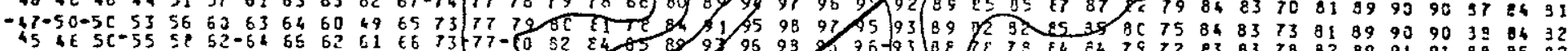
$\begin{array}{llll} & \end{array}$

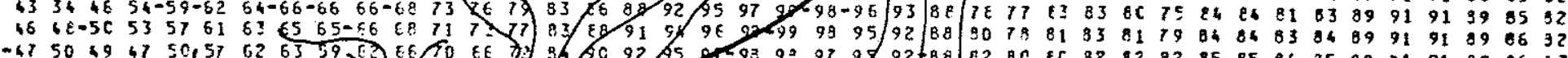

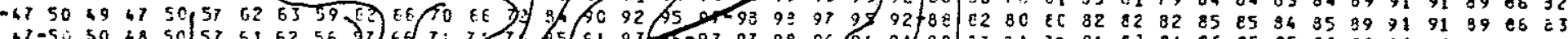

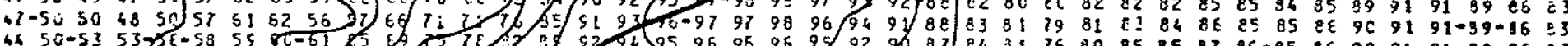

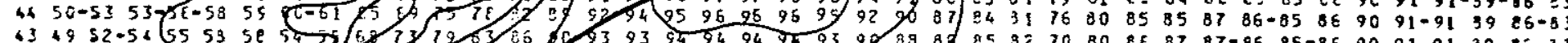

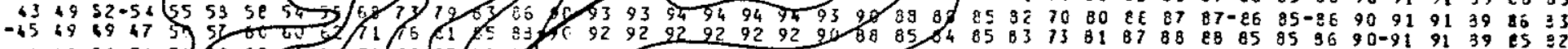

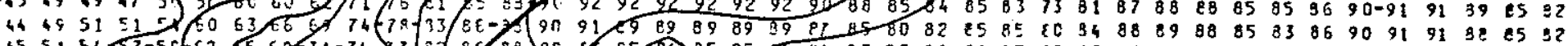

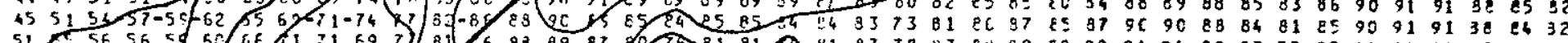

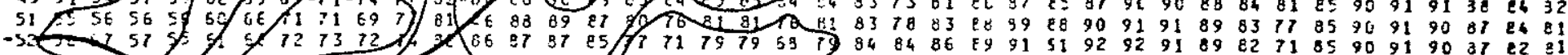

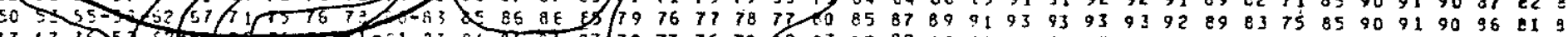
4747 3.

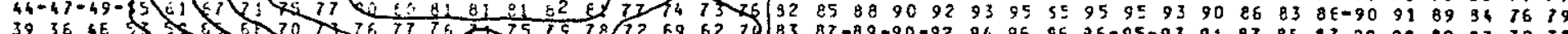
$37-406550=50$.

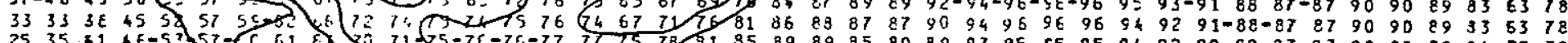

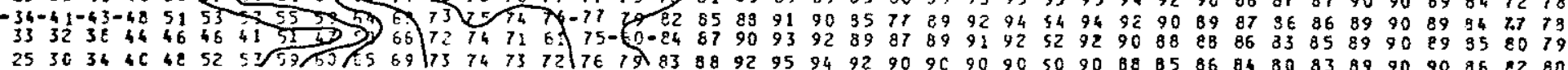

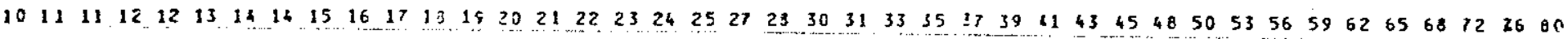
Período (s)

Fig. B-02 


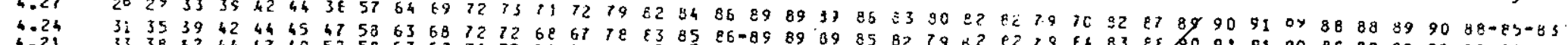

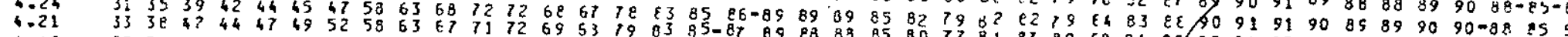

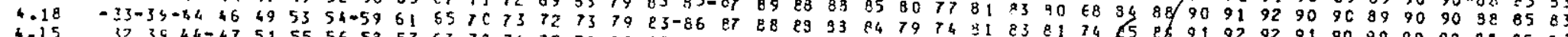

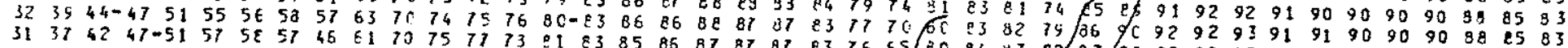

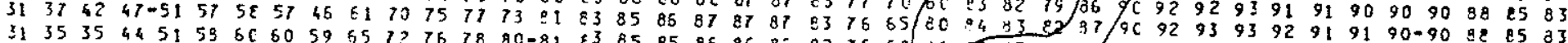

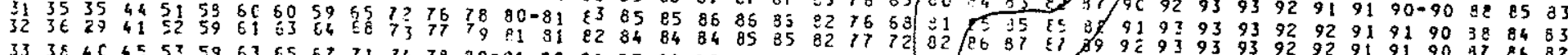

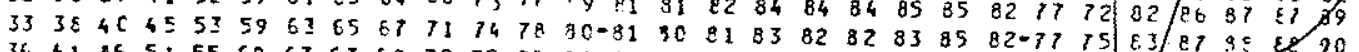

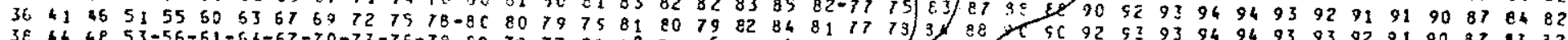

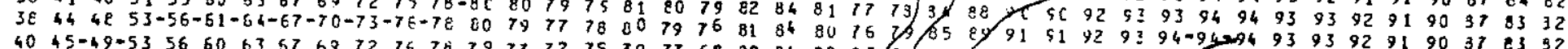

$-3.91$

is 3.8

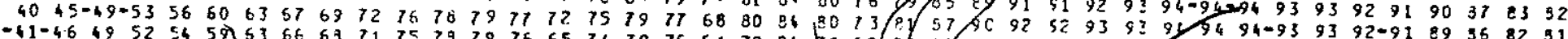

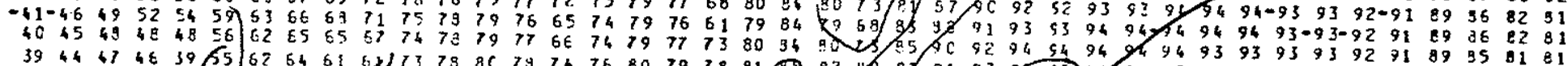

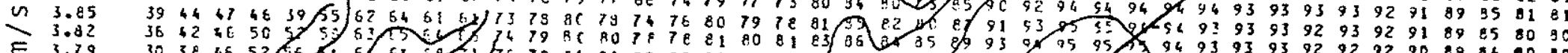

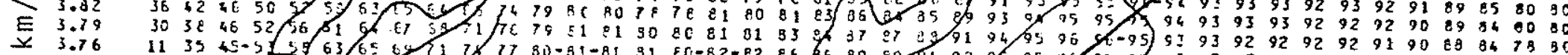

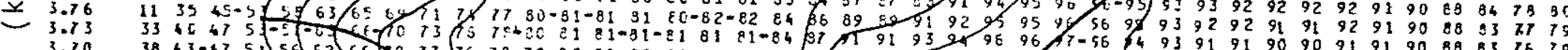

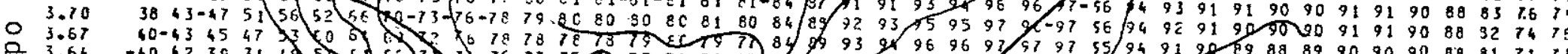

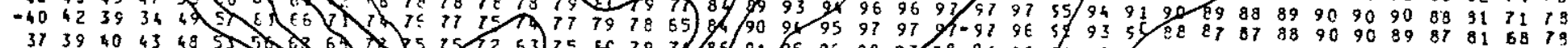

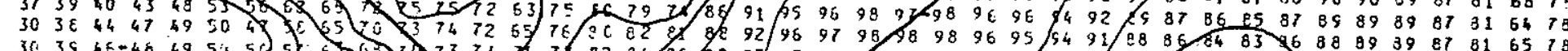

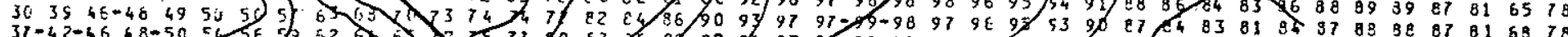

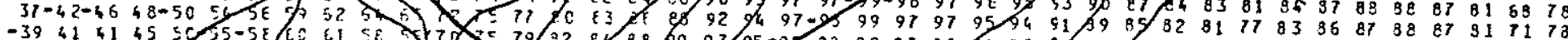

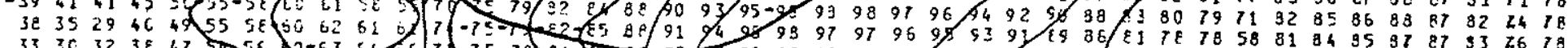

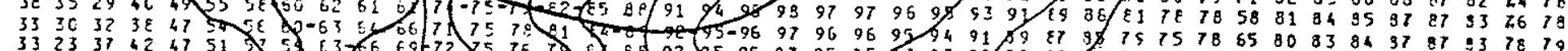

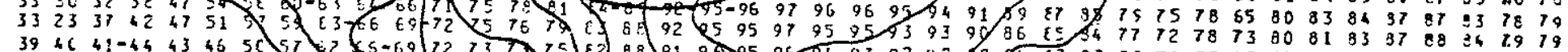

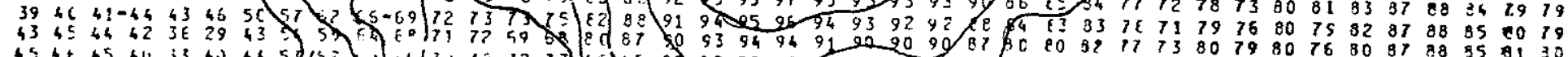

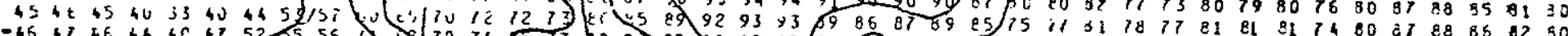

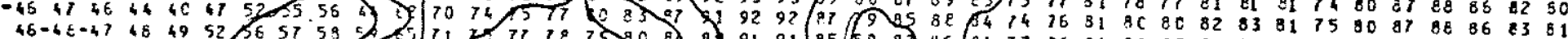

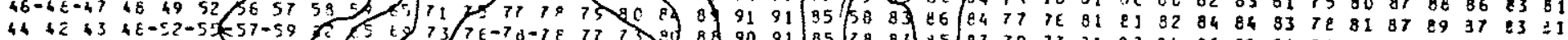

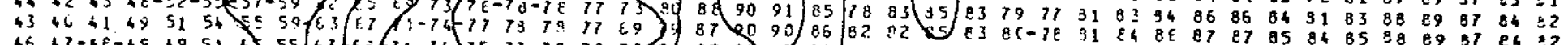

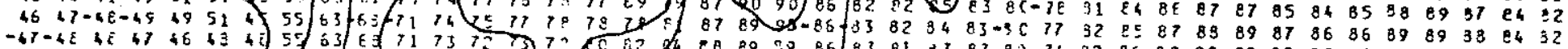

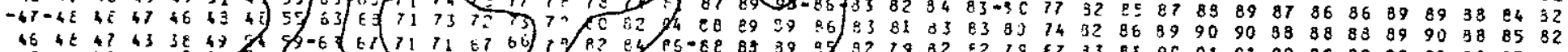

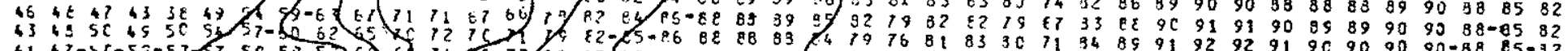

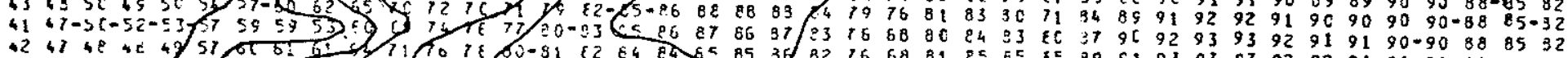

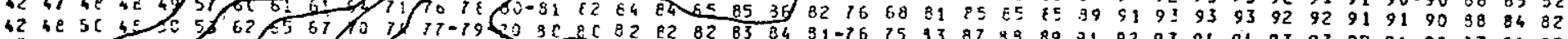

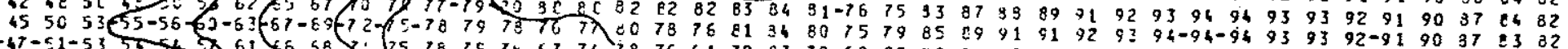

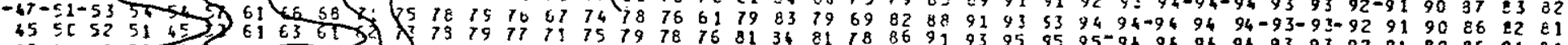

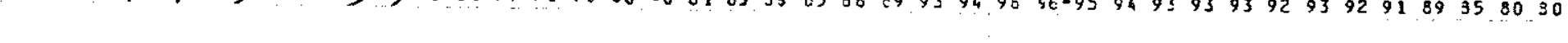

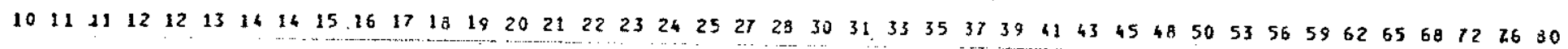
Período (s)

Fig. B-03 


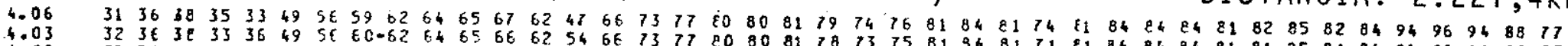

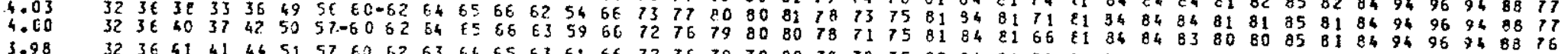

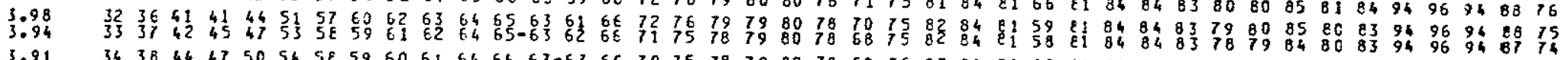

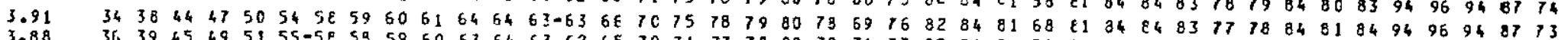

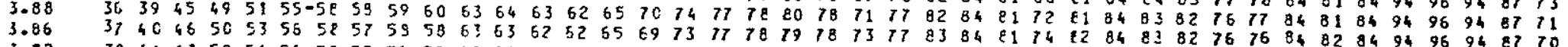

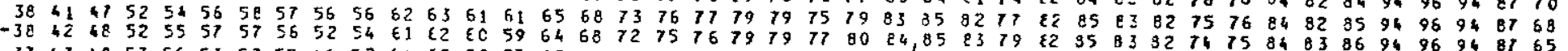

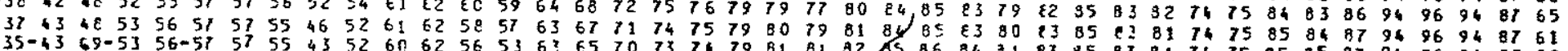

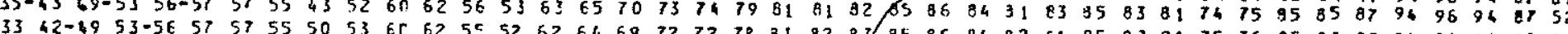

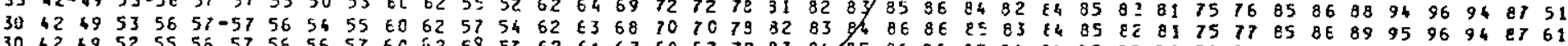

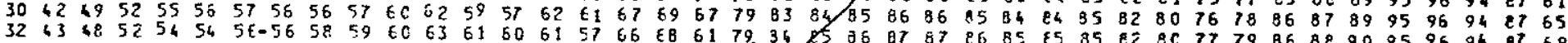

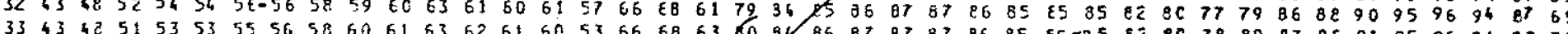

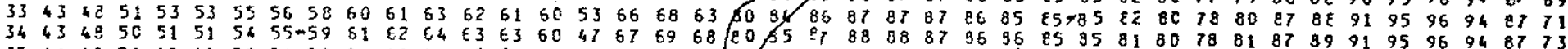

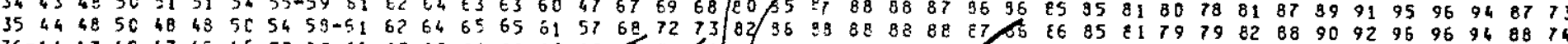

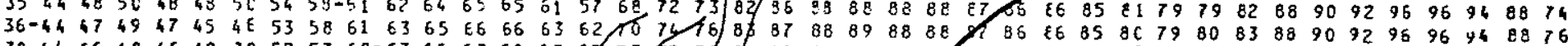

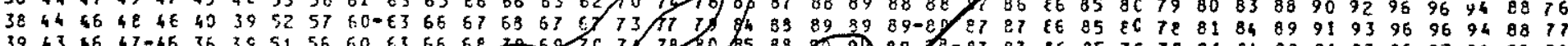

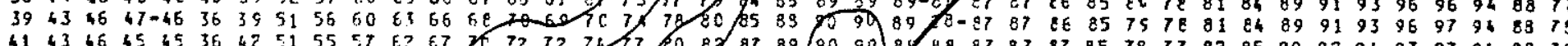

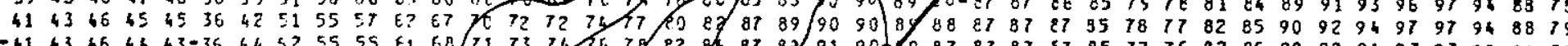

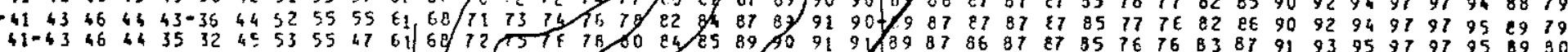

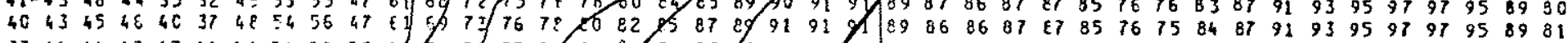

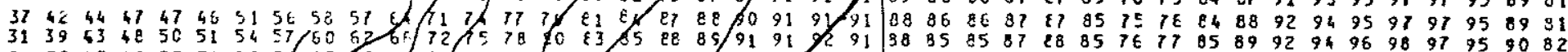

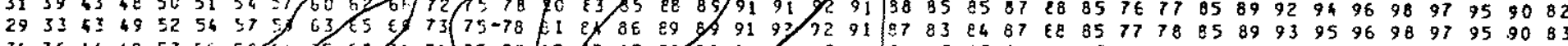

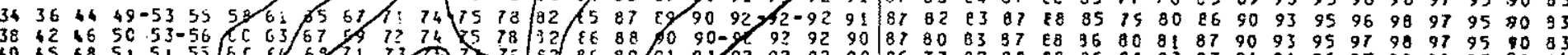

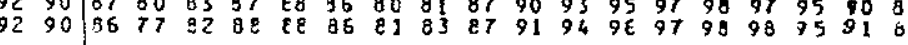

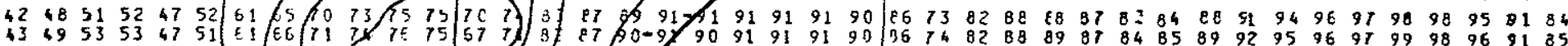

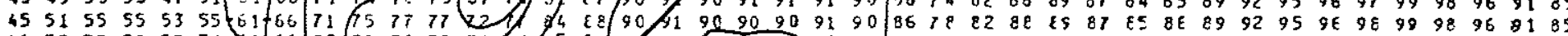

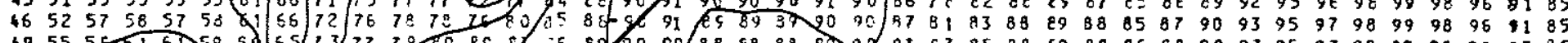

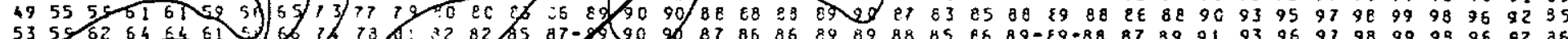

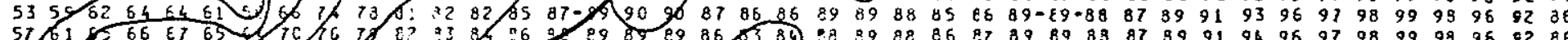
$57610=66$ ह

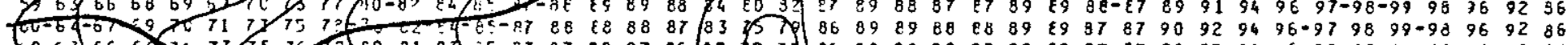

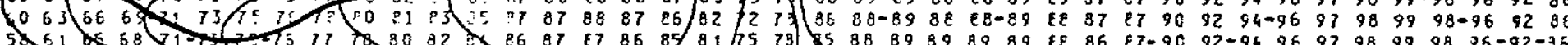

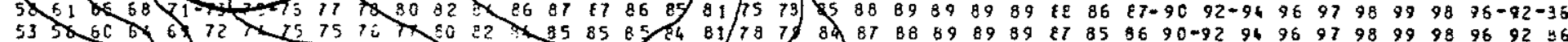

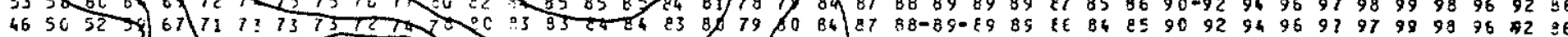

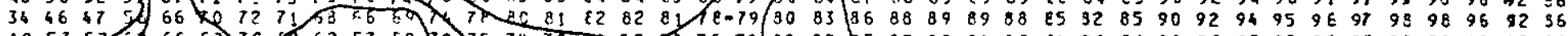

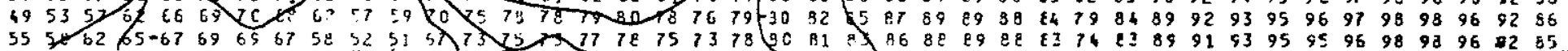

$10111112121314141516171819202122 \quad 2324252720303133 \quad 3537394143454850 \quad 535659626568 \quad 72 \quad 1630$ Período ( $s$ )

Fig. B-04 


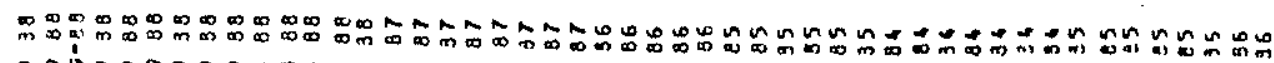

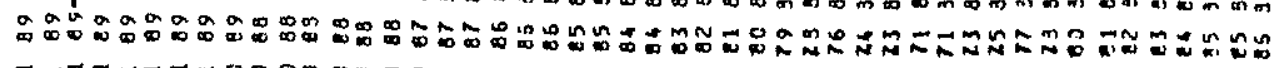

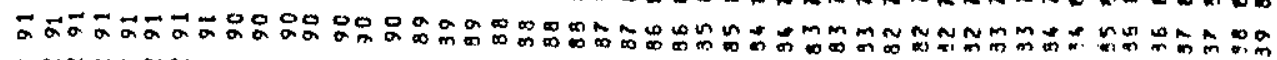

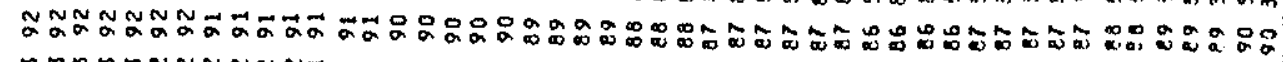

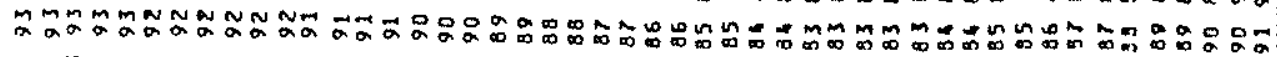

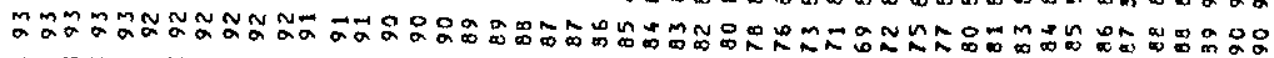

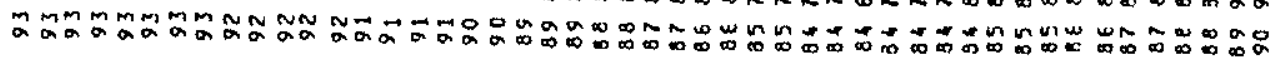

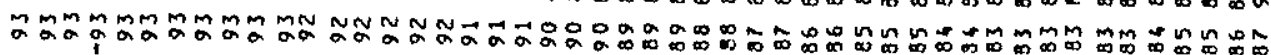
N NลN N NNN

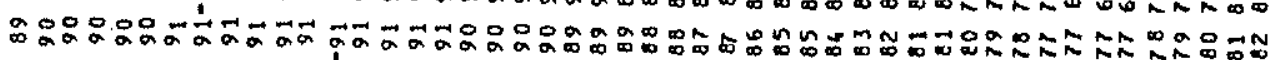

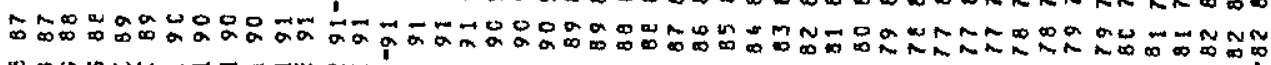

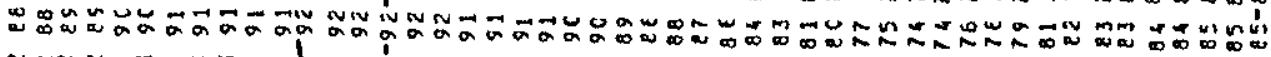

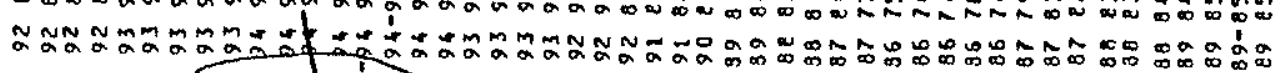

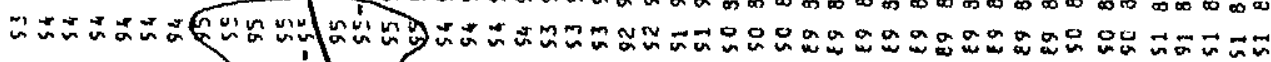

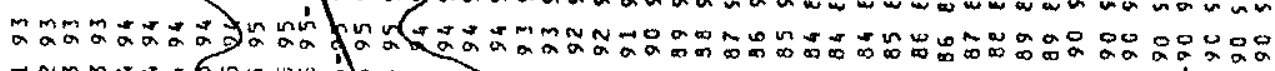

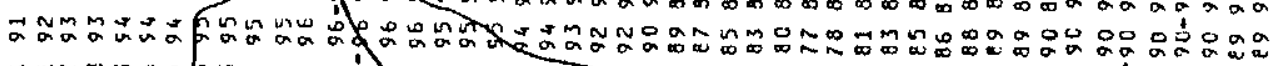

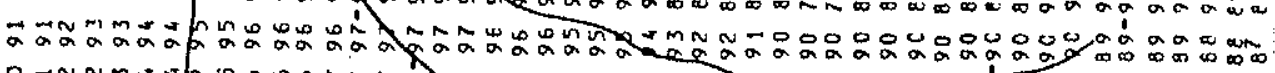

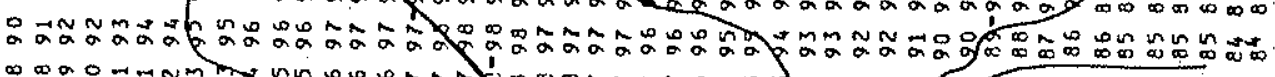

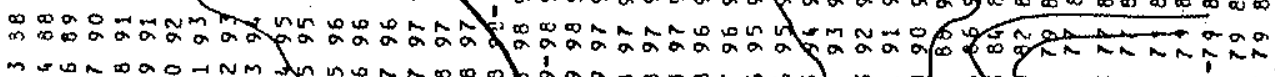

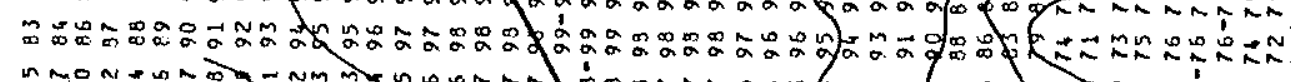
궁ํำ

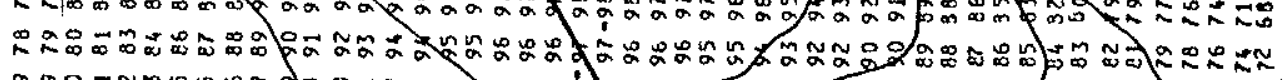

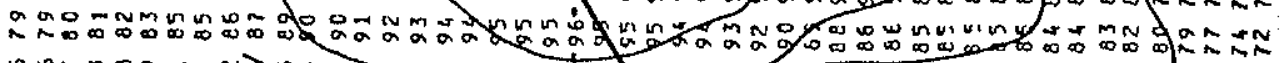

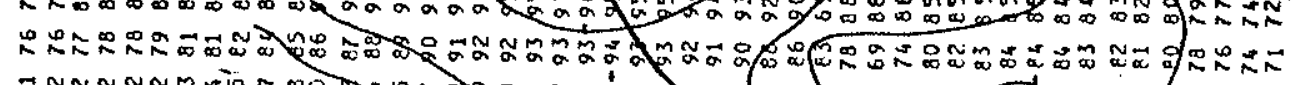
ZNNNNNMANA

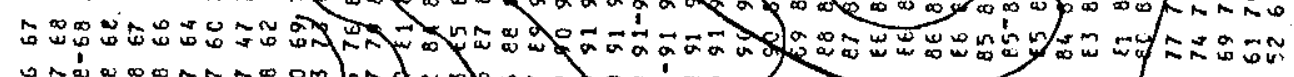

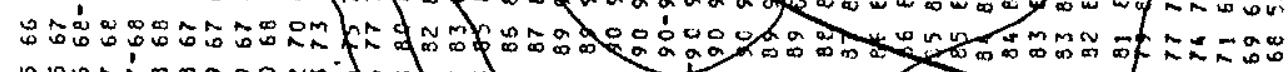

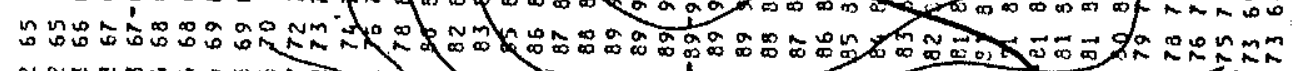

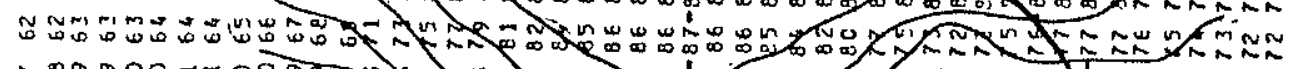

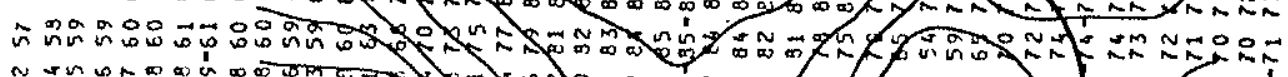

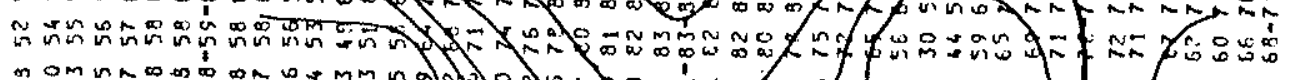

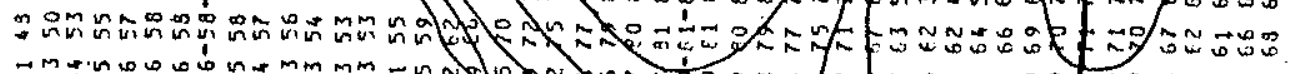

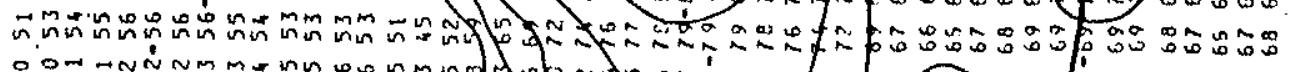

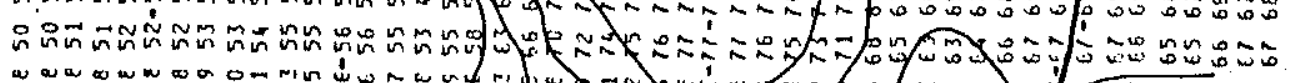
\% แ ڤ4⿻一𠃋十

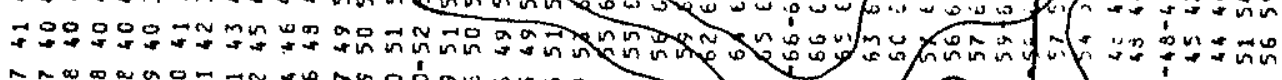
in $A$ m

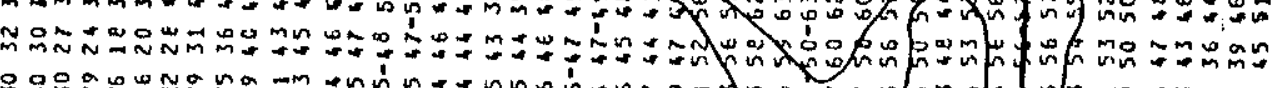

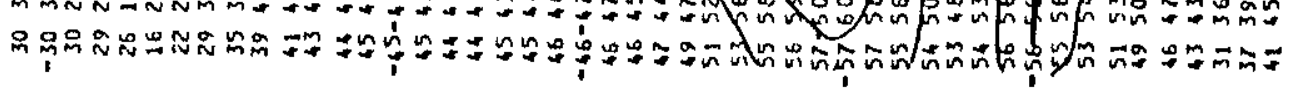

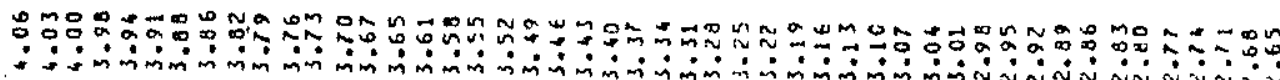

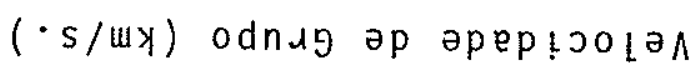


$4.06 \quad 2511334044454856 \quad 636871716684656569727277818293943790939595949393949595949696949180$

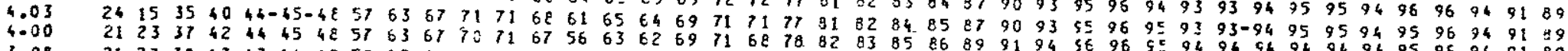

$3.98 \quad 21273843434447-57633667070665063606871657883869687390919$

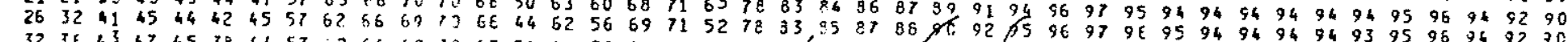

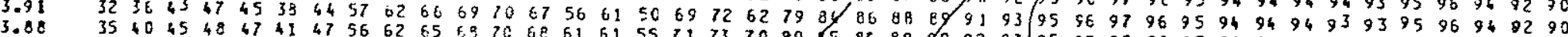

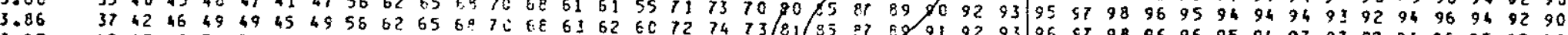

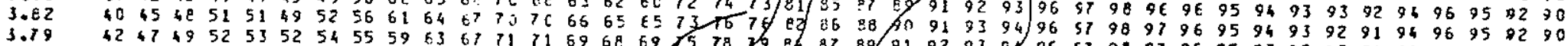

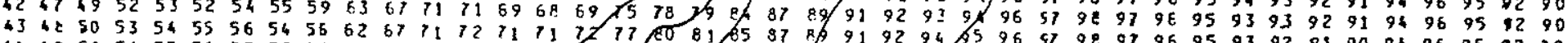

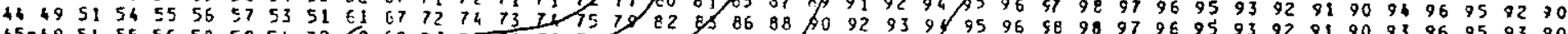

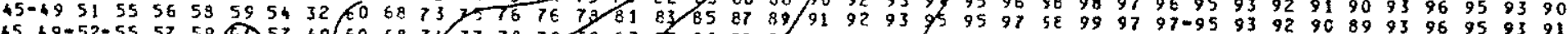

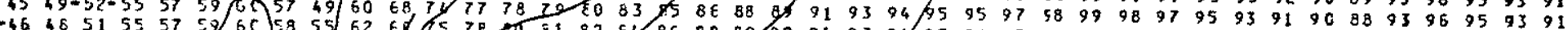

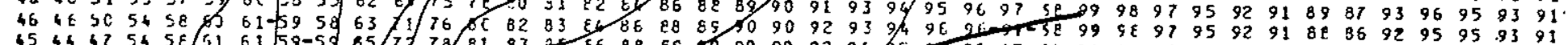

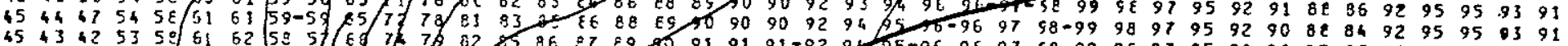

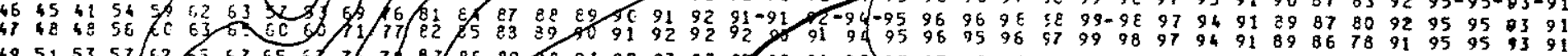

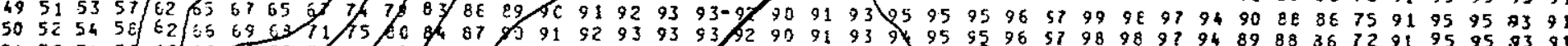

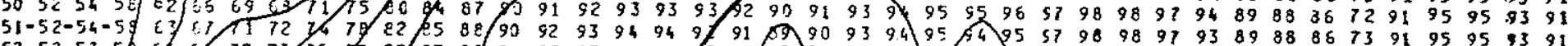

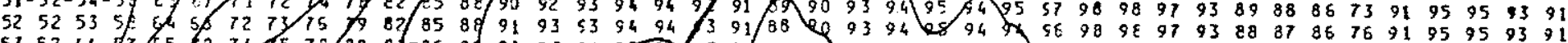

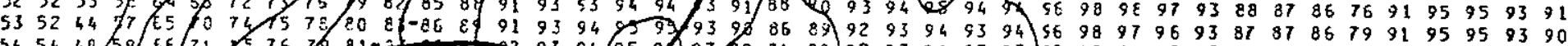

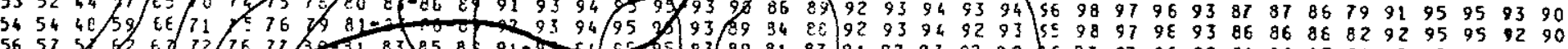

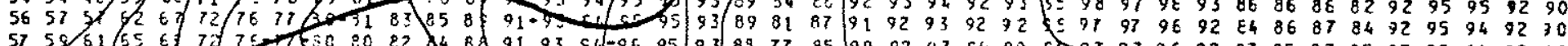

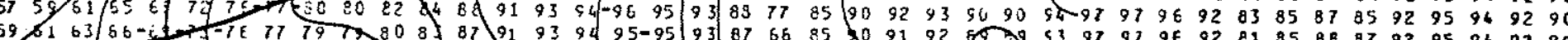

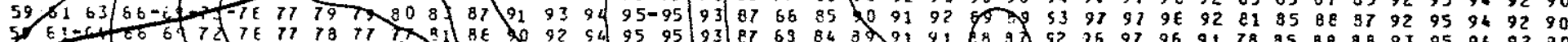

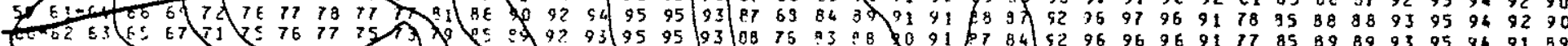

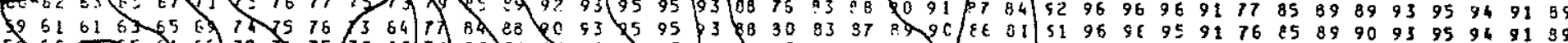

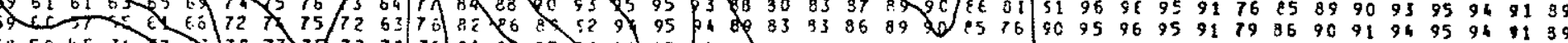
58 5656 (20)

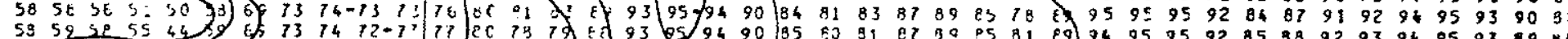

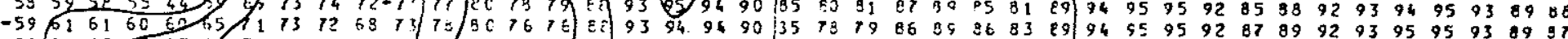

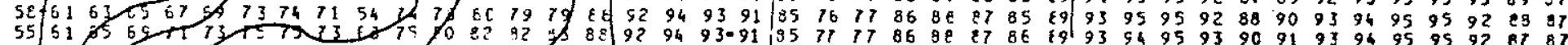

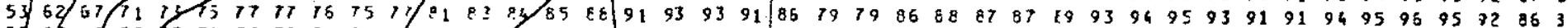

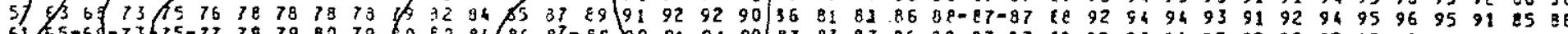

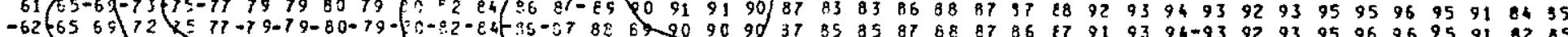

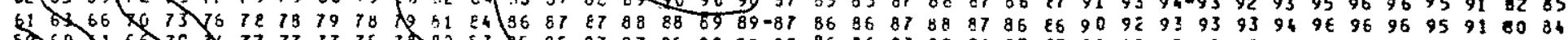
55 5

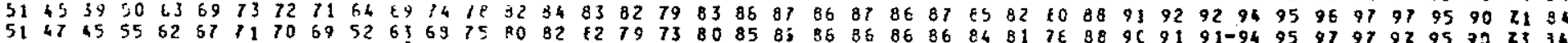

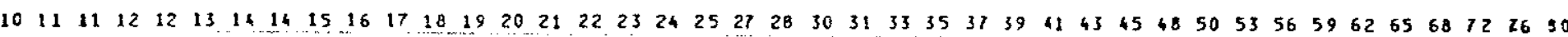
Período (s)

Fig. B-06 


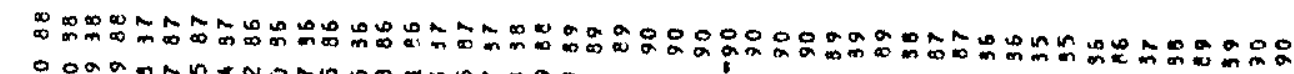

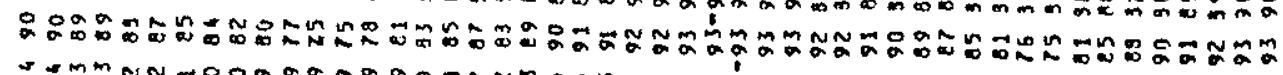

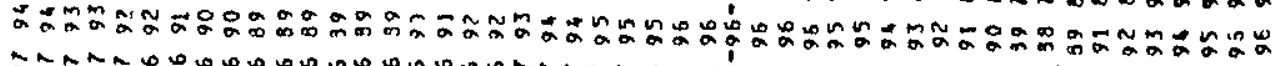

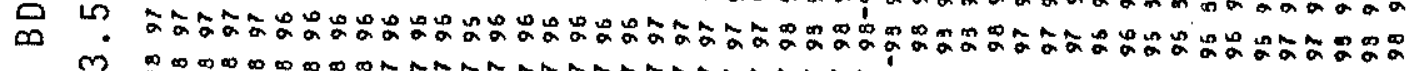

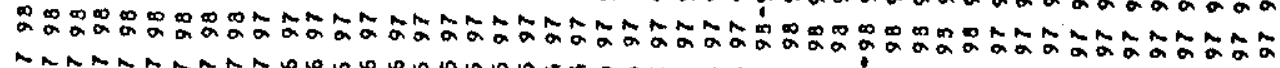

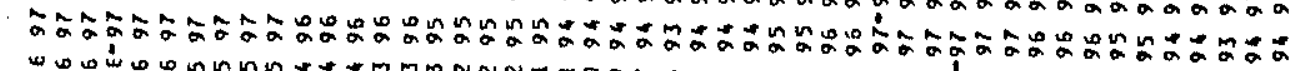

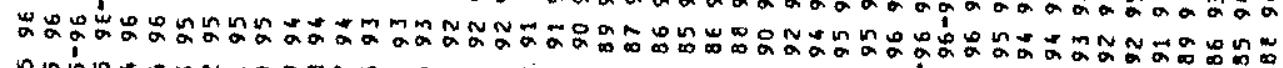

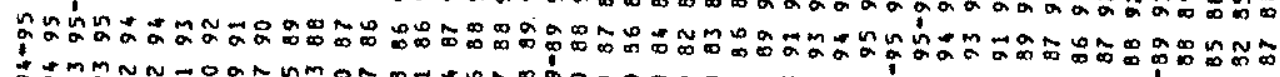

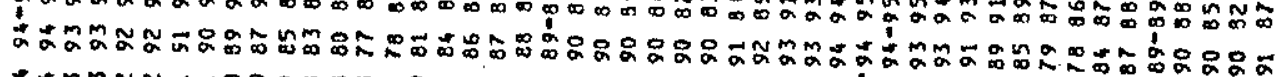

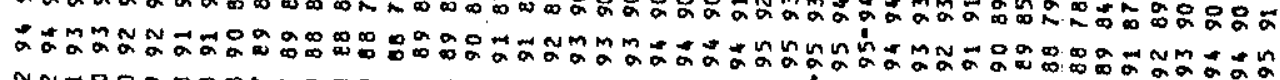
ヘ

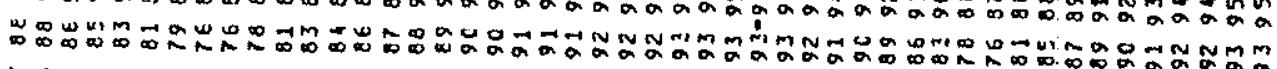

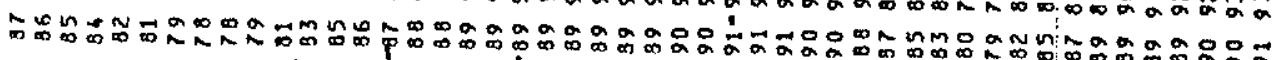

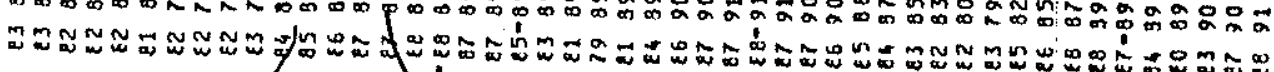

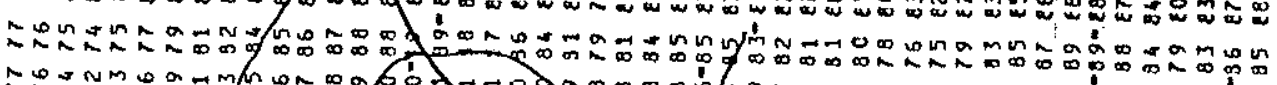

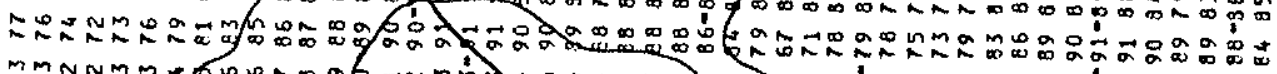
MMNNNMM

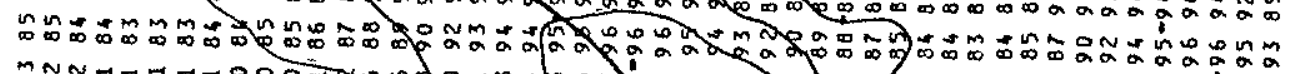

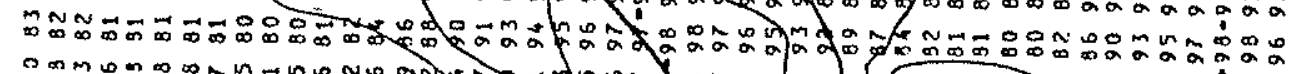

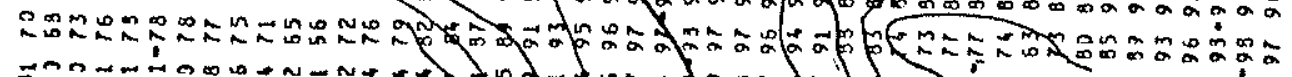

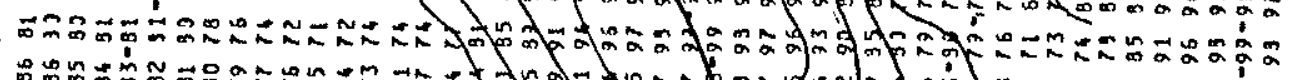

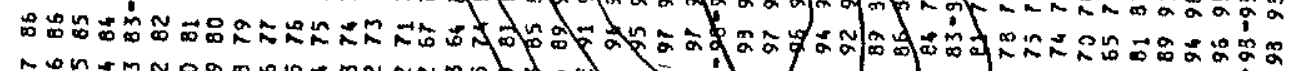

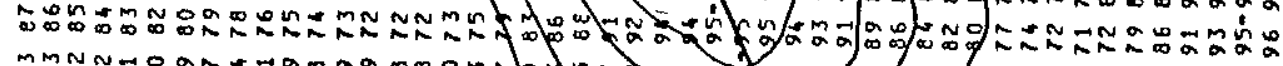

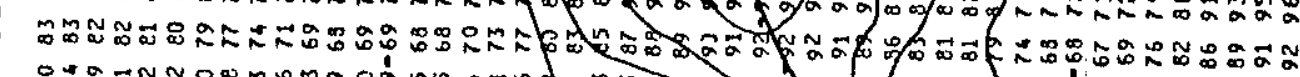

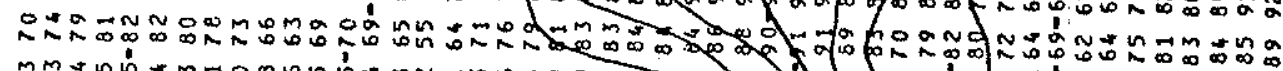

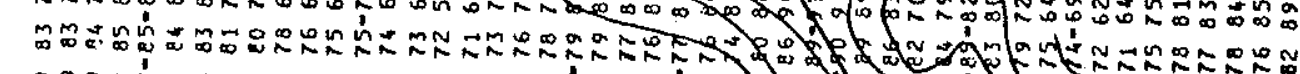

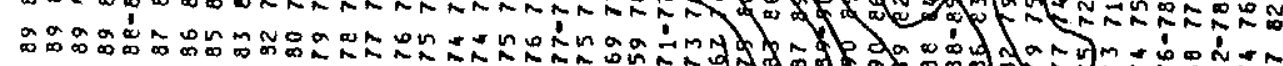

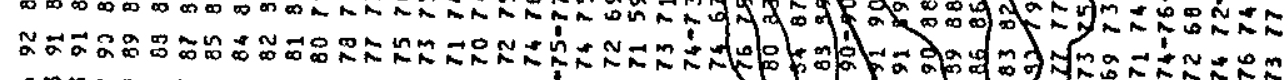

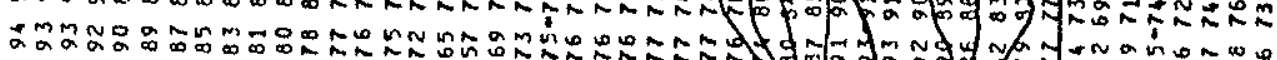

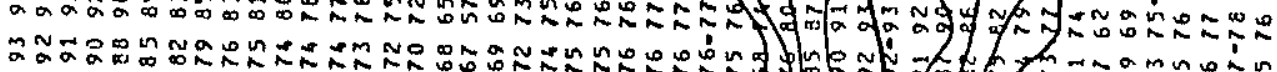

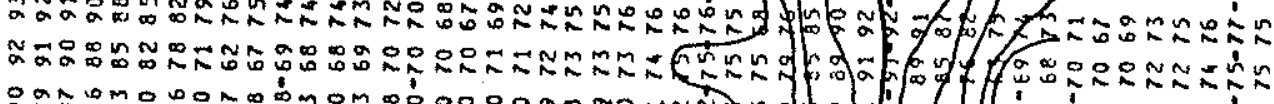

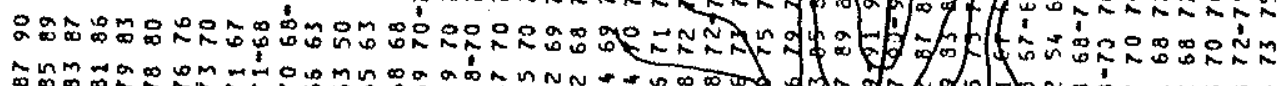
由๊

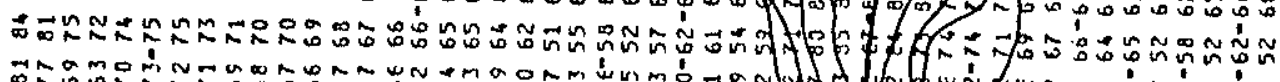

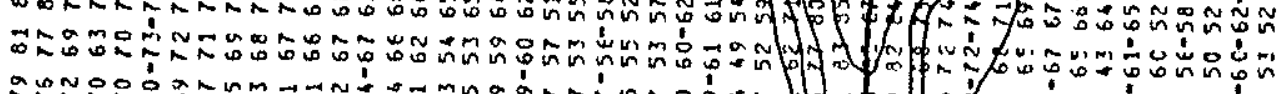

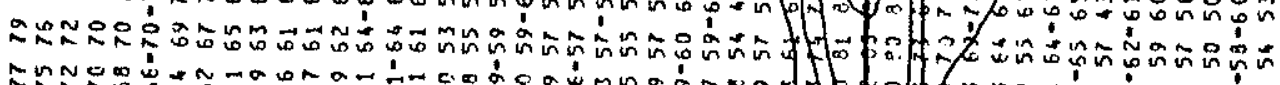

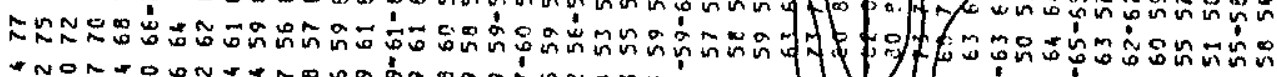

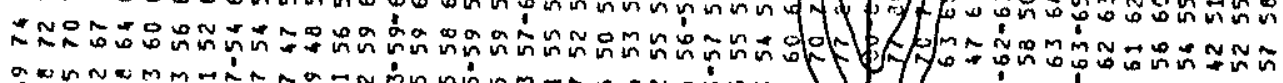

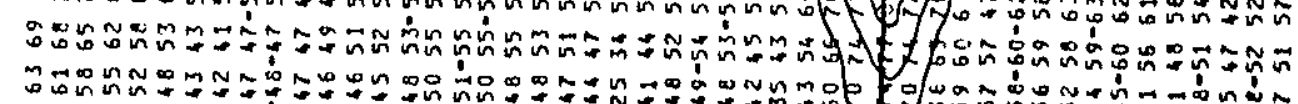

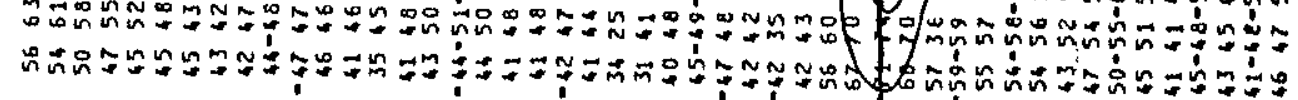




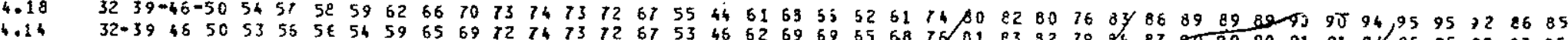

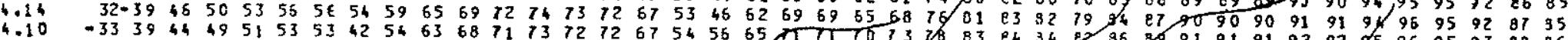

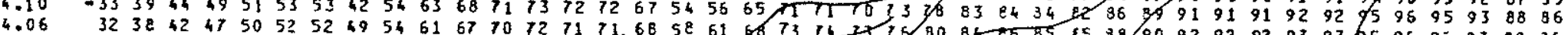

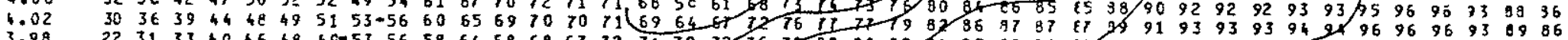

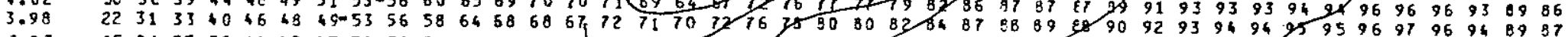

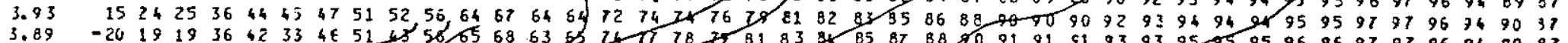

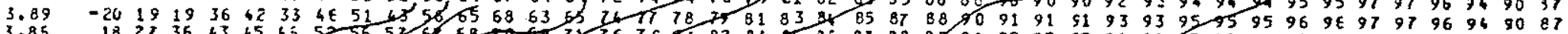

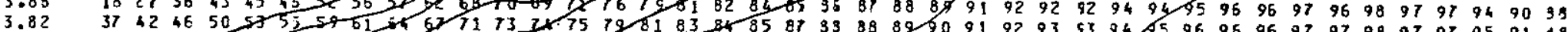

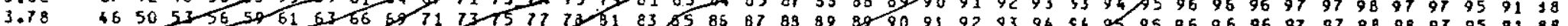

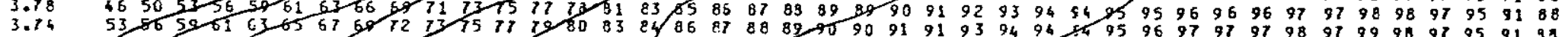

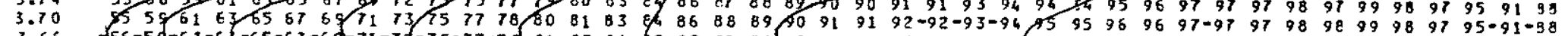

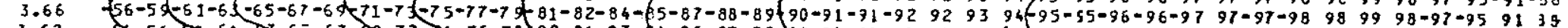

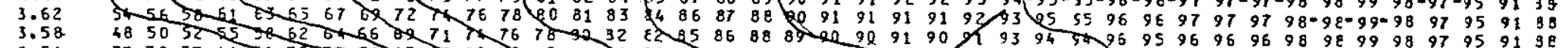

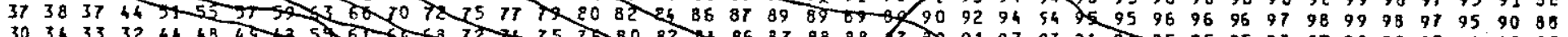

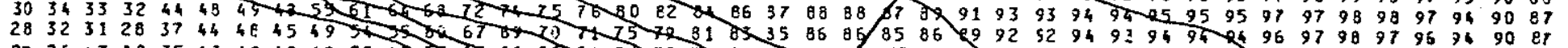

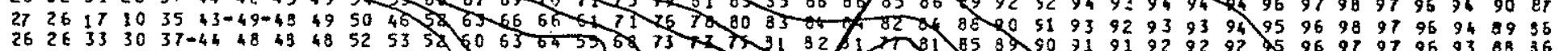

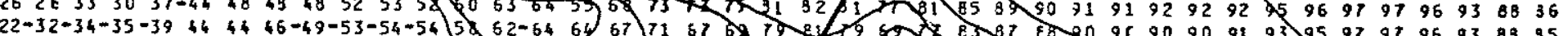

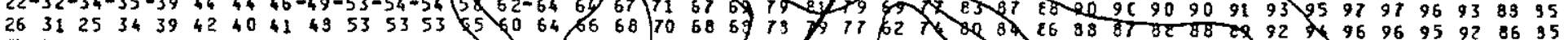

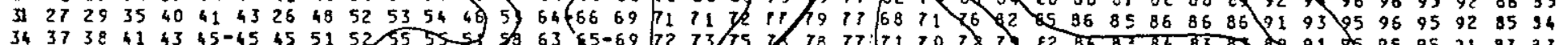

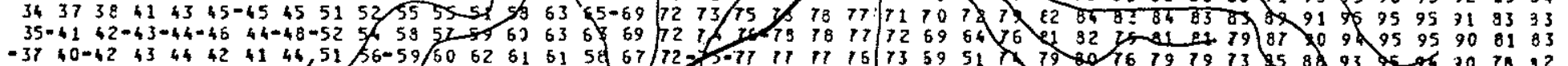

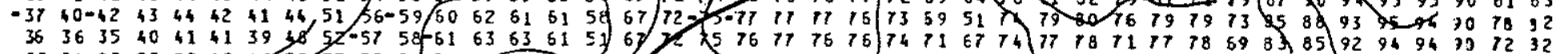

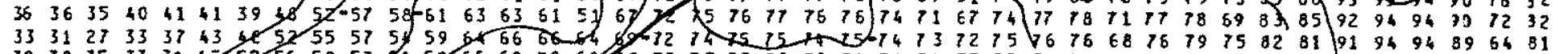

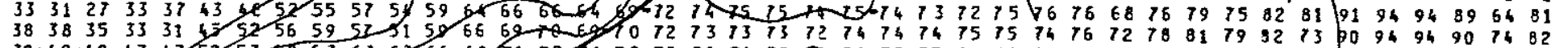

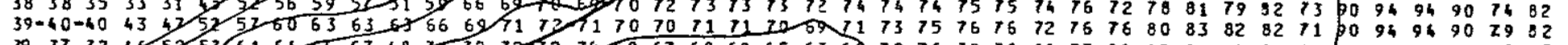

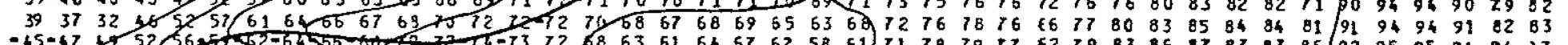

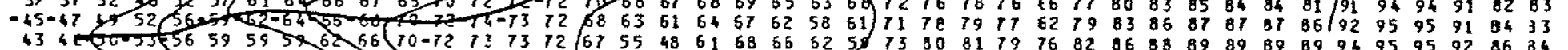

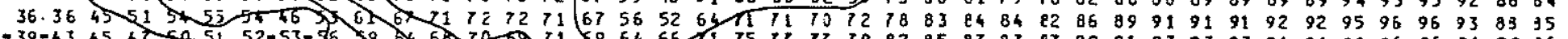

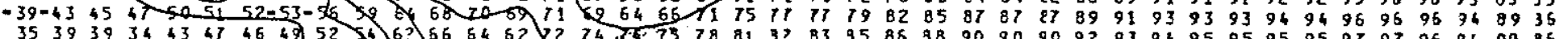

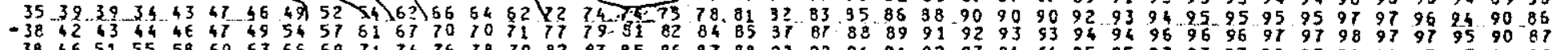

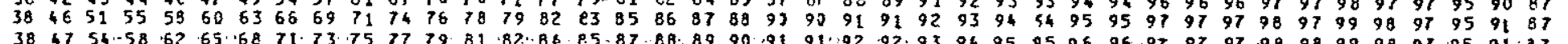

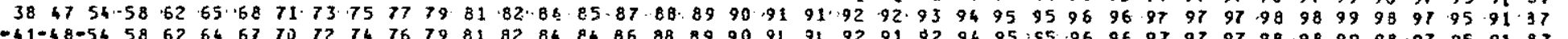

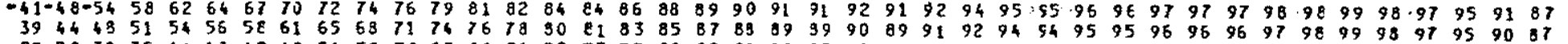

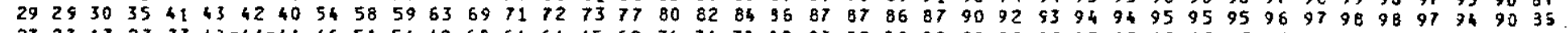

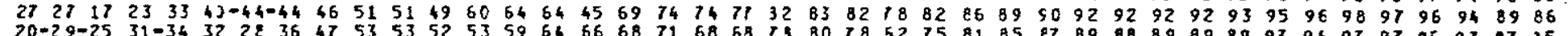

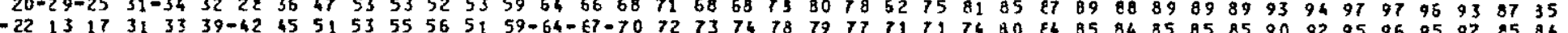

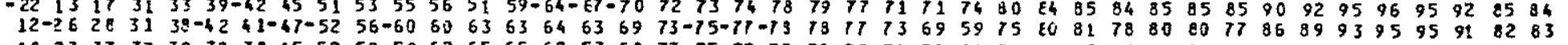

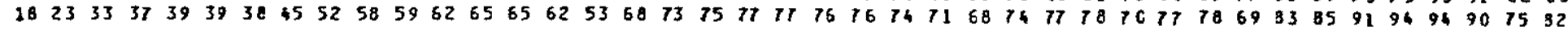




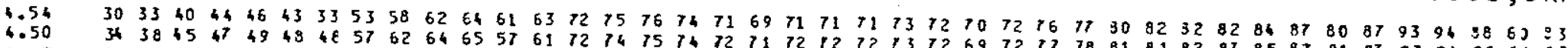

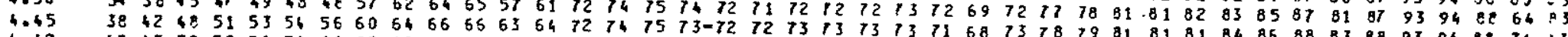

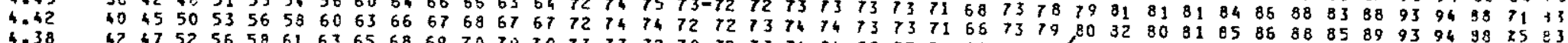

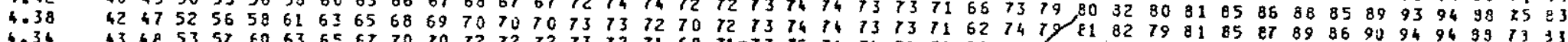

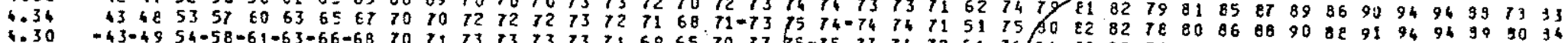

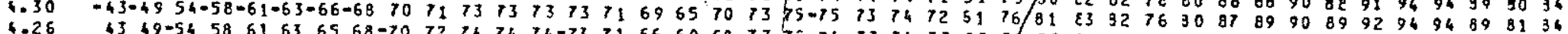

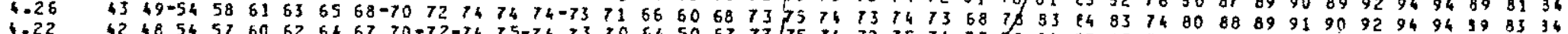

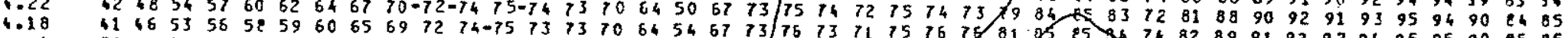
$614 \quad 3944515456555362687174747372696559677375727175767581.558594748289919292949595908595$

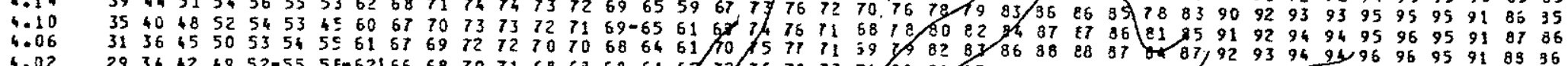

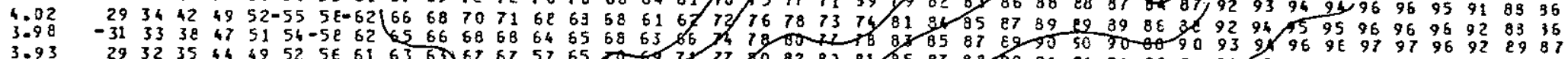

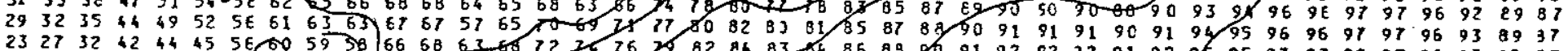

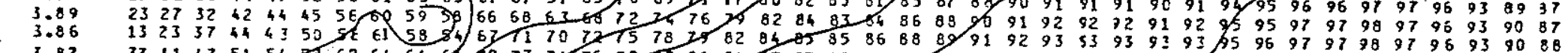

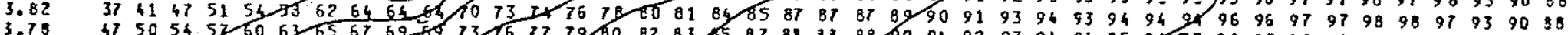

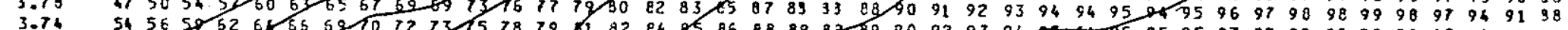

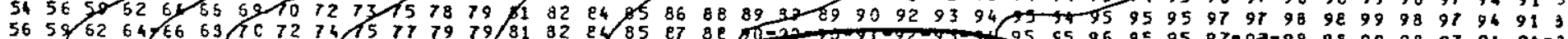

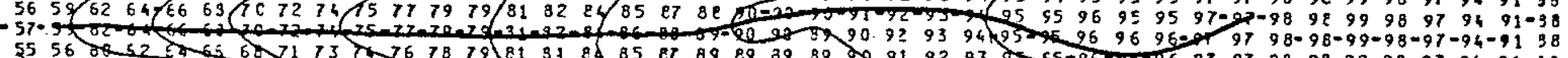

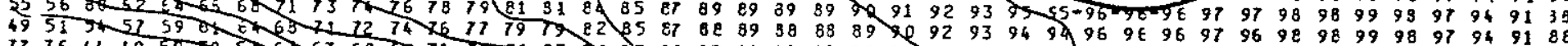

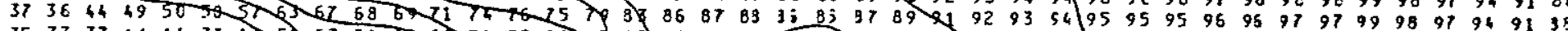

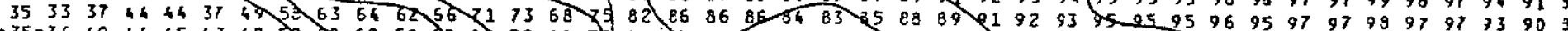
$\begin{array}{llllllllll} & \end{array}$

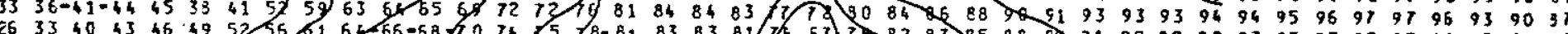

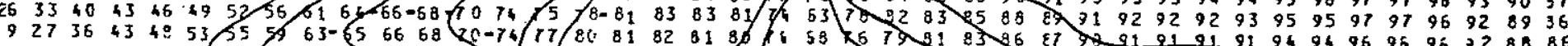

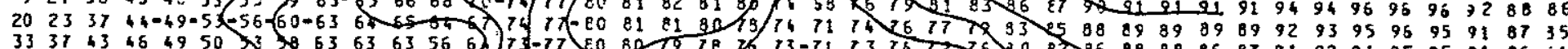

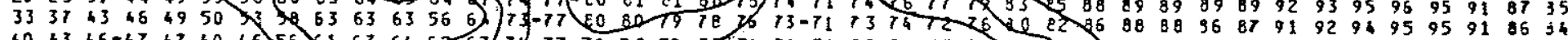

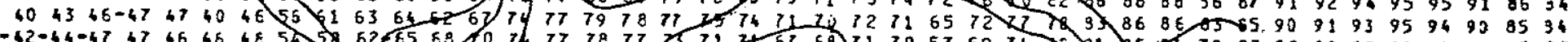

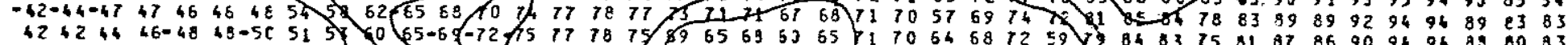

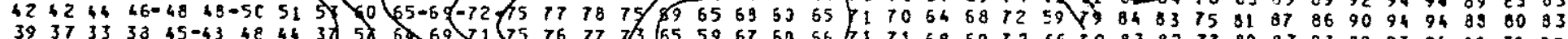

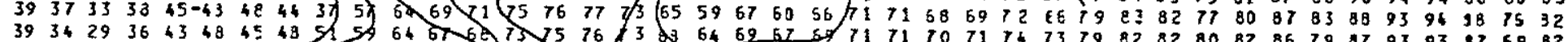

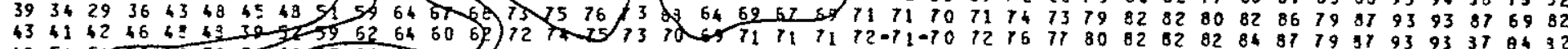

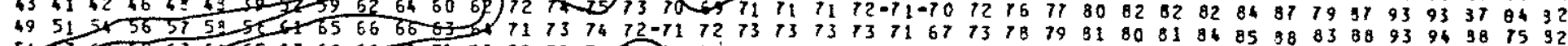

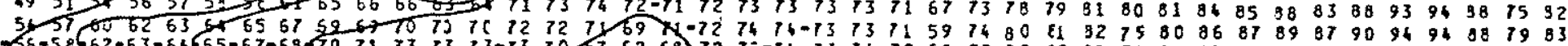

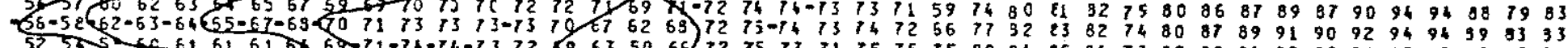
525
35

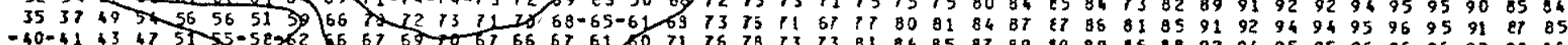

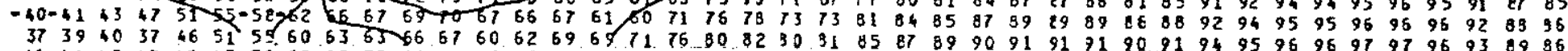

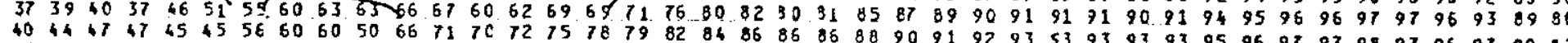

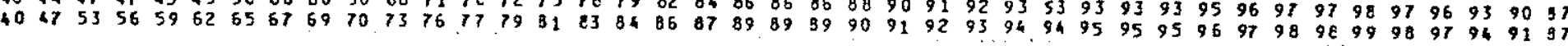

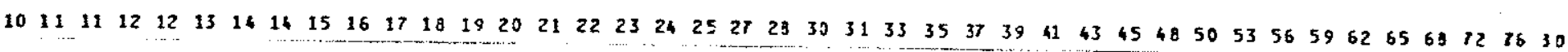
Período ( $s$ )

Fig. B -09 


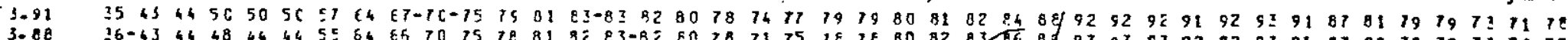

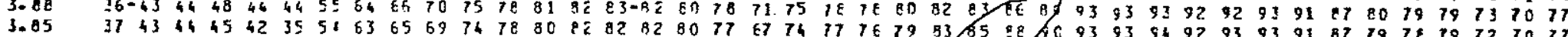

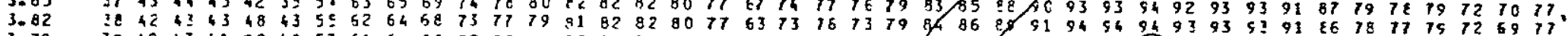

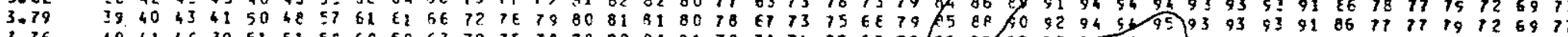

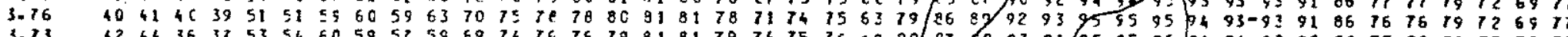

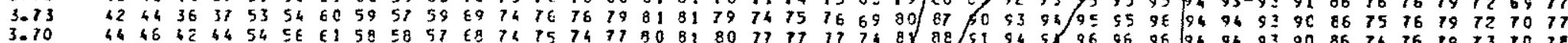

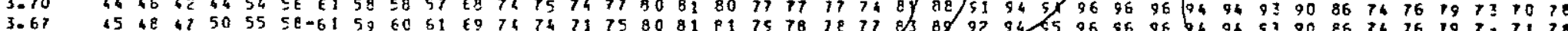

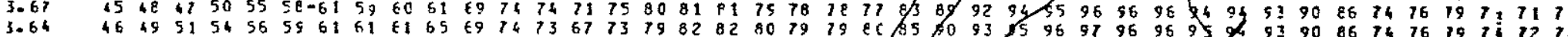

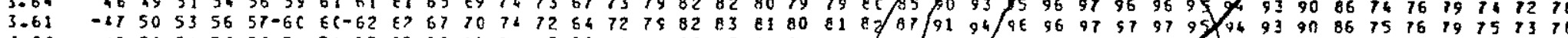

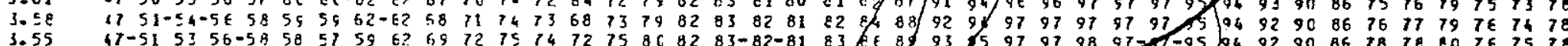

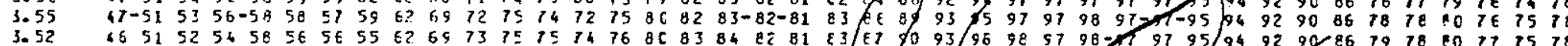

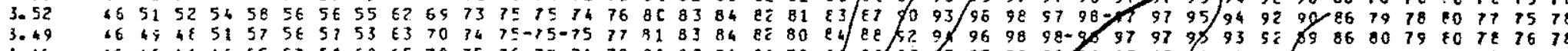

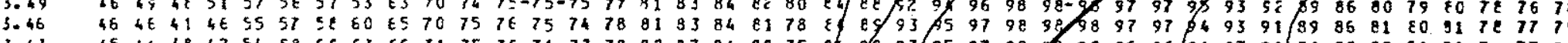

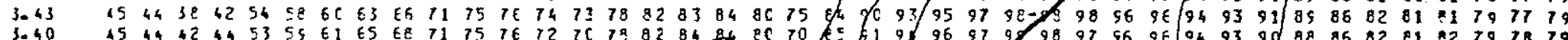

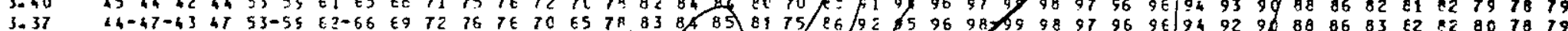

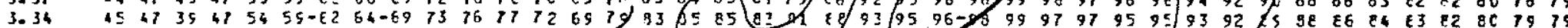

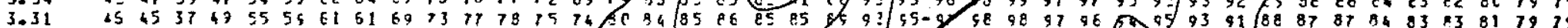

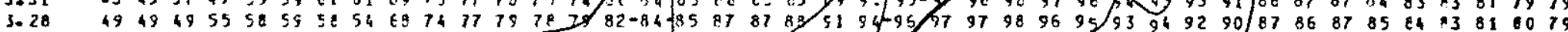

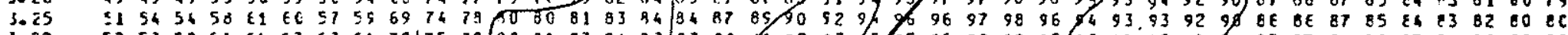
3.22 3.19

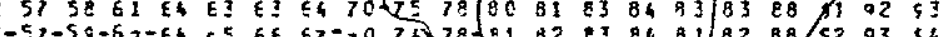

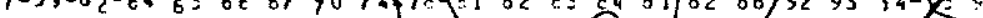

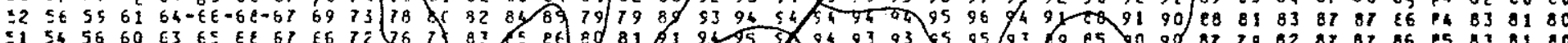

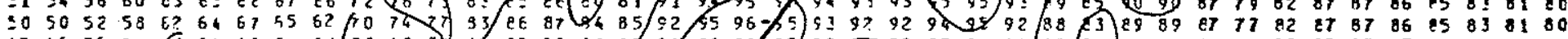

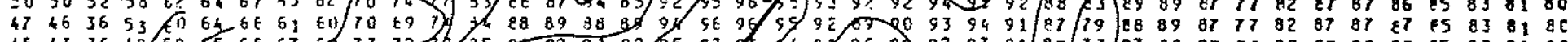

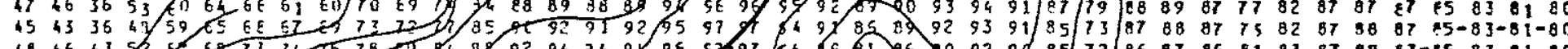

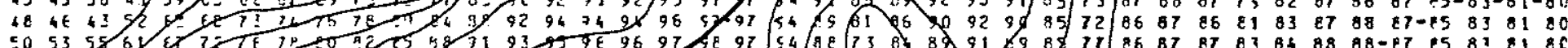

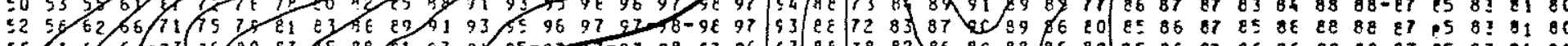
$\leq 5$ t 1 bh 6 政

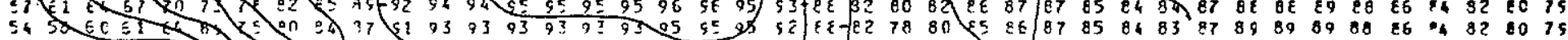

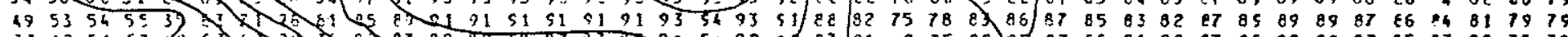

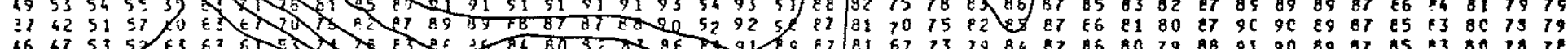

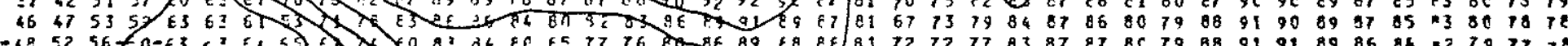

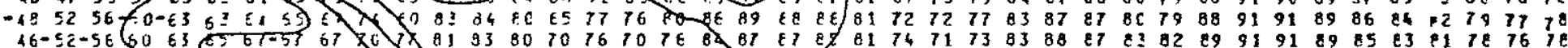

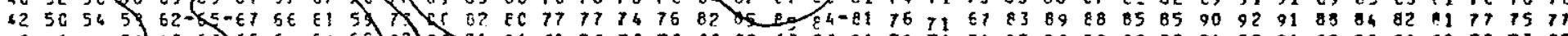

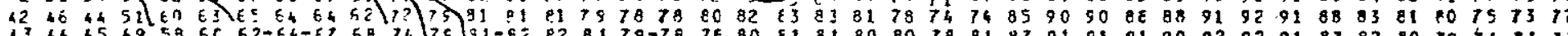

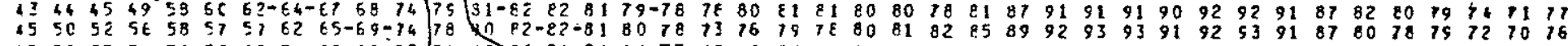

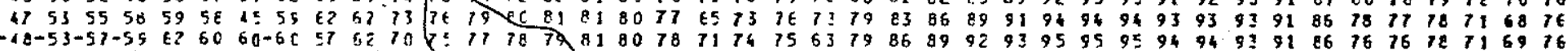
$1011111212131414151617181920212223242527 \quad 28303133 \quad 35 \quad 3739414345485053565962 \quad 656872 \quad 76 \quad 30$ Período (s)

Fig. $B-10$ 


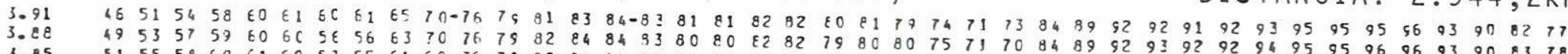

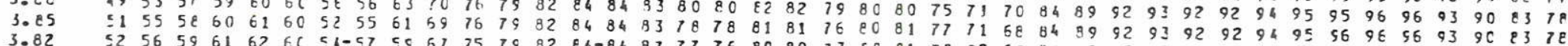

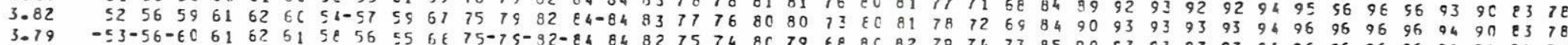

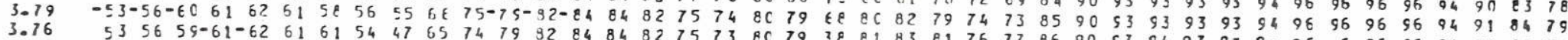

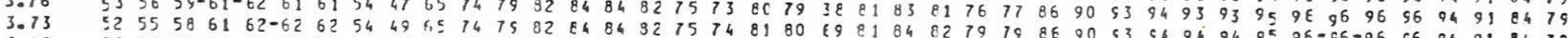

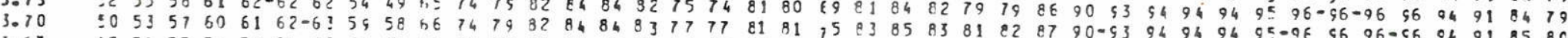

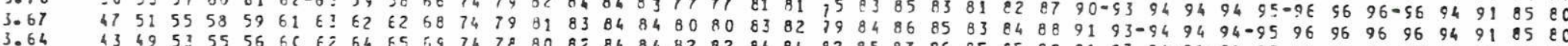

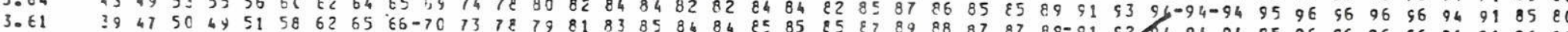

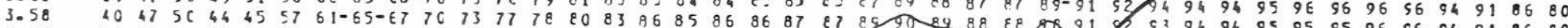
Y) 539496959595959694918680

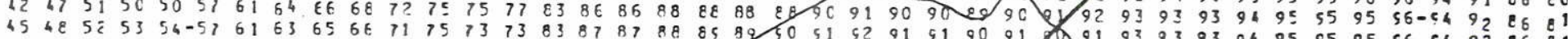

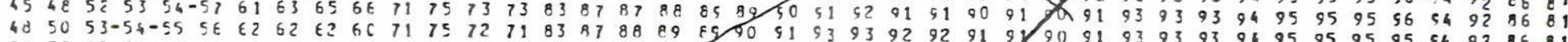

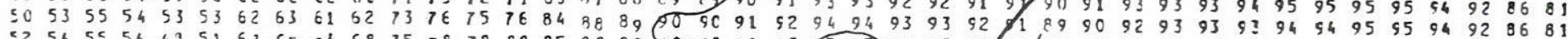

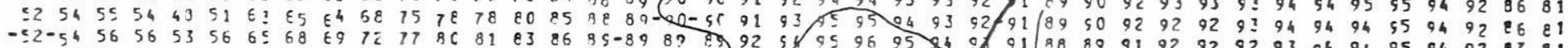

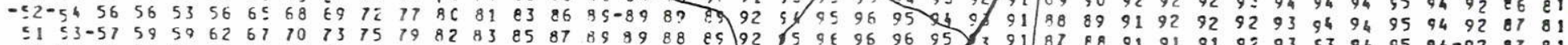

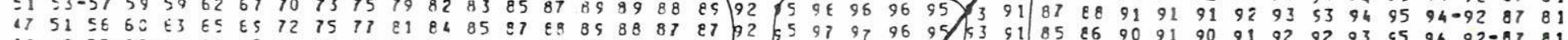

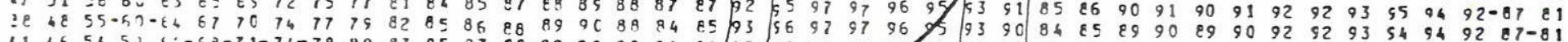

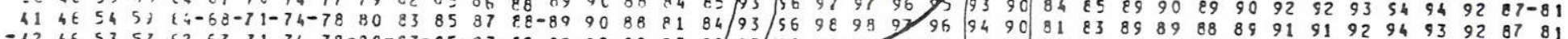

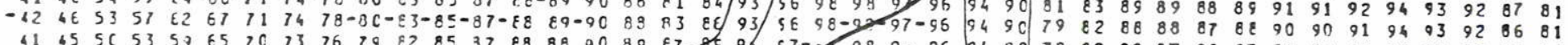

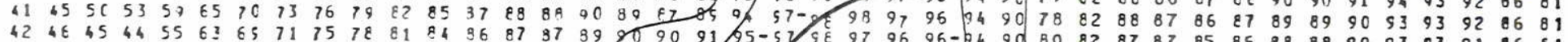

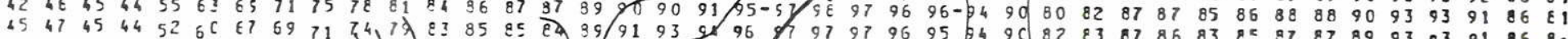

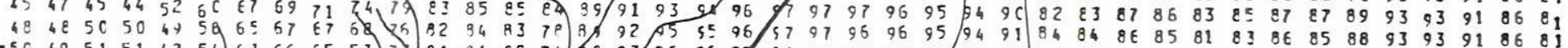

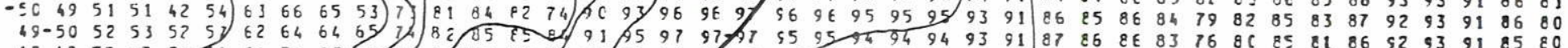

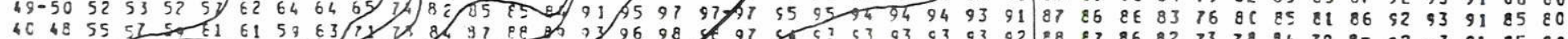

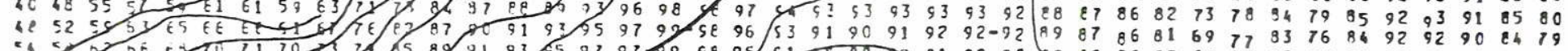

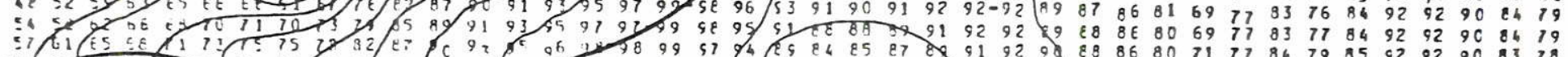

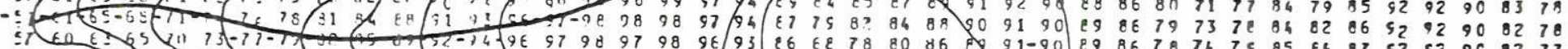

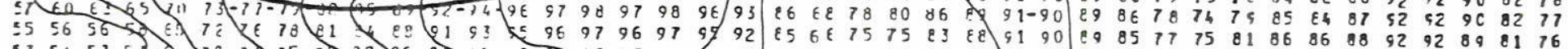

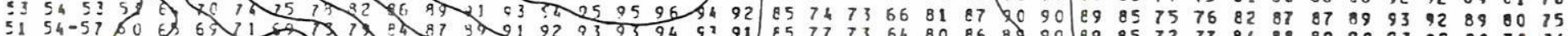
47565752 E $58 \varepsilon \varepsilon 56$ (2)

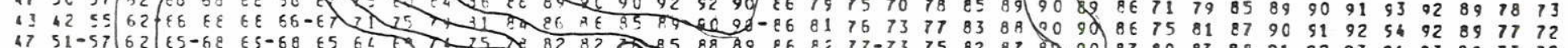

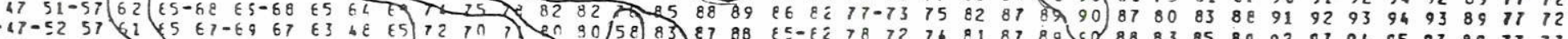

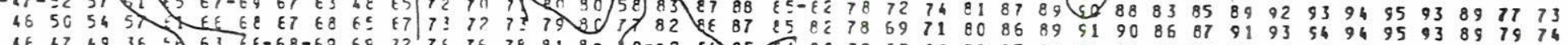

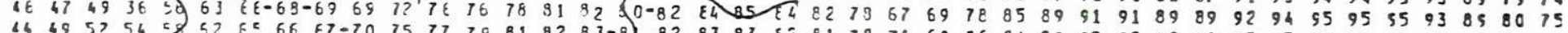

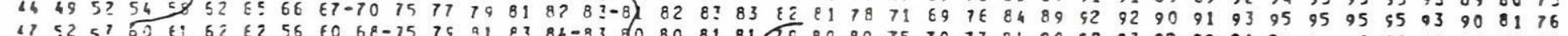

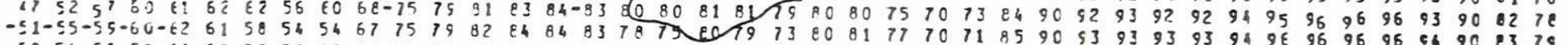

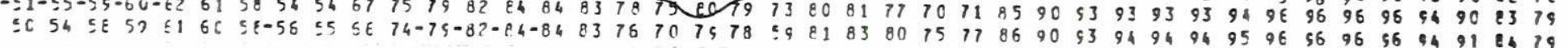

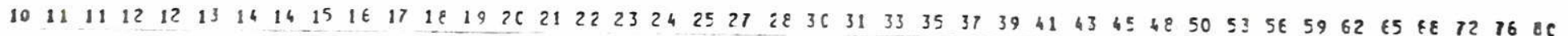

Período (s)

Fig. B-11 


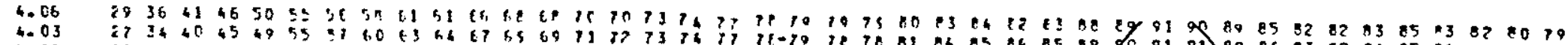

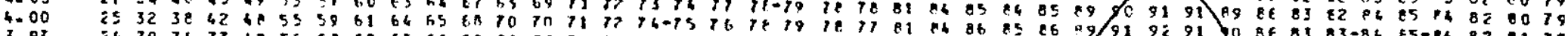
3.97

3.94

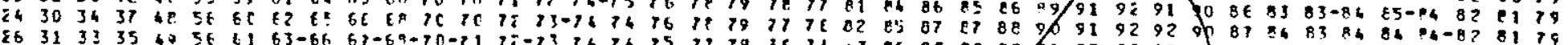

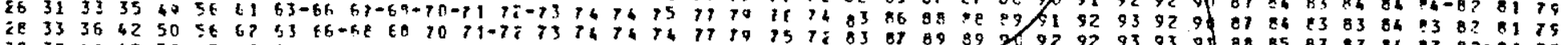

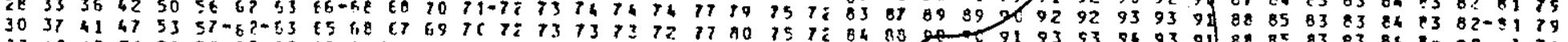

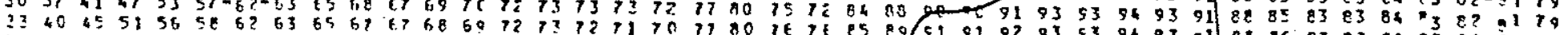

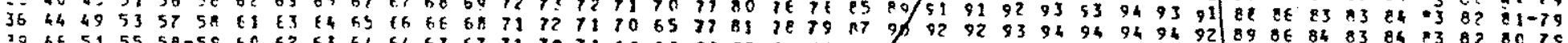

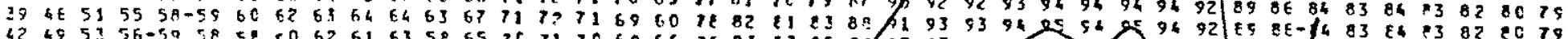

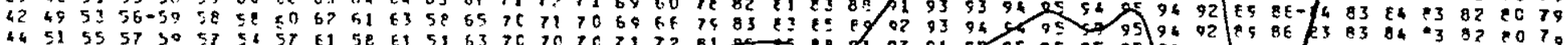

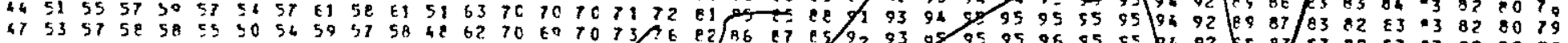

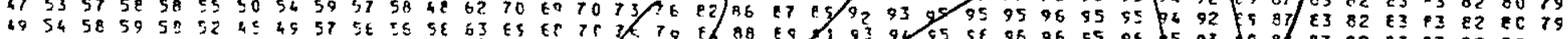

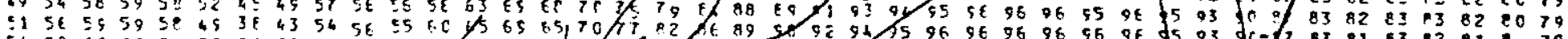

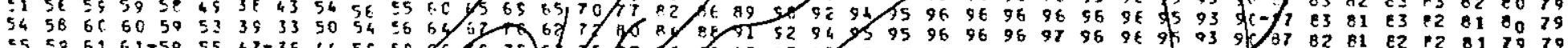

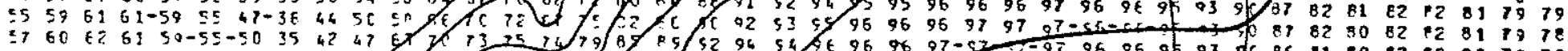

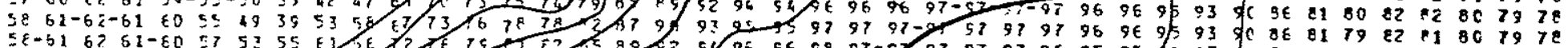

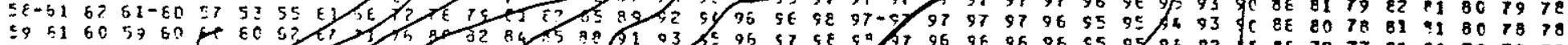

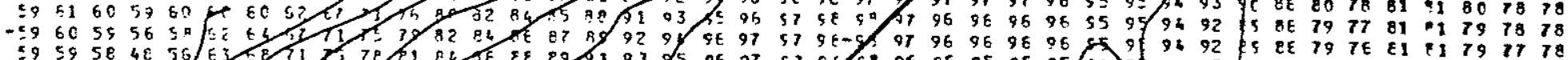

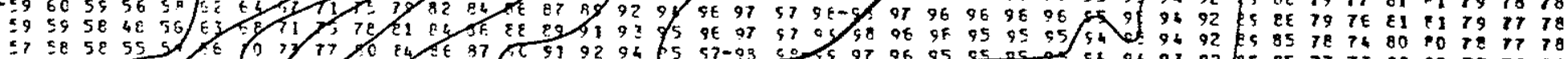

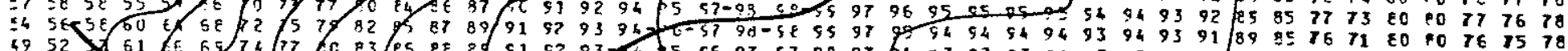

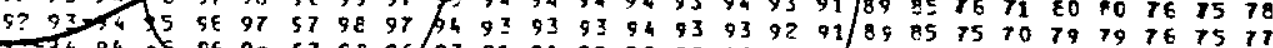

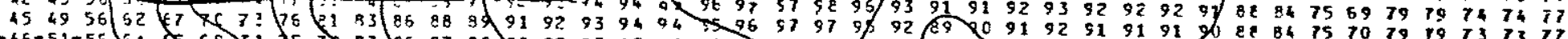

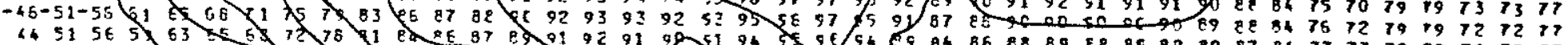

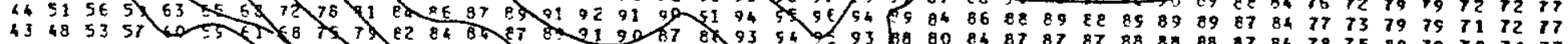

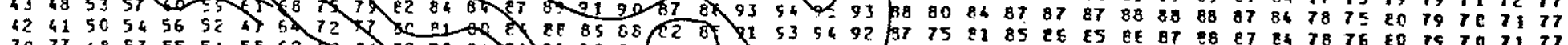

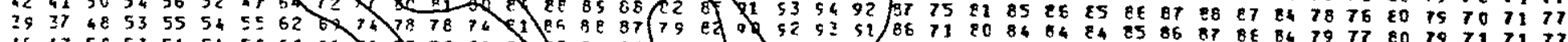

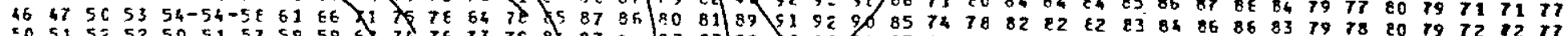

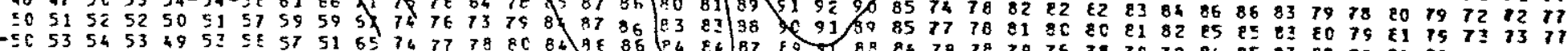

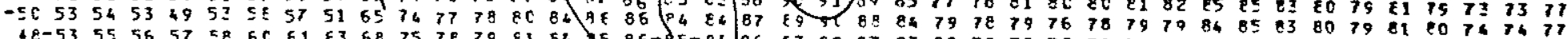

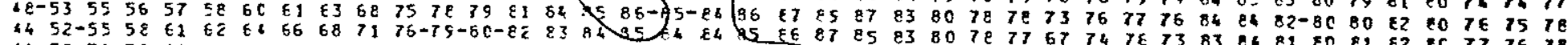

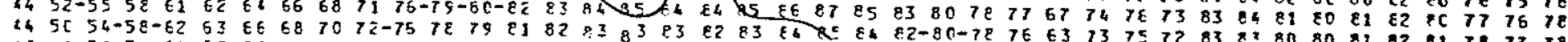
77

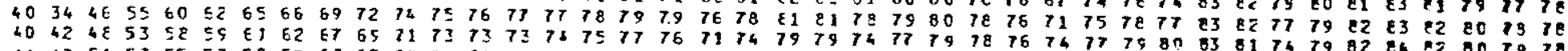

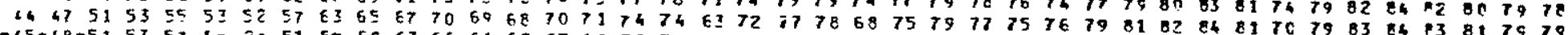

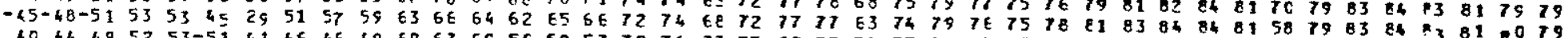

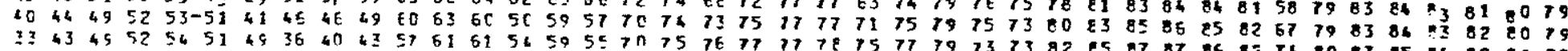

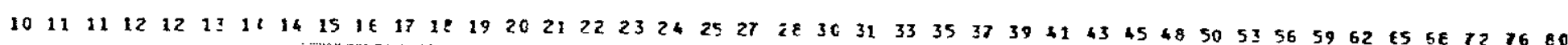

Período (s)

Fig. $B-12$ 


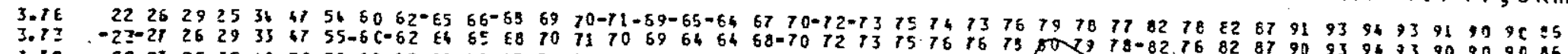

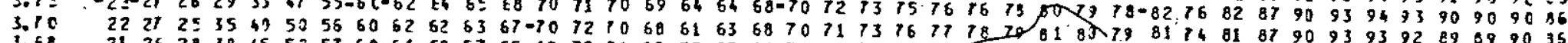

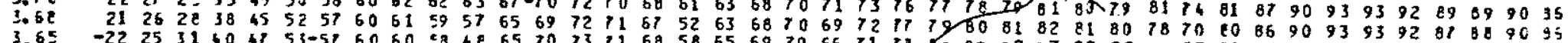

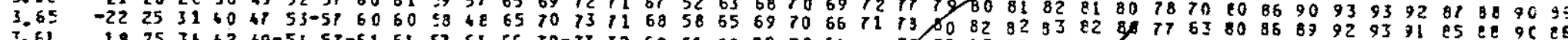

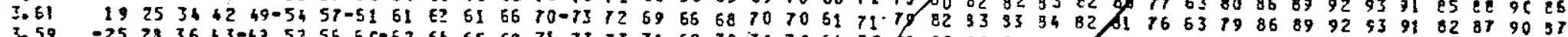

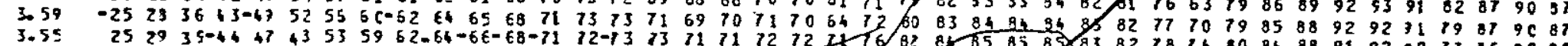

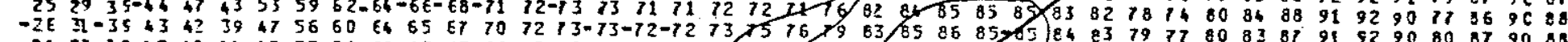

3.50 .

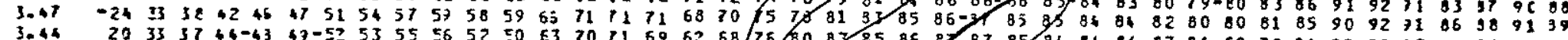

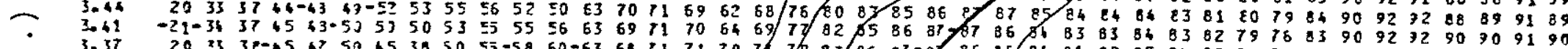

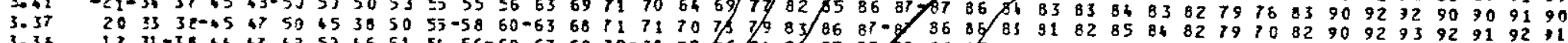

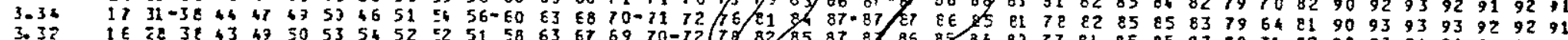

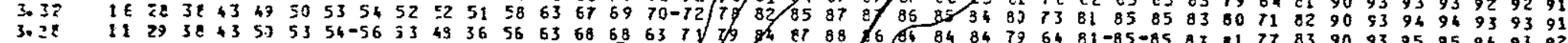

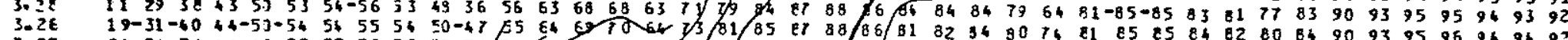

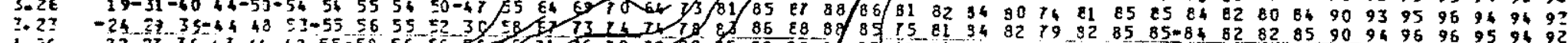

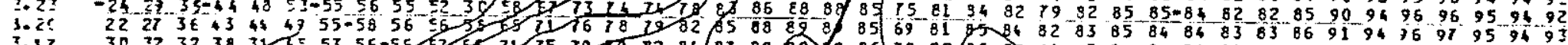

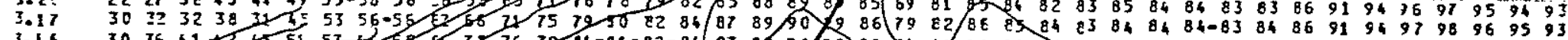

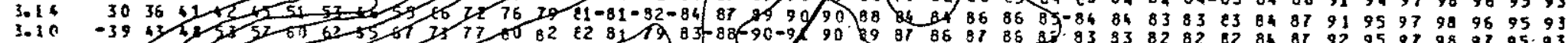

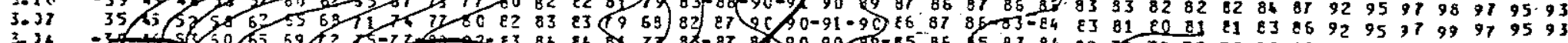
3.34

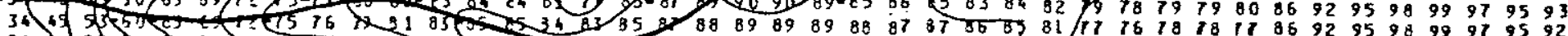

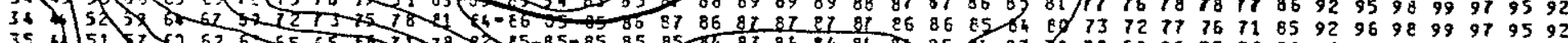
35 . 35
-35 27

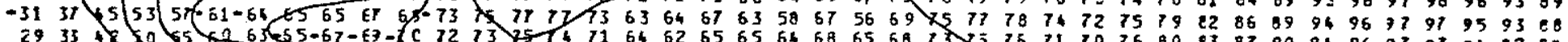

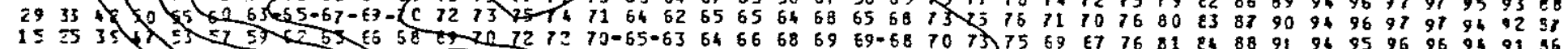

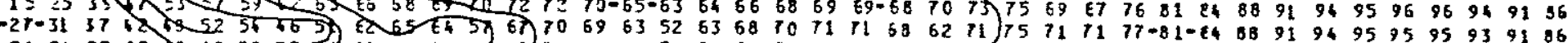

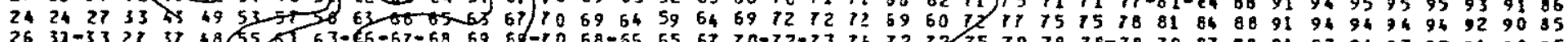

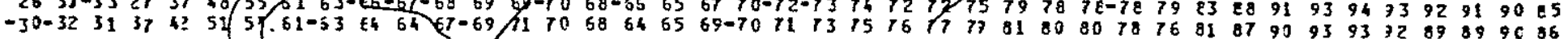

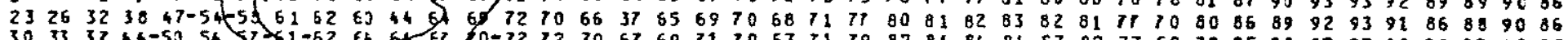

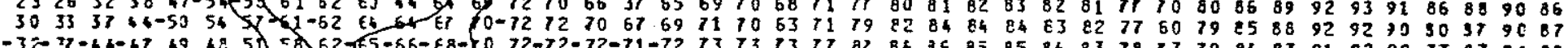

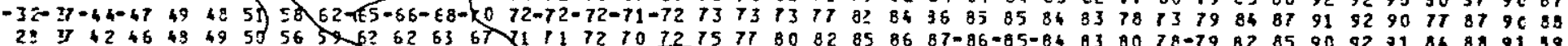

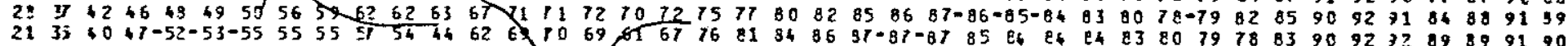

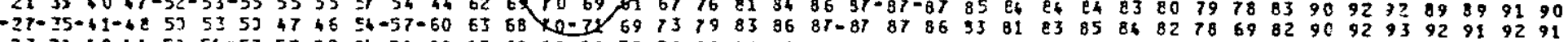

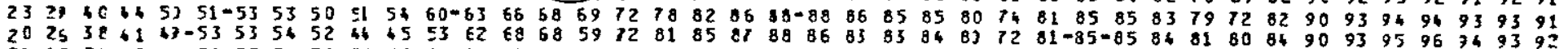

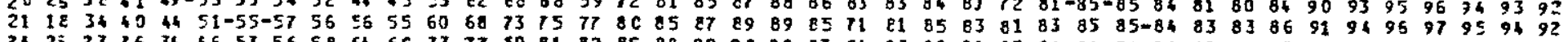

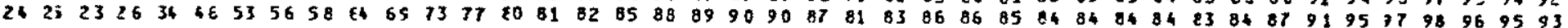

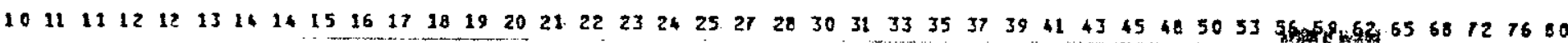

$$
\text { Período (s) }
$$

Fig. B -13 


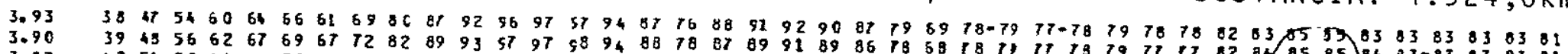

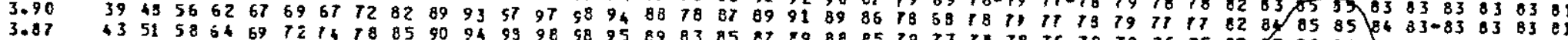

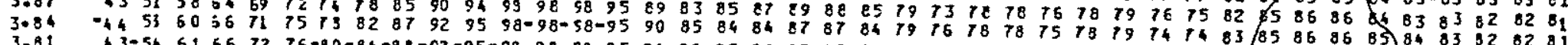

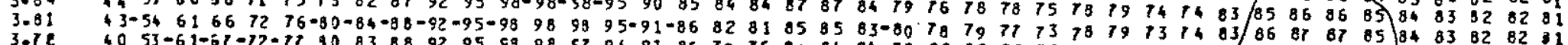

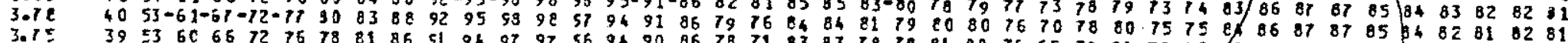

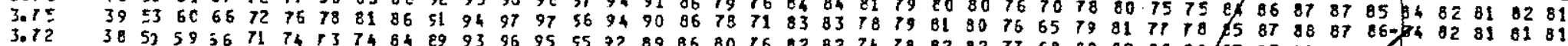

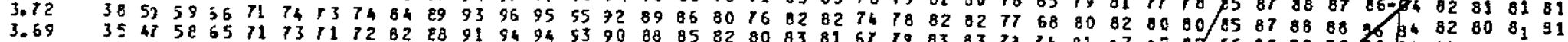

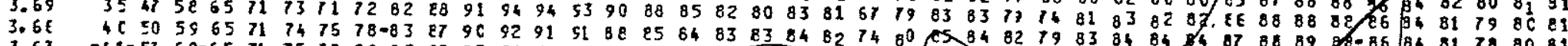
3.63 -

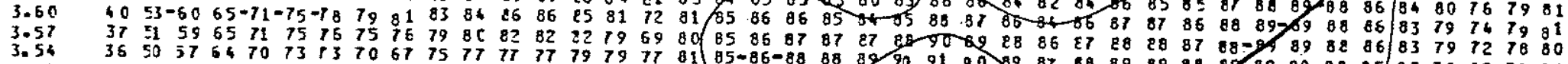

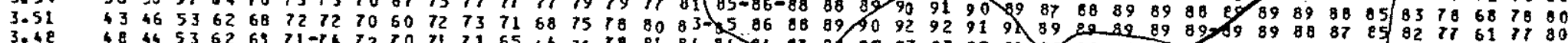

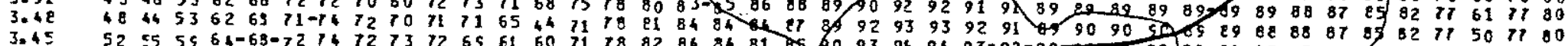

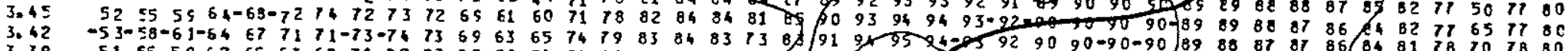

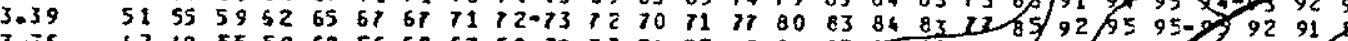

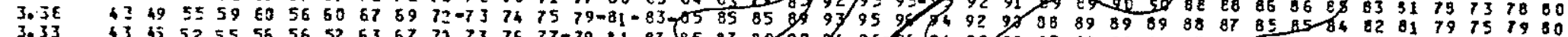

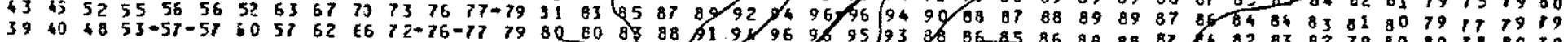

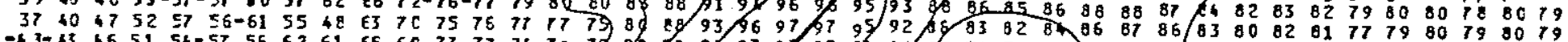

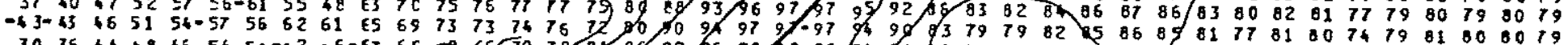

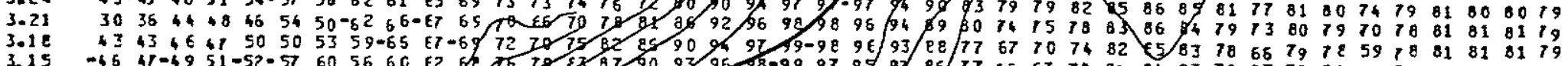

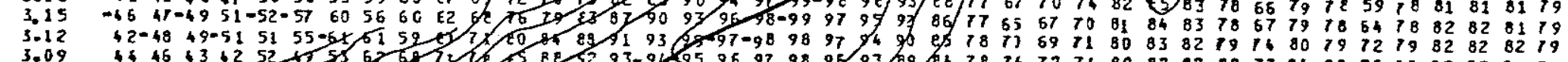

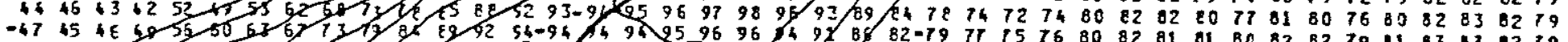

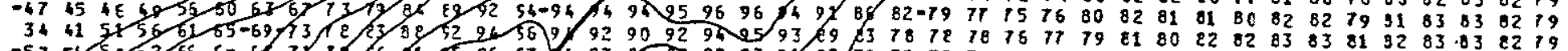

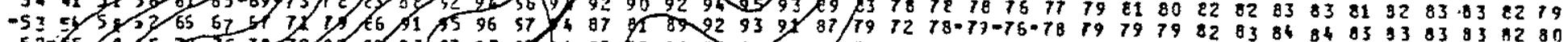

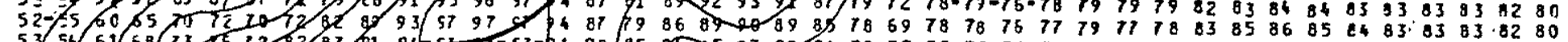

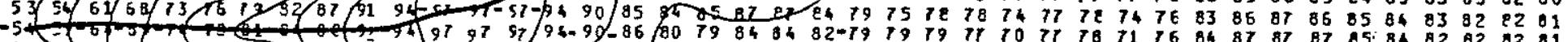

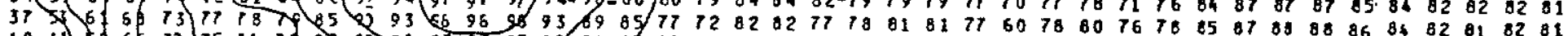

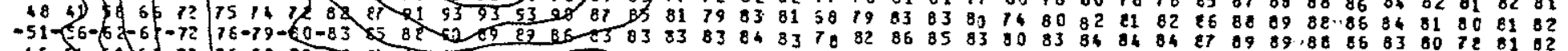

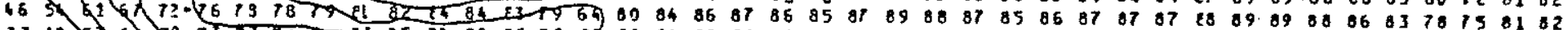

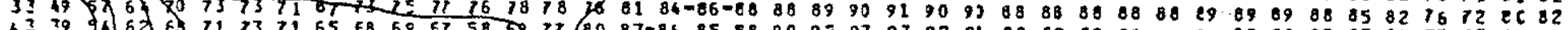

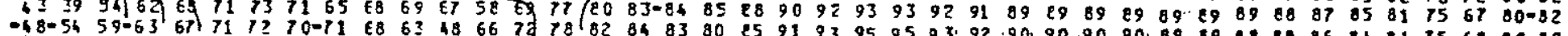

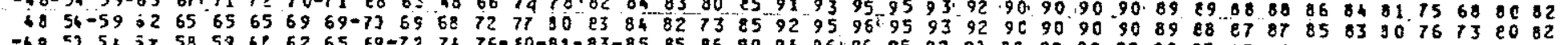

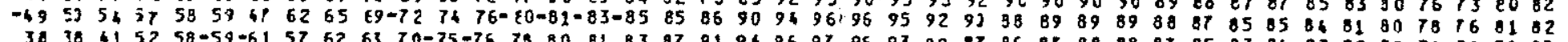

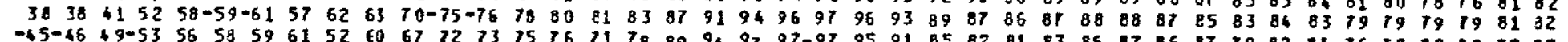

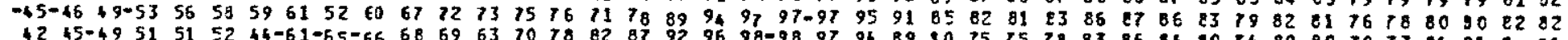

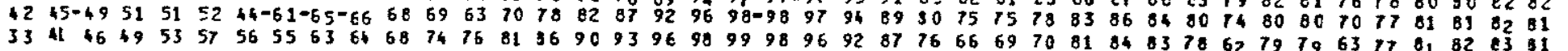

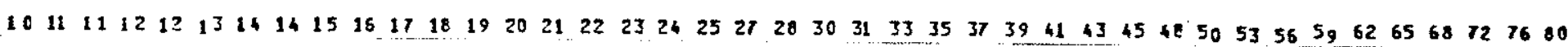
Período ( $s$ )

Fig. $B-14$ 


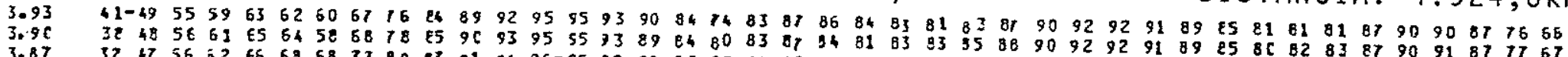

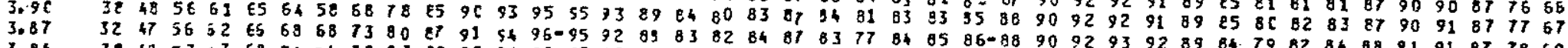

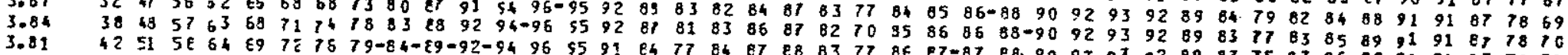

$x_{3,15}$

3.15

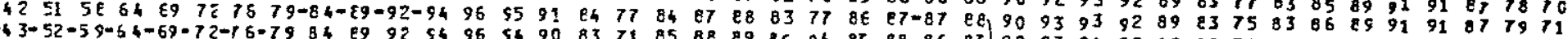

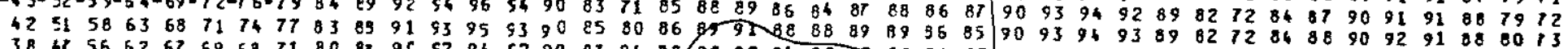

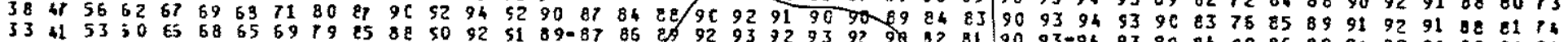

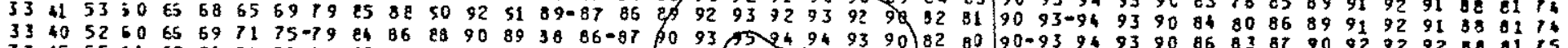

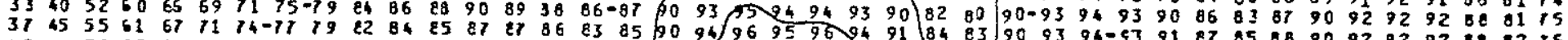

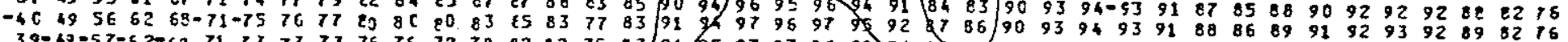

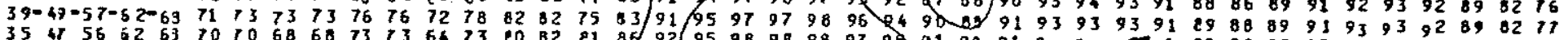

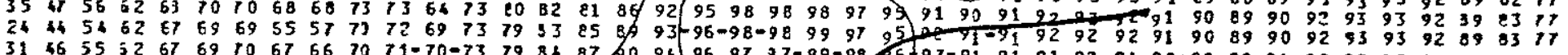

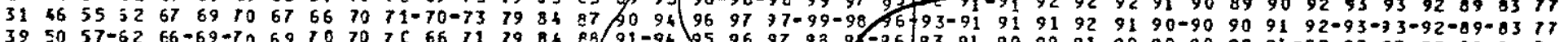

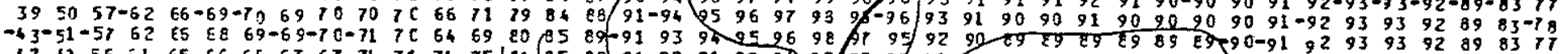

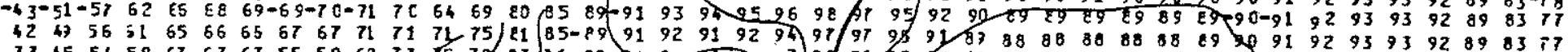

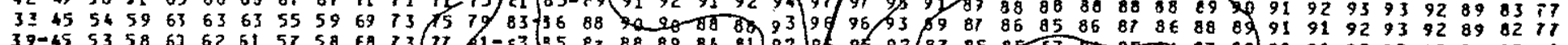

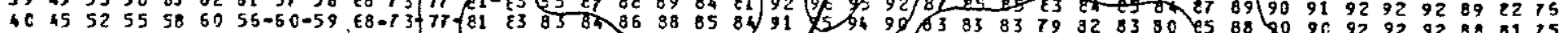

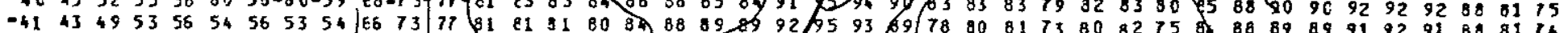

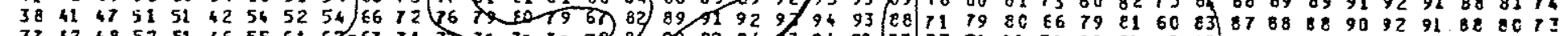

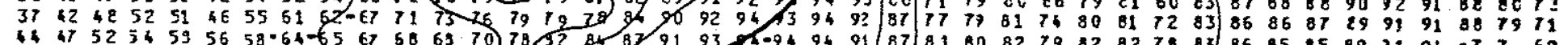

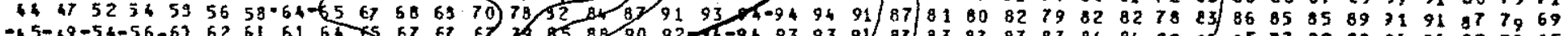

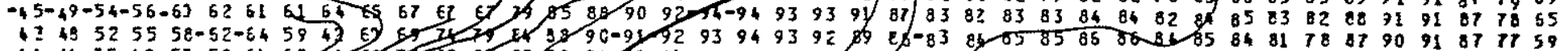

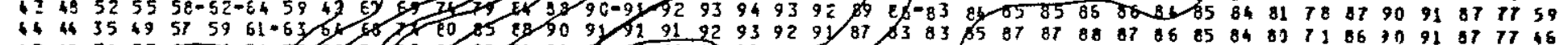

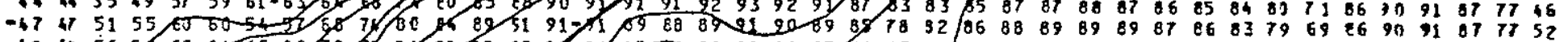

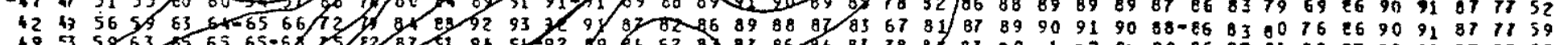

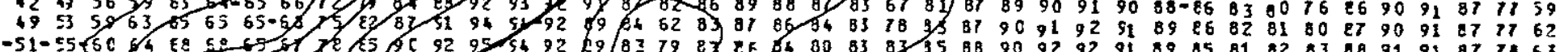

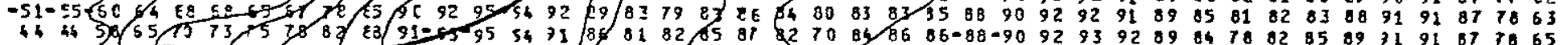

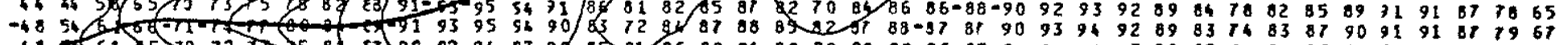

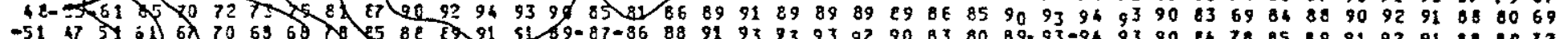
(2)

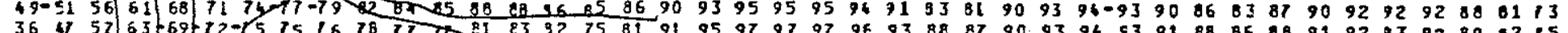

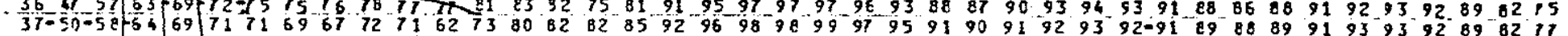

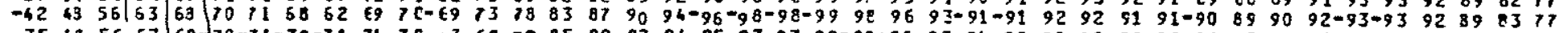
$3540565368-70-71-70-71717663 \quad 68798589-92-9495979799-98 * 96-9391909090909090-9091-9293 \quad 93-92-89-93 \quad 13$

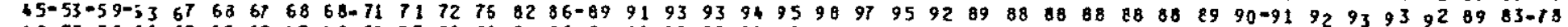

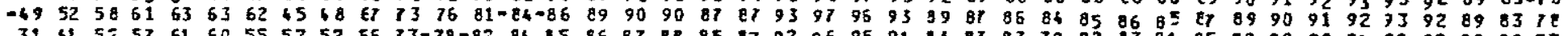

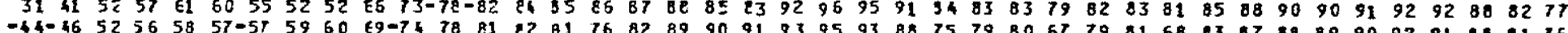

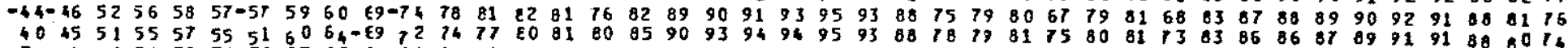

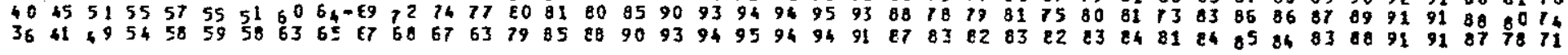

$10111112121314141516178919202122 \quad 2324252728303133 \quad 353739414345485053565962658072 \quad 7610$ Período (s)

Fig. $B-15$ 


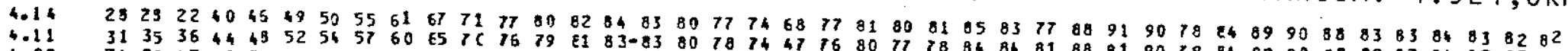

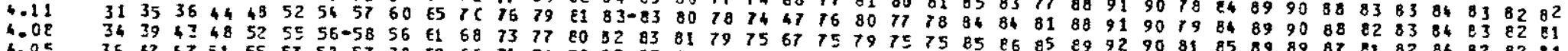

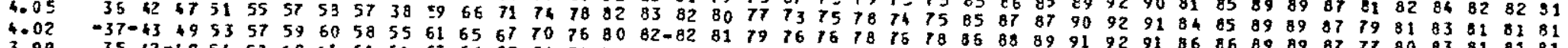

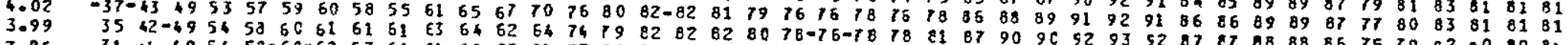

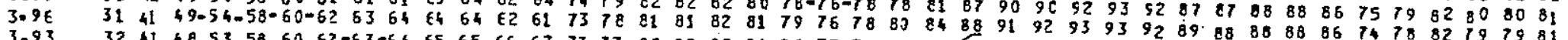

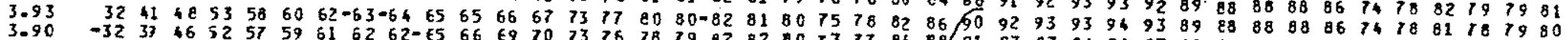

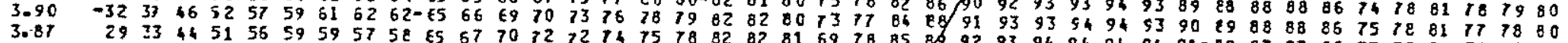

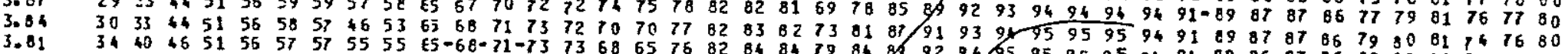

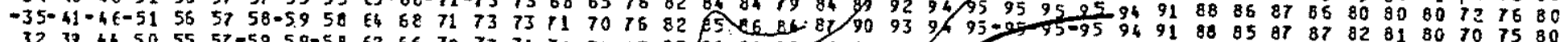

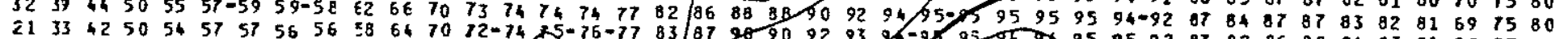

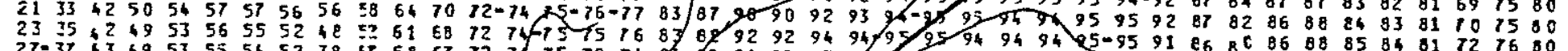

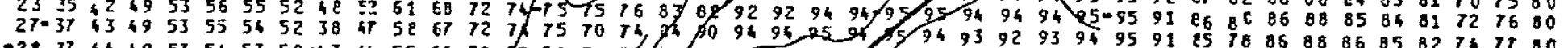

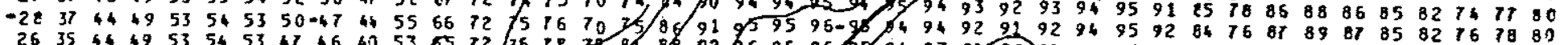

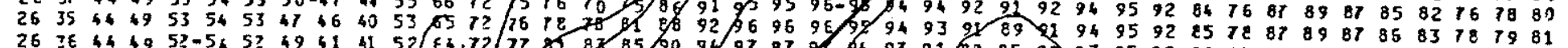

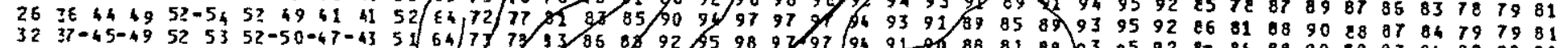

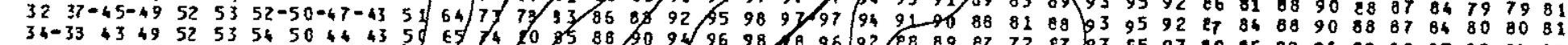

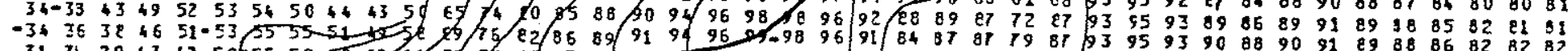

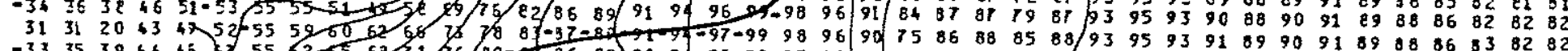

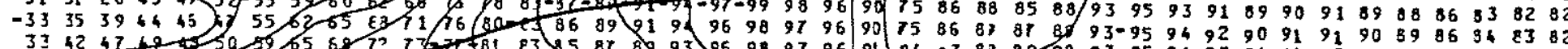

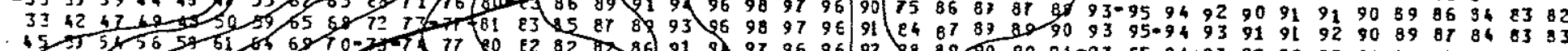

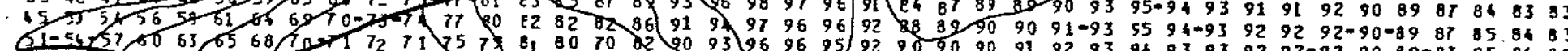
5150
5 $\begin{array}{ll}35 & 52 \\ 38 & 36\end{array}$

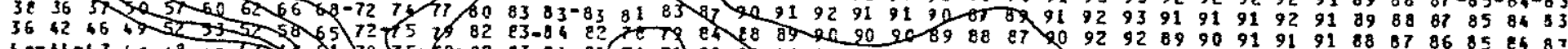

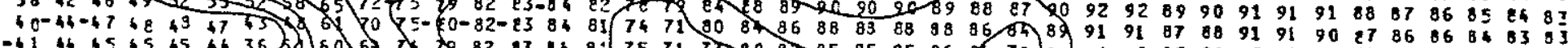

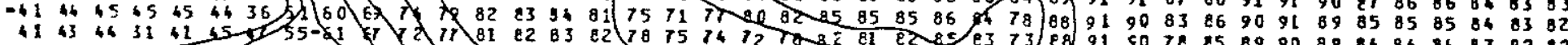

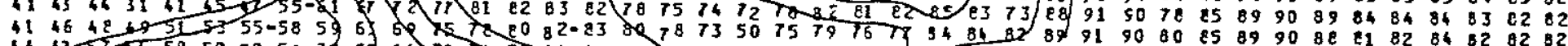

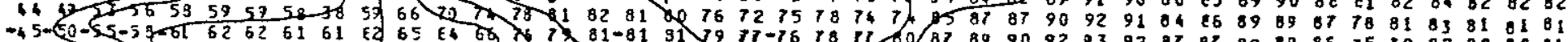

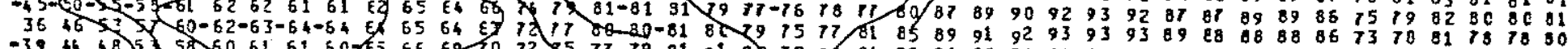

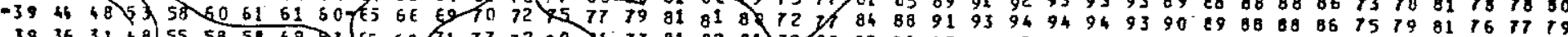

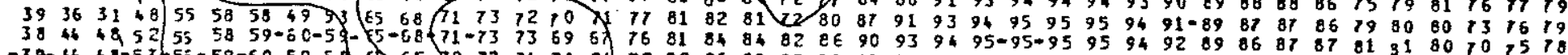

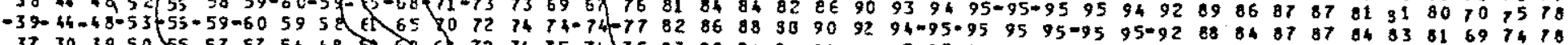

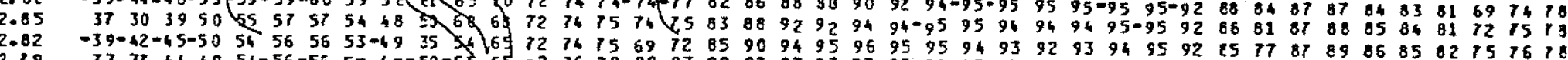

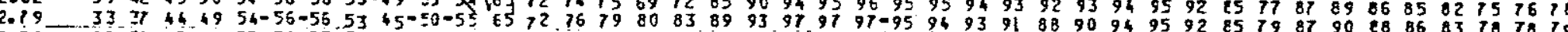

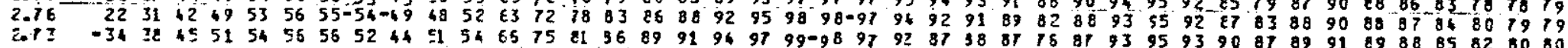

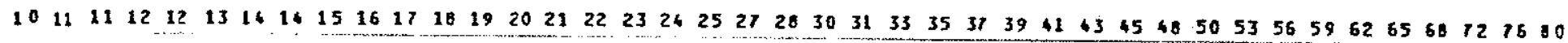

$$
\text { Período (s) }
$$

Fig. B-16 


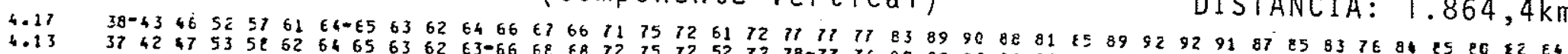

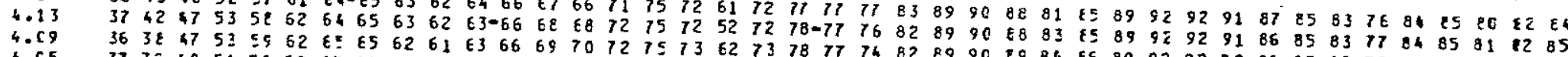

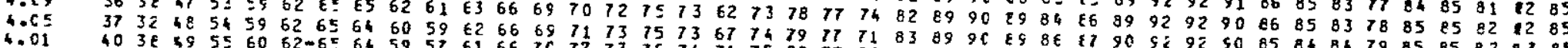

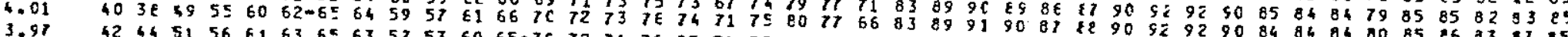

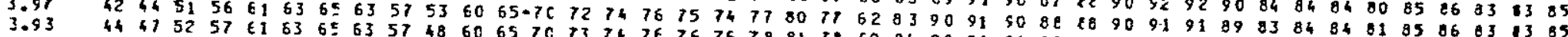

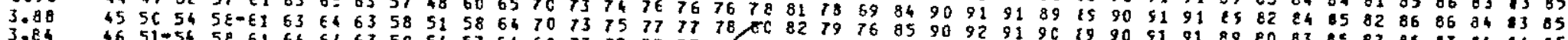

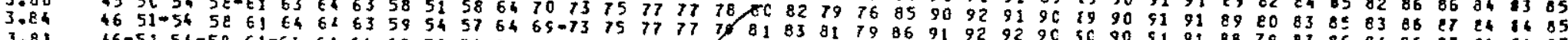

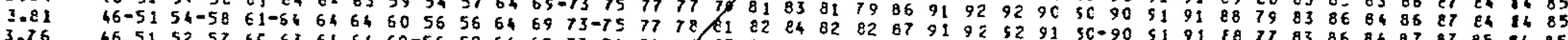

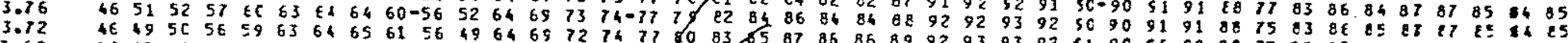

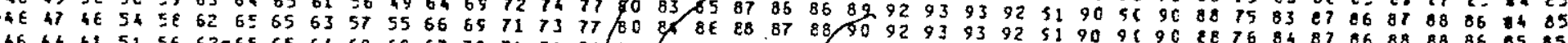

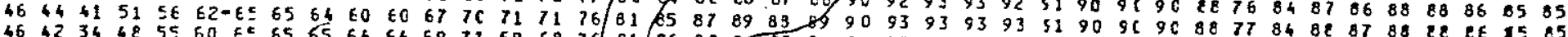

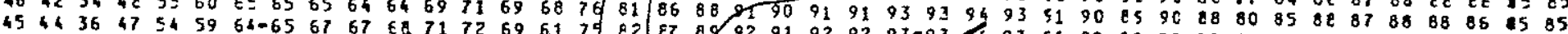

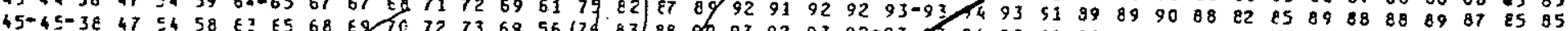

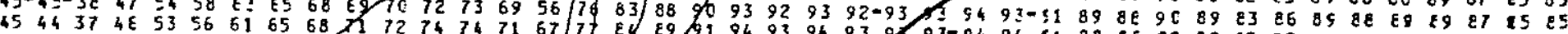

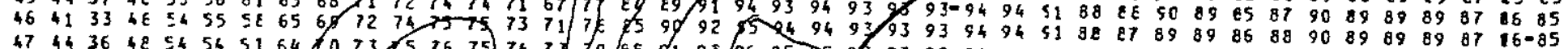

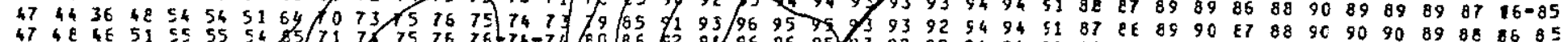

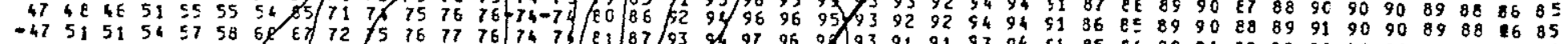

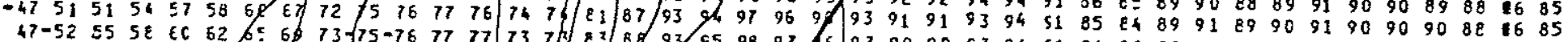

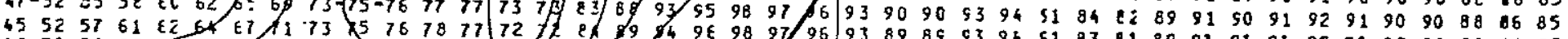

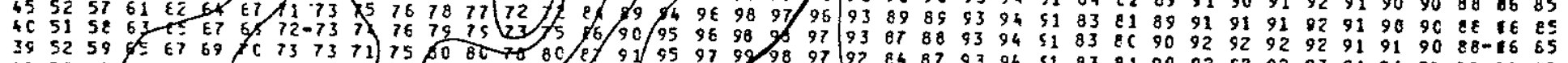

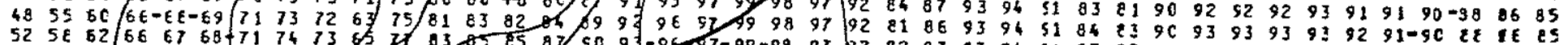

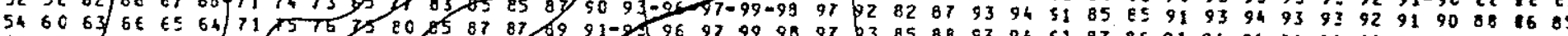

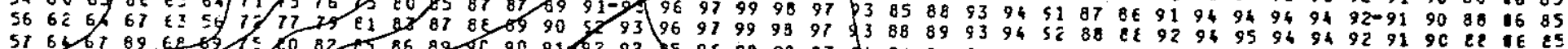

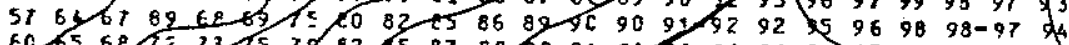

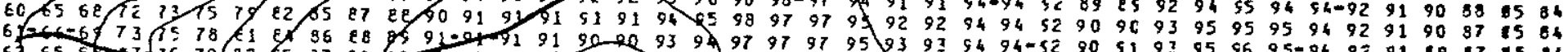

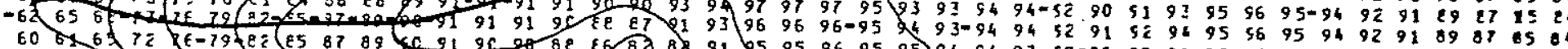

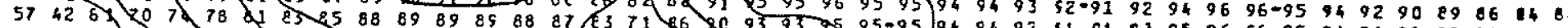

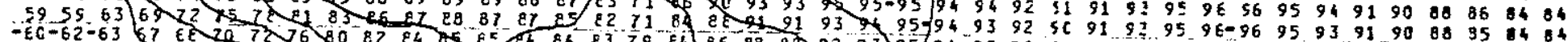

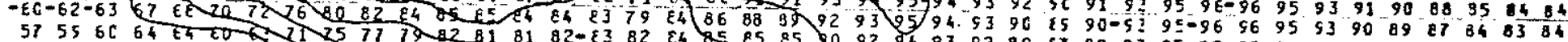

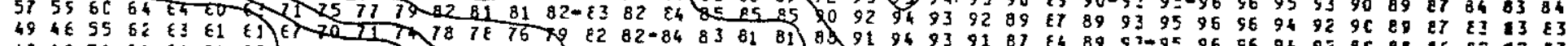

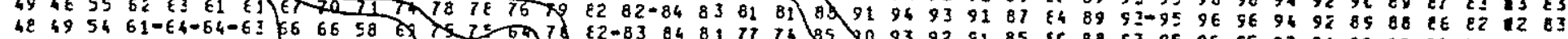

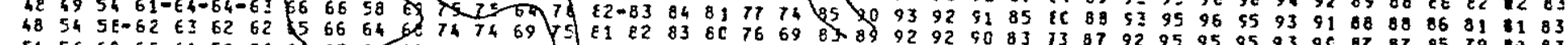

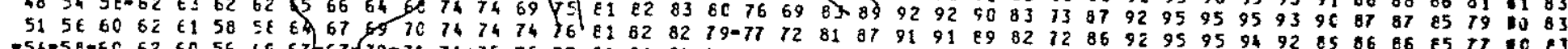

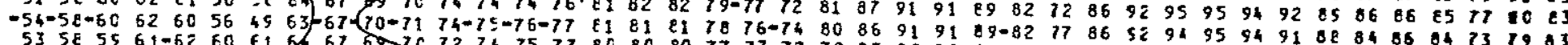

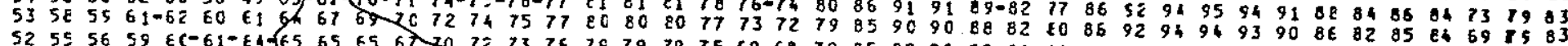

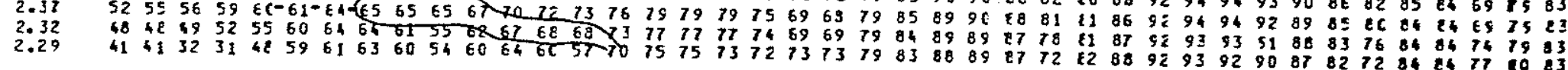

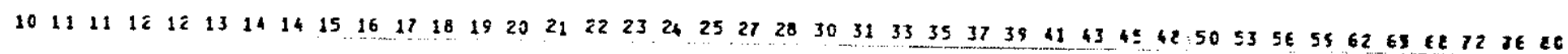
Período (s)

Fig. $\mathrm{B}-17$ 


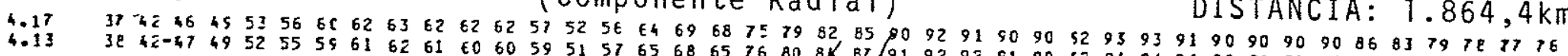

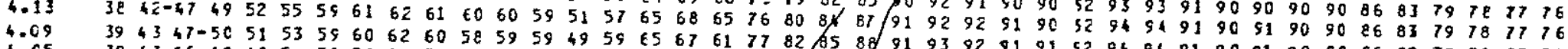

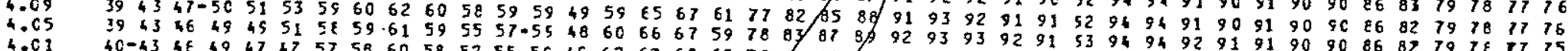

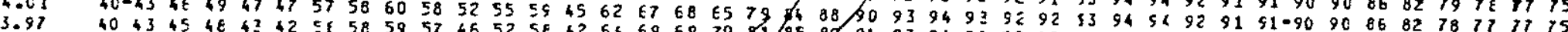

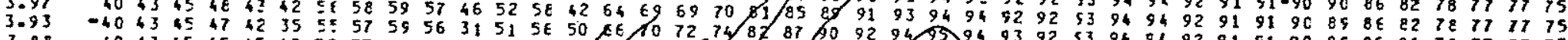

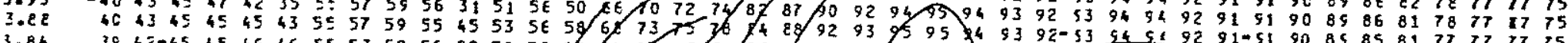
$494 \overline{2}-4505464655575956 \quad 5256 \quad 59$

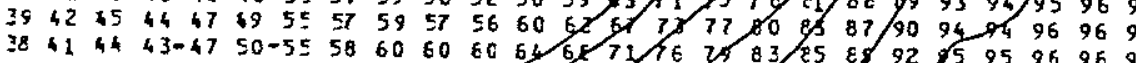
4.

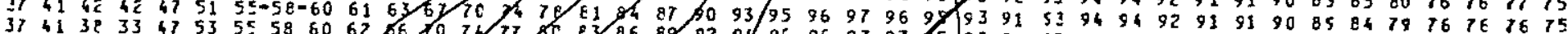

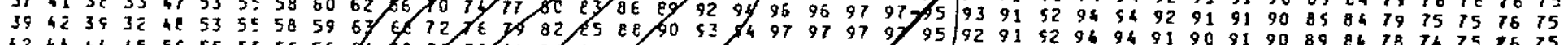

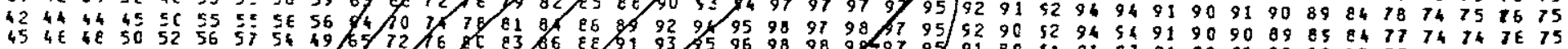

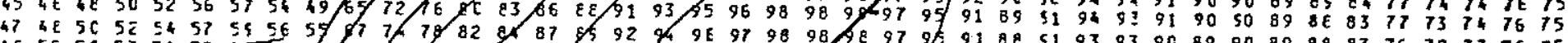

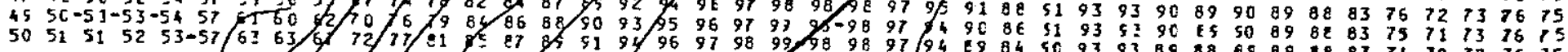

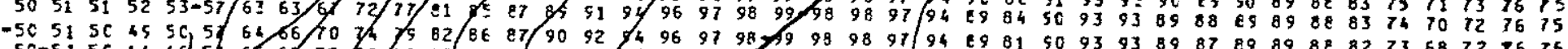
$\begin{array}{lllllllllllll} & \end{array}$

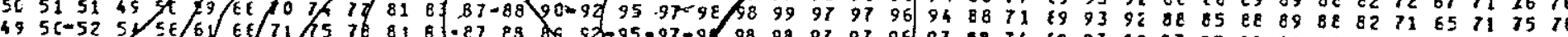

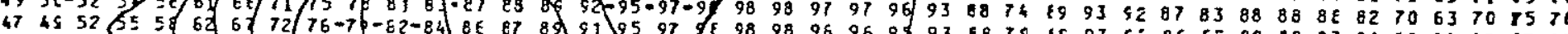

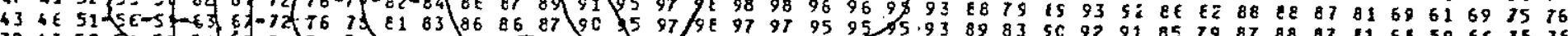

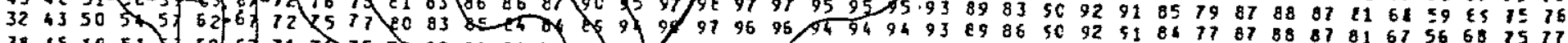

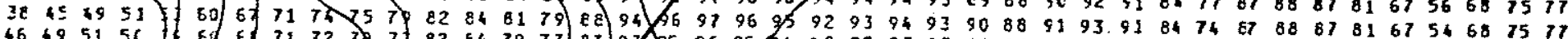

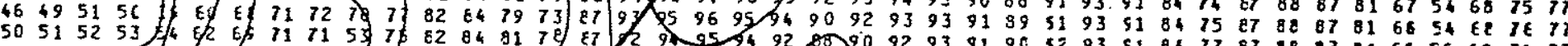

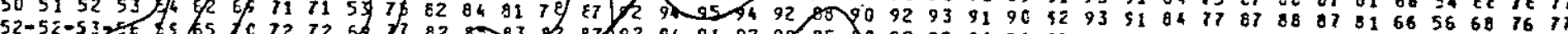

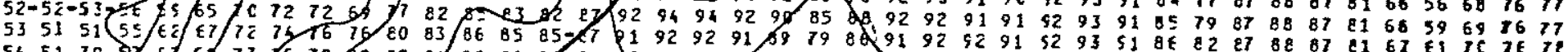

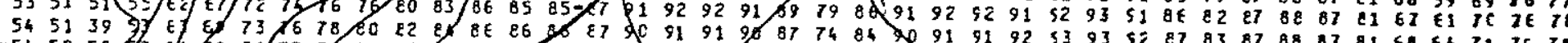

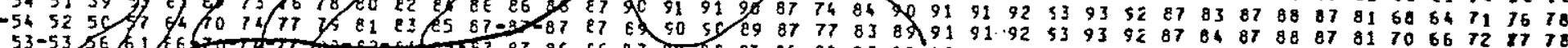
$53-53$
47

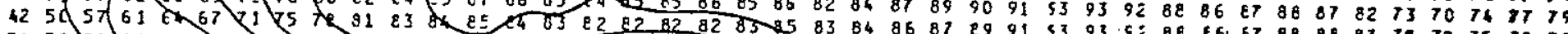

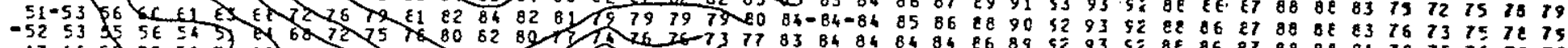

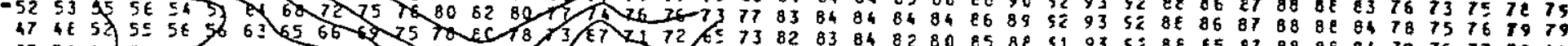

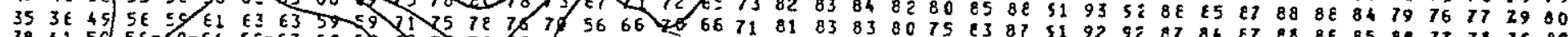

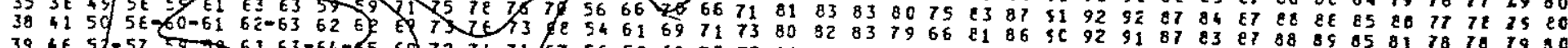

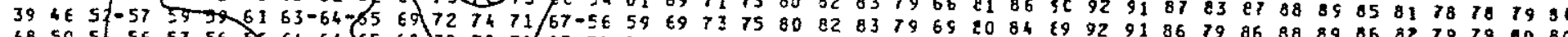

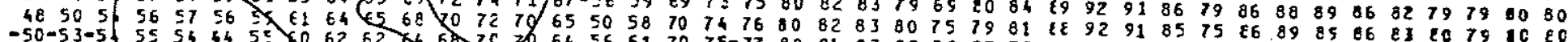

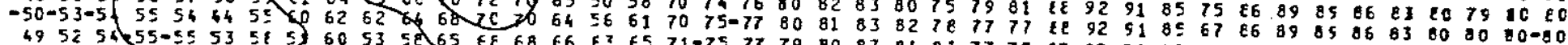

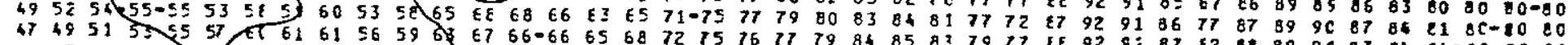

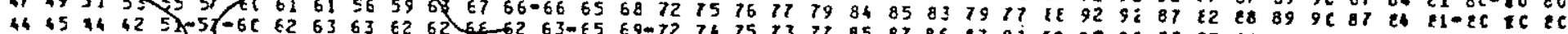

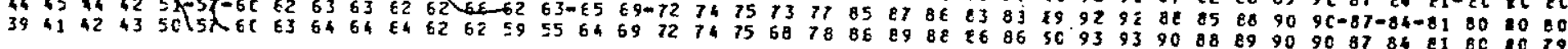

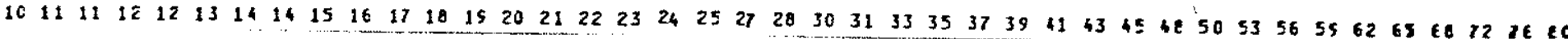
Período (s)

Fig. B-18 
(Componente Transversal)

DISTÂNCIA: $1.864,4 \mathrm{~km}$

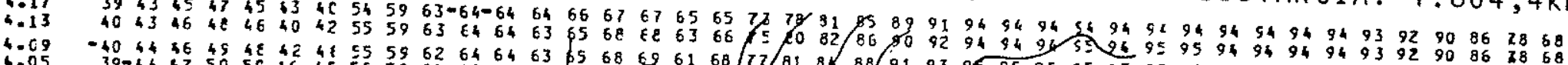

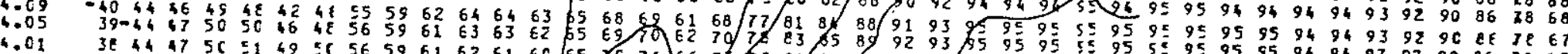

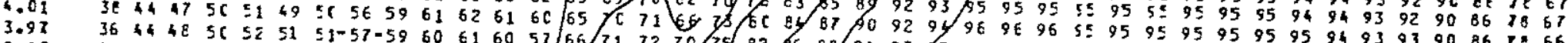

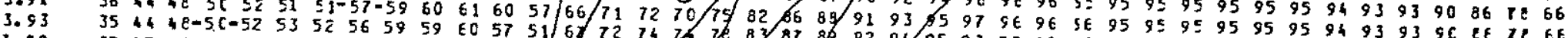

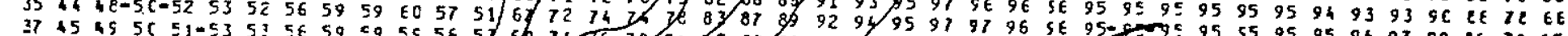

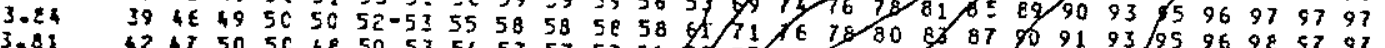

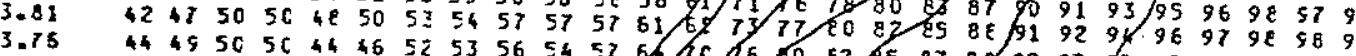

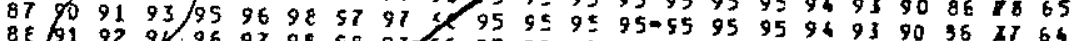

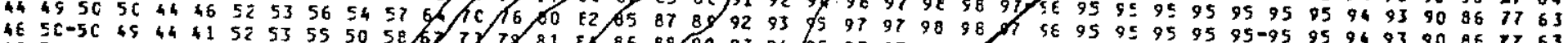

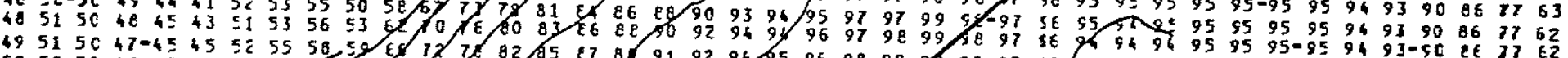

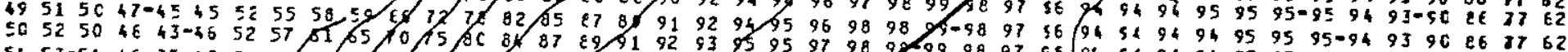

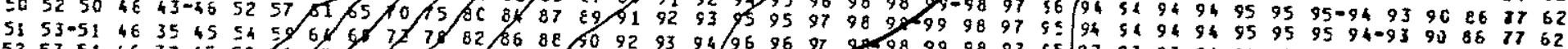

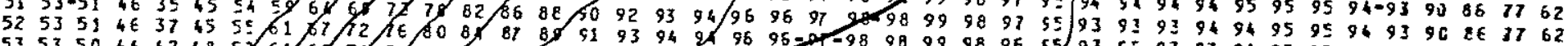

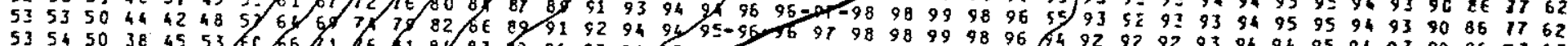

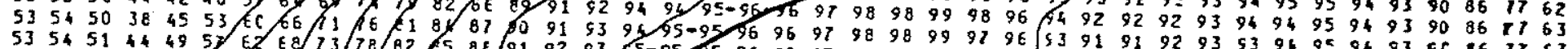

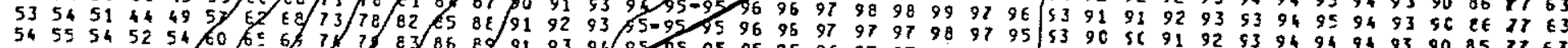

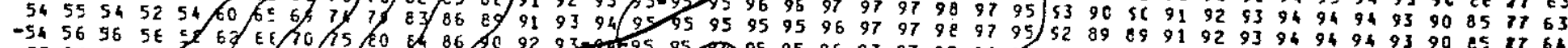

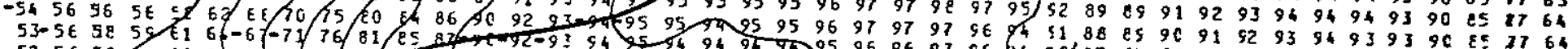

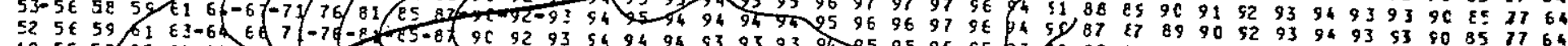

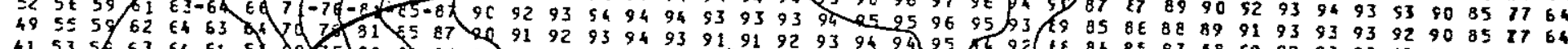

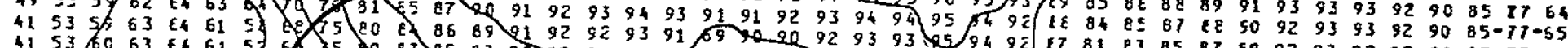

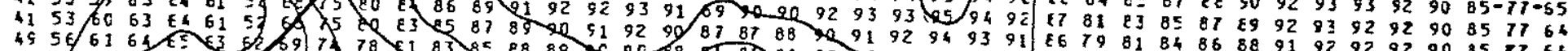

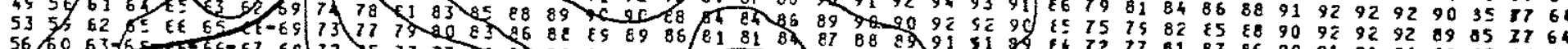

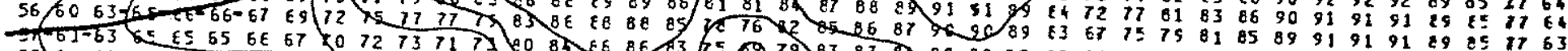

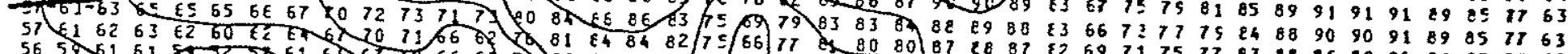

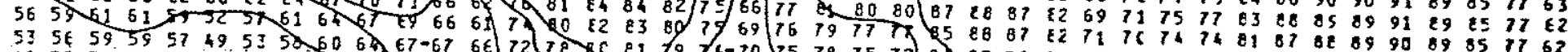

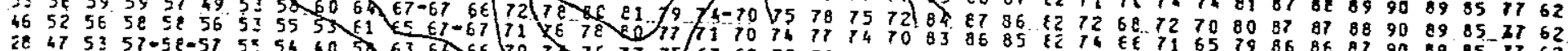

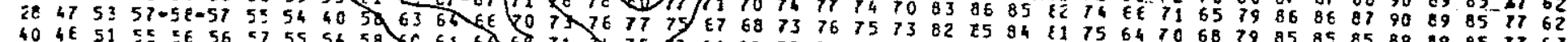

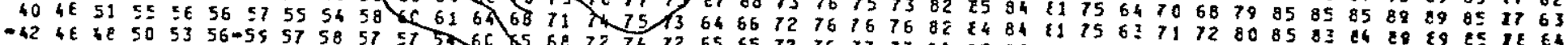

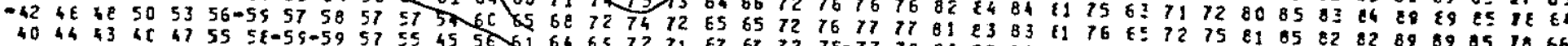

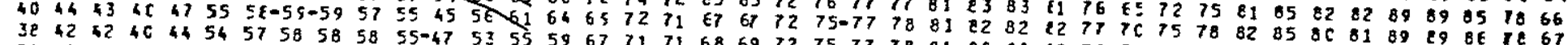

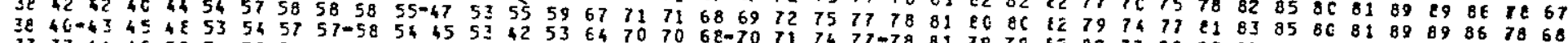

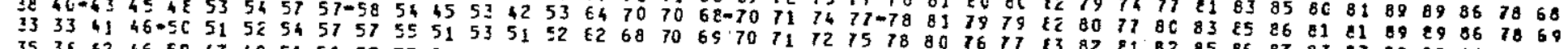

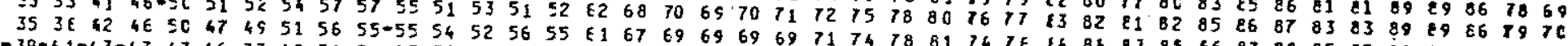

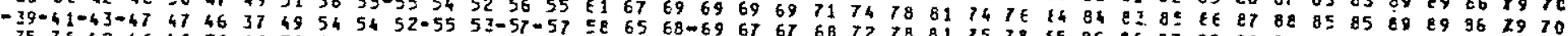

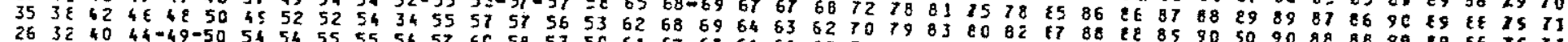

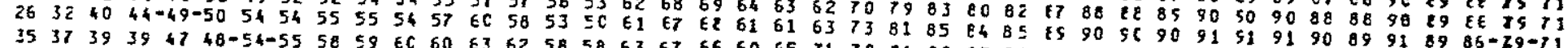

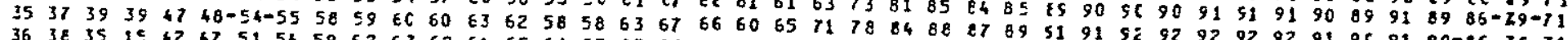
$\begin{array}{lllllllll} & \end{array}$

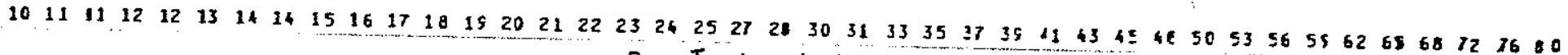
Periodo (s)

Fig. $B-19$ 


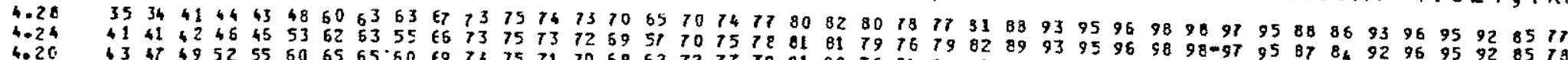

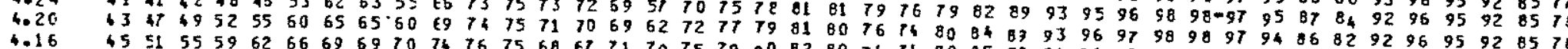

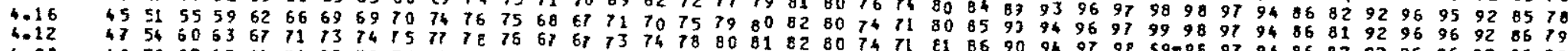

4.08

4.04

3.96

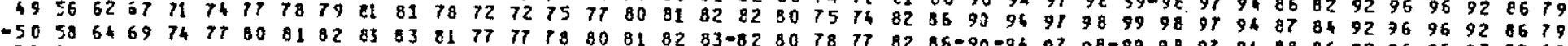

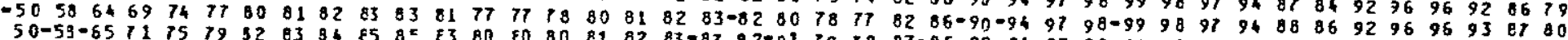

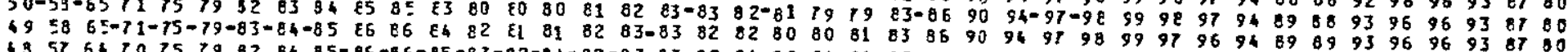

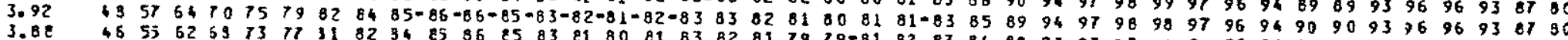

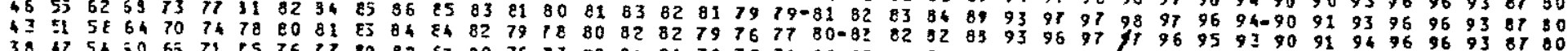

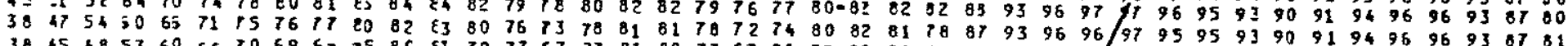

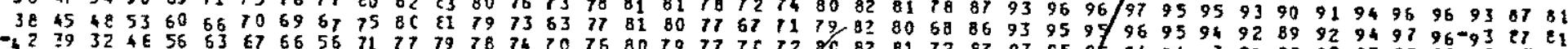

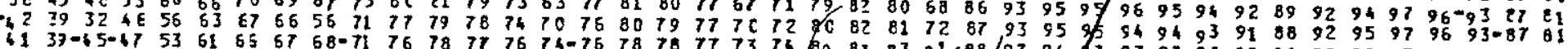

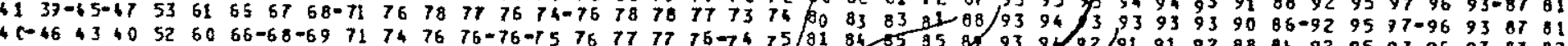

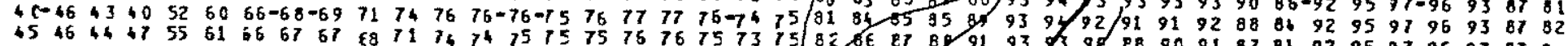

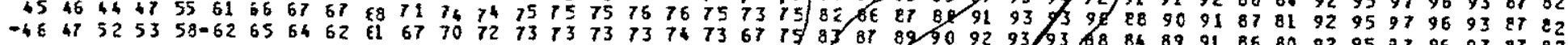

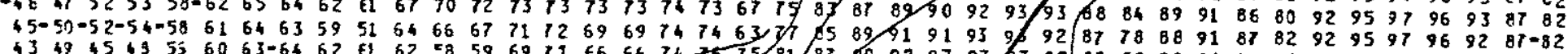

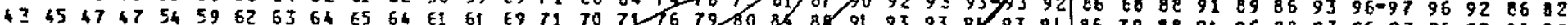

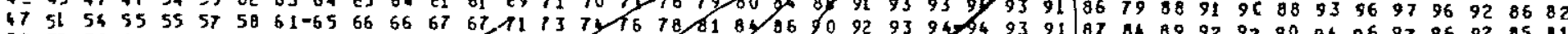

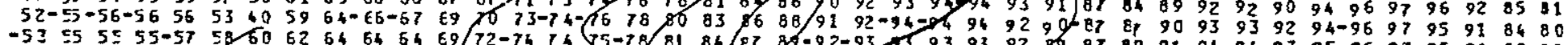

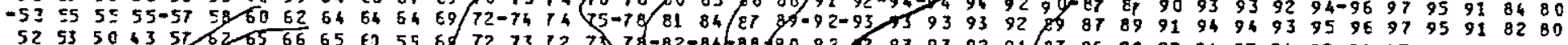

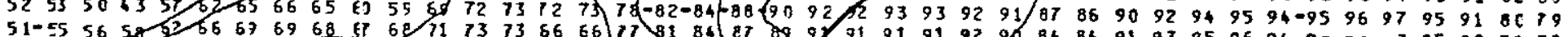

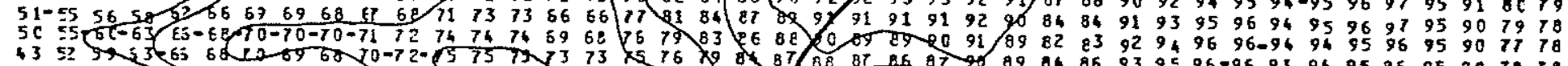

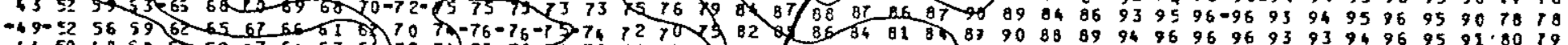

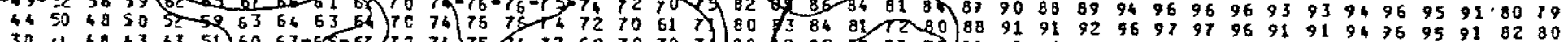

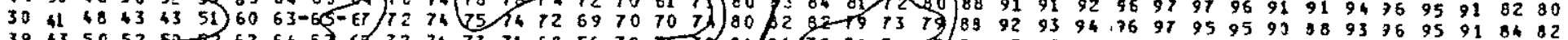

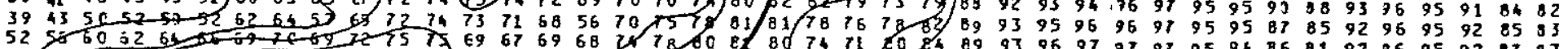

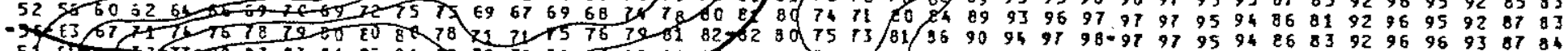
5 .

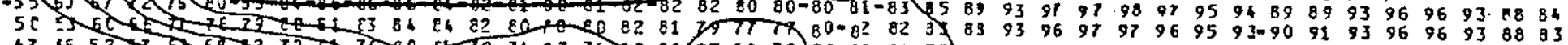

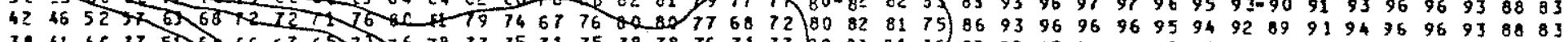

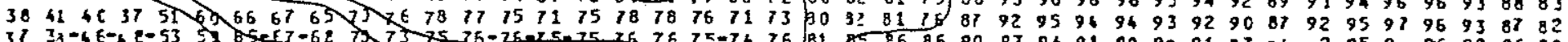

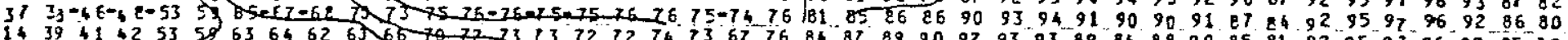

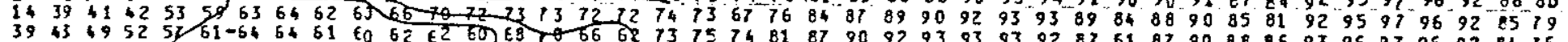

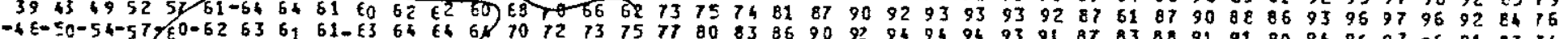

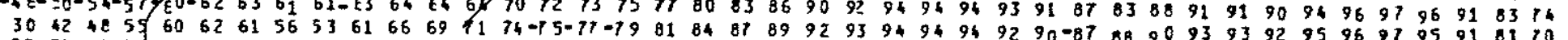

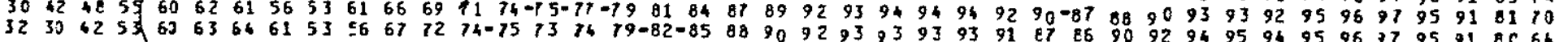

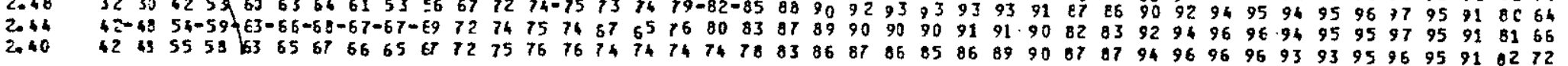
$10111142121316141516171819202122 \quad 2324252728303133 \quad 3537394143454050535659626568 \quad 727680$ Período (s)

Fig. $B-20$ 


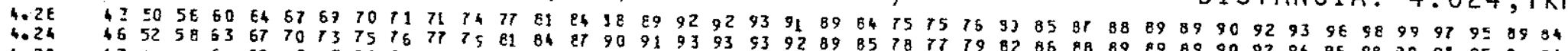

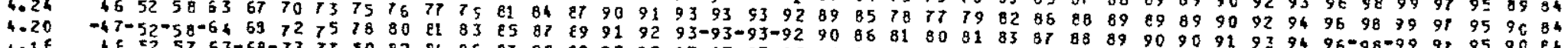

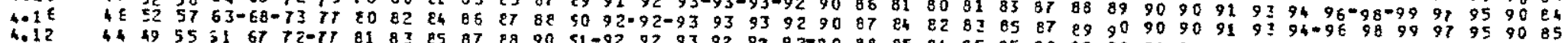

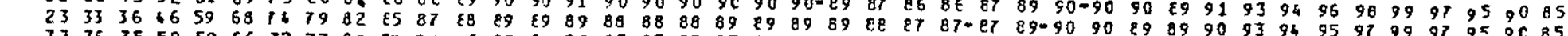

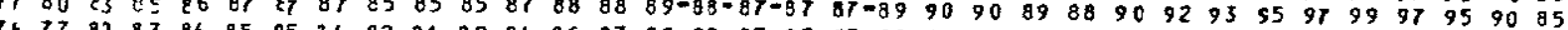

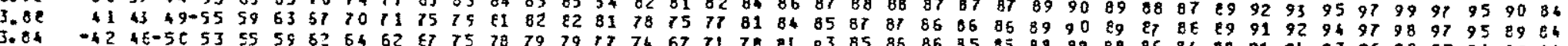

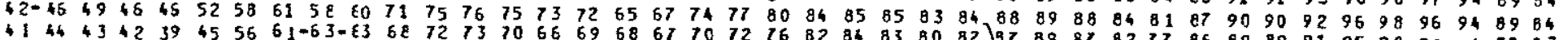

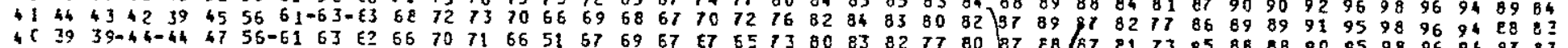

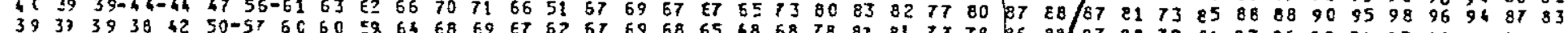

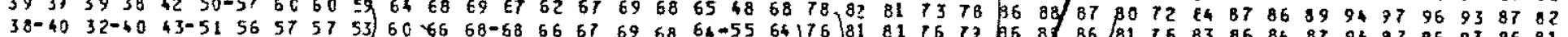

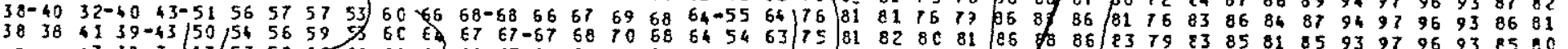

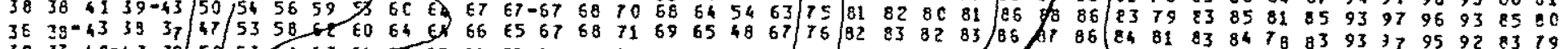

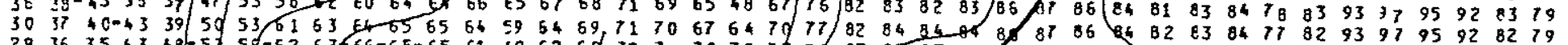

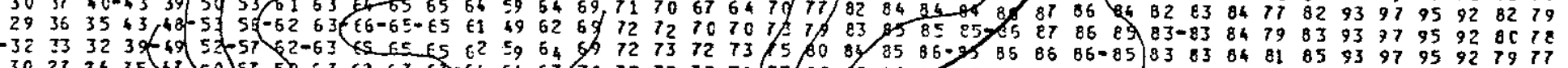

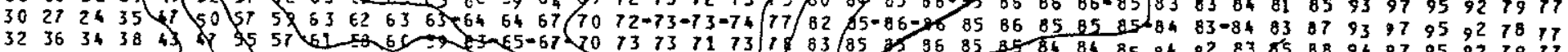

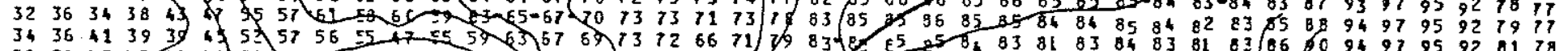

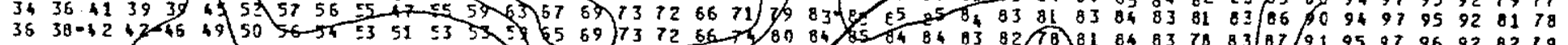

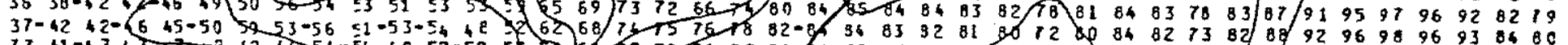

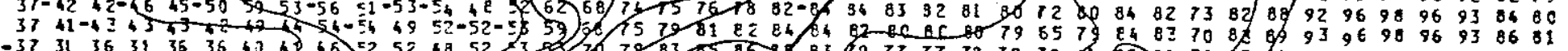

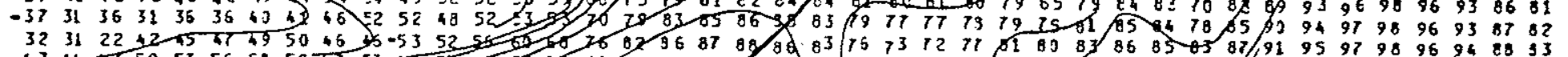

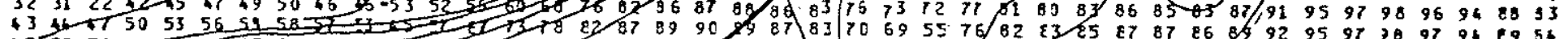

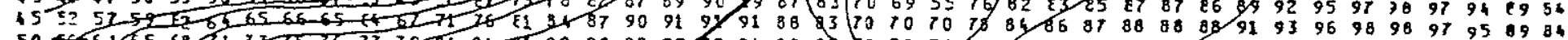

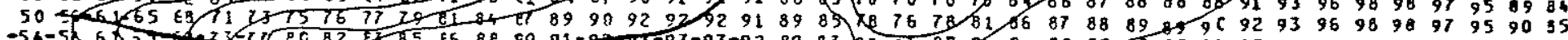

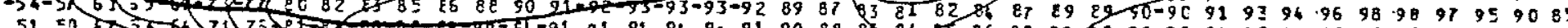

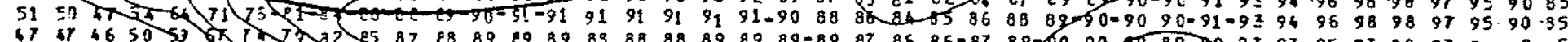

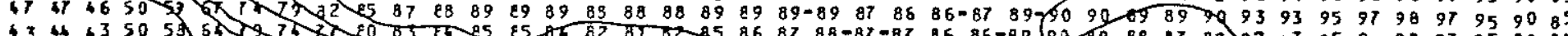

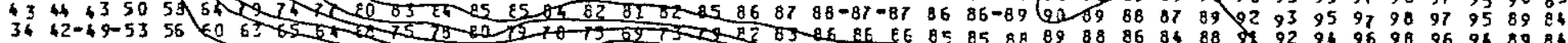

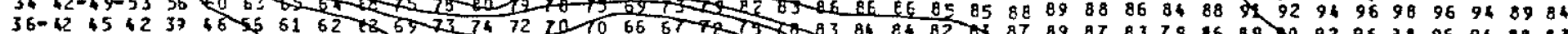

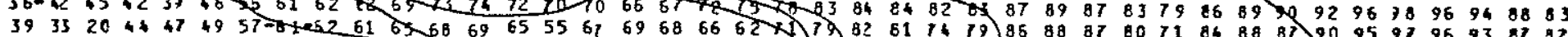

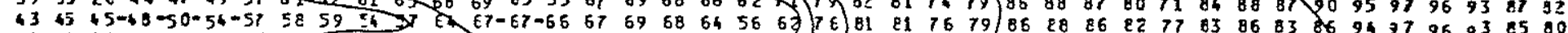

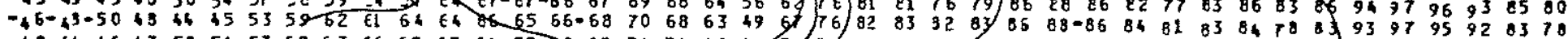

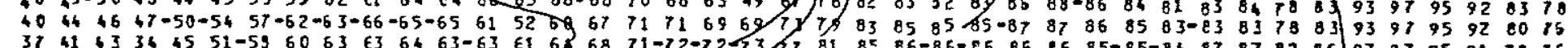

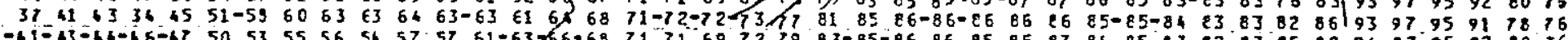

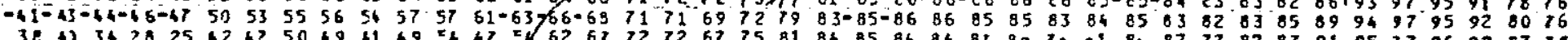

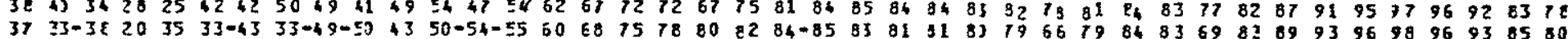
2727353338414239324951 51 $53546173 \quad 81848687868479767578 \quad 807882858481869194979096948782$

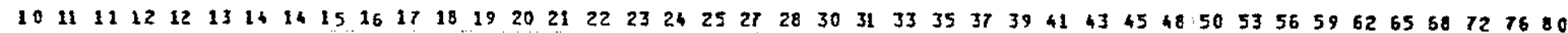
Período (s)

Fig. B-21 


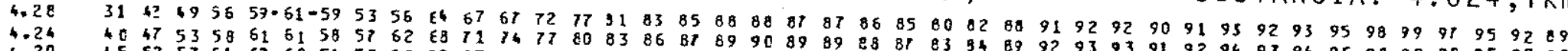

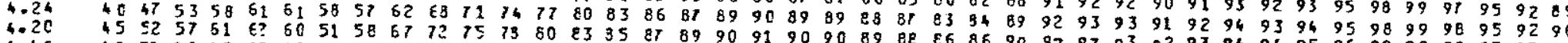

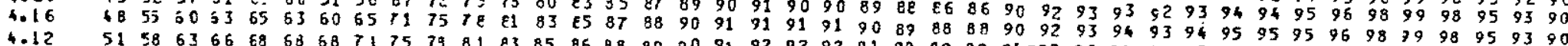

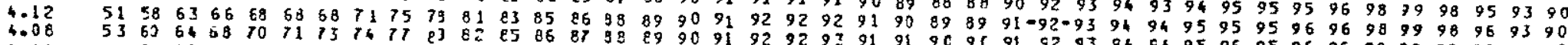

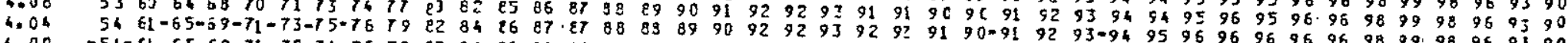
3.06 $3.92 \quad 515862660867 \quad 66707601033$

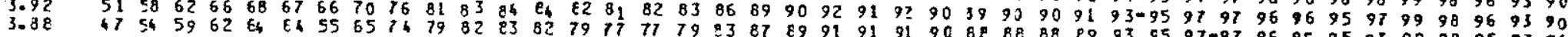

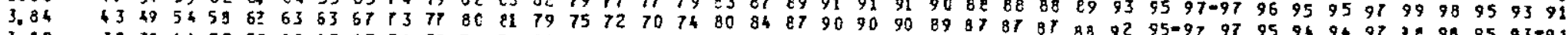

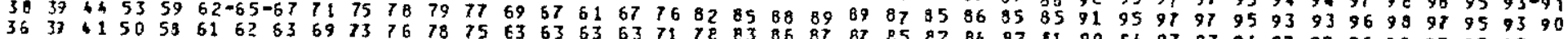

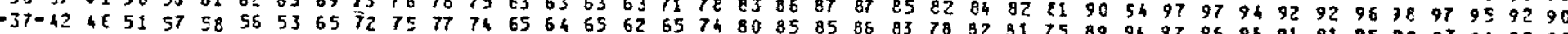

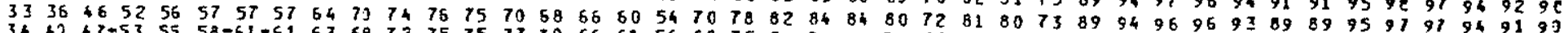

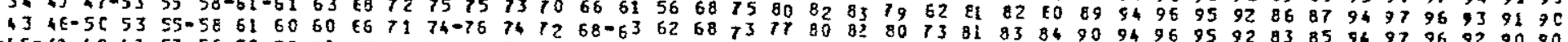

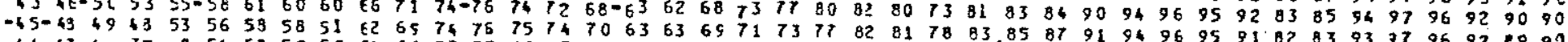

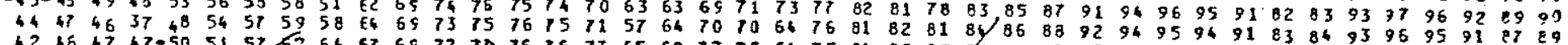

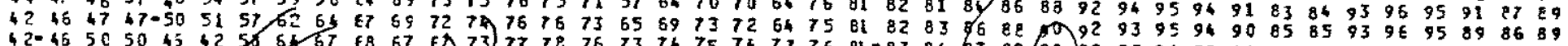

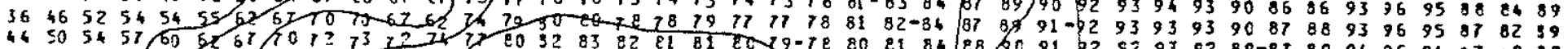

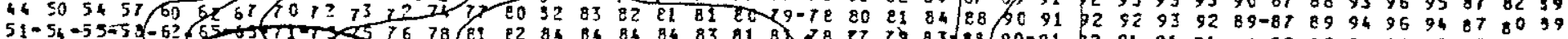

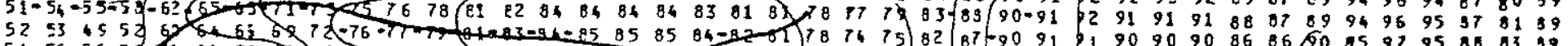

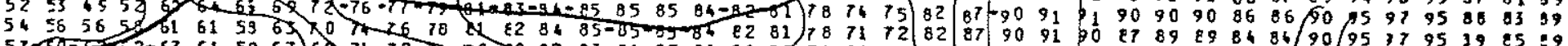

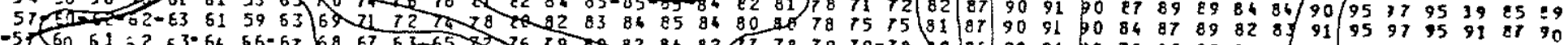

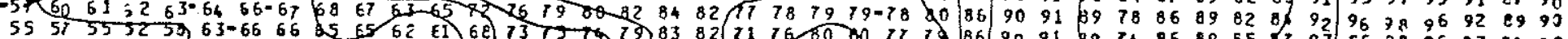

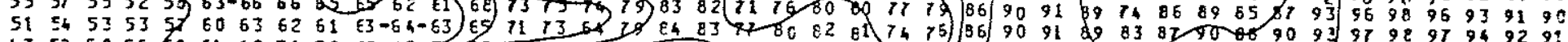

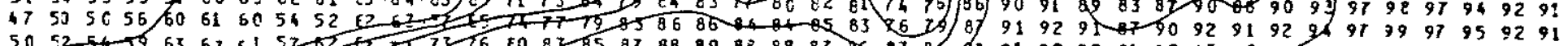

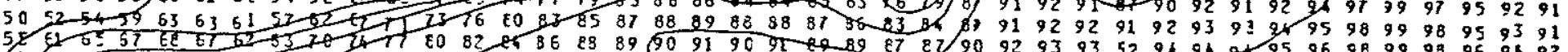

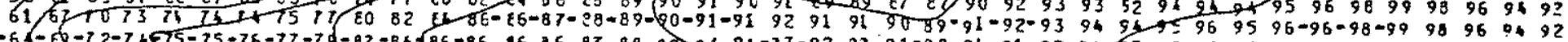

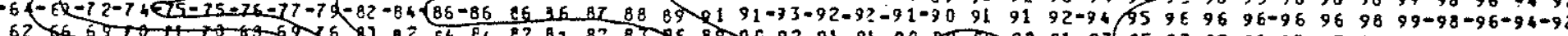

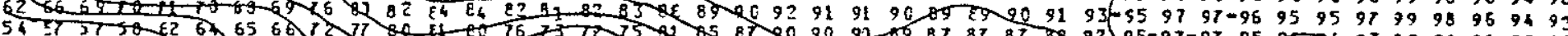

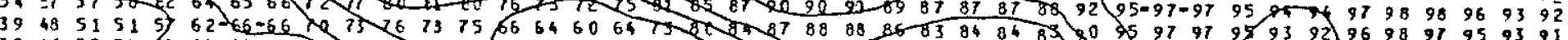

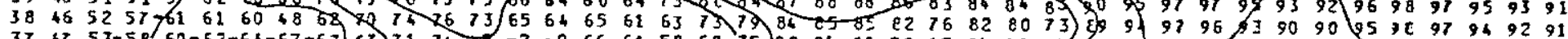

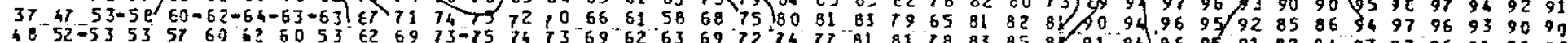

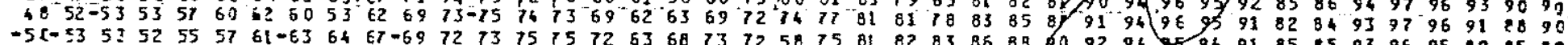

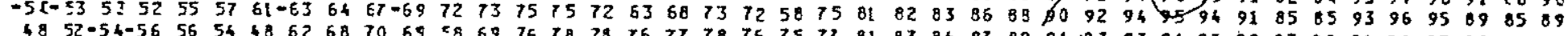

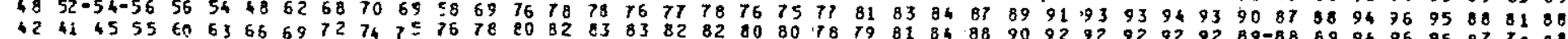

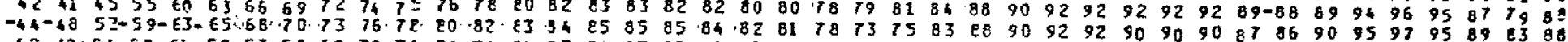

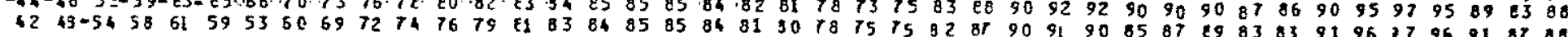

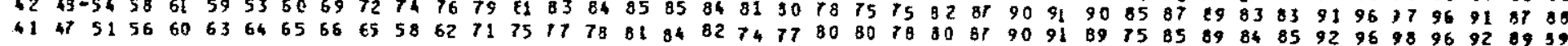

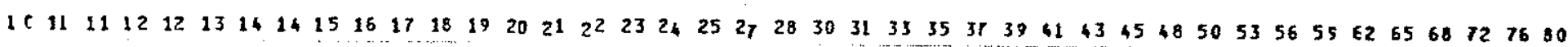
Período (s)

Fig. B-22 


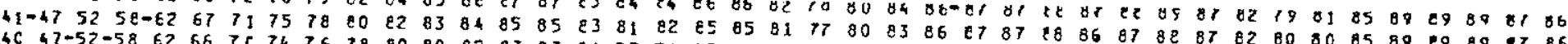

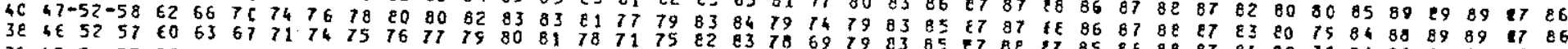

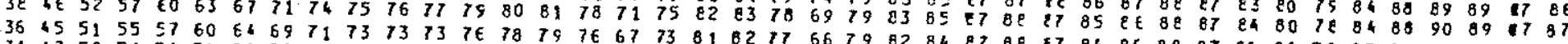

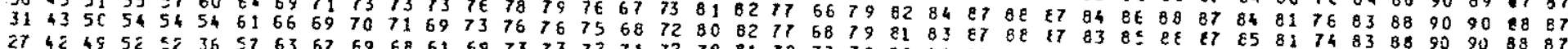

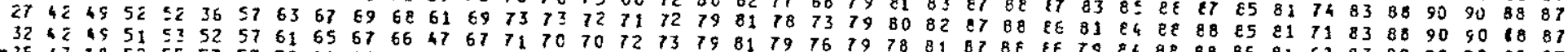

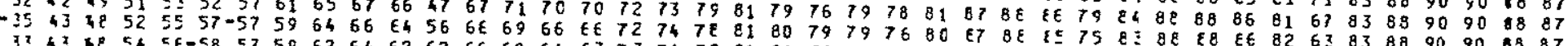

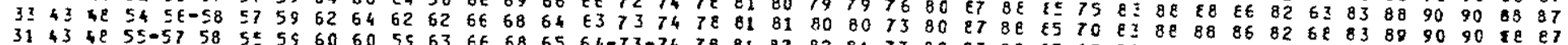

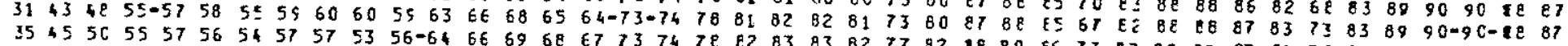

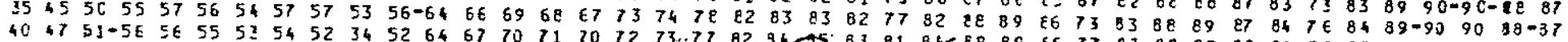

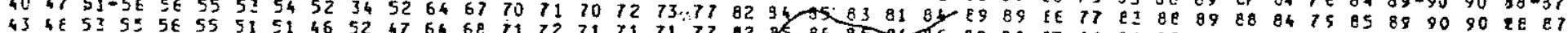

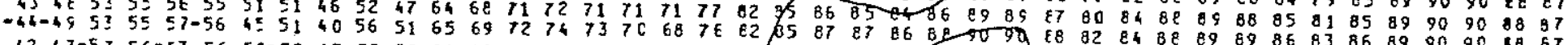

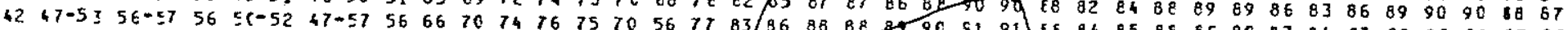

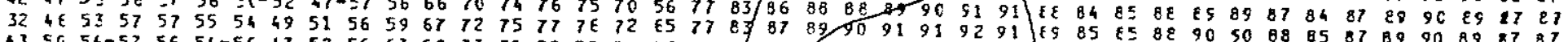

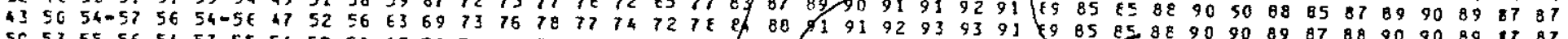

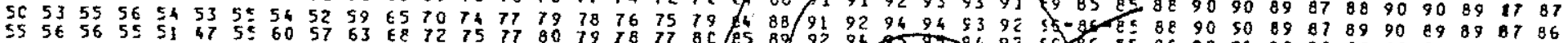

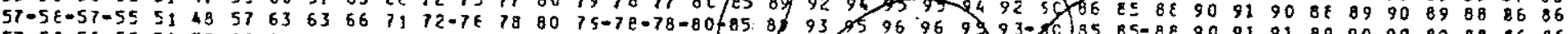

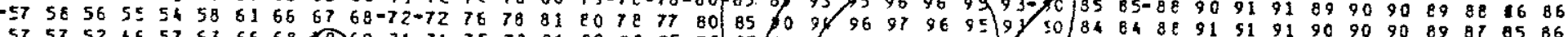

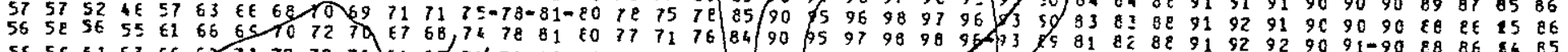

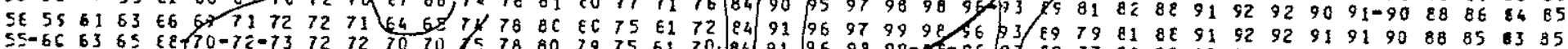
S6 $50-53-66-68$ E

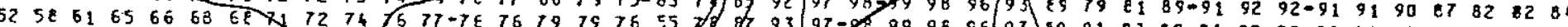

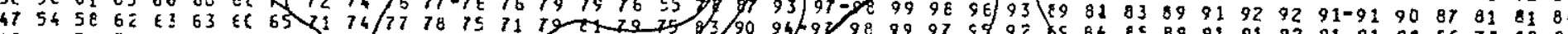

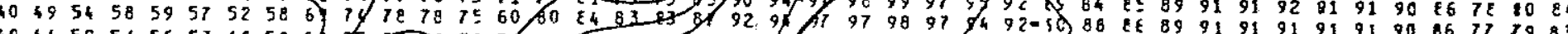

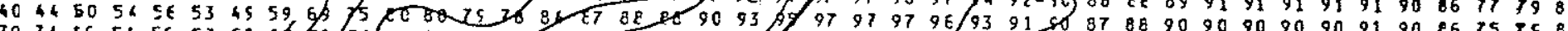
(1)

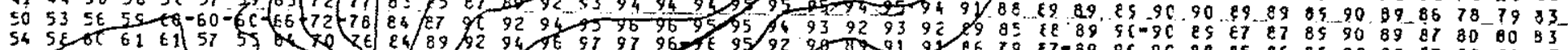

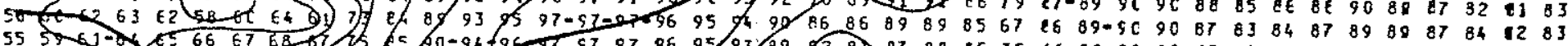

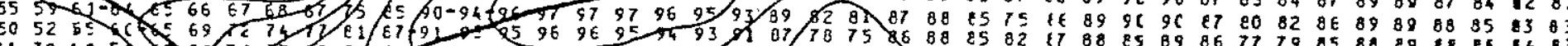

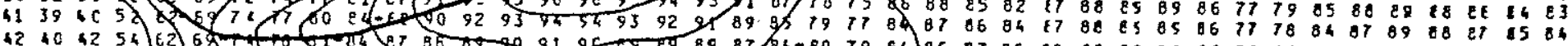

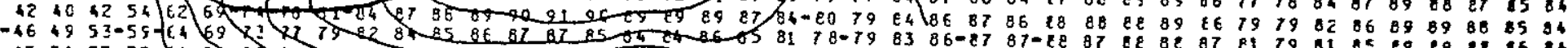

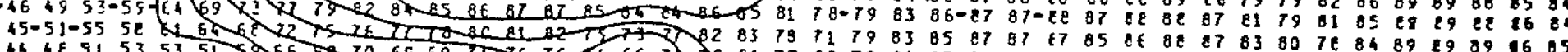

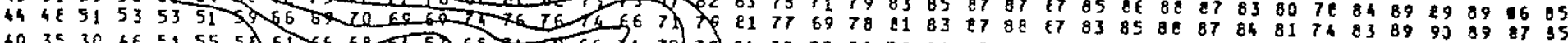

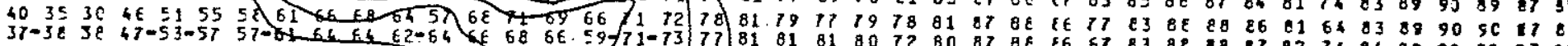

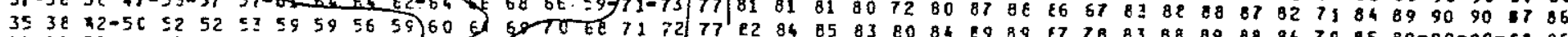

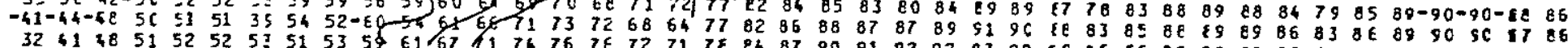

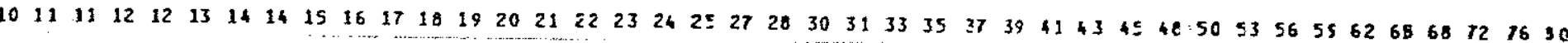

Periodo (s)

Fig. B-23 


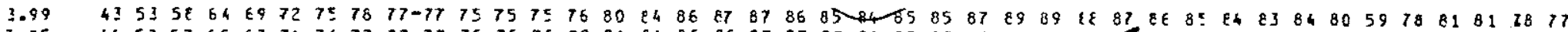

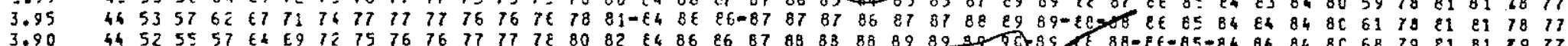

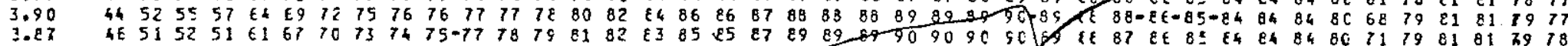

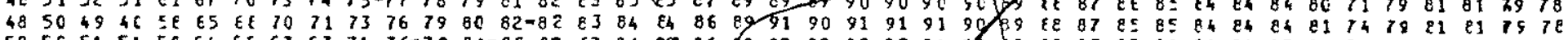

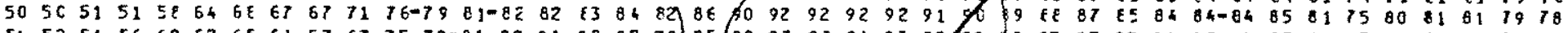

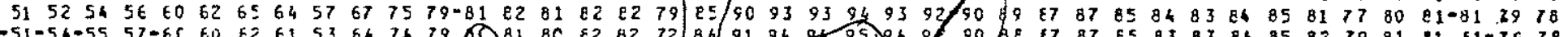
$50=5457=5 C$

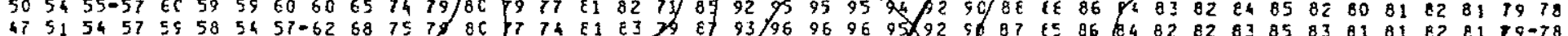

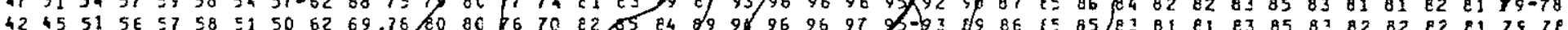

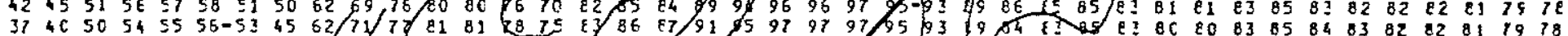

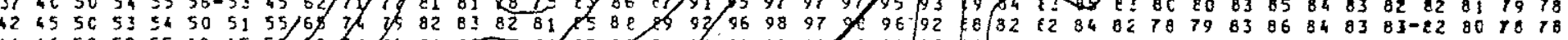

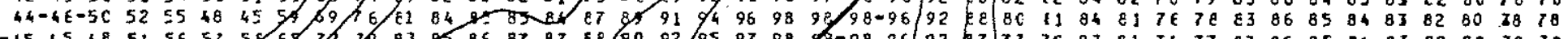

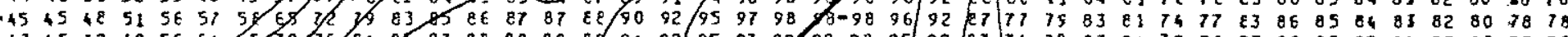

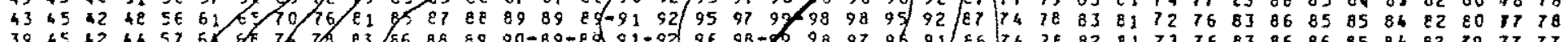

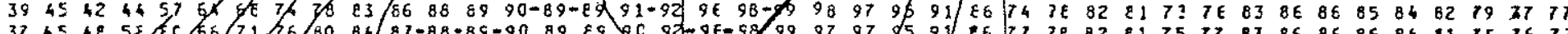

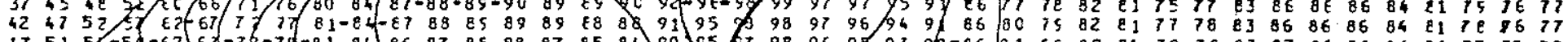

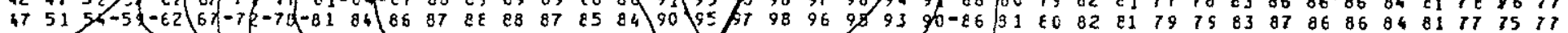

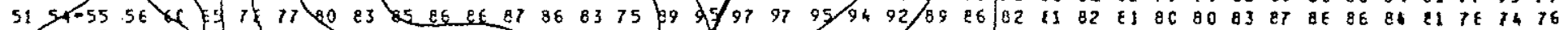

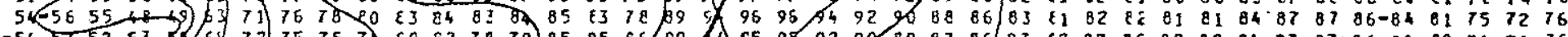

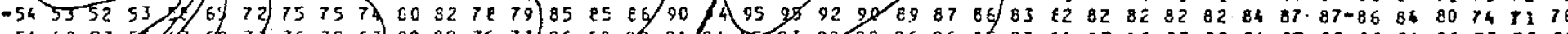

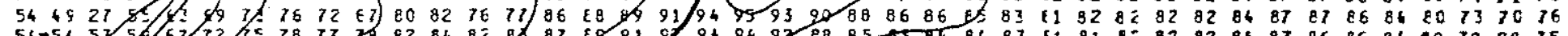
56-54

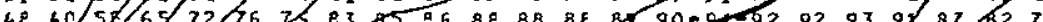
$\begin{array}{lll}-42 & 53 \\ -50 & 50\end{array}$

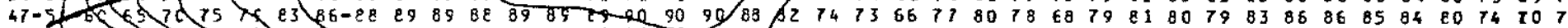

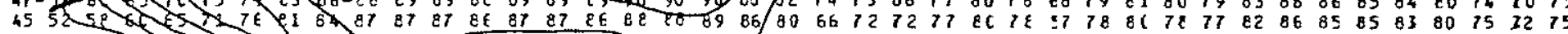

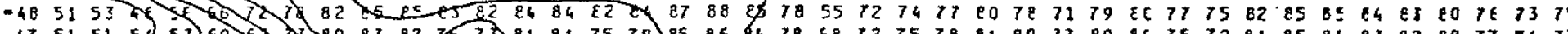

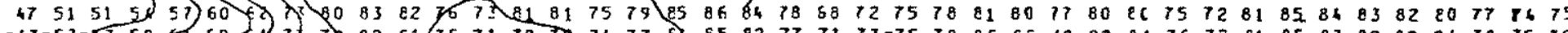

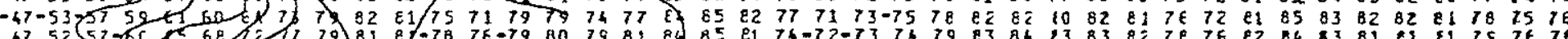

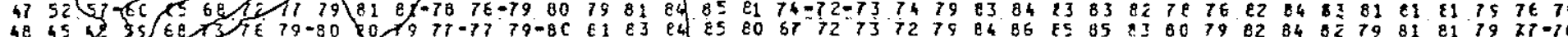

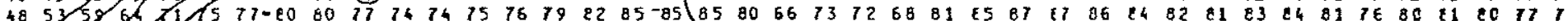

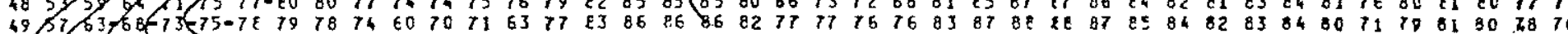

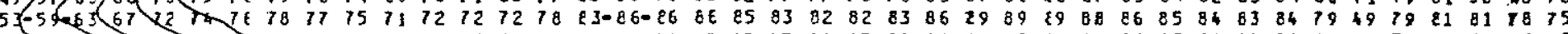

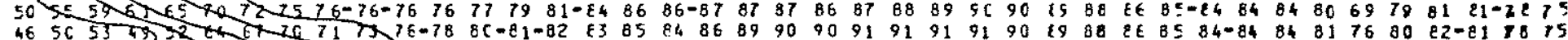

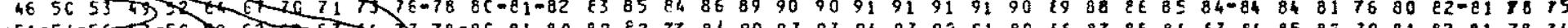

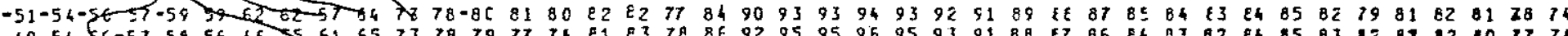

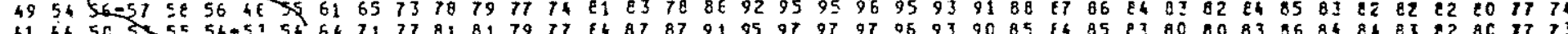

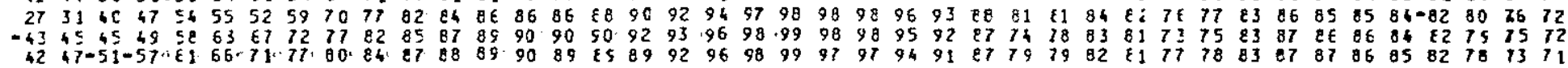

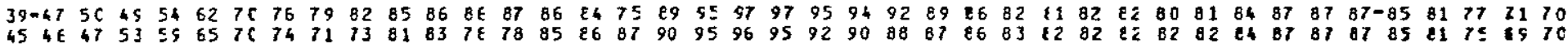

$101111 \quad 12121314141516171819202122 \quad 2324252728303133 \quad 353739414345485053565962 \quad 696872 \quad 86 \quad 80$

Período (s)

Fig. B-24 


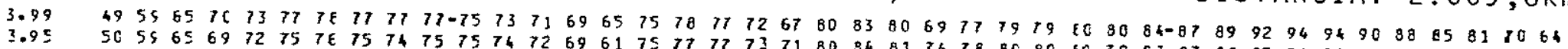

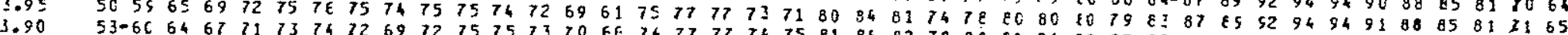

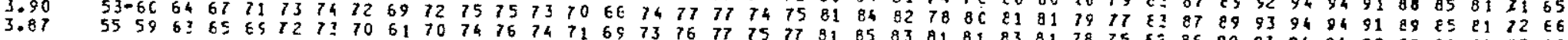

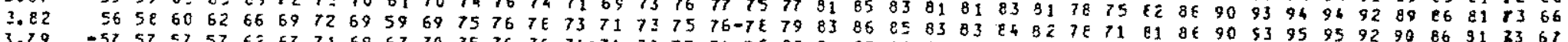

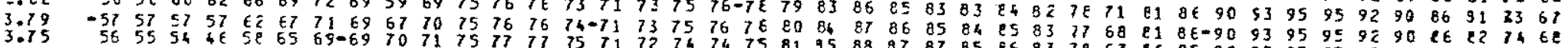

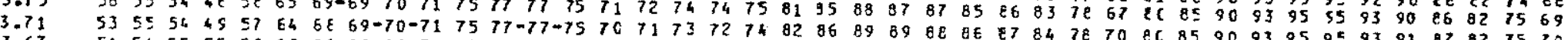

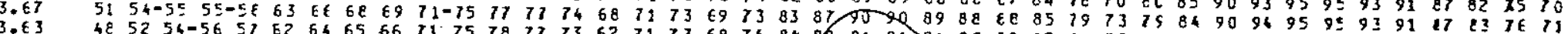
$485254-5657 \quad 526465667175787773627173687484939191918980$

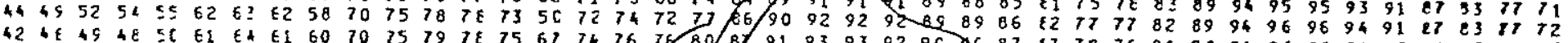

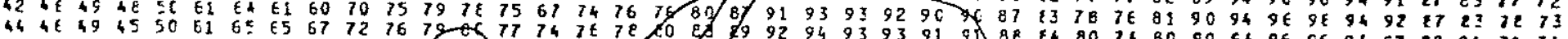

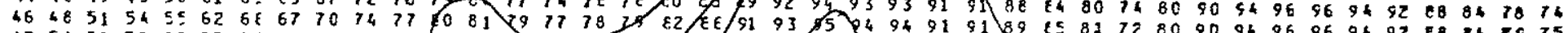

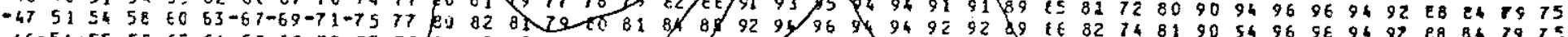

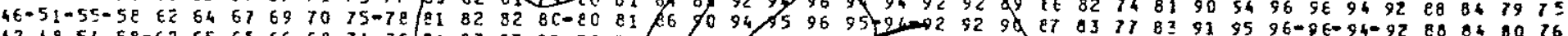

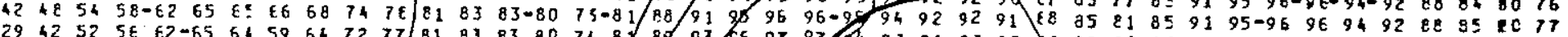
29 35 (5)

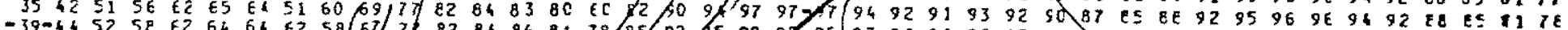
$3342536 C 52650358$

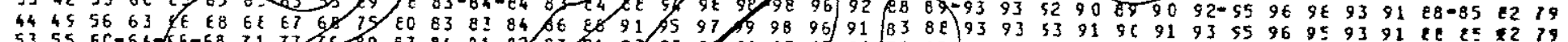

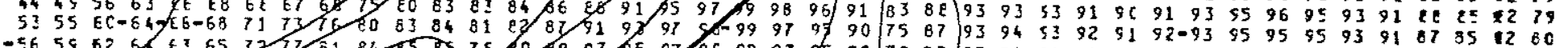

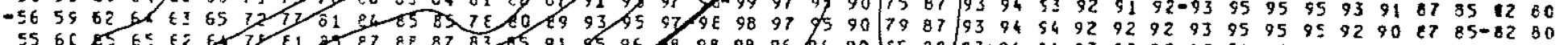

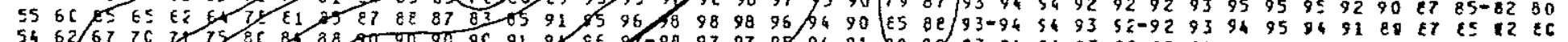

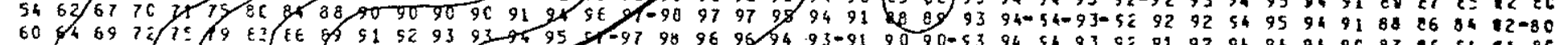

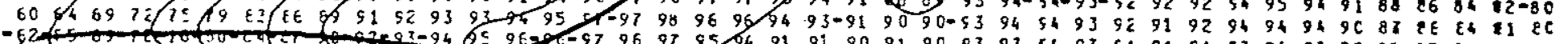

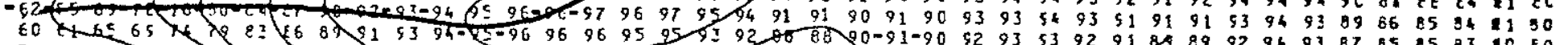

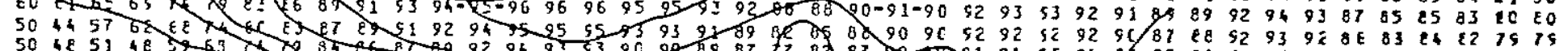

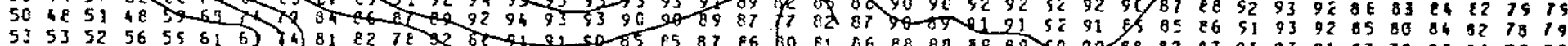

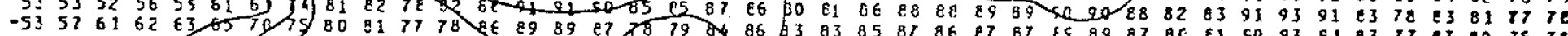

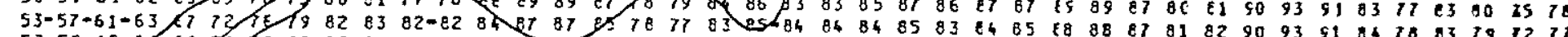

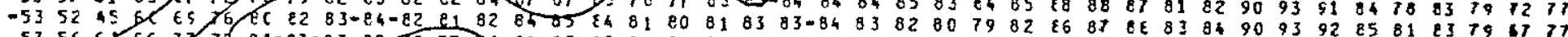

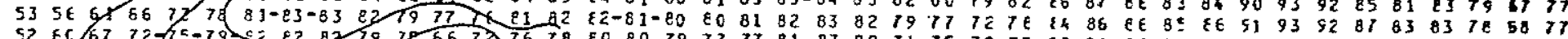

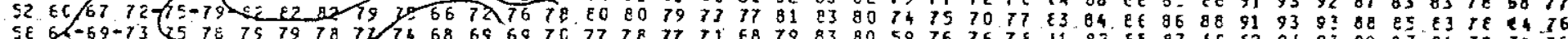

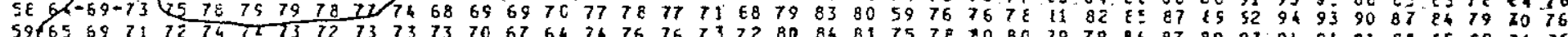

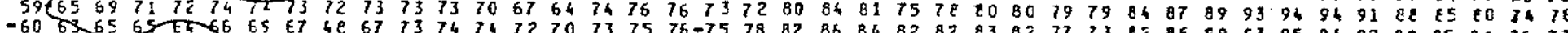

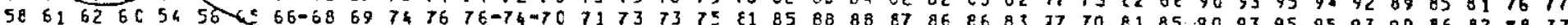

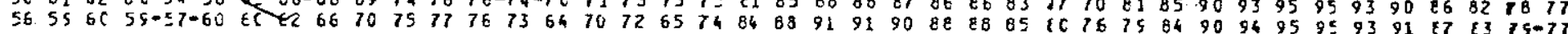

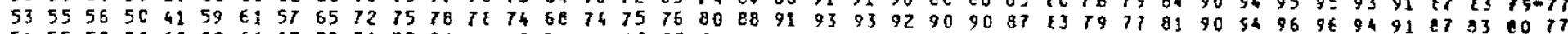

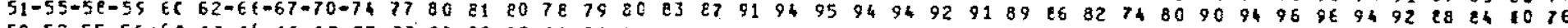

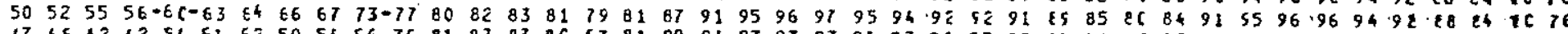
(69.

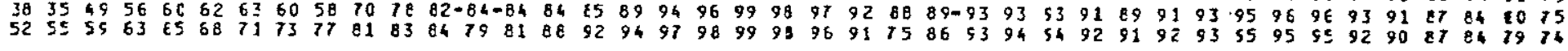

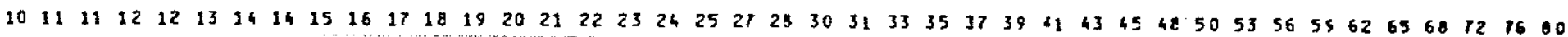

$$
\text { Período (s) }
$$

Fig. B -25 


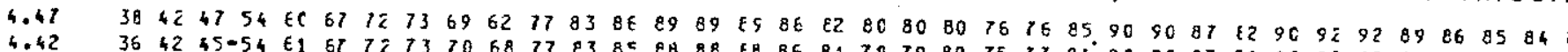

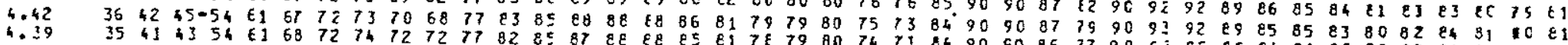

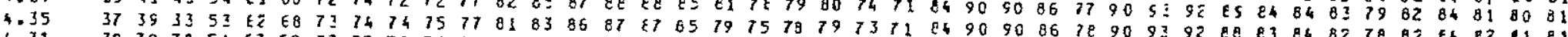

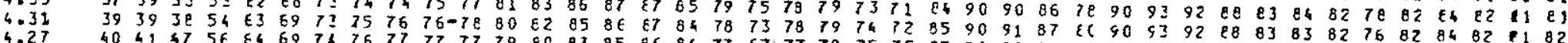

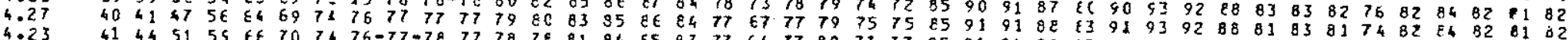

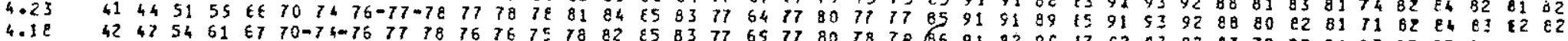

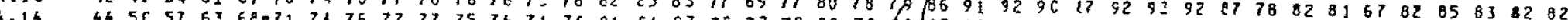

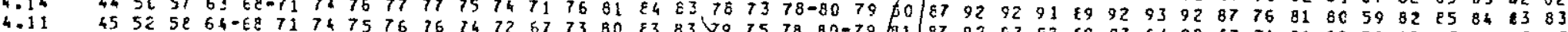

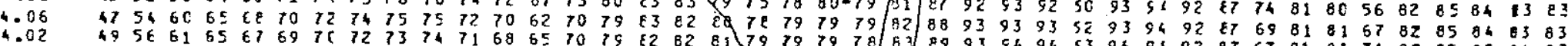
3.02

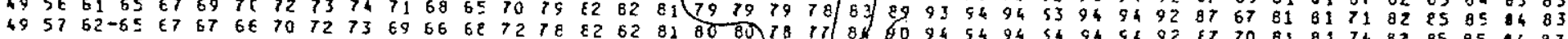

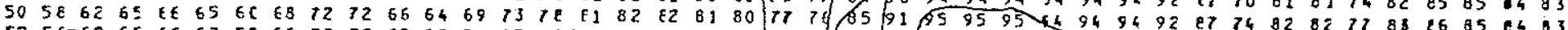

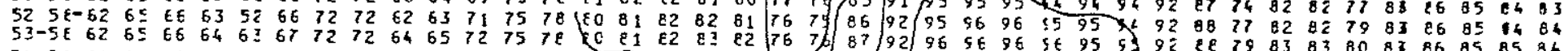

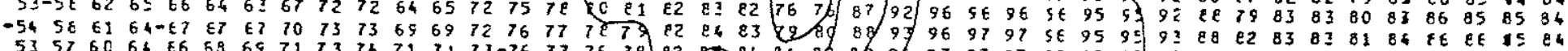

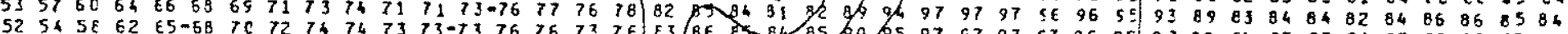

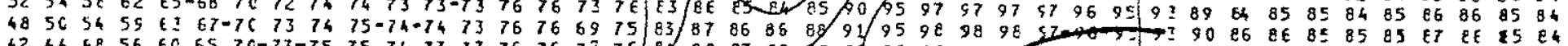

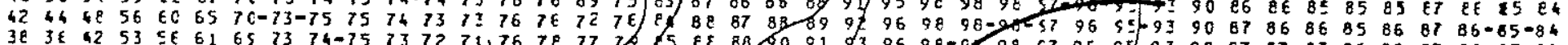

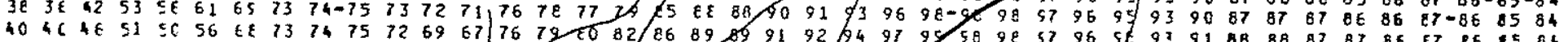

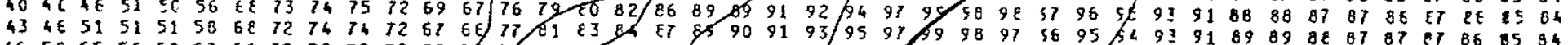

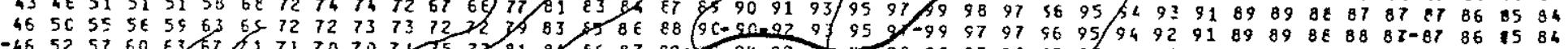

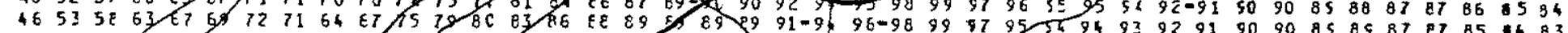

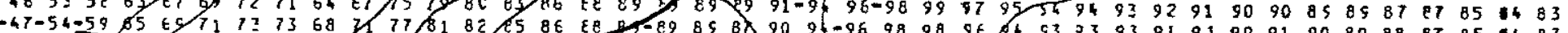

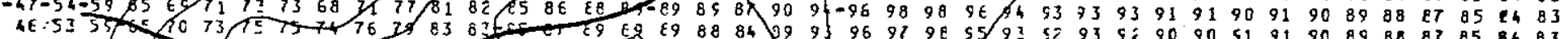

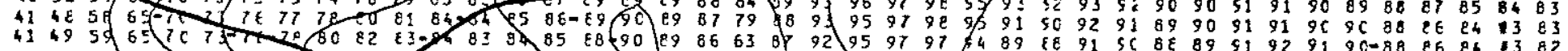

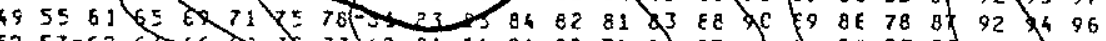

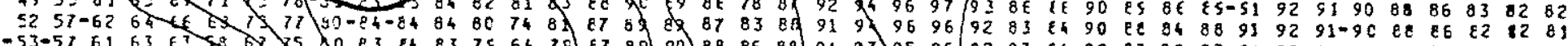
(1)

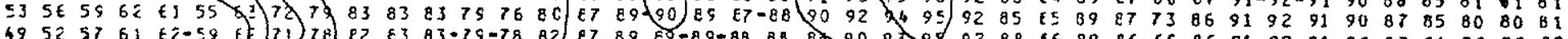

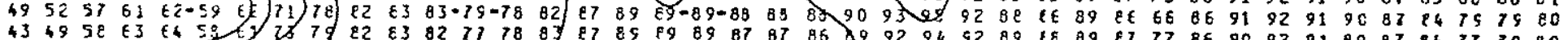

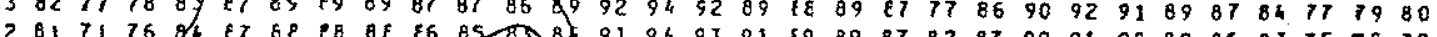

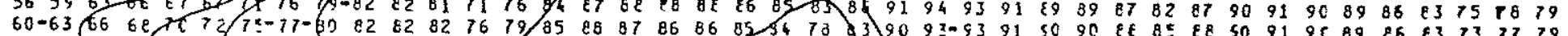

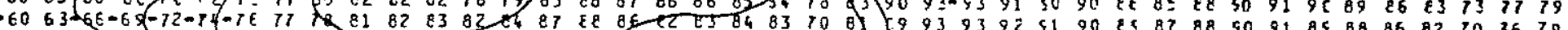

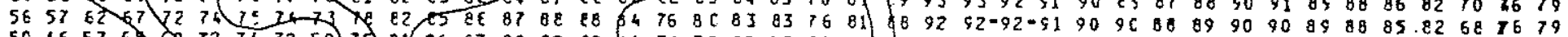

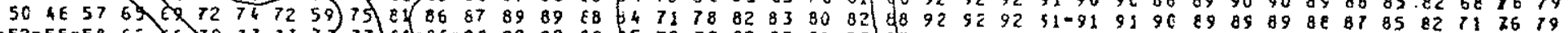

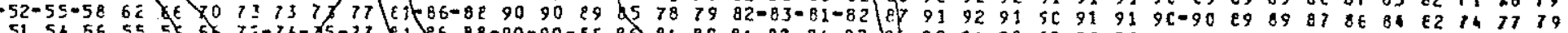

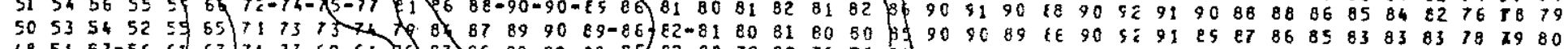

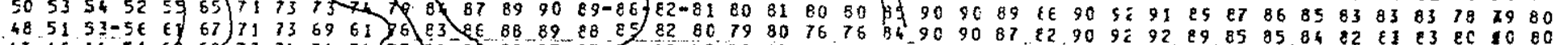

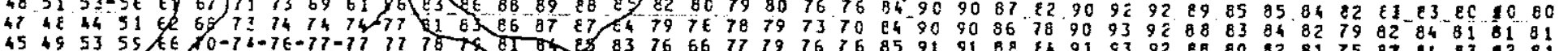

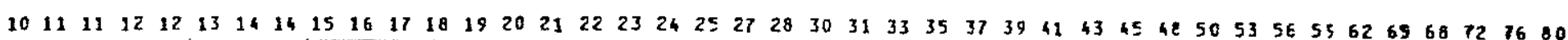
Período (s)

Fig. B-26 


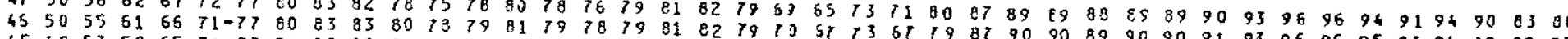

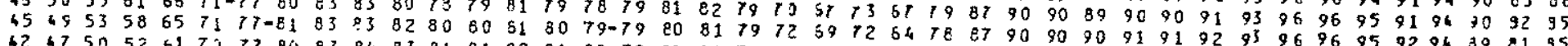

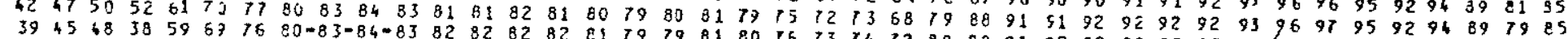

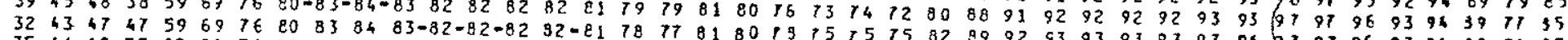

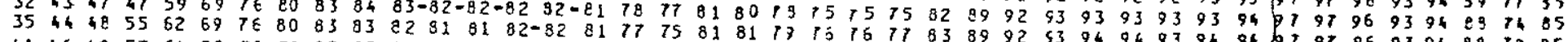

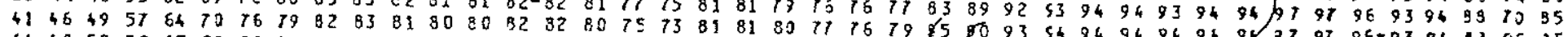

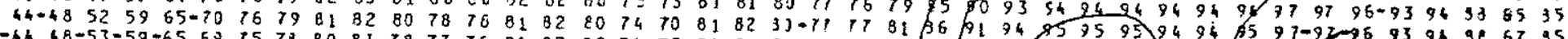

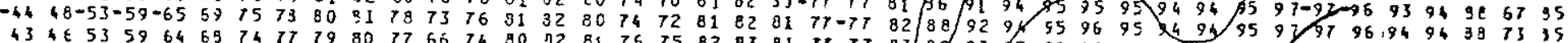

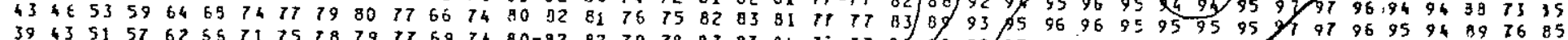

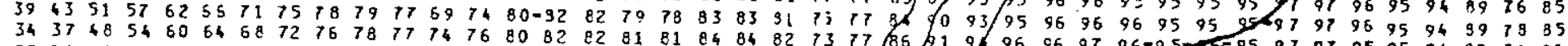

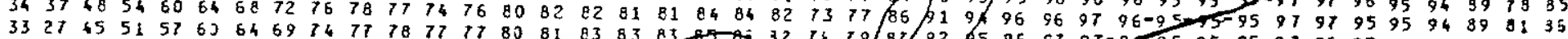

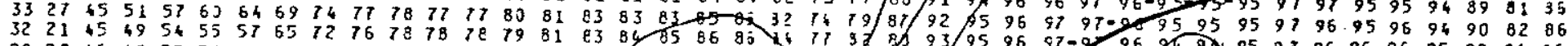

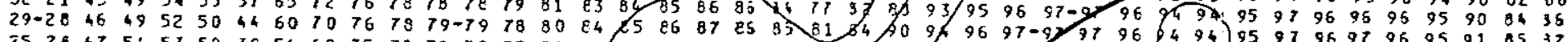

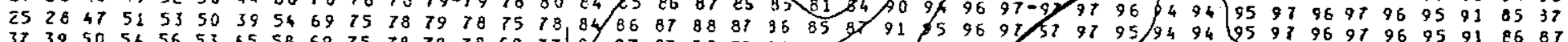

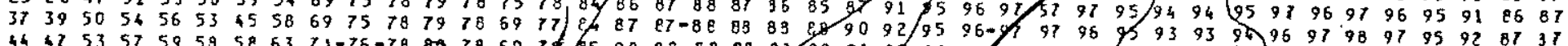

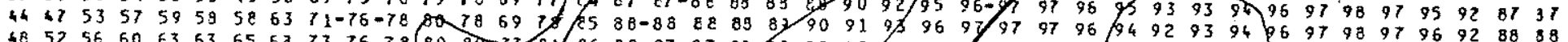

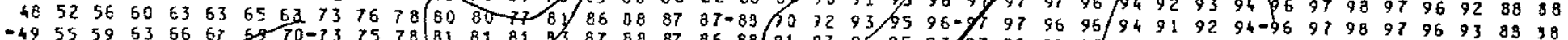

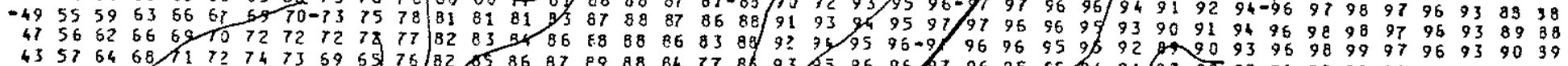

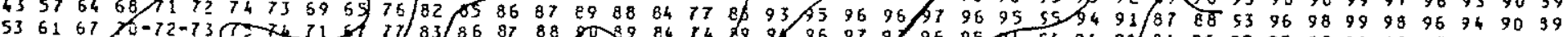

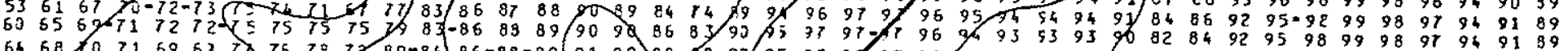

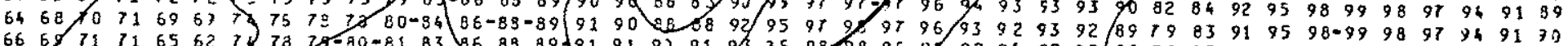

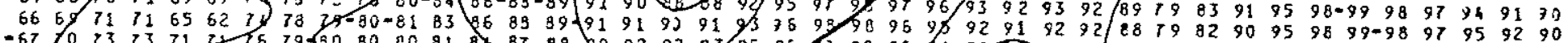

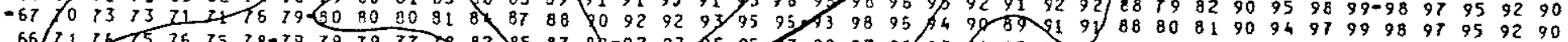

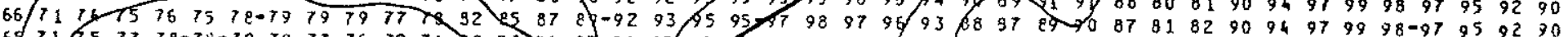

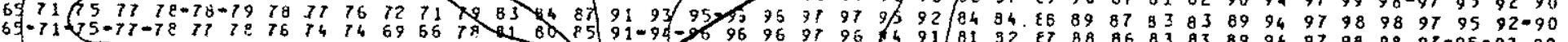

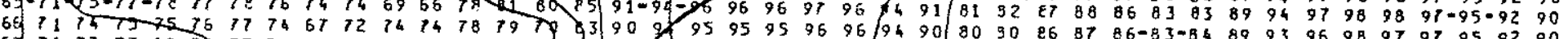

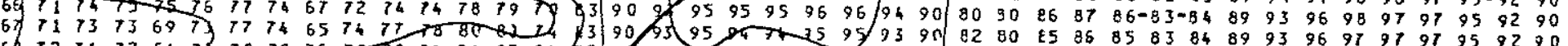

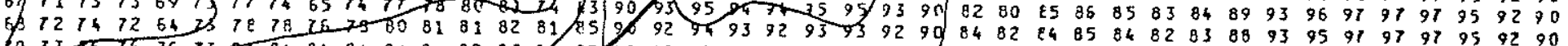

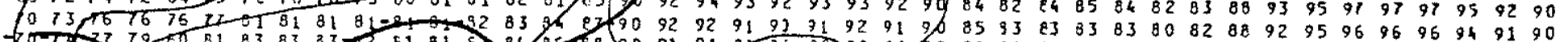
-

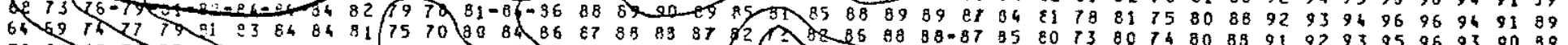

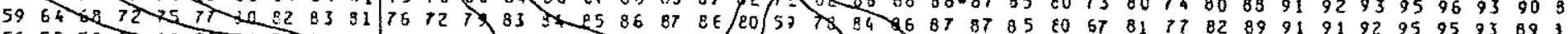

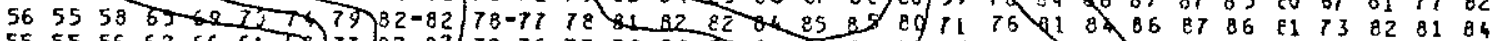

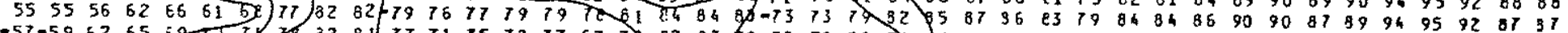

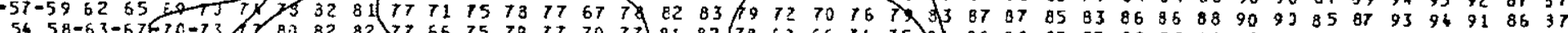
54 56 61 54

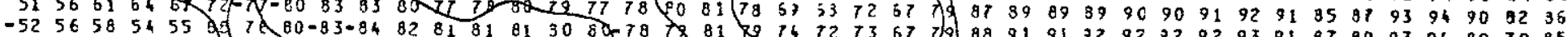

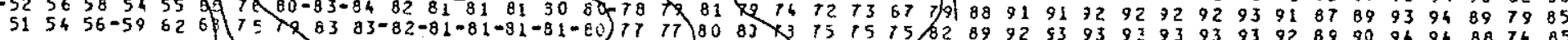

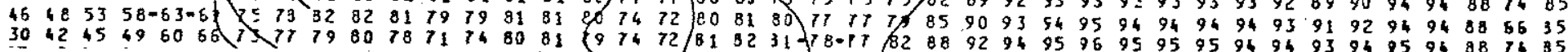

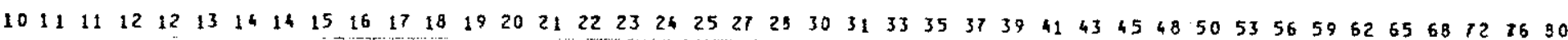
Período (s)

Fig. B- 27 


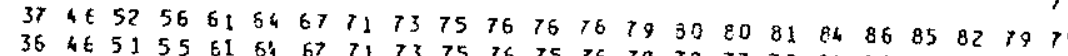

DISTĀNCIA: $3.512,7 \mathrm{~km}$

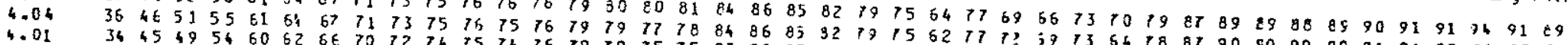

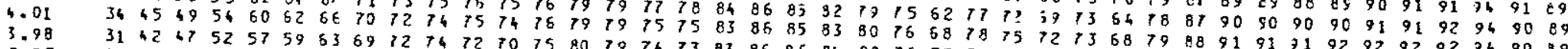

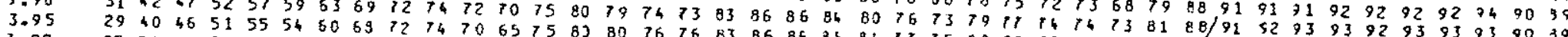

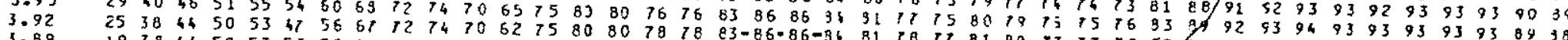

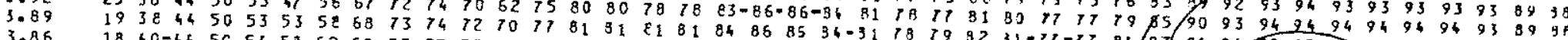

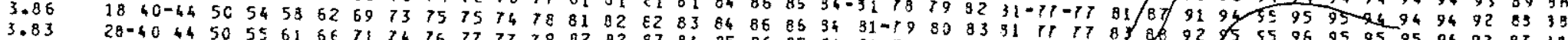

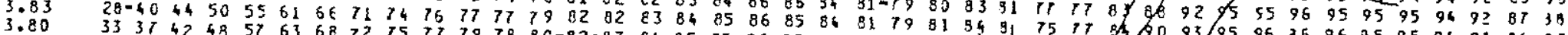

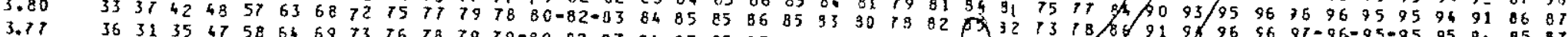

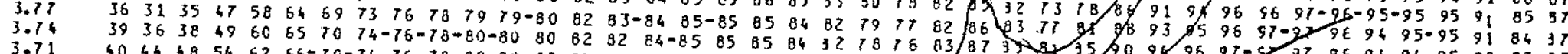

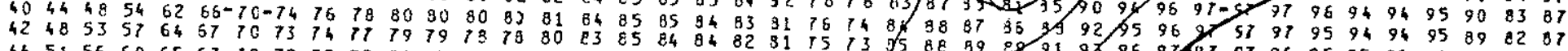

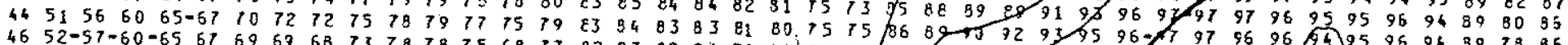

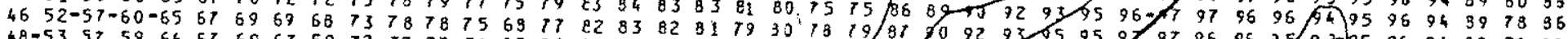

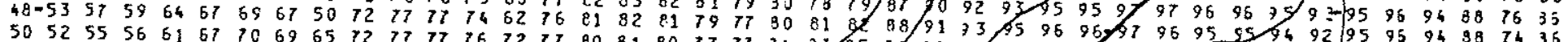

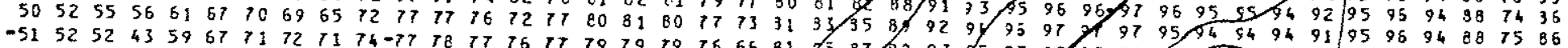

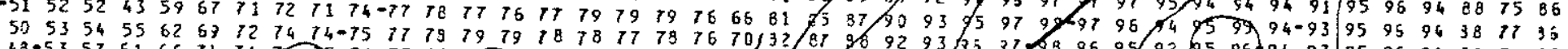

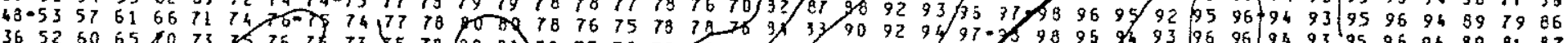

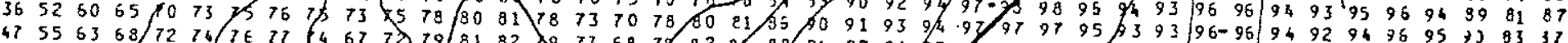

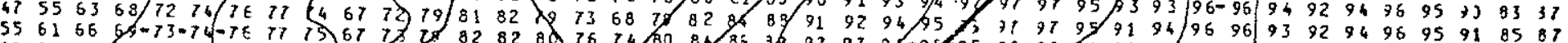

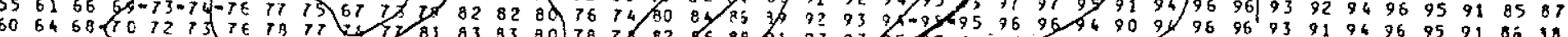

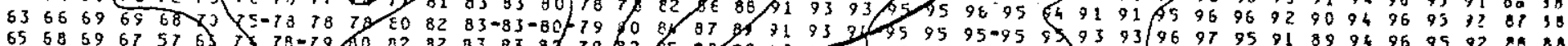

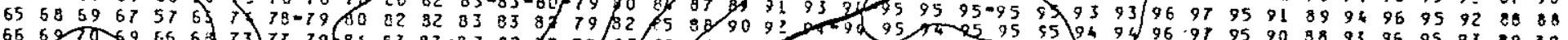

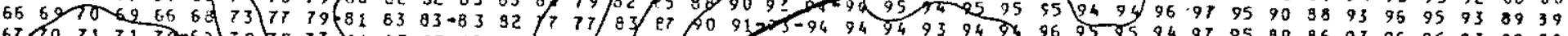
67. 67

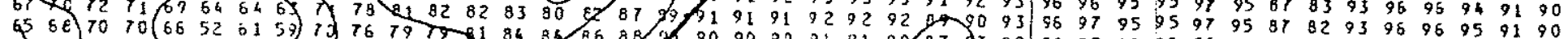

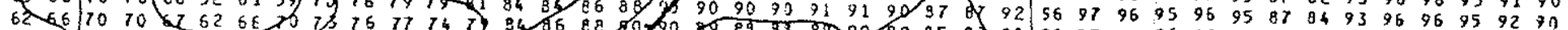

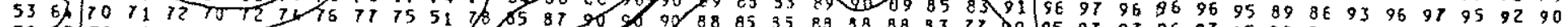

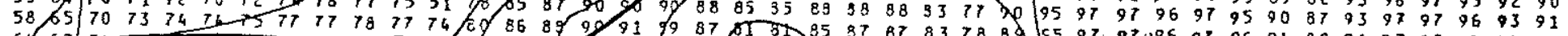

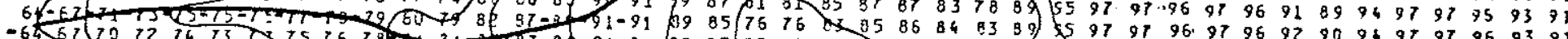

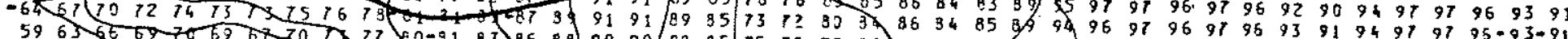

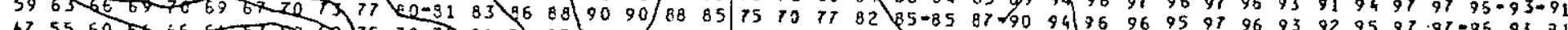

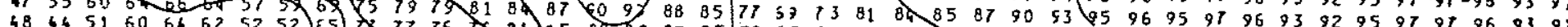

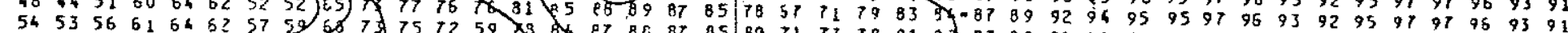

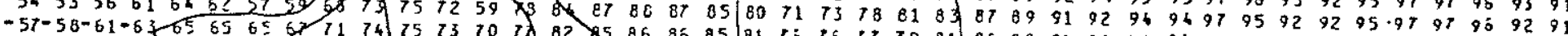

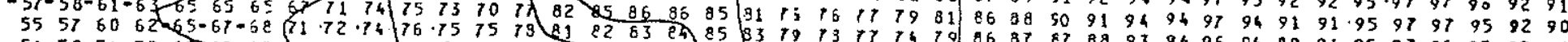

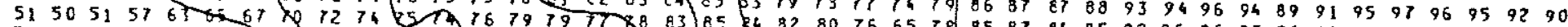

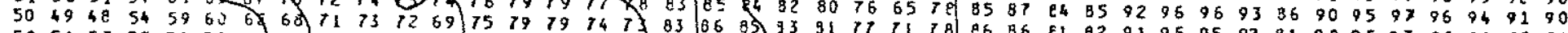

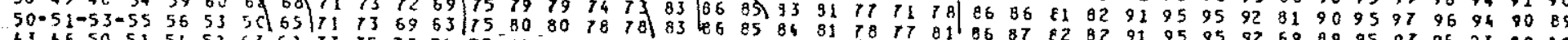

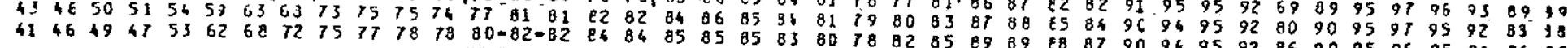

$101111121213141415161718192021222324252728303133 \quad 353739414345485053565962 \quad 658872 \quad 7680$

Período ( $\mathrm{s}$ )

Fig. B-28 


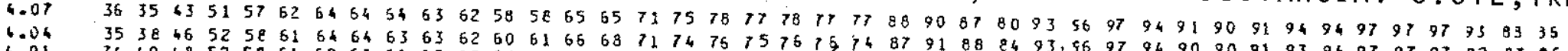

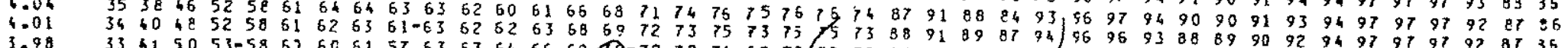

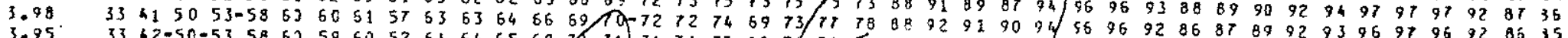

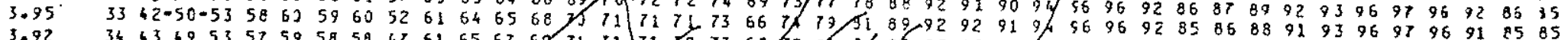

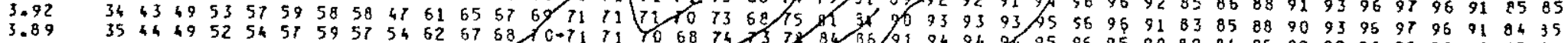

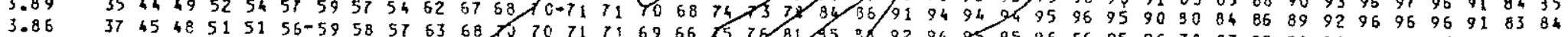

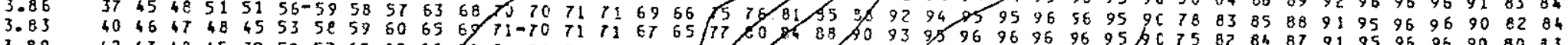
$\begin{array}{llllllllll}3.80 & 62\end{array}$

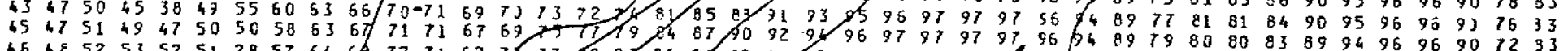

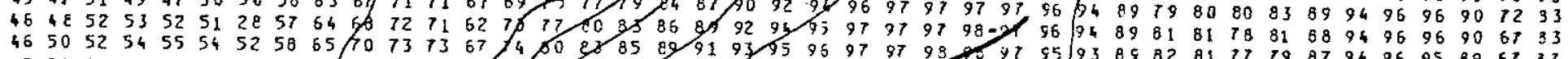

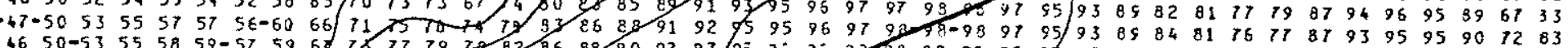

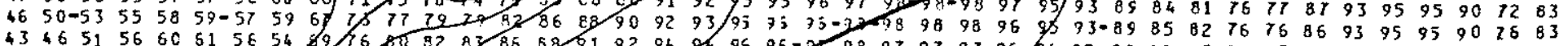

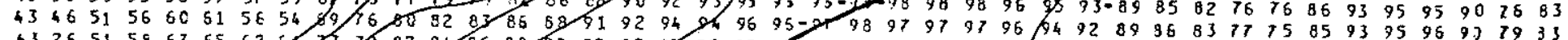

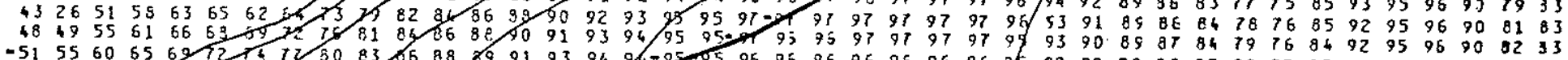

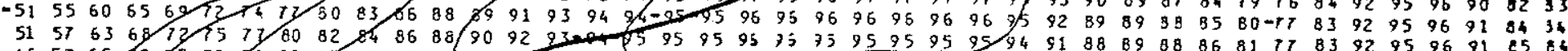

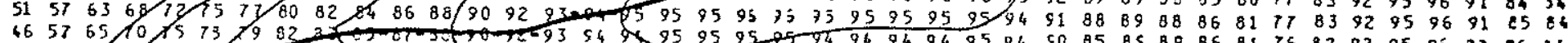

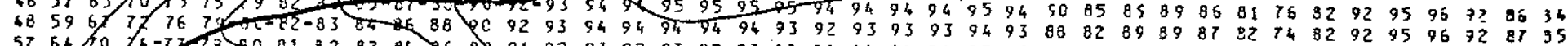

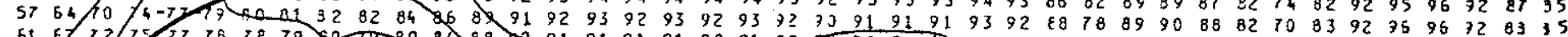

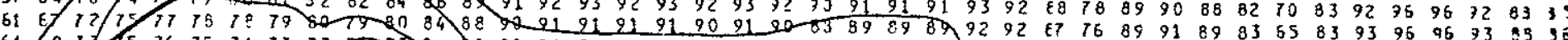

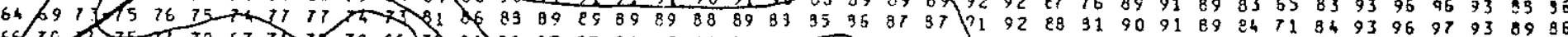

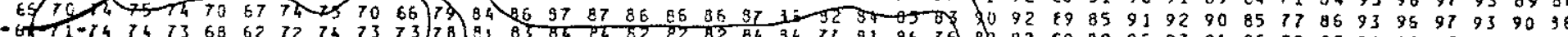
- G

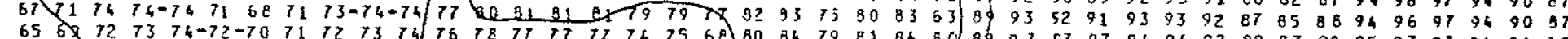

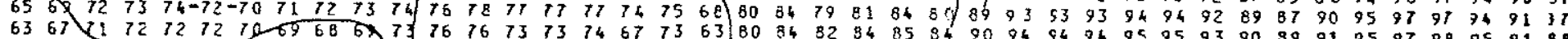

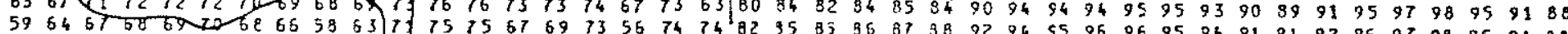

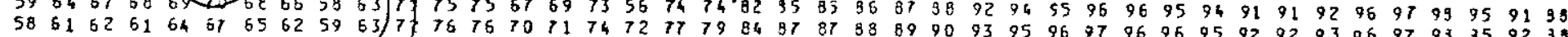

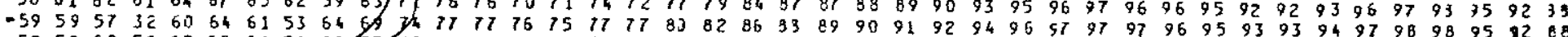

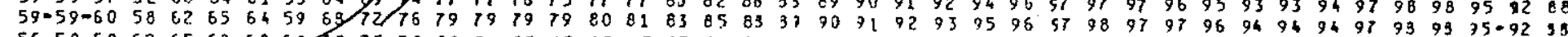

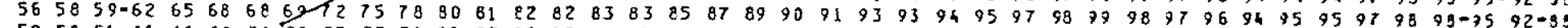

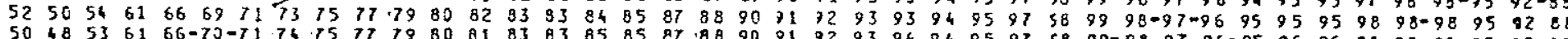

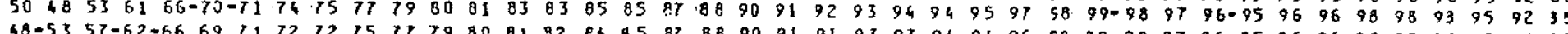

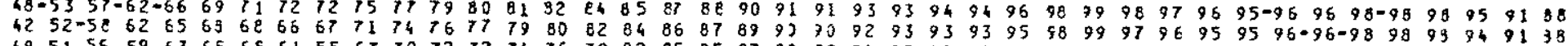

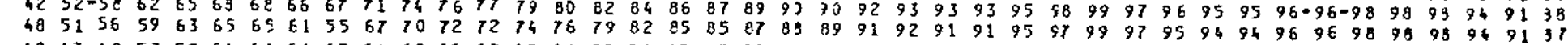

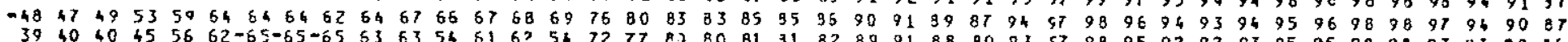

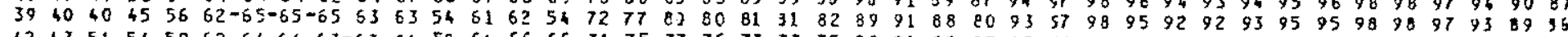

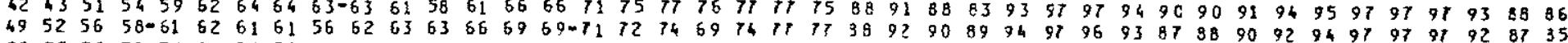

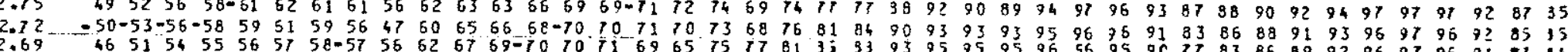

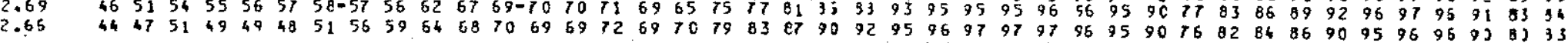

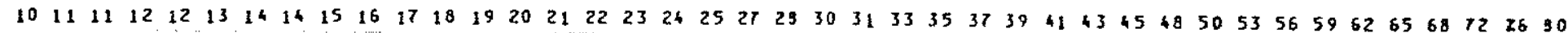
Período (s)

Fig. B-29 


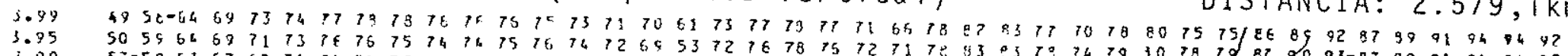

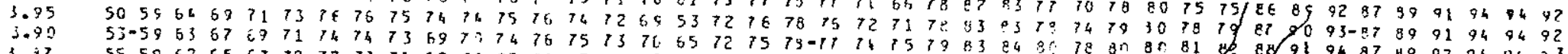

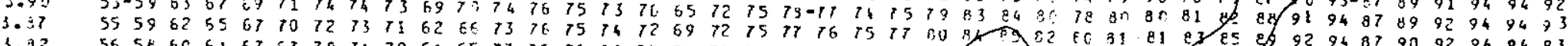

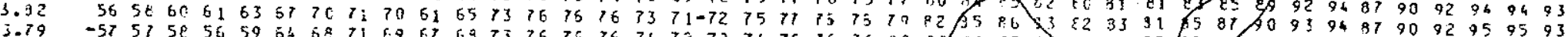

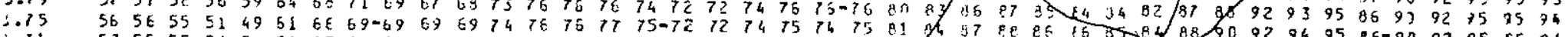

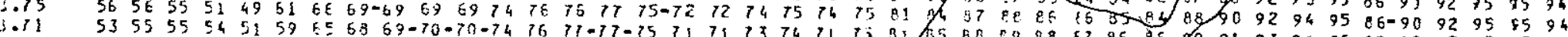

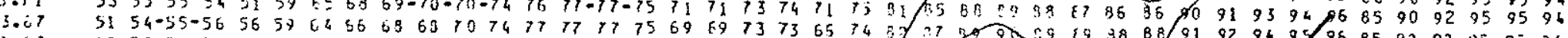

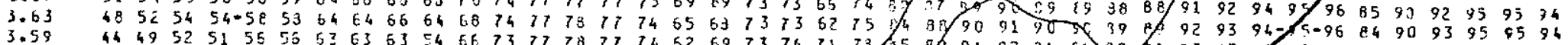

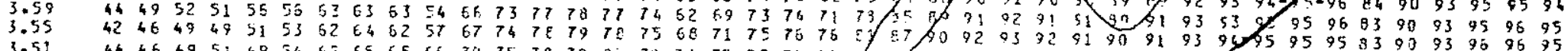
444649524954626565667075787986787475777937 \%

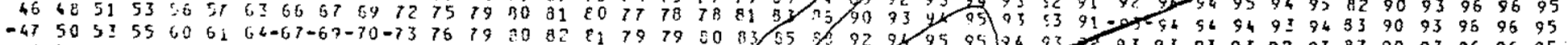

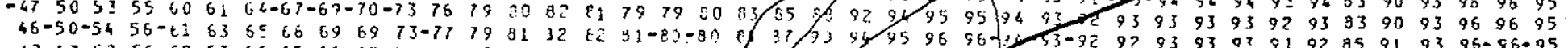

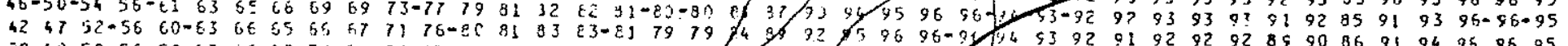

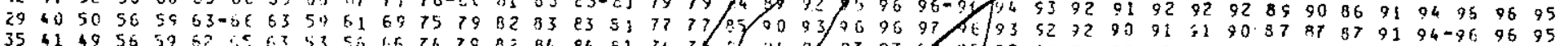

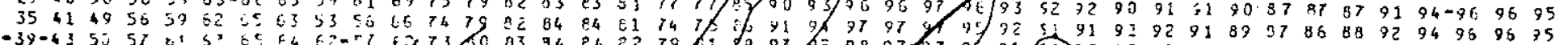

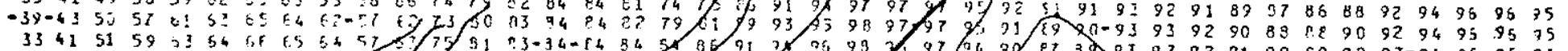

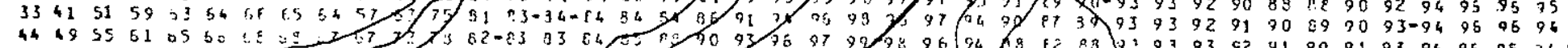

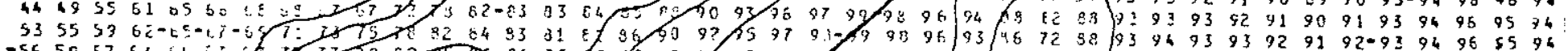

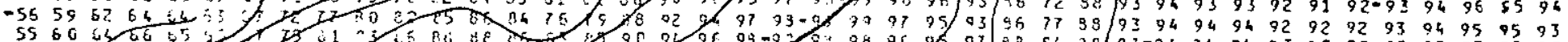

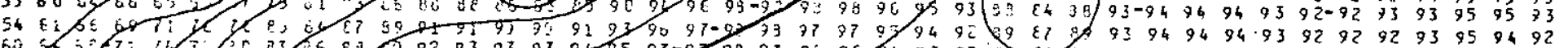

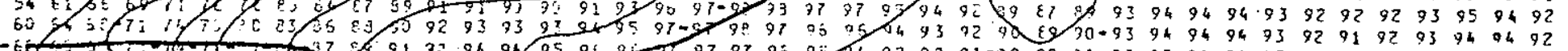

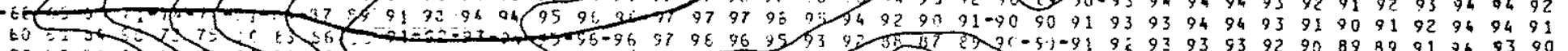

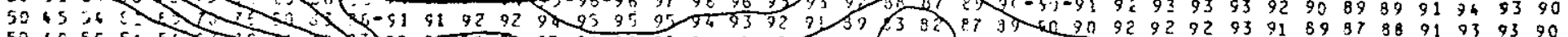

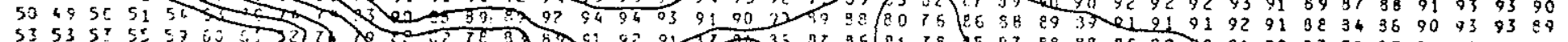

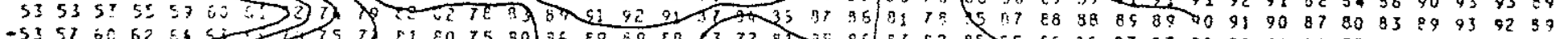

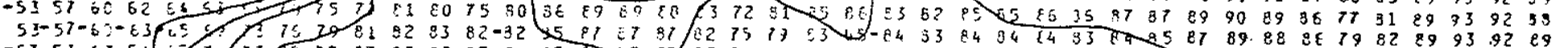

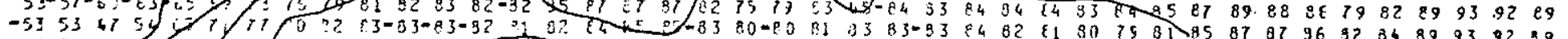

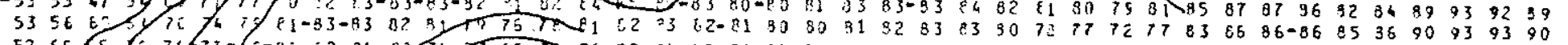
52 50.5 . S9-64.

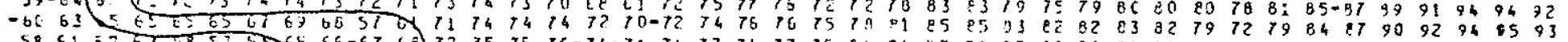

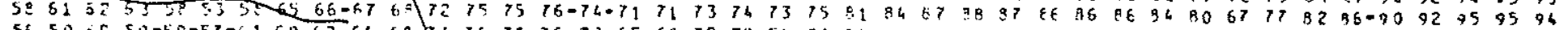

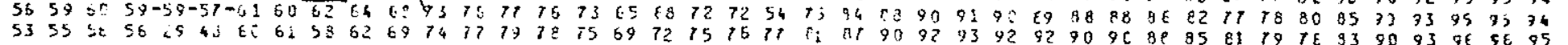

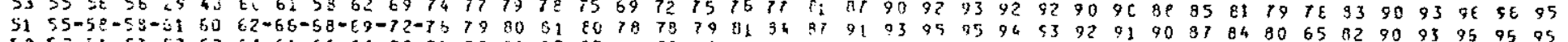

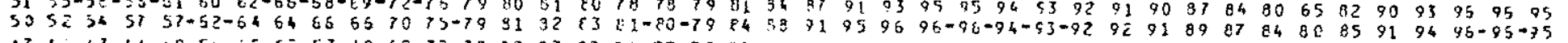

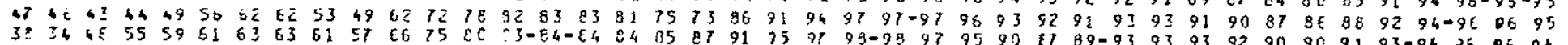

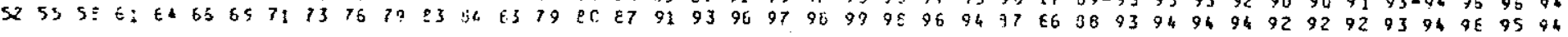

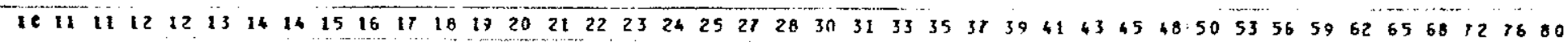
Período (s)

Fig. $B-30$ 


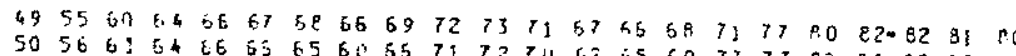

DISTANNCIA: $2.579,1 \mathrm{~km}$

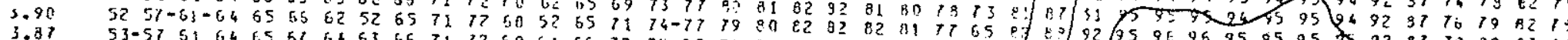

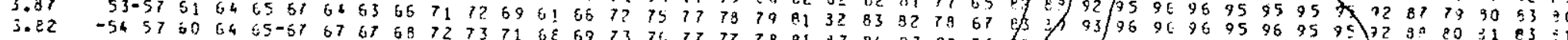

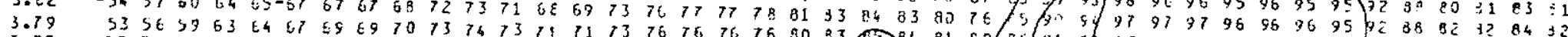

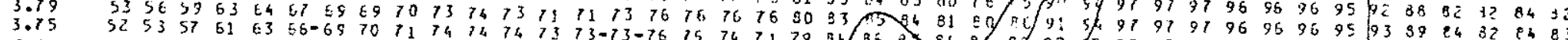

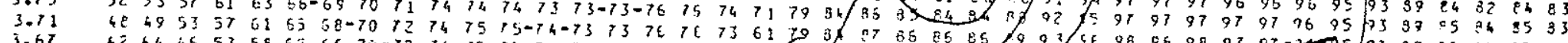

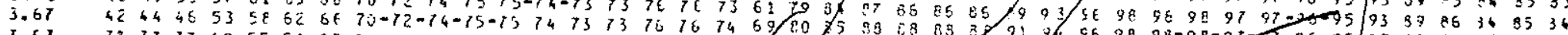

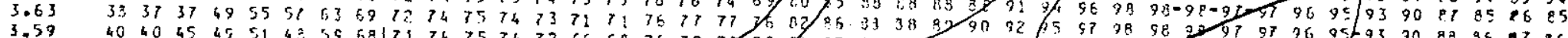

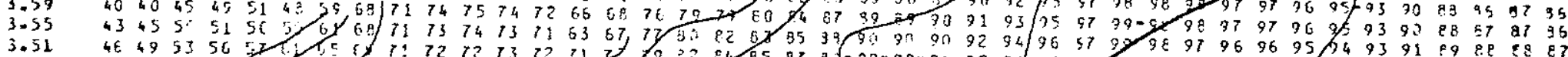

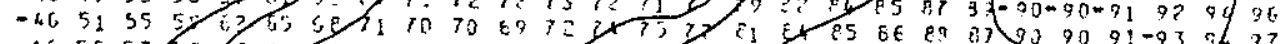

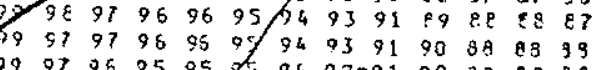

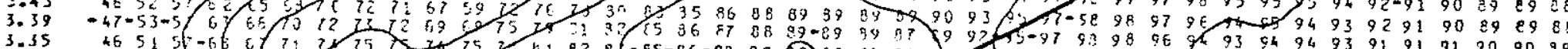

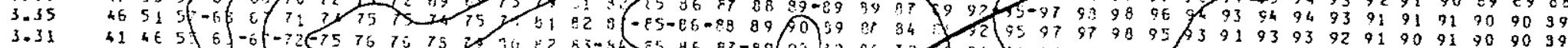

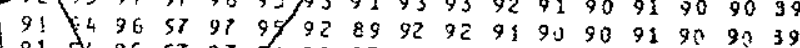

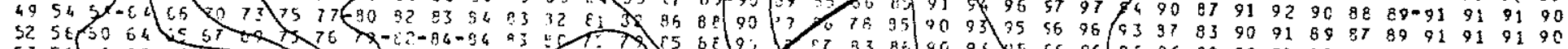

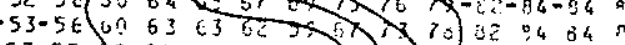

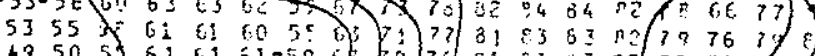

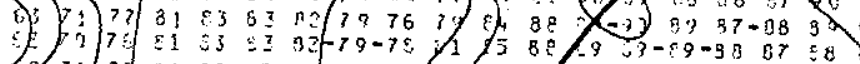

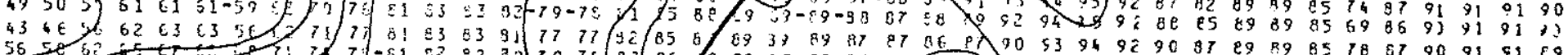

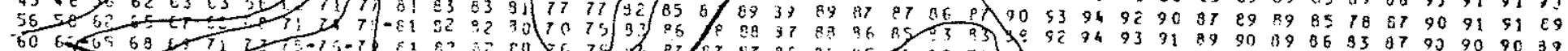
-60-60:500

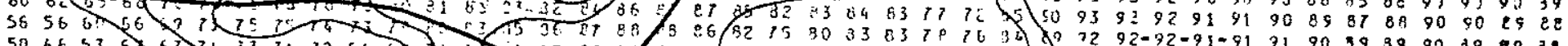

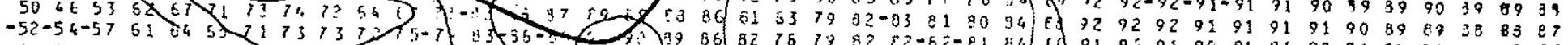

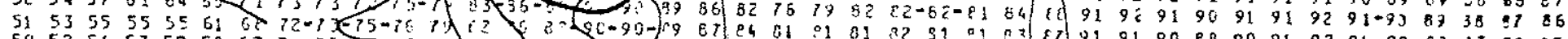

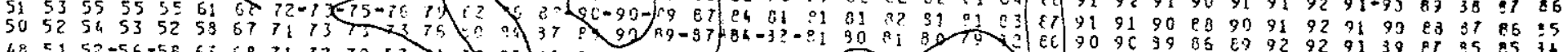

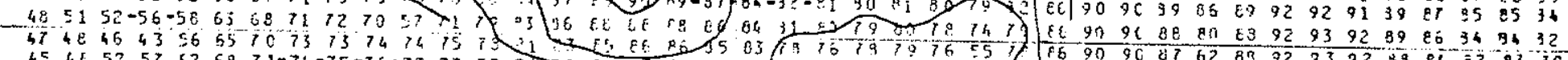

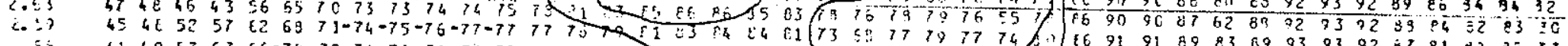

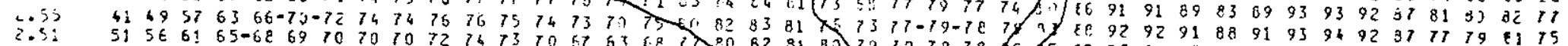

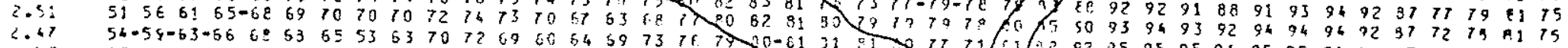

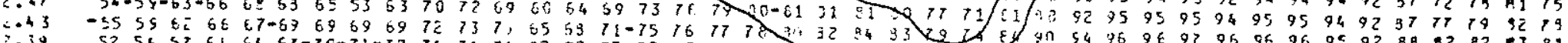

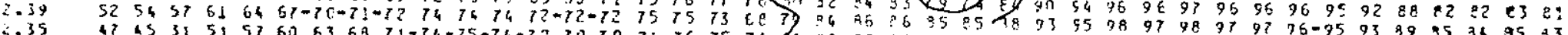

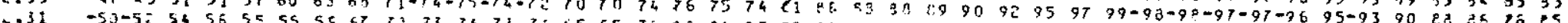

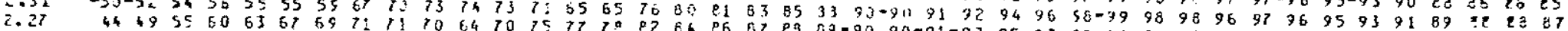

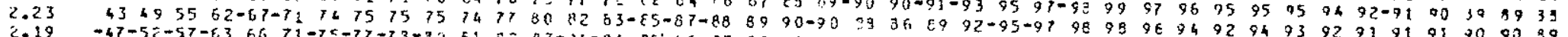

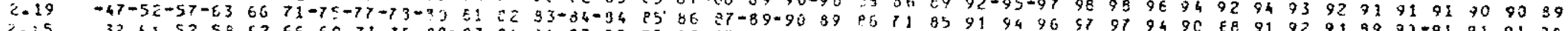

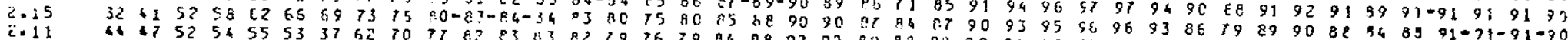

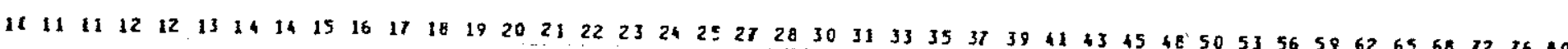
Perĩodo (s)

Fig. B-3] 


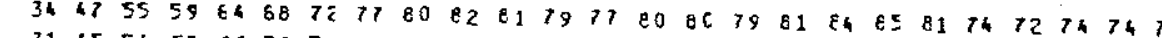

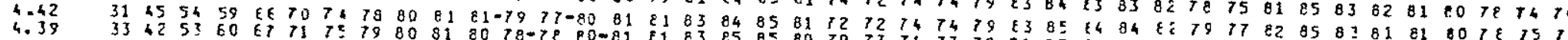

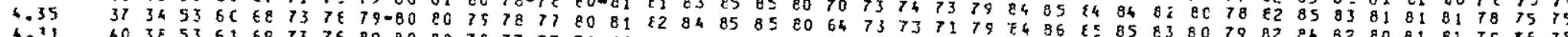

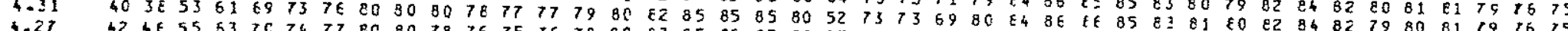

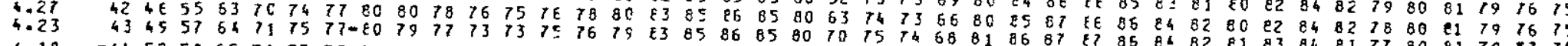

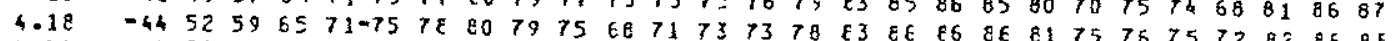

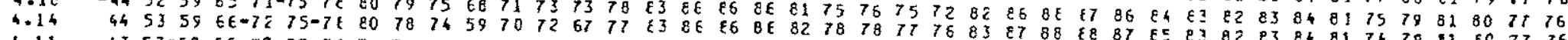

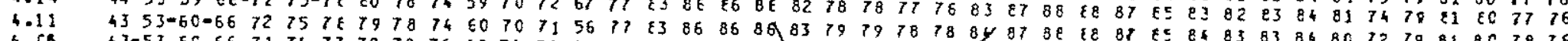

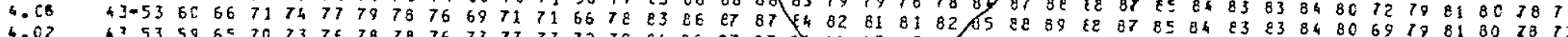

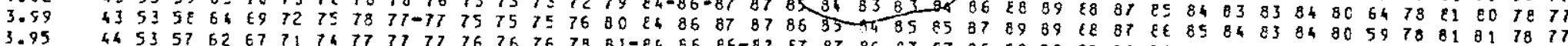

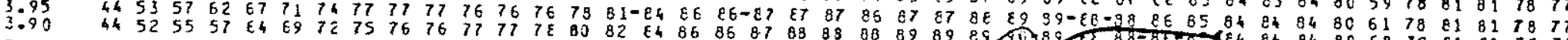

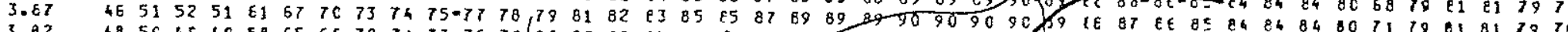

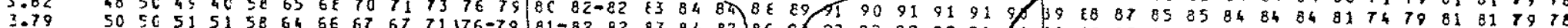

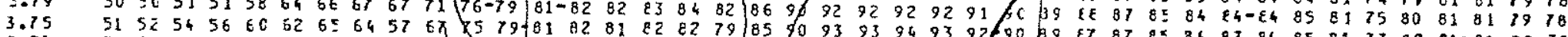

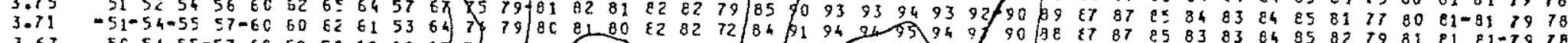

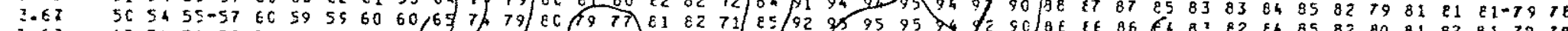

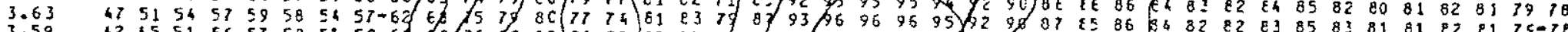

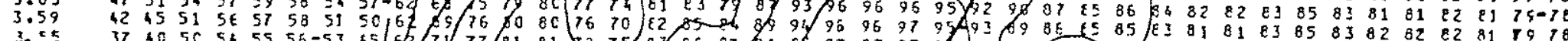
3. 3.51

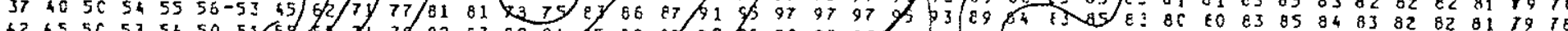

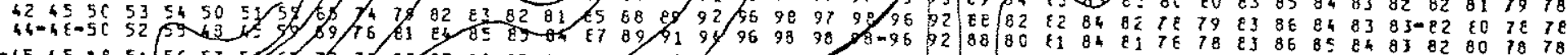

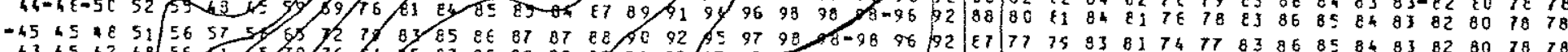

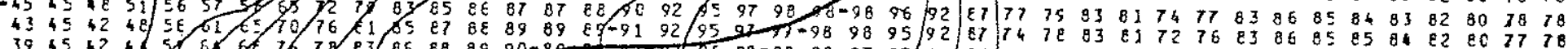

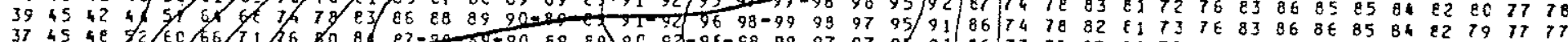

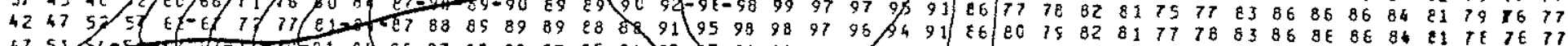

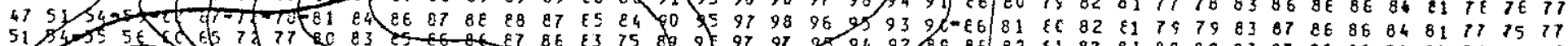

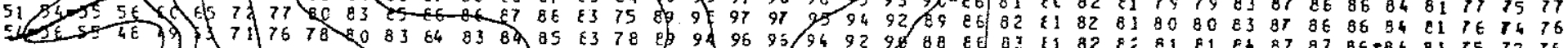

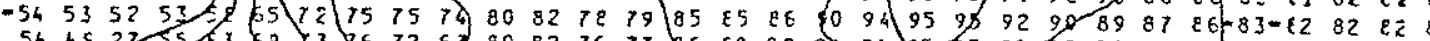

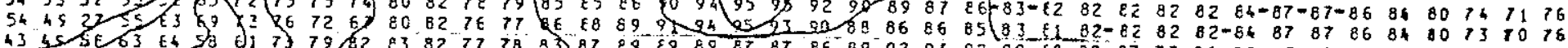
द 5563

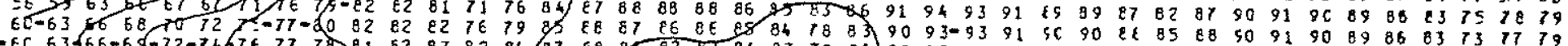

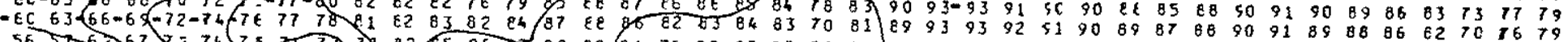

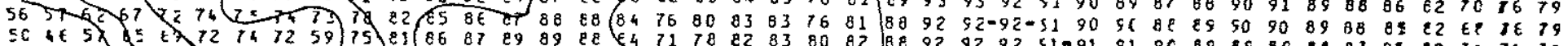

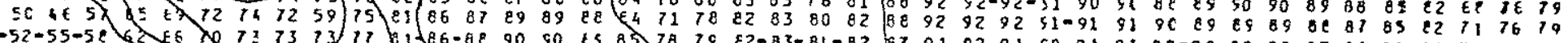

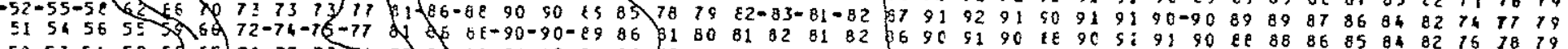

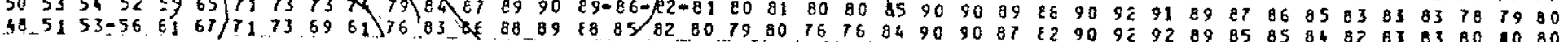

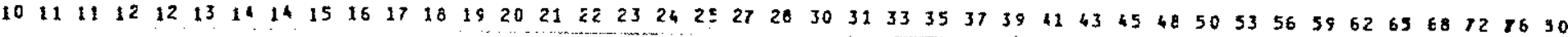

$$
\text { Período (s) }
$$

Fig. B-32 


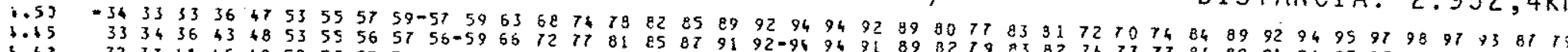

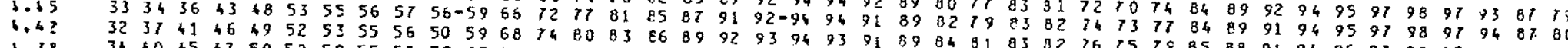

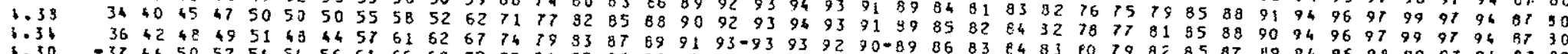

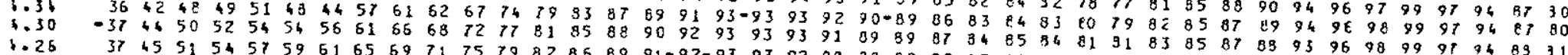

$\because \cdot 2 ?$

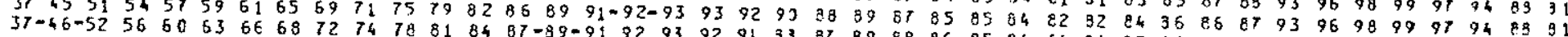

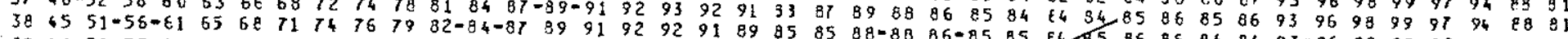

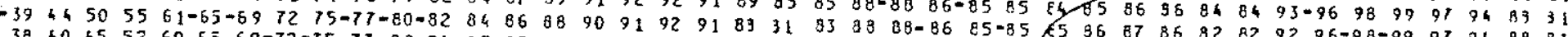

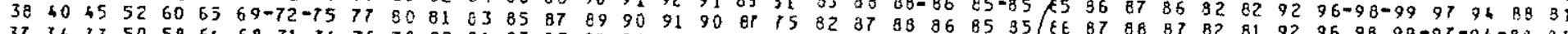

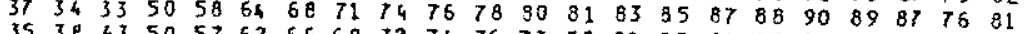

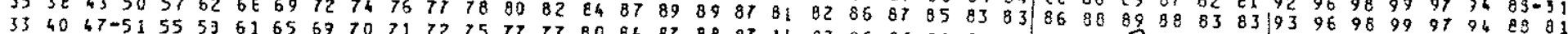

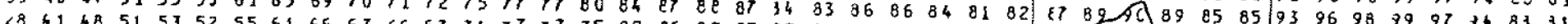

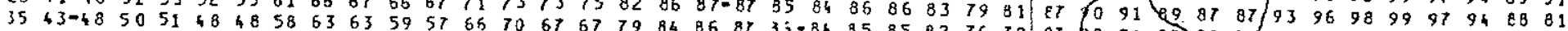

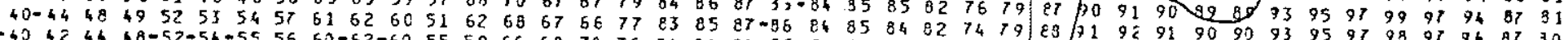

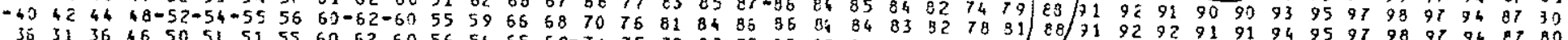

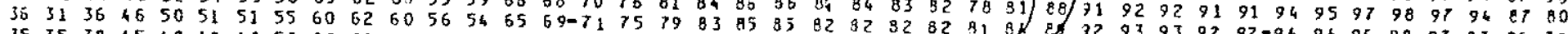

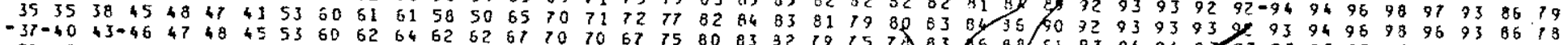

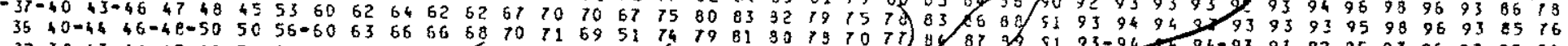

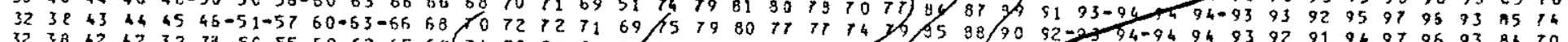

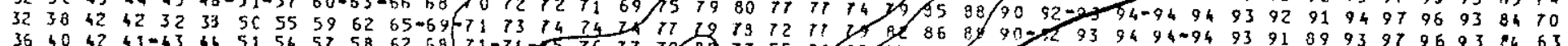

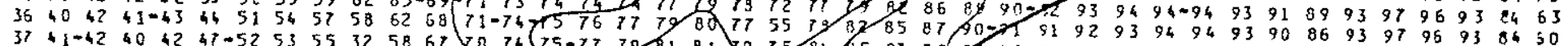

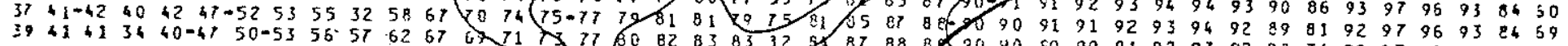

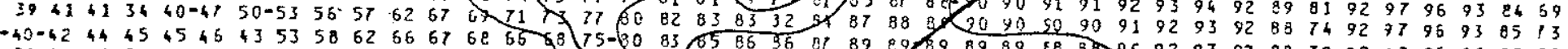

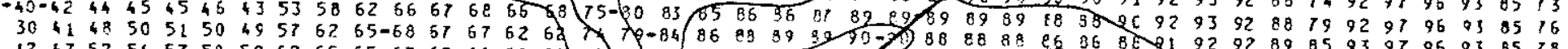

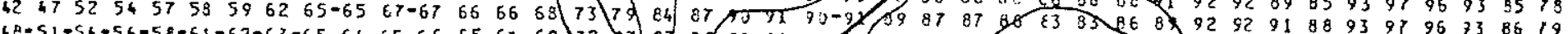
40.5 $434464304655596059525553 \quad 32$ (3)

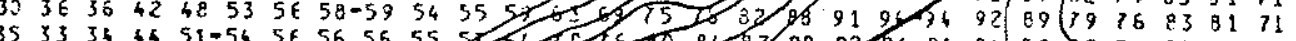

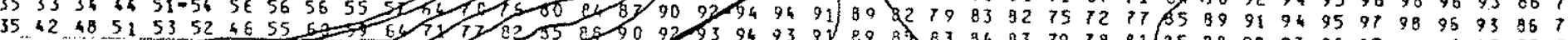

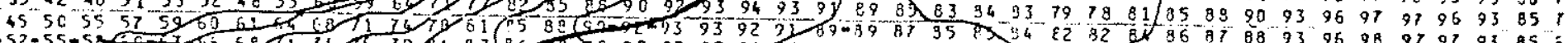

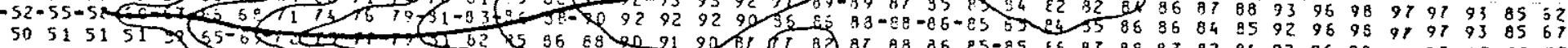
414750.5257 C5 L

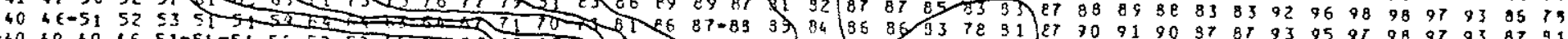

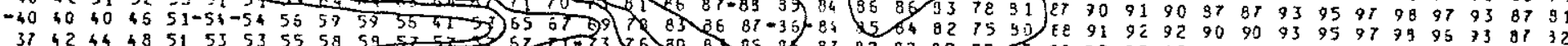

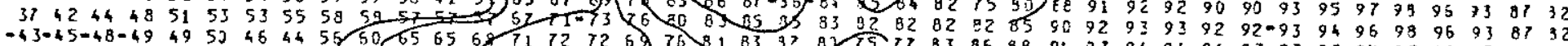

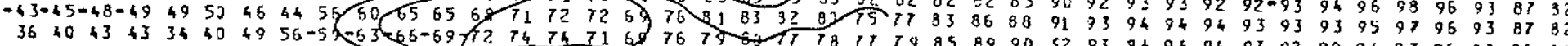

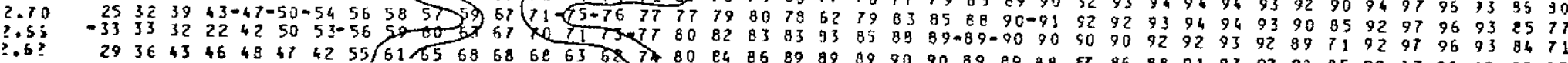

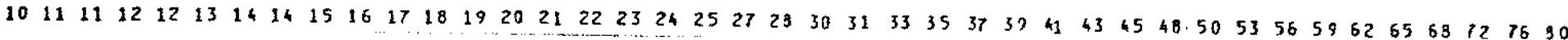
Período (s)

Fig. B -33 


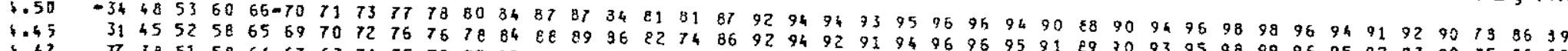

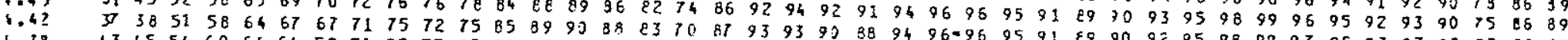

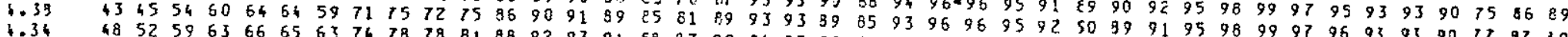

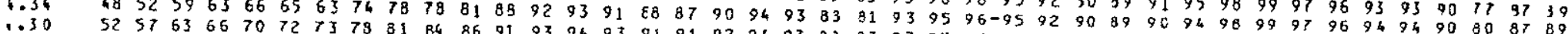

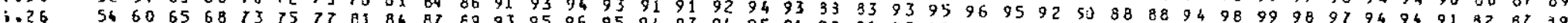

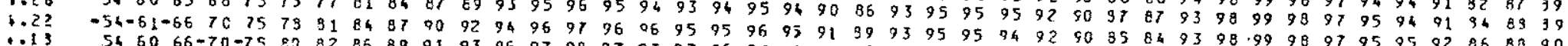

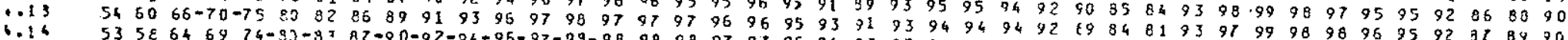

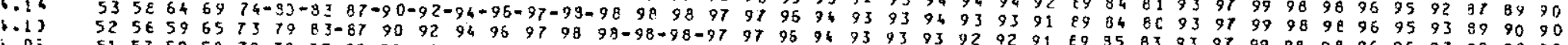

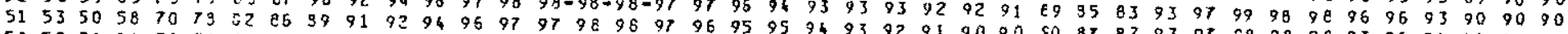

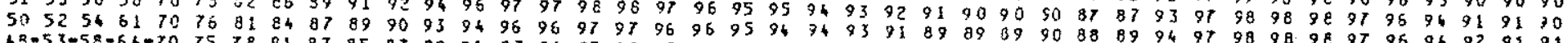

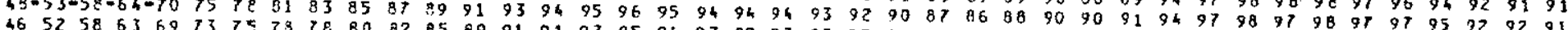

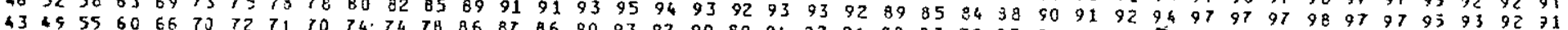

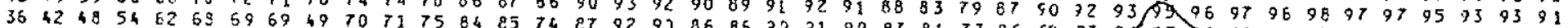

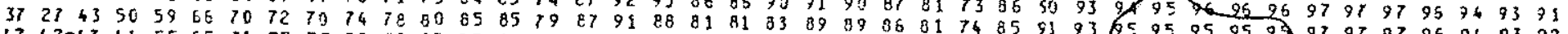

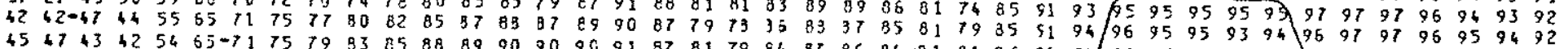

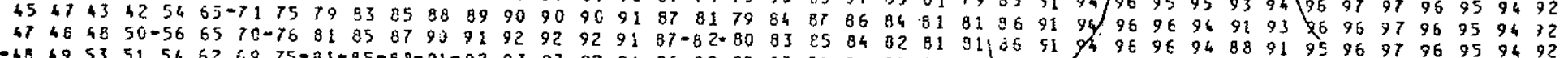

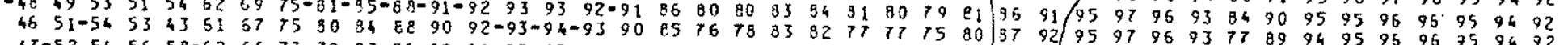

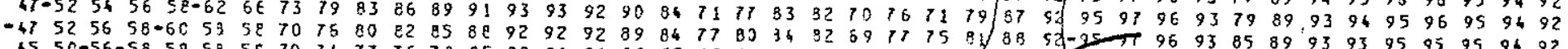

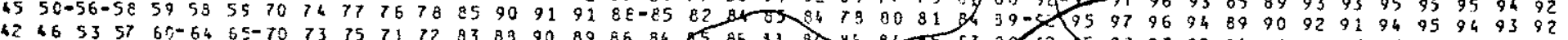

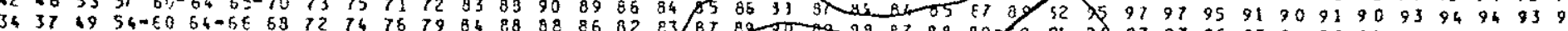

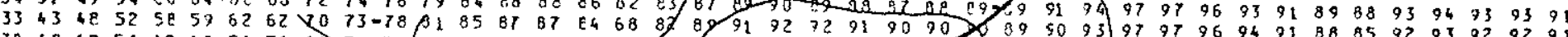

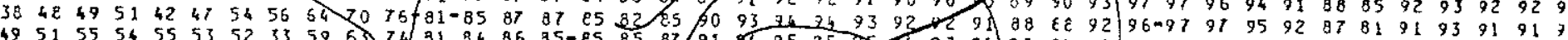

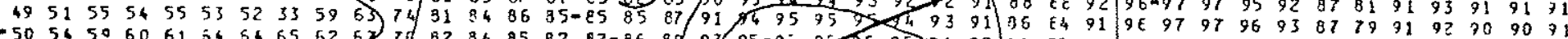

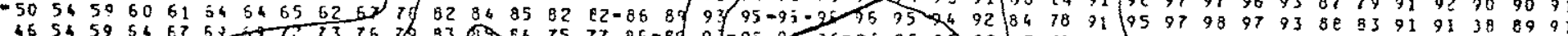

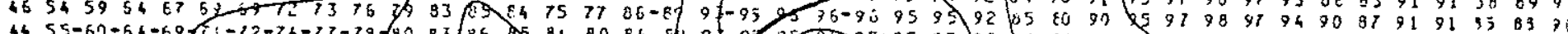

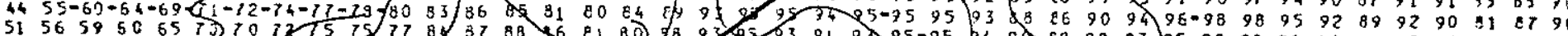

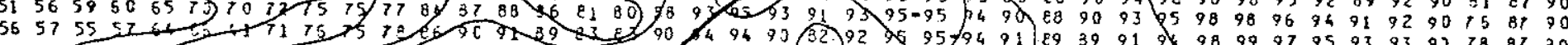

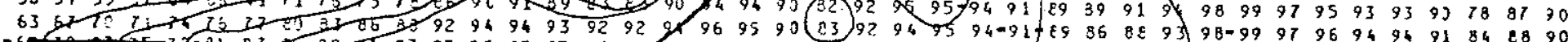

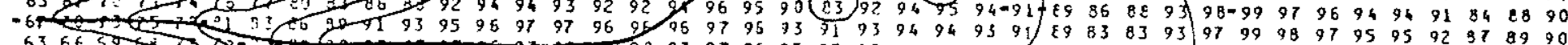

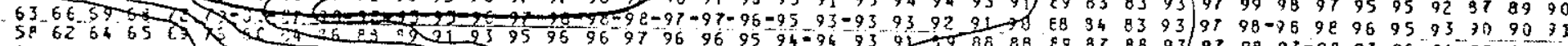

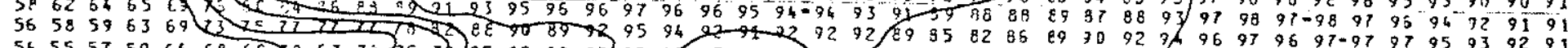

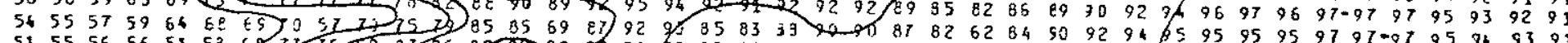

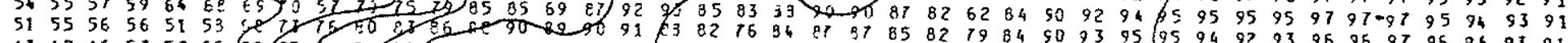

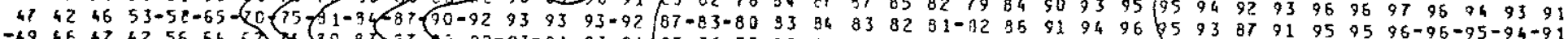

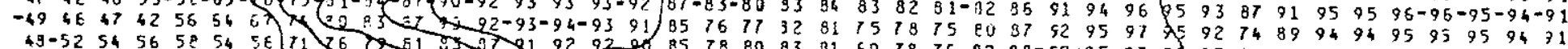

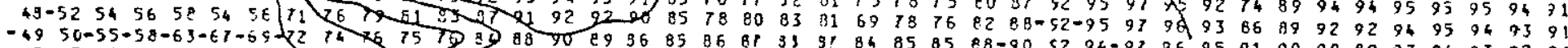

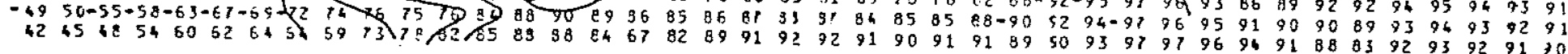

$101113121213141615161718192021222326252723 \quad 303133 \quad 3537394143454850535659626569 \quad 27630$ Período (s)

Fig. B-34 


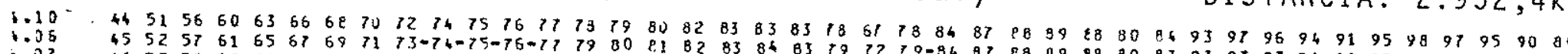

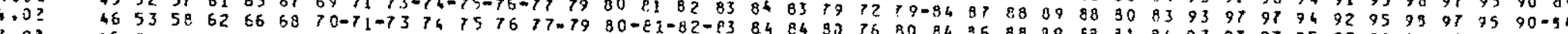

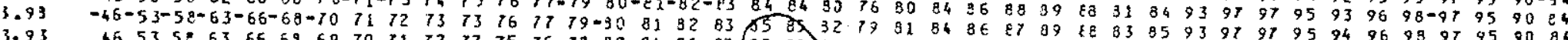

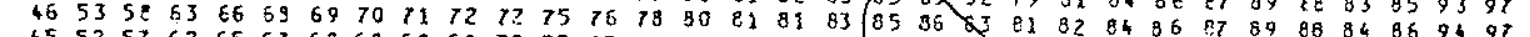

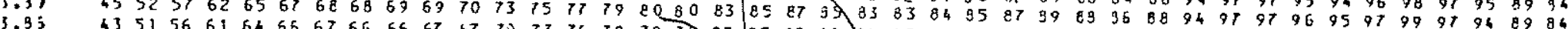

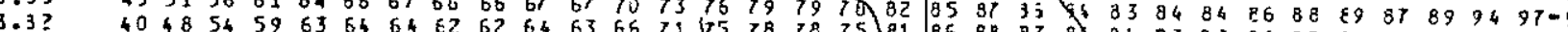

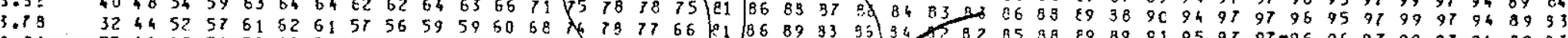

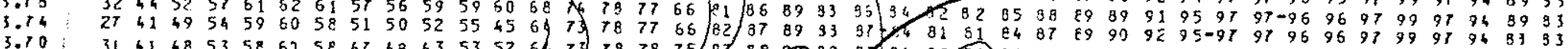

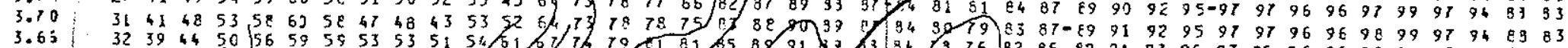

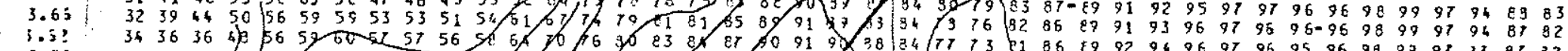

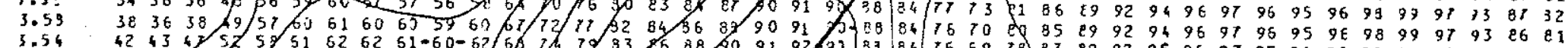

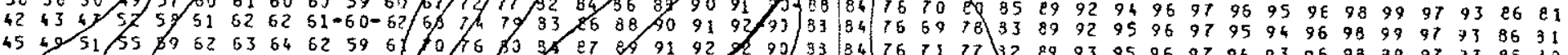

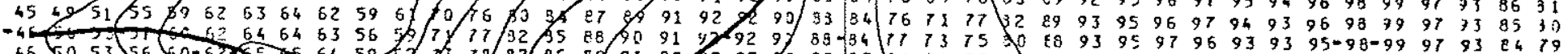

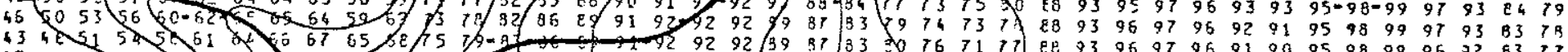

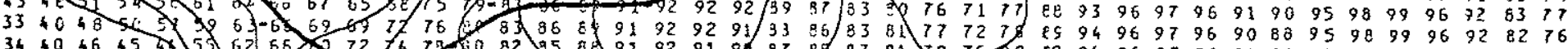

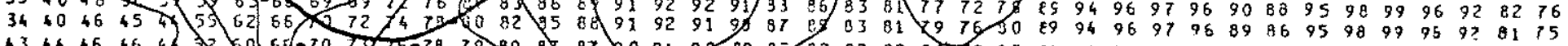
43444646 4)

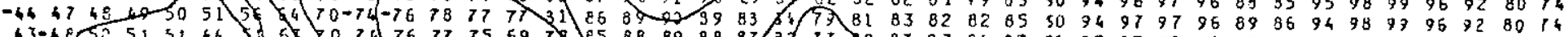

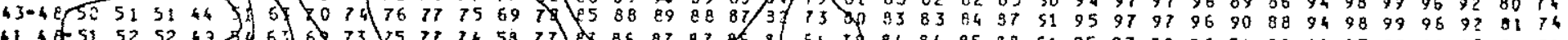

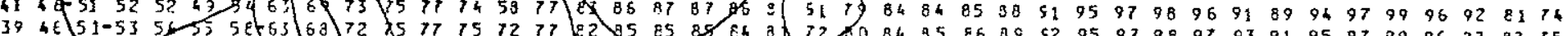

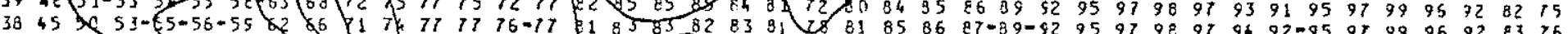

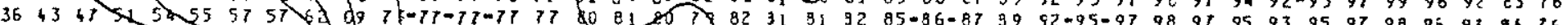

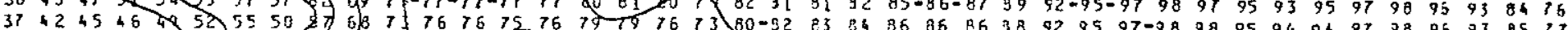

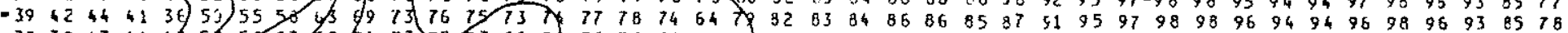

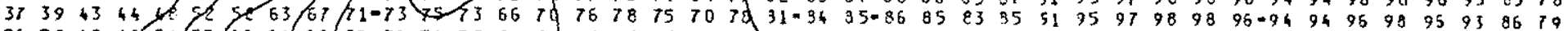

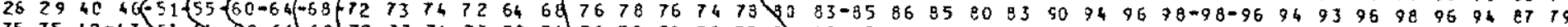

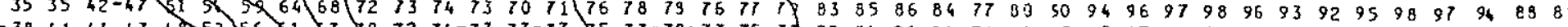

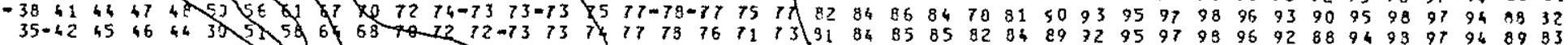

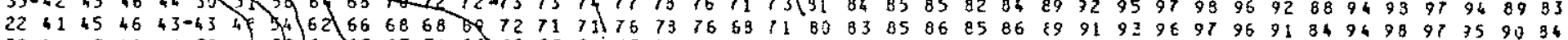

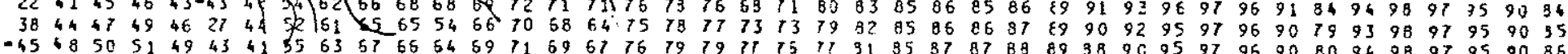

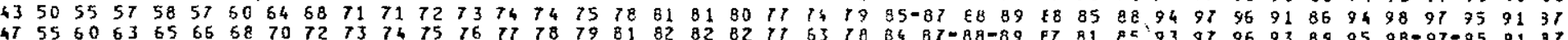

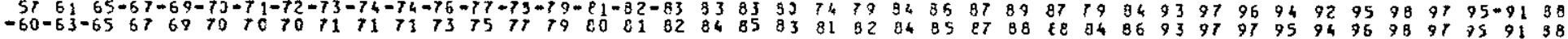

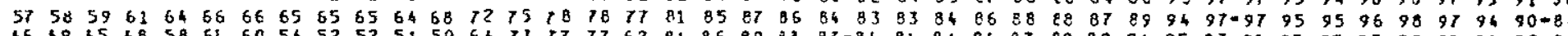

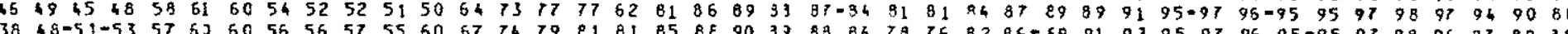

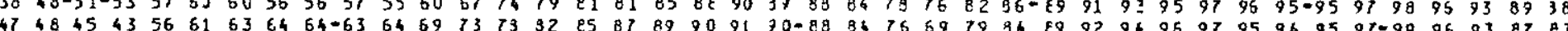

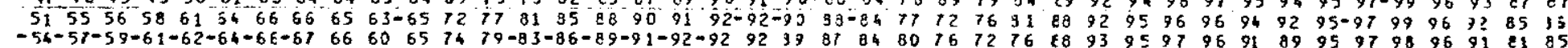

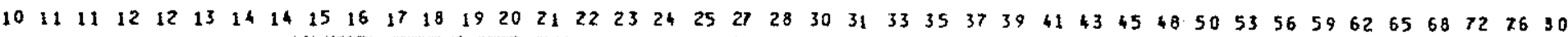
Período (s)

Fig. $B-35$ 